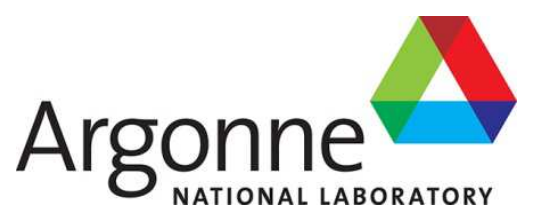

\title{
Initial Neutronics Analyses for HEU to LEU Fuel Conversion of the Transient Reactor Test Facility (TREAT) at the Idaho National Laboratory
}

Preliminary Calculations with 100\% Graphitization

Nuclear Engineering Division 


\section{About Argonne National Laboratory}

Argonne is a U.S. Department of Energy laboratory managed by UChicago Argonne, LLC under contract DE-AC02-06CH11357. The Laboratory's main facility is outside Chicago, at 9700 South Cass Avenue, Argonne, Illinois 60439. For information about Argonne and its pioneering science and technology programs, see www.anl.gov.

\section{DOCUMENT AVAILABILITY}

Online Access: U.S. Department of Energy (DOE) reports produced after 1991 and a growing number of pre-1991 documents are available free via DOE's SciTech Connect (http://www.osti.gov/scitech/)

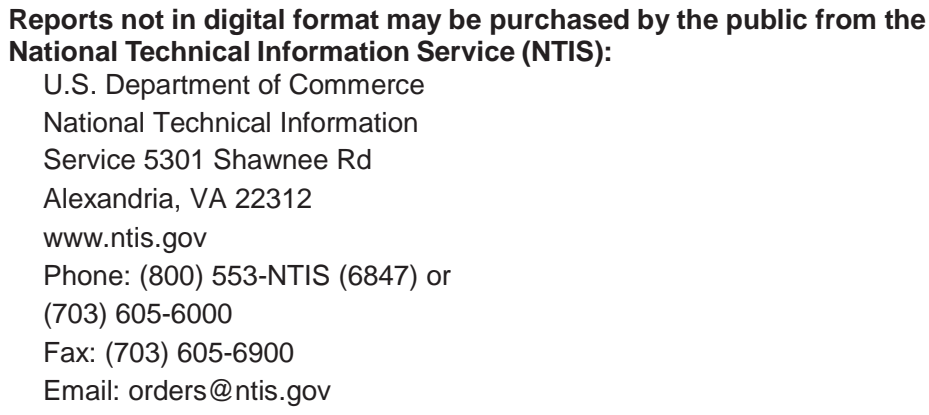

Reports not in digital format are available to DOE and DOE contractors from the Office of Scientific and Technical Information (OSTI):

U.S. Department of Energy

Office of Scientific and Technical Information

P.O. Box 62

Oak Ridge, TN 37831-0062

www.osti.gov

Phone: (865) 576-8401

Fax: (865) 576-5728

Email: reports@osti.gov

\footnotetext{
Disclaimer

This report was prepared as an account of work sponsored by an agency of the United States Government. Neither the United States Government nor any agency thereof, nor UChicago Argonne, LLC, nor any of their employees or officers, makes any warranty, express or implied, or assumes any legal liability or responsibility for the accuracy, completeness, or usefulness of any information, apparatus, product, or process disclosed, or represents that its use would not infringe privately owned rights. Reference herein to any specific commercial product, process, or service by trade name, trademark, manufacturer, or otherwise, does not necessarily constitute or imply its endorsement, recommendation, or favoring by the United States Government or any agency thereof. The views and opinions of document authors expressed herein do not necessarily state or reflect those of the United States Government or any agency thereof, Argonne National Laboratory, or UChicago Argonne, LLC.
} 


\section{Initial Neutronics Analyses for HEU to LEU Fuel Conversion of the Transient Reactor Test Facility (TREAT) at the Idaho National Laboratory}

Preliminary Calculations with 100\% Graphitization

prepared by

D. Kontogeorgakos, K. Derstine, A. Wright, T. Bauer, J. Stevens

Nuclear Engineering Division, Argonne National Laboratory

sponsored by

U. S. Department of Energy, National Nuclear Security Administration

Office of Material Management and Minimization

June 2013 


\section{Executive Summary}

Neutronics analyses were performed as part of the feasibility study to convert the Transient Reactor Test Facility (TREAT) of the Idaho National Laboratory, from the use of high enriched uranium (HEU) fuel to the use of low enriched uranium (LEU) fuel. The analyses were performed by the GTRI Reactor Conversion staff at the Argonne National Laboratory (ANL).

The purpose of the TREAT reactor is to generate large transient neutron pulses in test samples without over-heating the core to simulate fuel assembly accident conditions. The power transients in the present HEU core are inherently self-limiting such that the core prevents itself from overheating even in the event of a reactivity insertion accident.

The objective of this study was to support the assessment of the feasibility of the TREAT core conversion based on the present reactor performance metrics and the technical specifications of the HEU core. The LEU fuel assembly studied had the same overall design, materials $\left(\mathrm{UO}_{2}\right.$ particles finely dispersed in graphite) and impurities content as the HEU fuel assembly. The Monte Carlo N-Particle code (MCNP) and the point kinetics code TREKIN were used in the analyses.

An MCNP 3D detailed model of the TREAT HEU core was designed based on the core drawings and descriptions. Preliminary validation of the model was performed by comparison of predictions to experimental measurements for the M8CAL irradiation. The validation is presently limited and can be further improved by using a larger set of measurements and evaluating uncertainties in both the computations and measurements. A method to apply the TREKIN point kinetics code with MCNP model based feedback tables was developed, and preliminary validation was performed against measurements (again for a limited set of data and without uncertainty evaluation of measurement data and method). The codes were used to assess the changes due to the fuel conversion simulating transients that were experimentally performed earlier in the HEU core.

For comparing the performance of an LEU core in TREAT with that of the HEU core, the data from the last of the neutronics-calibration campaigns that was conducted in TREAT was used as a benchmark. That campaign, called M8CAL and performed in support of the LMR safety program, included the performance of three temperature-limited (natural bursts) power transients which were used to characterize the core, and several shaped transients which were used to irradiate flux wires and fuel pins. Two of the shaped transients had been specified in M8CAL to raise the power with $8 \mathrm{~s}$ and $80 \mathrm{~s}$ periods and yield the maximum energy allowable without exceeding the facility administrative limits on maximum fuel assembly temperature. A neutronics mockup (calibration vehicle) of a typical late-model sodium loop was located in the core center. The core also had an open radial slot (half-slotted core) which was typically used in LMR fuel melt-down experiments to allow for measurement of test fuel motion by the TREAT hodoscope.

The optimum graphite-to-uranium ratio for the LEU-fueled M8CAL core loading was calculated that produces equal excess reactivity as with the HEU cold core with all rods out under the assumption that the LEU fuel will contain the same impurities content as in the HEU fuel. The input data (transient reactivity, temperature reactivity feedback, effective delayed neutron fraction, prompt generation 
lifetime, core maximum temperature) required for the TREKIN calculations were produced with MCNP for the HEU and the LEU cores. The performance of the LEU core was compared with the HEU core in terms of power generated in a test sample located inside the M8CAL vehicle during steady state and transient irradiations. The addition of $\mathrm{BeO}$ filled assemblies was considered in order to enhance the population of the thermal neutrons reaching the test sample and consequently increase the power produced in the test sample. To minimize the temperature in the fuel assemblies adjacent to the $\mathrm{BeO}$ assemblies, a lower LEU uranium loading was studied (higher graphite to uranium ratio) for those assemblies.

For a straight-forward comparison study, four M8CAL transients were initially selected for evaluation: the three temperature-limited transients (none of which were at the allowed limit for temperaturelimited transients) and the $8 \mathrm{~s}$ period shaped transient (which had been chosen to reach the allowed limit for shaped transients). Data from flux wires located in the center of the M8CAL vehicle were used as a reference measure of the neutron flux at that location. The intent was to determine how well an LEU core could reproduce the three temperature-limited transients and the $8 \mathrm{~s}$ period shaped transient, and also to determine the corresponding neutron flux in a flux wire located at the center of the unfueled calibration vehicle relative to the flux using the HEU core. The result of this comparison was encouraging: the computations indicated that the LEU core could reasonably replicate the core power and energy histories of those transients. Furthermore, the proposed LEU core would generate a fission density in the flux wire in the center of the vehicle within roughly $90 \%$ of the HEU compared cases. An evaluation of some of the factors which contribute to uncertainties in the computations showed that this level of difference between the two core types was within the overall uncertainty of the analysis. Detailed evaluation of specific test fuels was not included in this initial evaluation.

This initial conclusion did not hold in the case of the maximum-allowed temperature-limited transients and after more consideration was given to fission heating of actual test fuel pins. These additional considerations and further analysis of heating of fuel pins used in M8CAL have led to results that are not as encouraging and which suggest that additional work will be needed to improve the LEU core design to the point where it will perform as well, or nearly as well, as the HEU core. Thus, to develop a stronger basis for determining feasibility of TREAT core conversion, plans for further work include improved benchmarking of the analysis using results from several other experiments (including an LWR-fuel experiment), an evaluation of uncertainties in the measurements and computations, consideration of further optimizations of the LEU core design, and evaluation of LEU core design improvements against definitive facility performance requirements.

All the calculations presented in this report were performed assuming $100 \%$ graphitization of the fuel graphite. Information about the level of graphitization acquired after the completion of this report show that the TREAT fuel is graphitized by $59 \%$. This is expected to increase the calculated $k_{\text {eff }}$ and decrease the power coupling factor. 


\section{Table of Contents}

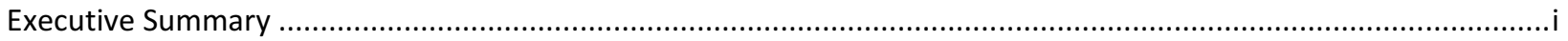

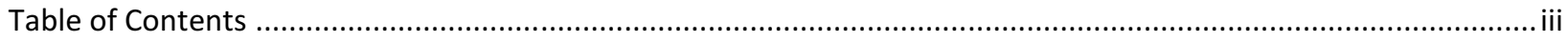

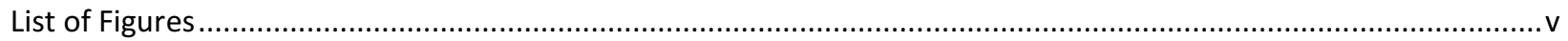

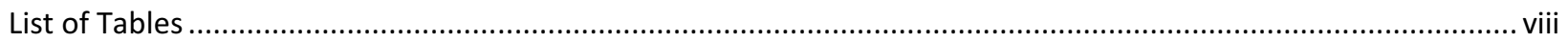

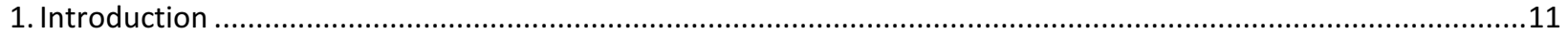

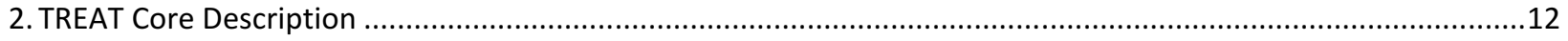

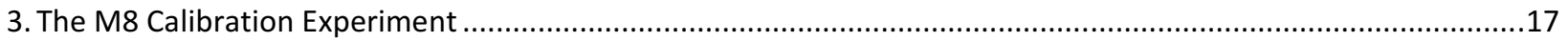

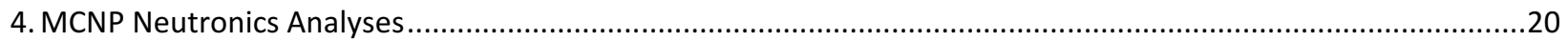

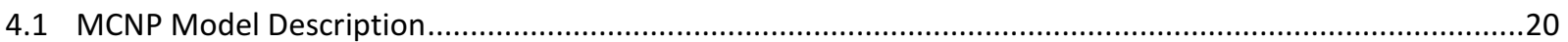

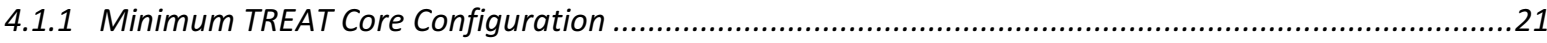

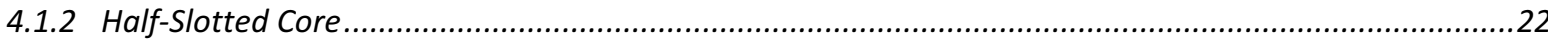

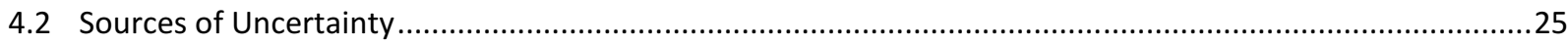

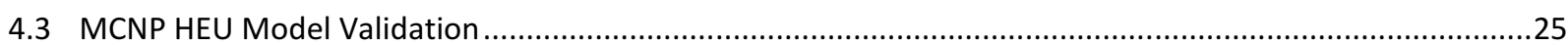

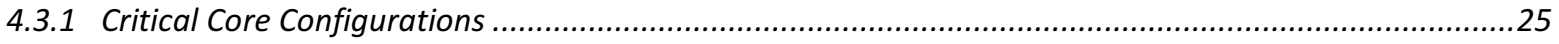

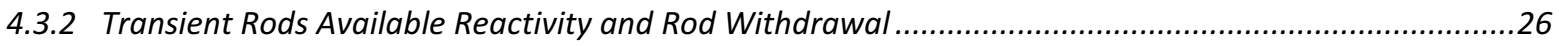

4.3.3 Power Coupling Factor for the Low Level Steady State (LLSS) Irradiations ..........................................28

4.3.4 Fission Density Axial Profile in Monitor Wire and Fuel Pins ................................................................30

4.3.5 Prompt Generation Lifetime and Effective Delayed Neutron Fraction................................................32

4.3.6 Temperature Distribution and Temperature Reactivity Feedback ......................................................32

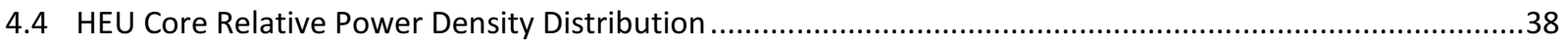

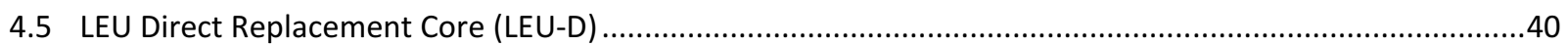

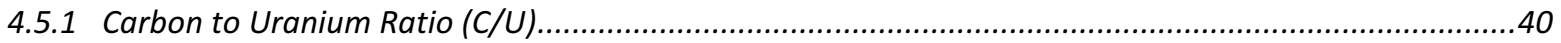

4.5.2 Neutron Spectrum Inside the M8Cal Test Vehicle for the HEU and LEU-D Cores .................................40

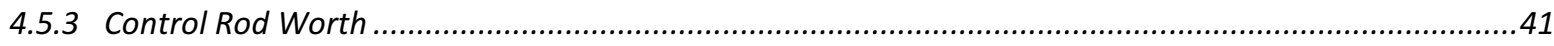

4.5.4 Effective Delayed Neutron Fraction and Prompt Generation Lifetime ..................................................42

4.5.5 LEU-D MCNP Calculated Temperature Reactivity Feedback .........................................................42

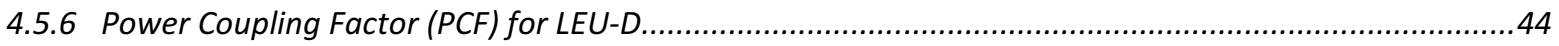

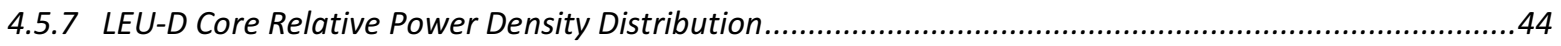

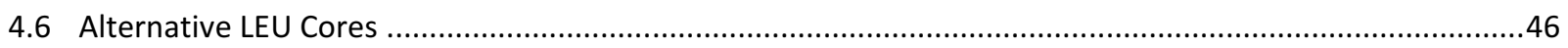

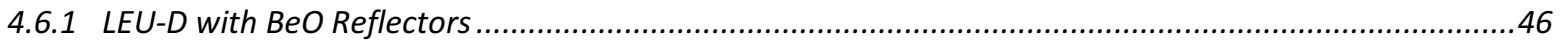

4.6.1.1 LEU-D with BeO Relative Power Density Distribution ...............................................................47

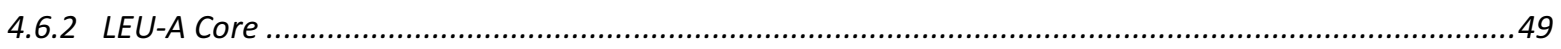

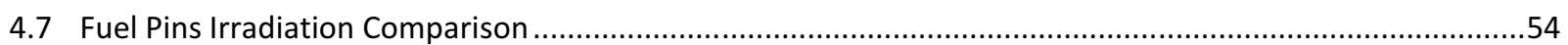

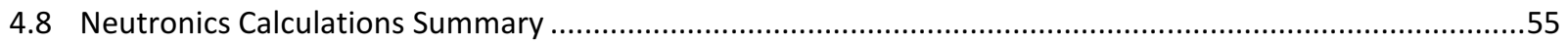

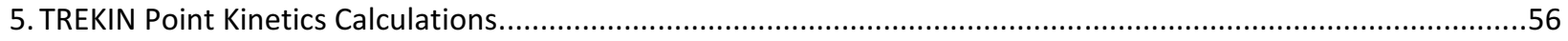

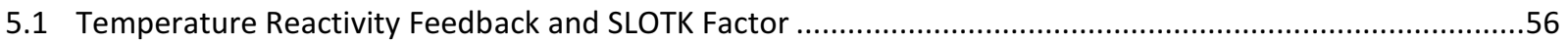

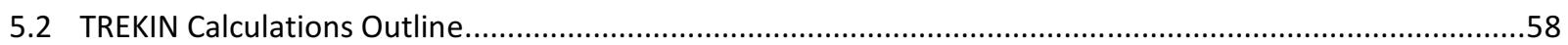

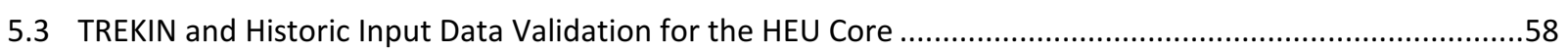


5.3.1 Temperature-Limited Transients for the HEU Core Using Historic Input Data

5.3.2 Shaped Transient: HEU Rod Driven and Power Driven TREKIN Runs Using the Historic Input Data ........59

5.4 TREKIN Calculations Using MCNP-Produced Input Data .....................................................................62

5.4.1 Temperature-Limited Transients for the HEU Core ....................................................................62

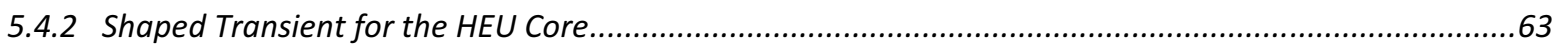

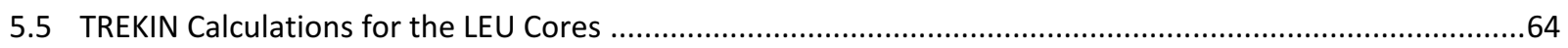

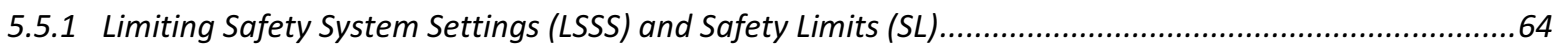

5.5.2 Temperature-Limited Transients for the LEU-D and LEU-A Cores ...............................................6.

5.5.2.1 Temperature Limited Transients \#2855, \#2856 and \#2857..........................................................66

5.5.2.2 TREKIN Calculations for the Maximum Allowed HEU Temperature-Limited Transient .....................67

5.5.2.3 Maximum Core Temperature for the LEU Cores Delivering Equal with the HEU Core Peak Power and

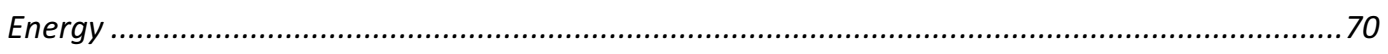

5.5.2.4 Peak Power and Total Energy Delivered for Different Wire Compositions and Diameter .................71

5.5.3 Shaped Transients for the LEU-D and LEU-A Cores ....................................................................72

5.5.3.1 Rod-Driven TREKIN Calculations for Equal Peak Power Delivered in the Flux Wire as with Transient

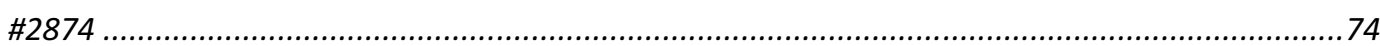

5.5.3.2 Period-Driven TREKIN Calculations Using Equal Periods with HEU ..................................................76

5.5.3.3 Power-Driven TREKIN Calculations with Second Period Adjusted to Produce Equal-to-HEU Peak

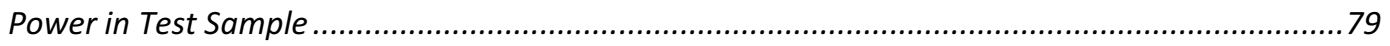

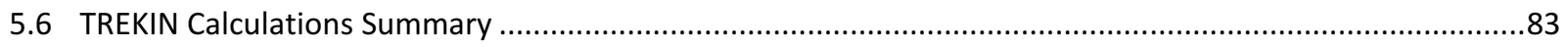

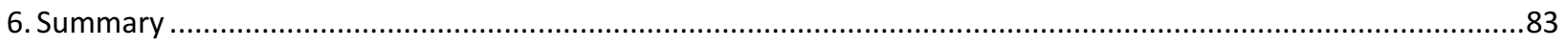

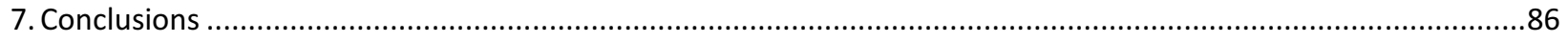

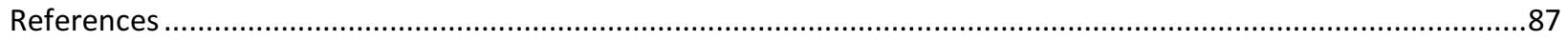

Appendix A : Material Compositions Used in the HEU MCNP Model.............................................................8

Appendix B : Equation Used to Calculate the Fuel Assembly Temperature ...................................................90 


\section{List of Figures}

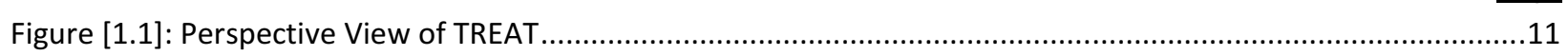

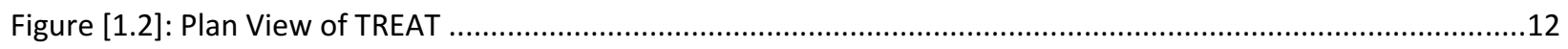

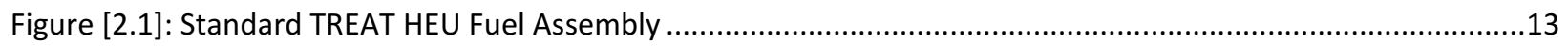

Figure [2.2]: Control Rod (Left) and Aluminum Canned Dummy (Right) Assemblies .............................................15

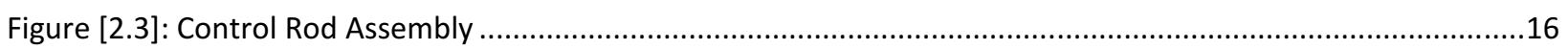

Figure [2.4]: Control Rods Position in the Studied HEUTREAT Core ................................................................

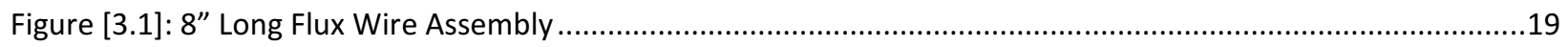

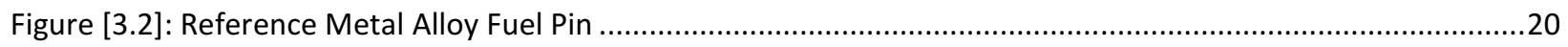

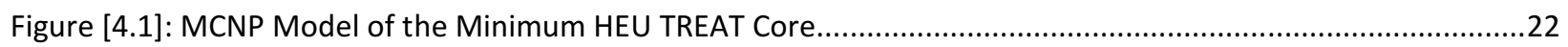

Figure [4.2]: MCNP Model of the Half Slotted HEU TREAT core. The M8CAL Vehicle in Core Center.........................23

Figure [4.3]: MCNP Model Showing the Test Section Leg of the M8CAL Test Vehicle with Two Fuel Test Pins (T-462-

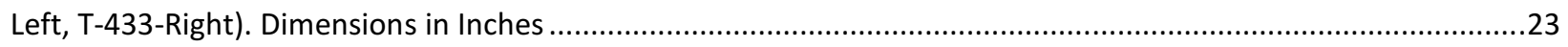

Figure [4.4]: M8CAL Dysprosium Shaping Collars Configuration (Dimensions in Inches)..........................................24

Figure [4.5]: Cross Section View of the Fueled M8CAL Vehicle in the Center of TREAT (Dimensions in Inches) ........24

Figure [4.6]: MCNP Calculated and Measured Transient Rod Bank Available Reactivity as a Function of Rod

Withdrawal for the HEU Core.

Figure [4.7]: Corrected-MCNP Calculated and Measured Transient Rod Bank Available Reactivity as a Function of

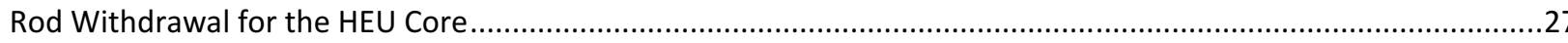

Figure [4.8]: MCNP Calculated and Measured Normalized-to-Maximum Axial Fissions per Gram Axial Distribution for the 60 inches $(152.4 \mathrm{~cm})$ Long Flux Wire Irradiated in the HEU Core.

Figure [4.9]: MCNP Calculated and Measured Normalized-to-Maximum Axial Distribution of Fissions per Gram for

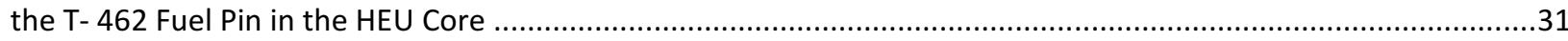

Figure [4.10]: Calculated and Measured Normalized-to-Maximum Axial Distribution of Fissions per Gram for the T-

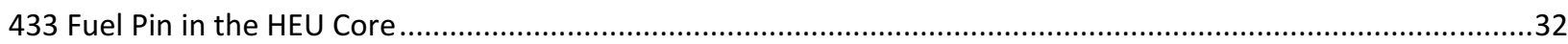

Figure [4.11]: Graphite Heat Capacity as a Function of Graphite Temperature in the HEU Fuel ............................34

Figure [4.12] Flow Diagram for the Temperature Distribution Calculations using MCNP and the MAKXS Utility. The Temperature Reactivity Feedback was Calculated from the Change of the Multiplication Factor from the 'Cold' to the 'Hot' Core

Figure [4.13]: Reported Calculated Using the MCNP Produced Power Density Distribution Maximum Fuel Assembly

Temperature as a Function of the Total Core Energy for the HEU

Figure [4.14]: Reported and MCNP Calculated Temperature Reactivity Feedback as a Function of Total Core Energy for the HEU Core.

Figure [4.15]: MCNP Calculated Power Density Relative-to-Core-Average Distribution for the Flux Wire Irradiation in the HEU Core. The Different Colors Show the In-Core Positions of the Rods (Red: Transient Rods, Green:

Control/Shutdown, Light Blue: Compensation) and the Assembly with the Maximum Value (Yellow)......................39 Figure [4.16]: MCNP Calculated Normalized to Total Neutron Energy Spectrum for the HEU and LEU-D (FA with $\mathrm{C} / \mathrm{U}=5200)$ Inside the Low Enriched Flux Wire

Figure [4.17]: Maximum Fuel Assembly Temperature Calculated with the MCNP Produced Power Density Distribution as a Function of the Total Core Energy for the HEU and LEU-D (FA with C/U=5200).....

Figure [4.18]: MCNP Calculated HEU and LEU-D (FA with C/U=5200) Temperature Reactivity Feedback (Rod Configuration: Compensation/Shutdown 100\% Withdrawn, Control/Shutdown 38.6\% Withdrawn, Transients 100\% Withdrawn). 
Figure [4.19]: MCNP Calculated Relative to Core Average Power Density Distribution for the Flux-Wire Irradiation in the LEU-D (FA with $C / U=5200$ ) Core. The Different Colors Show the Position of the Rods (Red: Transient Rods, Green: Control/Shutdown, Light Blue: Compensation) and the Assembly with the Maximum Value (Yellow)..........45 Figure [4.20]: MCNP Model of the Half Slotted LEU-D Core with 12 BeO Blocks Around M8CAL...........................46 Figure [4.21]: MCNP Calculated Relative to Core Average Power Distribution for the Flux Irradiation in the LEU-D (w/ BeO FA with C/U=5200) Core. The Different Colors Show the Position of the Rods (Red: Transient Rods, Green: Control/Shutdown, Light Blue: Compensation), the Assembly with the Maximum Value (Yellow) and of the BeO Blocks (Grey)

Figure [4.22]: MCNP Model of the Half Slotted LEU-A TREAT Core with $12 \mathrm{BeO}$ Blocks and 12 Fuel Assemblies (FA) with Higher C/U Ratio (C/U=6619) ......

Figure [4.23]: MCNP Calculated Relative to Core Average Power Distribution for the Flux Irradiation in the LEU-A Core (With 12 BeO Blocks and 12 Fuel Assemblies with Lower Uranium Loading). The Different Colors Show the Position of the Rods and the Fuel Assemblies with the Lower Uranium Loading (Red: Transient Rods, Green: Control/Shutdown, Light Blue: Compensation, Purple: Fuel Assemblies with $C / U=6619)$, the Assembly with the Maximum Value (Yellow) and of the BeO Blocks (Grey)

Figure [4.24]: MCNP Calculated Normalized-to-Total Neutron Energy Spectrum for the HEU, LEU-D (FA with $C / U=5200)$ and LEU-A (BeO, FA with $C / U=5200$ and $C / U=6619)$ Core Configurations Inside the Flux Wire.

Figure [4.25]: Maximum Fuel Assembly Temperature Calculated with the MCNP Produced Power Density Distribution as a Function of the Total Core Energy for the HEU, LEU-D (FA with C/U=5200) and LEU-A (BeO, FA with $C / U=5200$ and $C / U=6619)$ Core Configurations

Figure [4.26]: MCNP Calculated Temperature Reactivity Feedback for the HEU, LEU-D (FA with C/U=5200), and LEUA (BeO, FA with $C / U=5200$ and $C / U=6619$ ) Core Configurations .....

Figure [5.1]: HEU Core Measured (Blue Line) and TREKIN Rod-Driven Calculated Power Time History (Red Line) with SLOTK=1 Using Historic Input Data (TROD, $I_{p}, \beta_{\text {eff }}$ TEMPER, HSLOT).

Figure [5.2]: HEU Core Measured (Blue Line) and Rod Driven TREKIN Calculated Power Time History with SLOTK=1.0 (Red Line) and SLOTK=0.93 (Green Line) Using Historic Input Data (TROD, $I_{p}, \beta_{\text {eff, }}$ TEMPER, HSLOT) .......................61 Figure [5.3]: HEU Core Measured (Blue Line) and TREKIN Power Driven Calculated Rod Position with SLOTK=1 (Red Line) and SLOTK=0.98 (Green Line) Using Historic Input Data (TROD, Ip, $\beta_{\text {eff, }}$ TEMPER, HSLOT) ..... . .61 Figure [5.4]: HEU Core Power Time History Measured (Blue Line) and TREKIN Calculated with SLOTK = 1.0 (Red Line) and SLOTK = 0.985 (Green Line) for Transient \#2874 with a Rod Driven TREKIN Run Based on MCNP Produced Input Data (TROD, $I_{p}, \beta_{\text {eff, }}$ TEMPER, HSLOT)... . .63 Figure [5.5]: HEU Core Measured (Blue Line) and TREKIN Calculated Rod Withdrawal History with SLOTK = 1.0 (Red Line) and SLOTK = 1.053 (Green Line) for Transient \#2874 with a Power Driven TREKIN Run Based on MCNP Produced Input Data (TROD, $I_{p}, \beta_{\text {eff, }}$ TEMPER, HSLOT) .....................................................................................64 Figure [5.6]: MCNP Calculated Maximum Fuel Assembly Temperature as a Function of Core Energy for the HEU, LEU-D (FA with $C / U=5200)$ and LEU-A (BeO, FA with $C / U=5200$ and $C / U=6619)$ core. The Total Core Energy for the $600^{\circ} \mathrm{C}$ Maximum Fuel Assembly Temperature (after $60 \mathrm{~s}$ ) are Shown.

Figure [5.7]: TREKIN Calculated Core Power Time History Delivered by HEU, LEU-D (FA with C/U=5200) and LEU-A (BeO, FA with $C / U=5200$ and $C / U=6619$ ) Temperature Limited Transients for the Maximum Allowed Reactivity Insertion.

Figure [5.8]: TREKIN Calculated Flux Wire Power Time History Delivered by HEU, LEU-D (FA with C/U=5200) and LEU-A (BeO, FA with $C / U=5200$ and $C / U=6619$ ) Temperature Limited Transients for the Maximum Allowed Reactivity Insertion. Wire Peak Power and Total Energy were Calculated Using the MCNP Calculated Peak Power Coupling Factors.

Figure [5.9]: TREKIN Calculated Fuel Pin Power Time History Delivered by HEU, LEU-D (FA with C/U=5200) and LEUA (BeO, FA with $C / U=5200$ and $C / U=6619)$ Temperature Limited Transients for the Maximum Allowed Reactivity 
Insertion. Wire Peak Power and Total Energy were Calculated Using the MCNP Calculated Peak Power Coupling Factors

Figure [5.10]: Rod Position Time Histories Calculated for the LEU-D (FA with C/U=5200) and (BeO, FA with $C / U=5200$ and $C / U=6619$ ) Cores with Power Driven TREKIN Runs that Produce the Same Peak Power to the Flux Wire with HEU Core with a Rod Starting Position Limited by the Pre-Transient Reactivity Limited. The Pre-Transient Reactivity Limit for each Core is Shown in the Parentheses.

Figure [5.11]: Power Delivered in the Flux Wire by the HEU, LEU-D (FA with C/U=5200) and LEU-A (BeO, FA with $C / U=5200$ and $C / U=6619$ ) Cores for Shaped Transients Limited by the Reactivity Safety Limits and the Transient Rods Span .....

Figure [5.12]: TREKIN Rod Driven Calculated Power Time History in the Flux Wire for $0.3 \mathrm{~s}$ and $8 \mathrm{~s}$ Period Power Increase in the HEU, LEU-D (FA with $C / U=5200$ ) and LEU-A (BeO, FA with $C / U=5200$ and $C / U=6619)$ Cores Using Adjusted with the Peak Power Coupling Flattop Values of 75, 129.3 and 79.8 MW, Respectively......

Figure [5.13]: TREKIN Calculated Rod Time History in the Flux Wire for $0.3 \mathrm{~s}$ and $8 \mathrm{~s}$ Period Power Increase in the HEU, LEU-D (FA with $C / U=5200$ ) and LEU-A (BeO, FA with $C / U=5200$ and $C / U=6619$ ) Cores Using Adjusted with the Peak Power Coupling Factor Flattop of 75, 129.3 and 79.8 MW, Respectively.

Figure [5.14]: TREKIN Calculated Power Time History in the T-462 Pin for $0.3 \mathrm{~s}$ and $8 \mathrm{~s}$ Period Driven Power Increase in the HEU, LEU-D (FA with $C / U=5200$ ) and LEU-A (BeO, FA with $C / U=5200$ and $C / U=6619$ ) Cores........

Figure [5.15]: TREKIN Calculated Rod Time History in the T-462 Pin for $0.3 \mathrm{~s}$ and $8 \mathrm{~s}$ Period Power Increase in the HEU, LEU-D (FA with $C / U=5200$ ) and LEU-A (BeO, FA with $C / U=5200$ and $C / U=6619)$ Cores ...............................78 Figure [5.16]: TREKIN Calculated Power Time History in the Flux Wire for the HEU, LEU-D (FA with C/U=5200) and LEU-A (BeO, FA with $C / U=5200$ and $C / U=6619$ ) Cores with Adjusted Second Period to Produce Equal to HEU Peak Power.

Figure [5.17]: TREKIN Calculated Rod Time History in the Flux Wire for the HEU, LEU-D (FA with C/U=5200) and LEU-A (BeO, FA with $C / U=5200$ and $C / U=6619$ ) Cores with Adjusted Second Period to Produce Equal to HEU Peak Power.

Figure [5.18]: TREKIN Calculated Power Time History in the T-462 Pin for the HEU, LEU-D (FA with C/U=5200) and LEU-A (BeO, FA with $C / U=5200$ and $C / U=6619$ ) Cores with Adjusted Second Period to Produce Equal with HEU Peak Power.

Figure [5.19]: TREKIN Calculated Rod Time History for the T-462 Fuel Pin for the HEU, LEU-D (FA with C/U=5200) and LEU-A (BeO, FA with $C / U=5200$ and $C / U=6619$ ) Cores with Adjusted Second Period to Produce the Same Peak Power as the HEU Core..... 


\section{List of Tables}

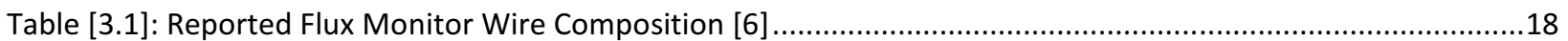

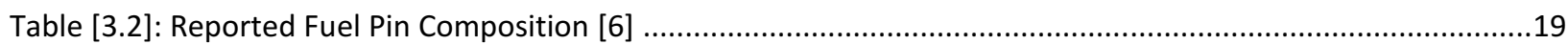

Table [4.1]: HEU Fuel Composition Used in the MCNP TREAT Core Models [8] .......................................................21

Table [4.2]: MCNP Criticality Calculations of the LLSS Configurations in the HEU Core ........................................26

Table [4.3]: Measured, MCNP Calculated and Corrected-MCNP Calculated Transient Rod Reactivity as a Function of Percentage of Transient Rod bank withdrawal for the HEU Core ......................................................................28

Table [4.4]: MCNP Calculated (C) and Measured (M) Axial Peak Fissions per U-235 gram per Total Core Energy for the LLSS Irradiations of the Flux Wire and the C/M Ratio in the HEU Core (C: Compensation Rods, C/S:

Compensation Shutdown Rods, T: Transient Rods).

Table [4.5]: MCNP Calculated (C) and Measured (M) Axial-Peak Energy per Fuel Pin Mass per Total Core Energy for the LLSS Irradiations of the Fuel Pins and the C/M Ratio in the HEU Core (C: Compensation Rods, C/S:

Compensation Shutdown Rods, T: Transient Rods)

Table [4.6]: MCNP Calculated (C) and Reported (R) Effective Delayed Neutron Fraction, Prompt Neutron Lifetime and the C/R Ratio for the HEU Core

Table [4.7]: MCNP Calculated and Reported Temperature Reactivity for the Experimentally Performed

Temperature Limited Transients \#2855, \#2856 and \#2857.

Table [4.8]: Graphite to Uranium Ratio to Produce Equal Excess Reactivity for the HEU and LEU-D (FA with $\mathrm{C} / \mathrm{U}=5200)$

Table [4.9]: MCNP Calculated Fast (Energy > $0.625 \mathrm{eV}$ ) to Thermal (Energy < $0.625 \mathrm{eV}$ ) Flux Ratio for the HEU and LEU-D (FA with C/U=5200) at the Low Enriched Flux Wire

Table [4.10]: MCNP Calculated Control Rod Reactivity (\%) for the LEU-D (FA with C/U=5200) and HEU and the LEUD/HEU Ratio

Table [4.11]: MCNP Calculated Effective Delayed Neutron Fraction and Prompt Generation Lifetime for the LEU-D

(FA with $\mathrm{C} / \mathrm{U}=5200$ ) and HEU and the LEU-D/HEU Ratio

Table [4.12]: MCNP Calculated Peak Power Coupling Factor (PCF) in Fissions per U-235 Grams and Total Core Energy for the LEU-D (FA with C/U=5200) and HEU Cores for the LLSS Wire Irradiations. The Rod Position and the Resulting LEU-D/HEU Ratio are also Shown

Table [4.13]: MCNP Calculated Peak Power Coupling Factor (PCF) in Joules per Total Mass per Total Core Energy for the HEU and LEU-D (FA with C/U=5200) for the T-433 and T-462 Test Pins LLSS Irradiations. The Rod Position and the Resulting LEU-D/HEU Ratio are also Shown

Table [4.14]: MCNP Calculated Relative to HEU Peak Power Coupling Factor in the Flux Wire for the LEU-D (FA with $\mathrm{C} / \mathrm{U}=5200$ ) and LEU-D (FA with $\mathrm{C} / \mathrm{U}=5200) \mathrm{w} / \mathrm{BeO}$ Core Configurations

Table [4.15]: MCNP Calculated Core Average Fuel Assembly (FA) Maximum Temperatures for the HEU, LEU-D (FA with $C / U=5200)$ and LEU-D (w/BeO FA with $C / U=5200$ ) Core Configurations and the Resulting Maximum to Average Ratio for Total Core Energy $500 \mathrm{MJ}$

Table [4.16]: MCNP Calculated Relative to HEU Peak Power Coupling Factor in the Flux Wire for the HEU, LEU-D (FA with $C / U=5200$ ), LEU-D (BeO FA with $C / U=5200$ ) and LEU-A (BeO FA with $C / U=5200$ and $C / U=6619$ ) Core

Configurations

Table [4.17]: MCNP Calculated Core Average and Fuel Assembly Average (FA) Maximum Temperatures for the HEU, LEU-D (FA with C/U=5200), LEU-D (BeO FA with C/U=5200) and LEU-A (BeO FA with $C / U=5200$ and $C / U=6619$ ) Core Configurations and the Maximum to Average Ratio 
Table [4.18]: MCNP Calculated Fast (Energy $>0.625 \mathrm{eV}$ ) to Thermal (Energy < $0.625 \mathrm{eV}$ ) Flux Ratio for the HEU, LEU$D(F A$ with $C / U=5200)$ and LEU-A (BeO, FA with $C / U=5200$ and $C / U=6619)$ Core Configurations Inside the Flux Wire

Table [4.19]: MCNP Calculated Control Rod Worth for the LEU-A (BeO FA with $C / U=5200$ and $C / U=6619$ ) and HEU Core Configurations and the LEU-A/HEU Ratio ..... .52

Table [4.20]: MCNP Calculated Effective Delayed Neutron Fraction, $\beta_{\text {eff }}$ and Prompt Generation Lifetime $\left(I_{p}\right)$ for the LEU-A (BeO FA with $\mathrm{C} / \mathrm{U}=5200$ and $\mathrm{C} / \mathrm{U}=6619$ ) and HEU Core Configurations and the LEU-A/HEU Ratio (Error Calculated Using Error Propagation Theory)..... 53 Table [4.21]: MCNP Calculated Relative to HEU Peak Power Coupling Factor (PCF) for the Fuel Pins Irradiations (T462 and T-433) for the HEU, LEU-D (FA with $C / U=5200)$, LEU-D (BeO, FA with C/U=5200) and LEU-A (BeO, FA with $\mathrm{C} / \mathrm{U}=5200$ and $\mathrm{C} / \mathrm{U}=6619)$ Core Configurations

Table [5.1]: HEU Core TREKIN Calculated and Measured Temperature Reactivity Feedback, Maximum Temperature, Total Energy and Peak Power Using the Historic Input Data (TROD, $I_{p}, \beta_{\text {eff }}$ TEMPER, HSLOT). The Calculated-to-

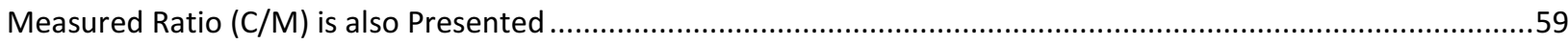
Table [5.2]: HEU TREKIN Calculations for the Temperature-Limited Transients Using MCNP Produced Input Data (TROD, $I_{p}, \beta_{\text {eff, }}$ TEMPER, HSLOT). SLOTK for the Best Agreement between the Calculated and the Measured Total Core Energy is also Shown (for \#2857 no SLOTK Adjustment was not needed).

Table [5.3] HEU Reactivity LSSS and SL Values Calculated with TREKIN and Reported for the HEU Half-Slotted Core for the Maximum Fuel Assembly Temperature of $600^{\circ} \mathrm{C}$ and $820^{\circ} \mathrm{C}$. Maximum Temperature at $60 \mathrm{~s}$.....................65 Table [5.4]: Reactivity LSSS and SL Values Calculated with TREKIN for the HEU, LEU-D (FA with C/U=5200) and LEUA (BeO, FA with $C / U=5200$ and $C / U=6619$ ) Cores with $S L O T K=1$ that Produce the Maximum Fuel Assembly Temperature of $600^{\circ} \mathrm{C}$ and $820^{\circ} \mathrm{C}$. Maximum Temperature at $60 \mathrm{~s}$

Table [5.5]: TREKIN Calculated Reactivity Insertion, Maximum Fuel Assembly Temperature, Full Width at Half Maximum (FWHM) and Flux Wire Total Energy for the LEU-D (FA with C/U=5200) and LEU-A (BeO, FA with $C / U=5200$ and $C / U=6619$ ) Cores to Deliver Equal Peak Power and Total Energy to the Flux Wire as the HEU Core Did for the Temperature Limited Transients \#2855, \#2856 and \#2857. End of Transient at $5 \mathrm{~s}$.....

Table [5.6] TREKIN Calculated Flux Wire Temperature-Limited Transients for the HEU, LEU-D (FA with C/U=5200) and LEU-A (BeO, FA with $\mathrm{C} / \mathrm{U}=5200$ and $\mathrm{C} / \mathrm{U}=6619$ ) Cores for the Maximum Allowed Reactivity Insertion. Flux Wire Peak Power and Total Energy were Calculated Using the MCNP Calculated Peak Power Coupling Factors. Total Energy and Maximum Temperature at $60 \mathrm{~s}$. . .69

Table [5.7]: Wire Peak Power and Total Energy Calculated Using the MCNP Calculated Peak Power Coupling Factors. Total Energy and Maximum Temperature at $60 \mathrm{~s}$, calculated with TREKIN for the Fuel Pin Temperature Limited Transient for the HEU, LEU-D (FA with C/U=5200) and LEU-A (BeO, FA with $C / U=5200$ and $C / U=6619$ ) Cores Using the Maximum Allowed Reactivity. . .70 Table [5.8]: TREKIN Calculated Temperature Limited Transients for the LEU-D (FA with C/U=5200) and LEU-A (BeO, FA with $C / U=5200$ and $C / U=6619$ ) Cores for Equal to the HEU Maximum Delivered Peak Power and Energy to the Flux Wire. Wire Peak Power and Total Energy were Calculated Using the MCNP Calculated Peak Power Coupling Factors. Core Energy and Maximum Temperature at $60 \mathrm{~s}$

Table [5.9]: TREKIN Calculated Temperature Limited Transients for the LEU-D (FA with C/U=5200) and LEU-A (BeO, FA with $C / U=5200$ and $C / U=6619$ ) Cores for Equal to HEU Maximum Delivered Peak Power and Energy to the Fuel Pin. Wire Peak Power and Total Energy were Calculated using the MCNP Calculated Peak Power Coupling Factors. Core Energy and Maximum Temperature at $60 \mathrm{~s}$. . .71 Table [5.10]: MCNP Calculated Peak Power Coupling Factor (PCF) for the HEU, LEU-D (FA with C/U=5200) and LEUA (BeO, FA with $C / U=5200$ and $C / U=6619$ ) Cores for Three Compositions; A: 1.19\% wt. U-235 B: 3.35\% wt. U-235 and C: $61.8 \%$ wt. U-235 and Two Wire Diameters (0.04 in. and 0.173 in.) ..... 
Table [5.11]: Peak Power Coupling Factor (PCF) Relative to 0.04 in. $0.016 \mathrm{~g}{ }^{235} \mathrm{U}$ Test Sample for the HEU, LEU-D (FA with $C / U=5200$ ) and LEU-A (BeO, FA with $C / U=5200$ and $C / U=6619$ ) Cores

Table [5.12]: TREKIN Calculated Relative to HEU Peak Power and Total Energy Delivered by the LEU-D (FA with $C / U=5200)$ and LEU-A (BeO, FA with $C / U=5200$ and $C / U=6619)$ Cores in the Flux Wire for Two Wire Diameters and Three Compositions; A) 1.19\% wt. U-235 B) 3.35\% wt. U-235 and C) $61.8 \%$ wt. U-235

Table [5.13]: Calculated Maximum Fuel Assembly (FA) Temperature, Peak Power and Total Energy Delivered in the Flux Wire for the \#2874 Shaped Transient Limited by the Safety Limits (SL) for the HEU, LEU-D (FA with C/U=5200) and LEU-A (BeO, FA with $\mathrm{C} / \mathrm{U}=5200$ and $\mathrm{C} / \mathrm{U}=6619$ ) Cores

Table [5.14]: TREKIN Period Driven Calculations For Flux Wire Irradiations for $0.3 \mathrm{~s}$ and 8s Period Power Increase in the HEU, LEU-D (FA with $C / U=5200$ ) and LEU-A (BeO, FA with $C / U=5200$ and $C / U=6619)$ Cores......

Table [5.15]: TREKIN Period Driven Calculations for $0.3 \mathrm{~s}$ and $8 \mathrm{~s}$ Period Power Increase in the T-462 Pin Irradiations in the HEU, LEU-D (FA with $C / U=5200$ ) and LEU-A (BeO, FA with $C / U=5200$ and $C / U=6619$ ) Cores.

Table [5.16]: TREKIN Period Driven Calculations for the LEU-D (FA with C/U=5200) and LEU-A (BeO, FA with $C / U=5200$ and $C / U=6619)$ for the Flux Wire Irradiation with Second Period to Deliver in the Flux Wire Equal Power with the HEU Core

Table [5.17]: TREKIN Period Driven Calculations for the LEU-D (FA with C/U=5200) and LEU-A (BeO, FA with $C / U=5200$ and $C / U=6619)$ for the $T-462$ Pin Fuel Irradiations with Second Period to Deliver the Same Peak Power as the HEU Core .81

Table [6.1]: Summary of Peak Power and Total Energy Delivered by the LEU-D (FA with C/U=5200) and LEU-A (BeO, FA with $C / U=5200$ and $C / U=6619)$ Cores in Flux Wire and Fuel Pin Computed for M8CAL Temperature-Limited Transient and $8 \mathrm{~s}$ Period Shaped Transient, for Low-enriched Flux Wire and for High-enriched Fuel Pin (T-462) 


\section{Introduction}

From the original startup of the Transient Reactor Test (TREAT) reactor in 1959 to being placed on a non-operational standby status in 1994, the TREAT facility was used to perform hundreds of experiments involving power transients. TREAT is a homogeneous, air-cooled, graphite-moderated and graphite-reflected reactor (Figures 1.1 and 1.2 from [2]). It was designed, built, and operated in a manner to allow a wide range of fueled test samples to be placed in the core and be subject to a wide variety of power transients, all performed such that strict TREAT core-temperature limits would not be exceeded, even in the event of a reactivity accident. The flexibility is provided by a variety of core assemblies and by the nature of the uranium-bearing graphite fuel itself. The core temperature limitation is set to prevent the potential for thermal damage to the Zircaloy cladding of the core assemblies. The self-limited nature of the power transients generated by the core is due to the temperature negative reactivity feedback provided by the large amount of graphite in the core. Power transients are generated by some of the control rods, called transient rods, which can be moved rapidly with precise position control in order to generate user-specified power-time histories.

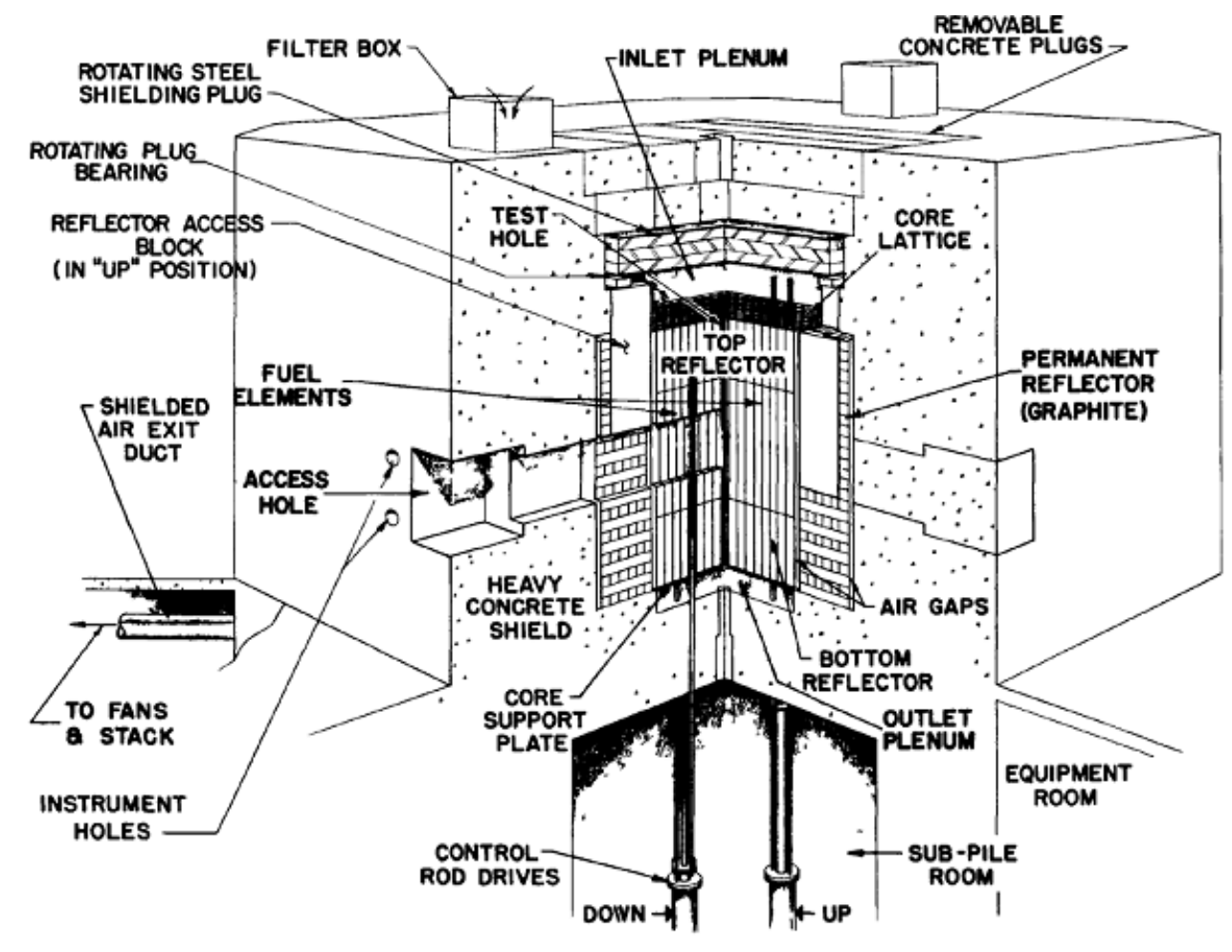

Figure [1.1]: Perspective View of TREAT

TREAT is operated in steady state mode at powers up to about $100 \mathrm{~kW}$ and in three categories of power transients: a. temperature-limited transients generated by computer-controlled sudden withdrawals of transient rods with typical time durations of several hundred milliseconds, b. shaped transients of various power-time histories generated by computer-controlled time-dependent movements of the transient rods with typical time durations of less than 20 seconds and c. extended transients generated by a combination of computer and manual control of the transient rods and other control rods, with 
durations of the order of minutes. (The term "Temperature-limited transient" is term used to denote a natural, bell-shaped power burst generated by a sudden "step" input of reactivity, with the power-time history controlled solely by the inherent negative temperature reactivity feedback characteristic of the core. In "shaped" transients, on the other hand, the power-time history is controlled principally by a more-complex program of transient rod motions.) The experiments typically involve irradiation of fuel samples located inside experiment test rigs (also called test vehicles, loops, or capsules), inserted into the TREAT core. The power generated in the test fuel sample during a TREAT power transient depends on the particular TREAT core loading, the neutronics characteristics of the test sample and test vehicle and the time-varying flux distribution in the TREAT core as the transient rods move during the transient.

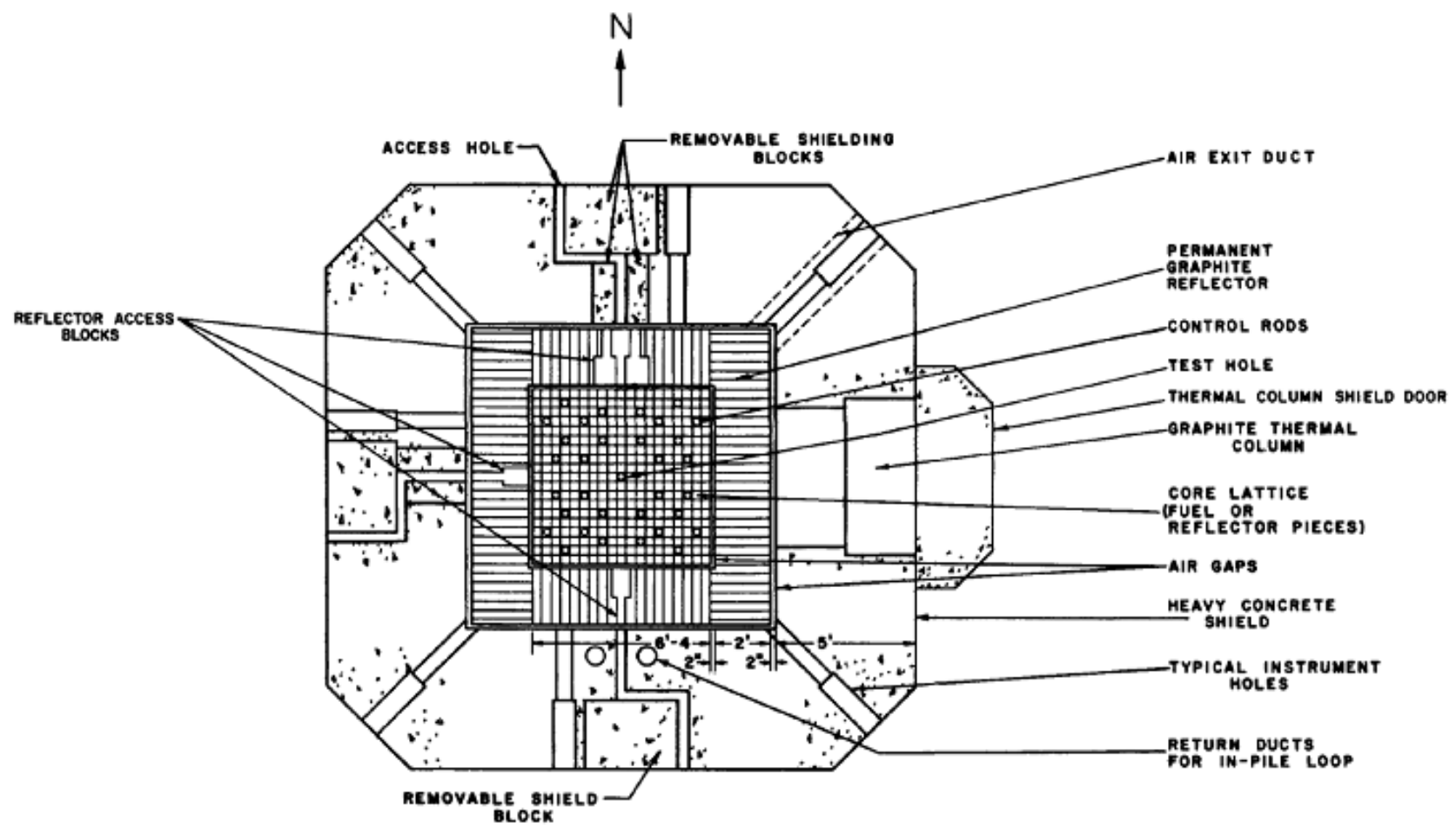

Figure [1.2]: Plan View of TREAT

\section{TREAT Core Description}

The reactor cavity is designed to accommodate a maximum core size of 76 in. $\times 76$ in. $\times 48$ in. (1.9 $\mathrm{m} \times$ $1.9 \mathrm{~m} \times 1.22 \mathrm{~m})$ high, or a total of 361 fuel assemblies, each about $4 \mathrm{in}$. $(10.16 \mathrm{~cm})$ square. The characteristics of the HEU fuel are tabulated in Table 2.1. The impurities in the TREAT fuel were reported [1] to be $7.6 \mathrm{ppm}$ by mass of boron and $600 \mathrm{ppm}$ by mass of iron. The standard fuel assembly (Figure 2.1) consists of upper and lower graphite reflector sections, and a central uranium oxide-bearing graphite fuel section. The $48 \mathrm{in}$. long $(121.92 \mathrm{~cm})$ fuel section contains six $8 \mathrm{in}$. long fuel blocks canned in Zircaloy-3, 25 mil thick, $(0.0635 \mathrm{~cm})$. The HEU fuel used during the 35 years of TREAT operation had a carbon to uranium atom ratio (C/U) of approximately 10,000 and a $\mathrm{U}-235$ enrichment of $93.1 \%$ wt. The upper and lower graphite reflector-sections, each $24 \mathrm{in}$. long $(60.92 \mathrm{~cm})$, contained in 50 mil thick $(0.127$ $\mathrm{cm}$ ) aluminum cans, are riveted to the ends of the fuel section. 


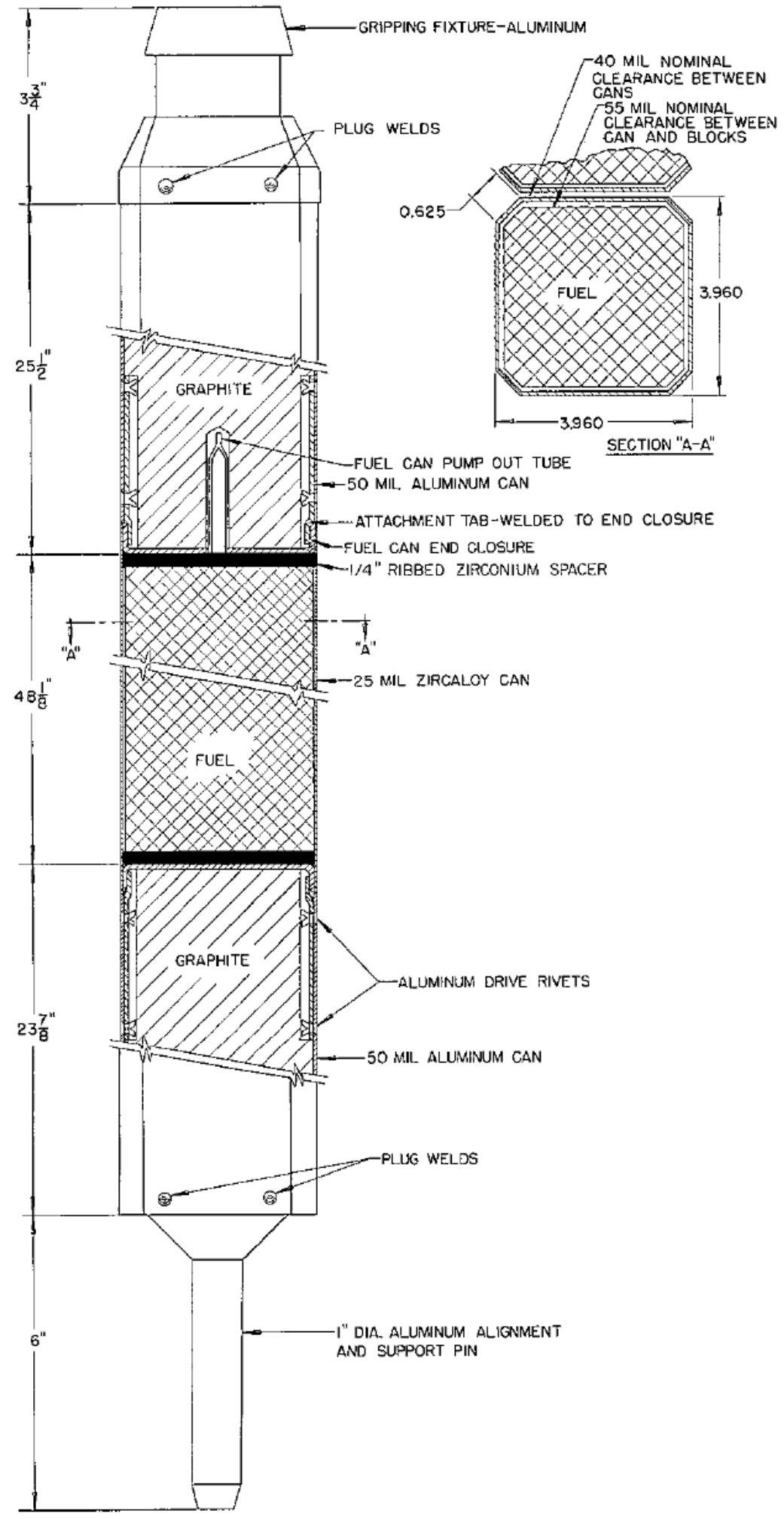

Figure [2.1]: Standard TREAT HEU Fuel Assembly 
The $1 / 4$-inch $(0.635 \mathrm{~cm})$ ribbed zirconium spacer above and below the fuel section delays the heat transfer from the fuel to reflector sections and thus protects the aluminum cans during the transients. A gripping fixture is welded to the upper reflector section, and a support and alignment pin are welded to the lower reflector section to complete the fuel assembly. The complete fuel assembly is slightly less than $108 \mathrm{in.} \mathrm{long}(2743.3 \mathrm{~cm})$, with a nominal cross section of 3.960 in. $\times 3.960 \mathrm{in.}(10.06 \mathrm{~cm} \times 10.06 \mathrm{~cm})$, and weighs $95 \mathrm{lb}(43.1 \mathrm{~kg})$. The four corners of each assembly are chamfered and when combined with those of the adjacent assemblies, form $0.625 \mathrm{in}$. $(1.5875 \mathrm{~cm})$ square coolant passages through the assembled core. The nominal clearances in the core are: $40 \mathrm{mil}(0.1016 \mathrm{~cm})$ between adjacent Zircaloy cans and $55 \mathrm{mil}(0.140 \mathrm{~cm})$ between the Zircaloy can and graphite-fuel blocks.

Table [2.1]: TREAT HEU Fuel Characteristics

\begin{tabular}{|l|l|}
\hline Fuel Material & $\mathrm{UO}_{2}$ in CP-2 graphite \\
\hline C/U-235 ratio & $\approx 10000$ \\
\hline Fuel assembly outer dimensions & $3.96 \times 3.96$ in. $^{2}$ \\
\hline Average Fuel density & $1.72 \mathrm{~g} / \mathrm{cm}^{3}$ \\
\hline${ }^{\mathbf{2 3 5}} \mathrm{U}$ wt (\%) in U & 93.1 \\
\hline${ }^{\mathbf{2 3 8}} \mathrm{U}$ wt(\%) in U & 6.8 \\
\hline Cladding Material & Zircaloy-3 \\
\hline Boron Impurity (per weight) & $7.6 \pm 1.4 \mathrm{ppm}$ \\
\hline Iron Impurity (per weight) & $600 \mathrm{ppm}$ \\
\hline
\end{tabular}

Control rod fuel assemblies (Figure 2.2) have the same geometry and composition as the standard fuel assembly except for a circular hole in the center. This hole accommodates a Zircaloy guide tube bearing the boron carbide $\left(\mathrm{B}_{4} \mathrm{C}\right)$ containing control rod. The tubular control rod sleeve, 1.75 in. diameter (4.445 $\mathrm{cm}) \times 1 / 8$ in. thick wall $(0.3175 \mathrm{~cm})$, is composed of three sections, each connected with a threaded joint and locking screw (Figure 2.3): a nickel-plated carbon steel poison section which contains $\mathrm{B}_{4} \mathrm{C}$ powder compacted with reported densities 1.5 to $1.8 \mathrm{~g} / \mathrm{cm}^{3}$, a Zircaloy follower filled with graphite to minimize streaming and a nickel-plated carbon steel follower, also filled with graphite, that connects to the drive mechanism. The entire control rod weighs $65 \mathrm{lb}(29.5 \mathrm{~kg})$. There are currently 20 control rods used in the TREAT core: eight attached to the four control/shutdown drives, four attached to the four compensation/shutdown rod drives and eight connected to the four transient rod drives. The position of rods, grouped according to the rod drives type, is shown in Figure 2.4.

"Dummy" assemblies are also available (Figure 2.2-right) which have 50 mil thick $(0.127 \mathrm{~cm})$ aluminum cans and are of the same geometry as the upper and lower reflectors of the fuel assembly but have graphite blocks in the core instead of fuel. Typically, the graphite dummy assemblies are also nominally 4 inches square like the fuel assemblies, although dummy assemblies of other cross sections have been made to fill in spaces around certain experiment vehicles.

Slotted "access hole" assemblies are used to provide open viewing access from the core edge to the core center, as needed (for example) for operation of the TREAT hodoscope. These assemblies have basically the same geometry as the standard assembly but with the fuel and opposite faces of the incore part of the can removed. 
The permanent graphite radial reflector (Figure 1.2) is constructed of $4 \mathrm{in.}(10.16 \mathrm{~cm})$ square stringers of graphite stacked $7 \mathrm{ft} .8 \mathrm{in} .(233.68 \mathrm{~cm})$ high and $2 \mathrm{ft} .(60.96 \mathrm{~cm})$ thick along the four inside walls of the shield cavity. Large, movable blocks of graphite $(\sim 275 \mathrm{lb} . / 124.74 \mathrm{~kg})$ are installed in regions with core viewing slots. These blocks move vertically and are supported in the "open" position by an aluminum lifting bracket mounted on the ledge of the concrete shield above the reflector. There is one movable block each in the south and west sides providing viewing slots of $4 \frac{1 / 4}{\mathrm{in}}$. wide $x 24 \mathrm{in}$. high (10.795 $\mathrm{x}$ $60.96 \mathrm{~cm}^{2}$ ) through the reflector. There are three movable blocks in the north side: the central block can be lifted to provide a slot 4 in. $\times 32$ in. $\left(10.16 \times 81.28 \mathrm{~cm}^{2}\right)$, or all three blocks can be removed (through the shutdown shield plug) to provide an opening slot of $14 \frac{1}{4} \mathrm{in.} \times 32 \mathrm{in.}(36.195 \mathrm{~cm} \times 81.28 \mathrm{~cm}$ ) There are two horizontal holes, 6 in. diameter $(15.24 \mathrm{~cm})$ in each of the north, south, and west faces to accommodate installation of fast-response instruments close to the core [2]. The graphite was formerly used in the $\mathrm{CP}-2$ reactor.

The fuel temperature limit under normal operations is set to $600{ }^{\circ} \mathrm{C}$. For the HEU core studied as a reference, this temperature limit would be reached at approximately $2100 \mathrm{MJ}$ of total fission energy. This limit is set due to the increasingly rapid oxidation rate of Zircaloy clad when heated to high temperatures in air. The corrosion rate of Zircaloy-3 is $<1 \mathrm{mil} /$ year $(0.0254 \mathrm{~mm} /$ year $)$ in air at $400^{\circ} \mathrm{C}$. Above $400^{\circ} \mathrm{C}$ the corrosion rate increases rapidly and is about $0.9 \mathrm{mil} /$ day $(0.02286 \mathrm{~mm} /$ day $)$ at $700^{\circ} \mathrm{C}$.

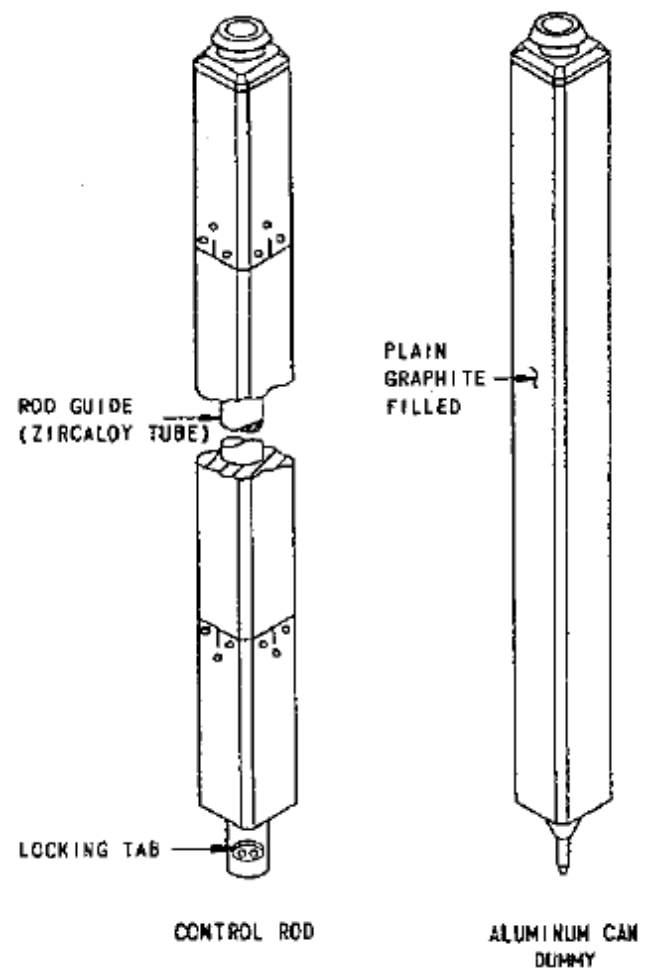

Figure [2.2]: Control Rod (Left) and Aluminum Canned Dummy (Right) Assemblies 


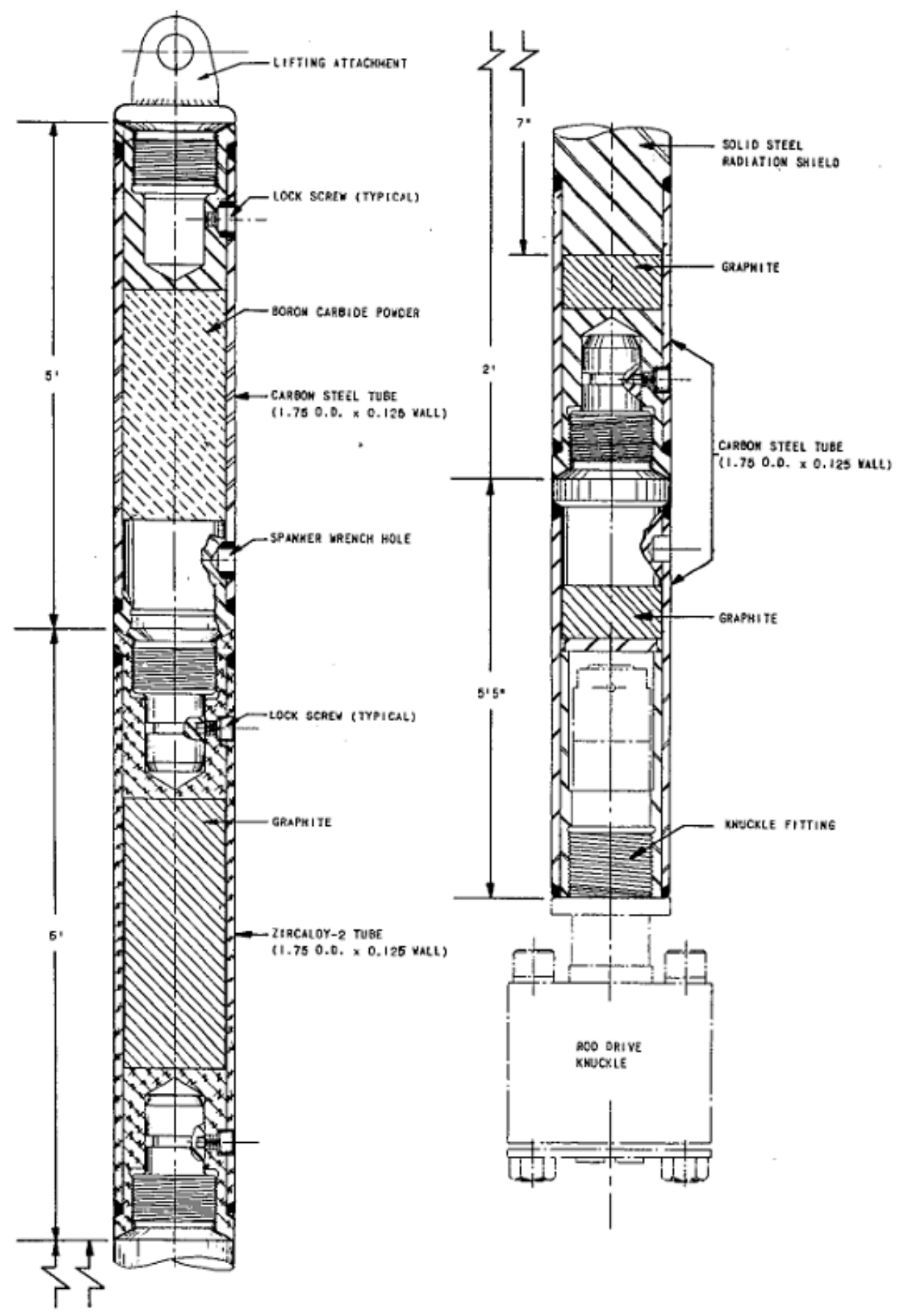

Figure [2.3]: Control Rod Assembly 


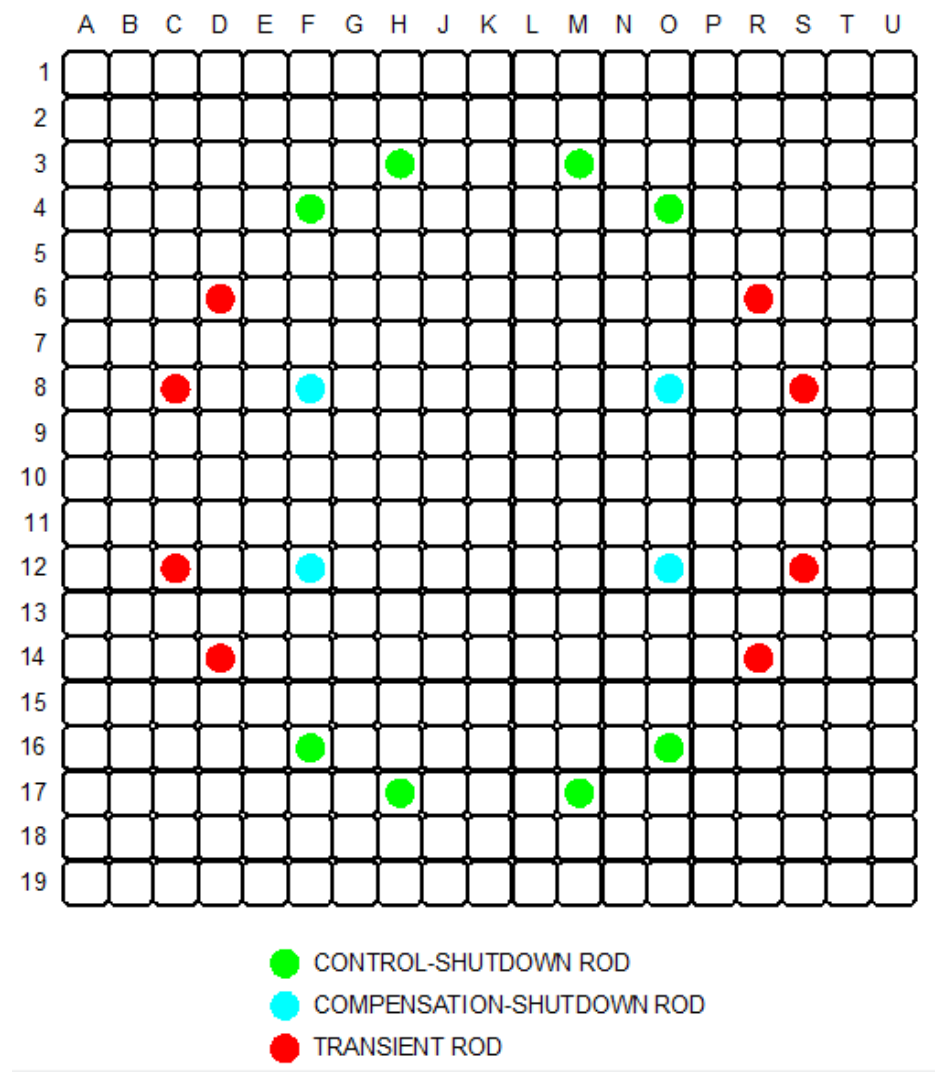

Figure [2.4]: Control Rods Position in the Studied HEUTREAT Core

\section{The M8 Calibration Experiment}

To help evaluate the performance of LEU core designs for TREAT, it was useful to consider a reference HEU core for comparison. Various cores have been historically used in experiment programs in TREAT, from small cores in early experiments on small fuel samples in small test vehicles to essentially maximum size cores generating high energy in large fuel samples contained in highly-absorbing experiment vehicles that were typically used later in TREAT's operational history. It is assumed that future utilization of TREAT would again need to employ the combination of large-core, large fuel sample, large test vehicle, and high fuel sample energy. In fact, the experiment program underway when TREAT was placed on standby in 1994 was a continuation of Integral Fast Reactor experiments intending to test two or more EBR-II-irradiated or Fast Flux Test Facility (FFTF)-irradiated pins (per test) in Mark-III sodium loops, utilizing the maximum-allowable TREAT energy and thus the largest practical core. In preparation for such tests, a series of neutronics calibrations irradiations (called M8CAL) were performed during the 1990-92 time period.

This M8CAL calibration campaign was the most extensive ever performed in TREAT because (a) it was the first time the re-configured TREAT core (i.e., the "Upgraded-TREAT" HEU core put in place in the late 1980s) would be used for loop experiments, (b) the neutronics characteristics of the upgraded core were expected to be significantly different from those of the previous core, and (c) the calibration campaign was to provide calibration information for a variety of future experiment options. Information from the 
M8CAL irradiations was considered to be by far the best for comparing the performance of the existing HEU core with the performance of a replacement LEU core because M8CAL is the only extensive evaluation of the maximum performance of the current HEU core and because M8CAL evaluated test conditions that were highly relevant programmatically then and will probably be in the foreseeable future. A description of M8CAL and the subset of the large body of M8CAL information that was chosen for this HEU-LEU core comparison study are described below.

The M8 calibration experiment [3] was a series of irradiations performed in TREAT to determine the relationship between the fission power generated in the TREAT core and the fission power generated in the test sample positioned in the calibration vehicle. (The calibration vehicle was a low-cost accurate neutronic mockup of the test vehicle.) This relationship is described with the Power Coupling Factor (PCF), which describes the relation between the reactor power (or energy) and the power (or energy) deposited in the test sample (by the number of fissions occurring in the test sample). This factor has units of test sample power per gram (or number of fissions per gram) of test sample per unit of TREAT power. The PCF depends upon several parameters including the composition of the fuel sample, the configuration of fuel assemblies in the core, the configuration of control rods and the axial location and movement of the absorbing portion of the control rods during irradiation experiments.

Four low-power-level steady-state (LLSS) irradiations were analyzed implementing two different critical rod configurations. The irradiated targets were (a) three axial low-enriched (19.8 wt \% U-235) U-Zr monitor wires (also referred to as "flux wires") [two were 8 in. $(20.32 \mathrm{~cm}$ ) long and one was $60 \mathrm{in}$. (152.4 $\mathrm{cm}$ ) long] composed of $3.6 \mathrm{wt}$. \% uranium with a total density of $8.16 \mathrm{~g} / \mathrm{cm}^{3}$ and (b) two fuel pins, T-433 $(\mathrm{U}-10 \mathrm{wt} \% \mathrm{Zr}$ ) and T-462 (U - $19 \mathrm{wt} \% \mathrm{Pu}-10 \mathrm{wt} \% \mathrm{Zr}$ ). The flux wires are used during pre-test transienttuning as surrogates for the fuel pins that will be subjected to the transient.

In the T-433 pin the uranium was $68.5 \mathrm{wt} \%$ enriched and the fuel density was $=14.98 \mathrm{~g} / \mathrm{cm}^{3}$. In pin T462 the uranium was $56.88 \mathrm{wt} \%$ enriched and the fuel density was $14.91 \mathrm{~g} / \mathrm{cm}^{3}$. The reported compositions of the flux wire and fuel pins are shown in Tables 3.1 and 3.2, respectively. The dimensions of the 8 in. long flux wire and a reference metal alloy fuel pin are shown in Figures 3.1 and 3.2, respectively.

Table [3.1]: Reported Flux Monitor Wire Composition [3]

\begin{tabular}{|r|c|}
\hline Element & wt (\%) \\
\hline Uranium & 6.0 \\
\hline U-233 & 0.0005 \\
\hline$U-234$ & 0.1114 \\
\hline$U-235$ & 19.833 \\
\hline U-236 & 0.1379 \\
\hline U-238 & 79.918 \\
\hline Zirconium & 94.0 \\
\hline
\end{tabular}


Table [3.2]: Reported Fuel Pin Composition [3]

\begin{tabular}{|c|c|c|c|c|}
\hline & \multicolumn{2}{|c|}{ wt (\%) } & \multicolumn{2}{c|}{ Mass (g) } \\
\hline element & T-462 & T-433 & T-462 & T-433 \\
\hline Uranium & 71.02 & 90.24 & 55.31 & 69.98 \\
\hline $\mathrm{U}-234$ & 0.56 & 0.63 & 0.31 & 0.44 \\
\hline $\mathrm{U}-235$ & 56.88 & 68.51 & 31.46 & 47.94 \\
\hline $\mathrm{U}-236$ & 0.33 & 0.37 & 0.18 & 0.26 \\
\hline $\mathrm{U}-238$ & 42.23 & 30.49 & 23.36 & 21.34 \\
\hline Plutonium & 19.15 & $\mathrm{n} / \mathrm{a}$ & 14.92 & $\mathrm{n} / \mathrm{a}$ \\
\hline $\mathrm{Pu}-239$ & 93.85 & $\mathrm{n} / \mathrm{a}$ & 14.00 & $\mathrm{n} / \mathrm{a}$ \\
\hline $\mathrm{Pu} 240$ & 5.83 & $\mathrm{n} / \mathrm{a}$ & 0.87 & $\mathrm{n} / \mathrm{a}$ \\
\hline $\mathrm{Pu}-241$ & 0.27 & $\mathrm{n} / \mathrm{a}$ & 0.04 & $\mathrm{n} / \mathrm{a}$ \\
\hline $\mathrm{Pu}-242$ & 0.05 & $\mathrm{n} / \mathrm{a}$ & 0.007 & $\mathrm{n} / \mathrm{a}$ \\
\hline Zirconium & 9.82 & 9.76 & 7.65 & 7.57 \\
\hline
\end{tabular}

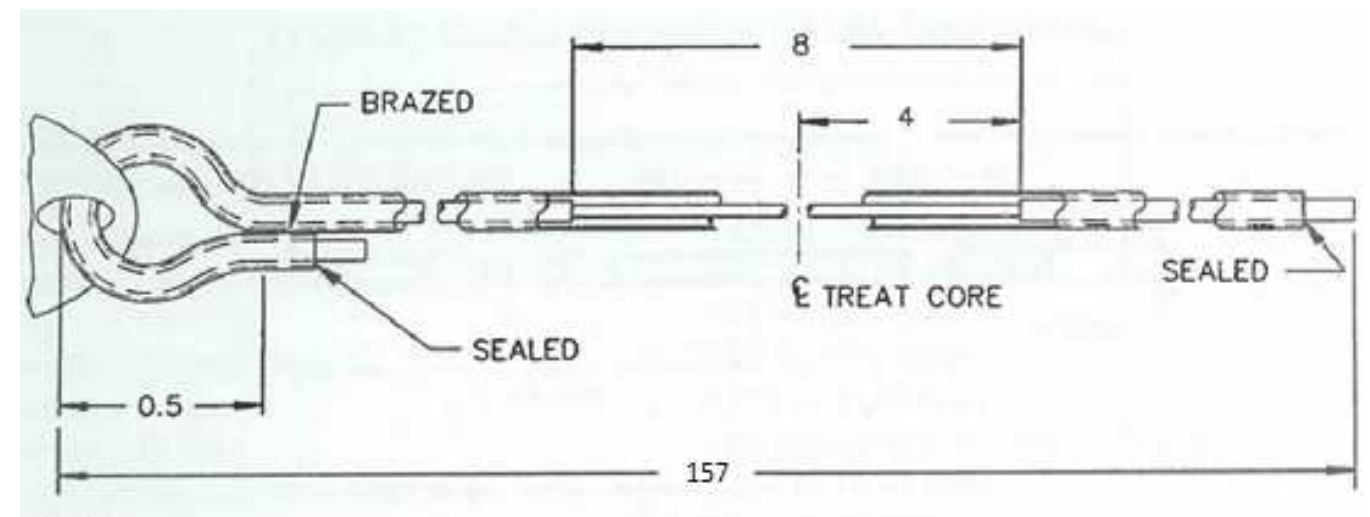

NOTE:

ALL DIMENSIONS IN inches

Figure [3.1]: 8" Long Flux Wire Assembly 

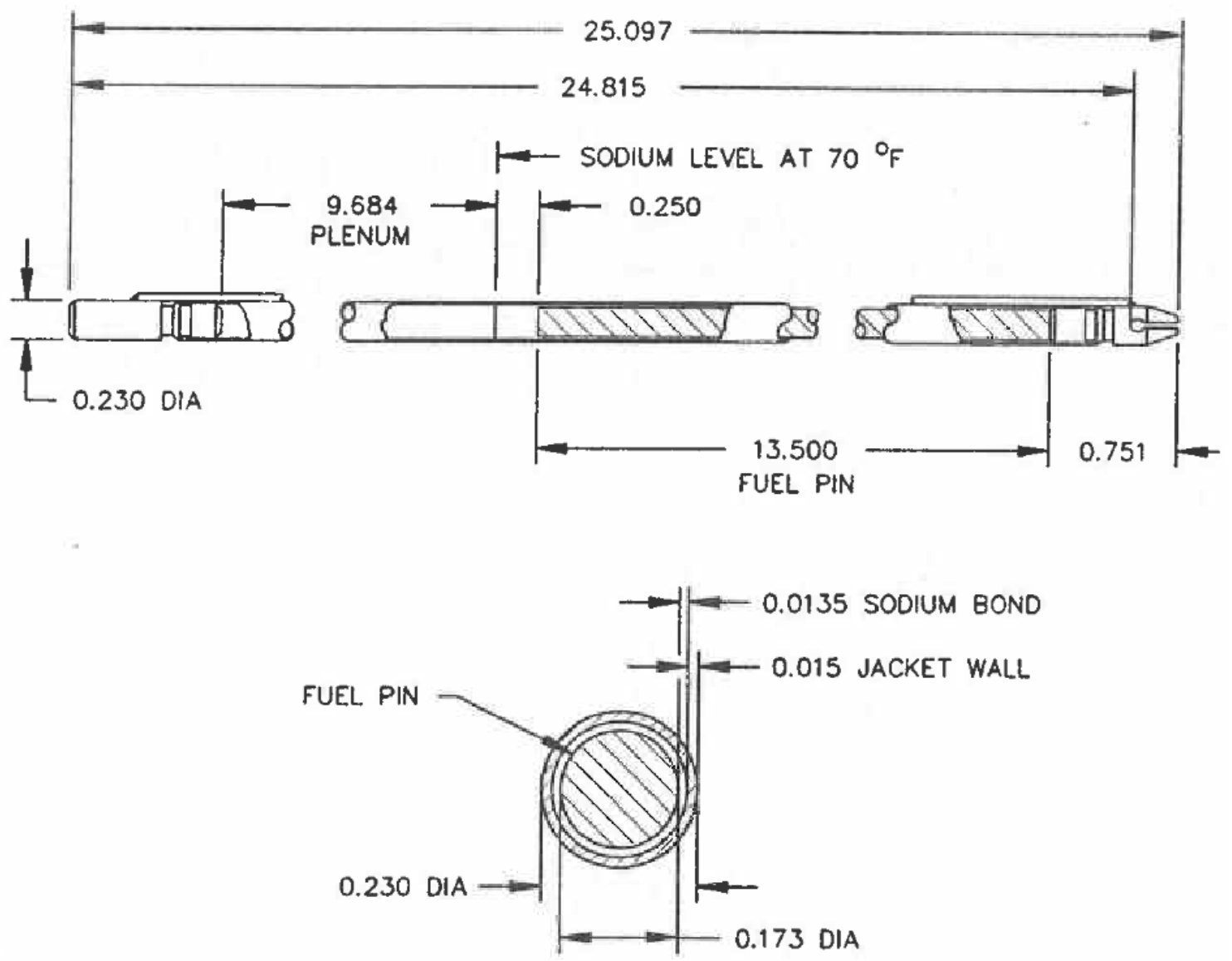

ALL DIMENSIONS IN inches

SCALE: $4 X$

Siocis

Figure [3.2]: Reference Metal Alloy Fuel Pin

\section{MCNP Neutronics Analyses}

\subsection{MCNP Model Description}

A detailed 3D model of the TREAT core was designed using the MCNP code [4] including the fuel assemblies, the control rods and the core-surrounding graphite reflector with slotted assemblies along one radius from core center to edge ("half-slotted" core). Nuclear cross sections were based on the ENDF/B-VII data set. The fuel and structural material compositions reported by Naberejnev [5] were used (the compositions are available in Appendix A), and a uniform fuel uranium-oxide powder distribution was assumed within the fuel.

The fuel composition used in the MCNP models is tabulated in Table 4.1 [5]. The reported ${ }^{235} \mathrm{U}$ critical mass for this configuration was 5171g [7]. Based on the fuel volume and the reported ${ }^{235} \mathrm{U}$ density $\left(3.3887 \times 10^{-3} \mathrm{~g} / \mathrm{cm}^{3}\right)$ Naberejnev calculated the total amount of ${ }^{235} \mathrm{U}$ to be $37.36 \mathrm{~g}$ per standard fuel assembly and $26.08 \mathrm{~g}$ per control fuel assembly. 
Table [4.1]: HEU Fuel Composition Used in the MCNP TREAT Core Models [5]

\begin{tabular}{|c|c|c|}
\hline Isotope & MCNP label & Atoms/b-cm \\
\hline${ }^{235} \mathrm{U}$ & $92235.70 \mathrm{c}$ & $8.6849 \mathrm{E}-6$ \\
\hline${ }^{238} \mathrm{U}$ & $92238.70 \mathrm{c}$ & $6.2967 \mathrm{E}-7$ \\
\hline${ }^{54} \mathrm{Fe}$ & $26054.70 \mathrm{c}$ & $6.5286 \mathrm{E}-7$ \\
\hline${ }^{56} \mathrm{Fe}$ & $26056.70 \mathrm{c}$ & $1.0239 \mathrm{E}-5$ \\
\hline${ }^{57} \mathrm{Fe}$ & $26057.70 \mathrm{c}$ & $2.3659 \mathrm{E}-7$ \\
\hline${ }^{58} \mathrm{Fe}$ & $26058.70 \mathrm{c}$ & $3.1248 \mathrm{E}-8$ \\
\hline $\mathrm{O}$ & $8016.70 \mathrm{c}$ & $1.8623 \mathrm{E}-5$ \\
\hline $\mathrm{C}$ & $6000.70 \mathrm{c}$ & $8.6227 \mathrm{E}-2$ \\
\hline${ }^{10} \mathrm{~B}$ & $5010.70 \mathrm{c}$ & $1.4495 \mathrm{E}-7$ \\
\hline${ }^{11} \mathrm{~B}$ & $5011.70 \mathrm{c}$ & $5.8343 \mathrm{E}-7$ \\
\hline
\end{tabular}

\subsubsection{Minimum TREAT Core Configuration}

The first step to validate the MCNP model was to analyze the TREAT minimum critical core [6]. This core was composed of 133 standard and 8 control rod fuel assemblies. The control rods were fully withdrawn in a way that the $\mathrm{B}_{4} \mathrm{C}$ part was above the upper reflector region. The number of Zircaloy clad dummy assemblies was not certain [6] so two MCNP calculations were performed with only aluminum cladded dummy assemblies and with 16 Zircaloy cladded dummy assemblies positioned as shown in Figure 4.1. The results of the MCNP calculations were $k_{\text {eff }}=0.98308 \pm 0.00014$ and $k_{\text {eff }}=0.98506 \pm 0.00014$ using only aluminum cladded and 16 Zircaloy cladded reflector assemblies, respectively. Using the MCNP model for the aluminum and Zircaloy cladded dummy assemblies, two runs were performed using the minimum $(7.6-1.4=6.2 \mathrm{ppm})$ and maximum $(7.6+1.4=9.0 \mathrm{ppm})$ boron impurity. The effective multiplication factor for the minimum and maximum boron impurity was $k_{\text {eff }(\min \text { boron) }}=0.99718 \pm$ 0.00016 and $k_{\text {eff }(\max \text { boron) }}=0.97334 \pm 0.00015$, respectively. Approximately a change of the boron impurity by $1 \mathrm{ppm}$ induces a $1 \% \Delta \mathrm{k} / \mathrm{k}(1000 \mathrm{pcm})$ change in the multiplication factor. 


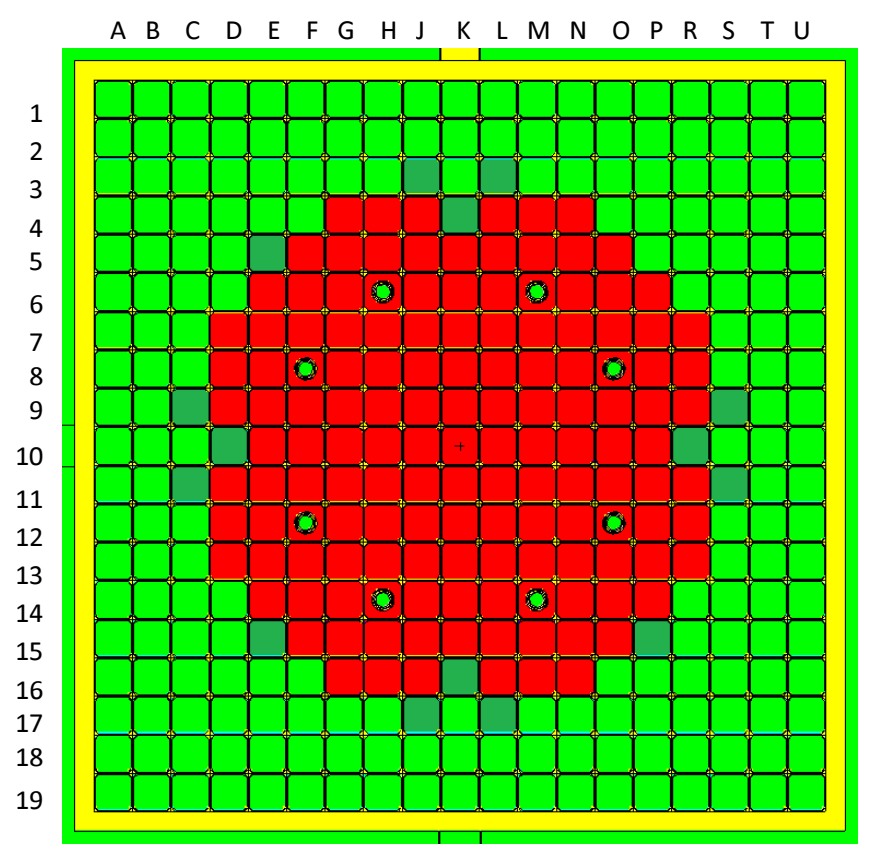

Figure [4.1]: MCNP Model of the Minimum HEU TREAT Core

\section{Al Clad Graphite Reflector,}

Fuel Assembly,

O. Control Assembly,

$\square$ Air,

Zr Clad Graphite Reflector)

\subsubsection{Half-Slotted Core}

The M8CAL half-slotted core, composed of 318 standard and 20 control-rod fuel assemblies with the M8CAL vehicle located at the center, was chosen as a reference case for these neutronics calculations. In this core configuration there were also eight slotted assemblies (positions K1 to K8) and one half-size slotted assembly (position K9) forming the hodoscope viewing slot to the M8CAL vehicle, and also one half-size size graphite dummy assembly in K11.

Figure 4.2 presents a cross section ( $x-y$ ) view of the HEU TREAT MCNP model and Figure 4.3 the M8CAL irradiation vehicle with the two test fuel pins. The axial dysprosium collars configuration (dimensions shown in Figure 4.4) of the M8CAL vehicle were also modeled. The dysprosium collars were positioned around the calibration vehicle, above and below the location of the fuel sample, to provide the desired axial neutron flux distribution incident upon the test fuel. The setup of the M8CAL in the center of the core is illustrated in Figure 4.5. The pump leg of the calibration loop was also included in the MCNP model. 


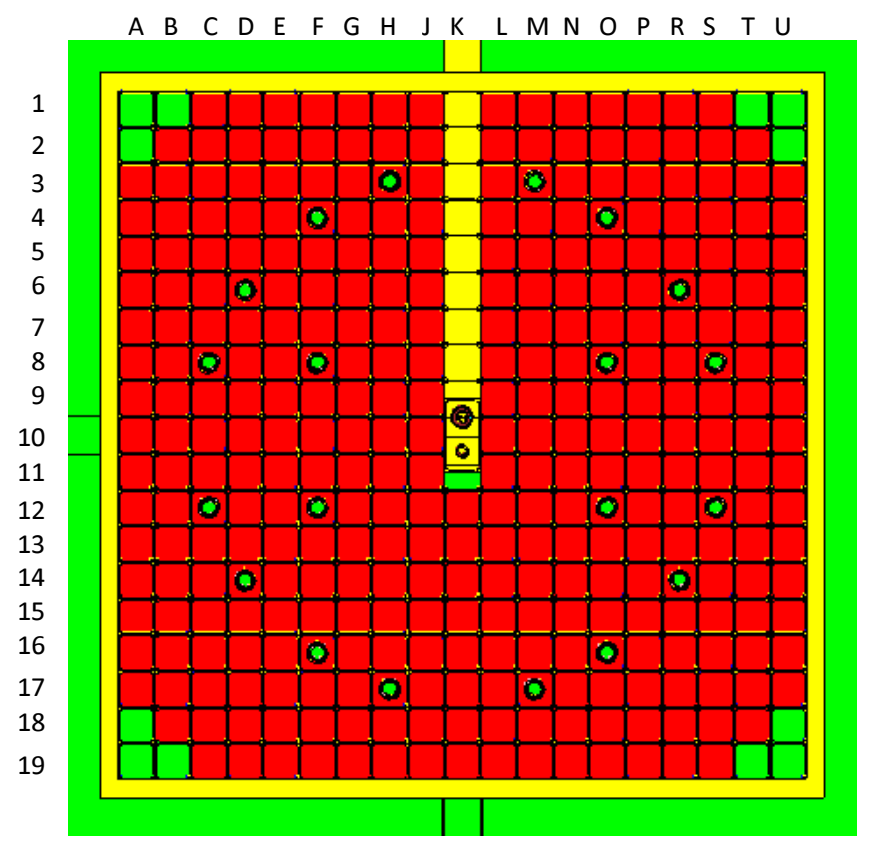

Figure [4.2]: MCNP Model of the Half Slotted HEU TREAT core. The M8CAL Vehicle in Core Center Graphite Reflector, $\square$ Fuel Assembly, $\mathrm{O}$ Control Assembly, $\square$ Air)

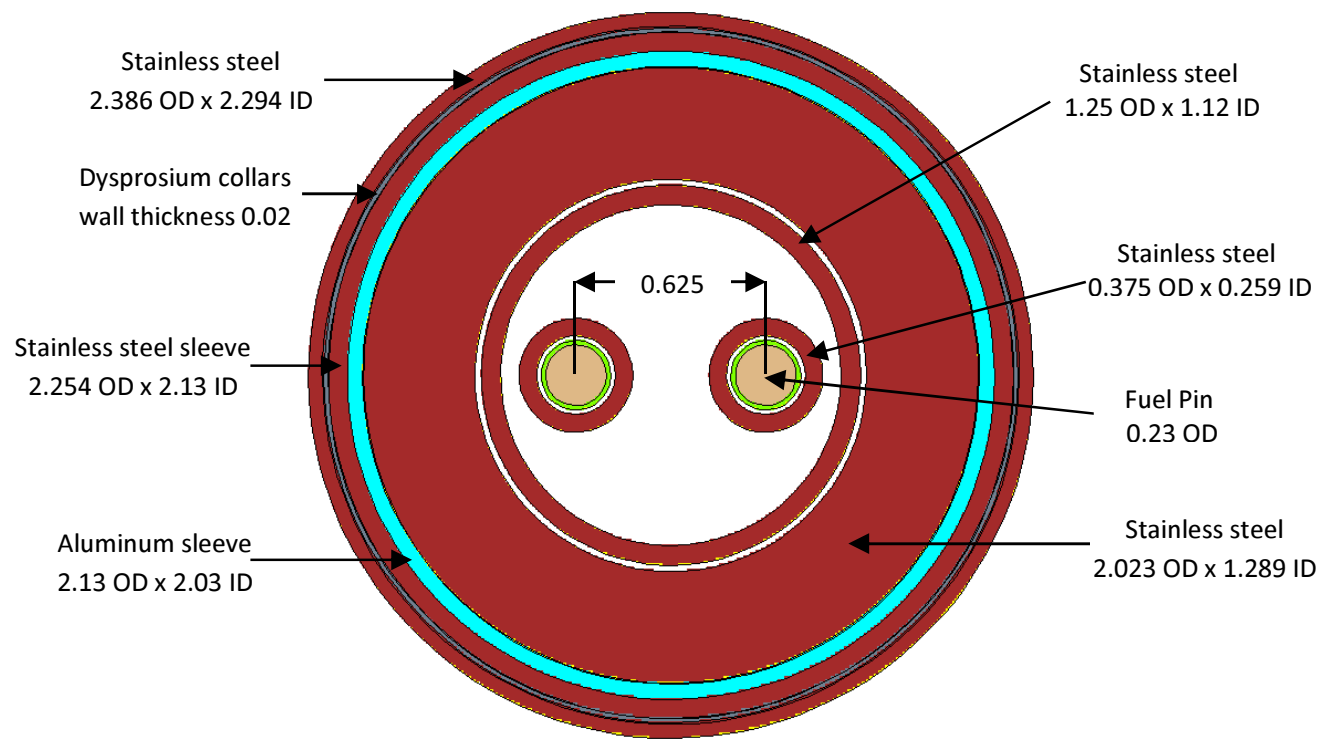

Figure [4.3]: MCNP Model Showing the Test Section Leg of the M8CAL Test Vehicle with Two Fuel Test Pins (T-462-Left, T-433Right). Dimensions in Inches 

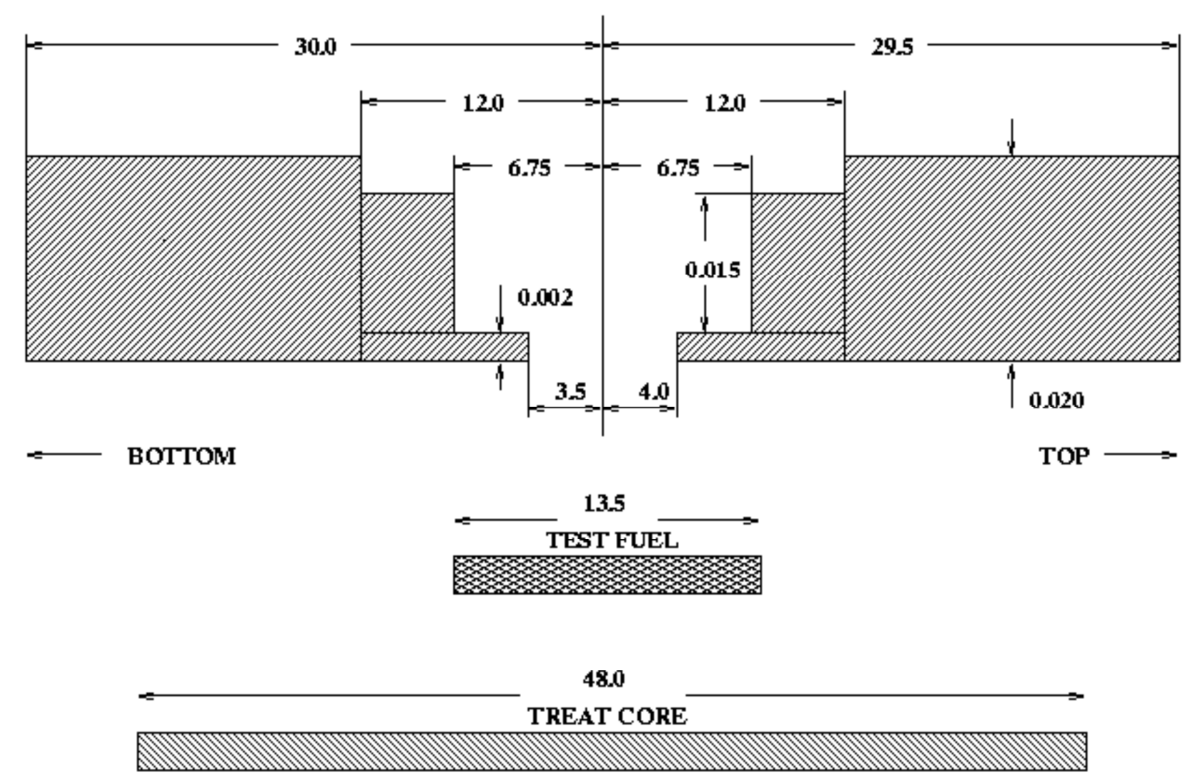

Figure [4.4]: M8CAL Dysprosium Shaping Collars Configuration (Dimensions in Inches)

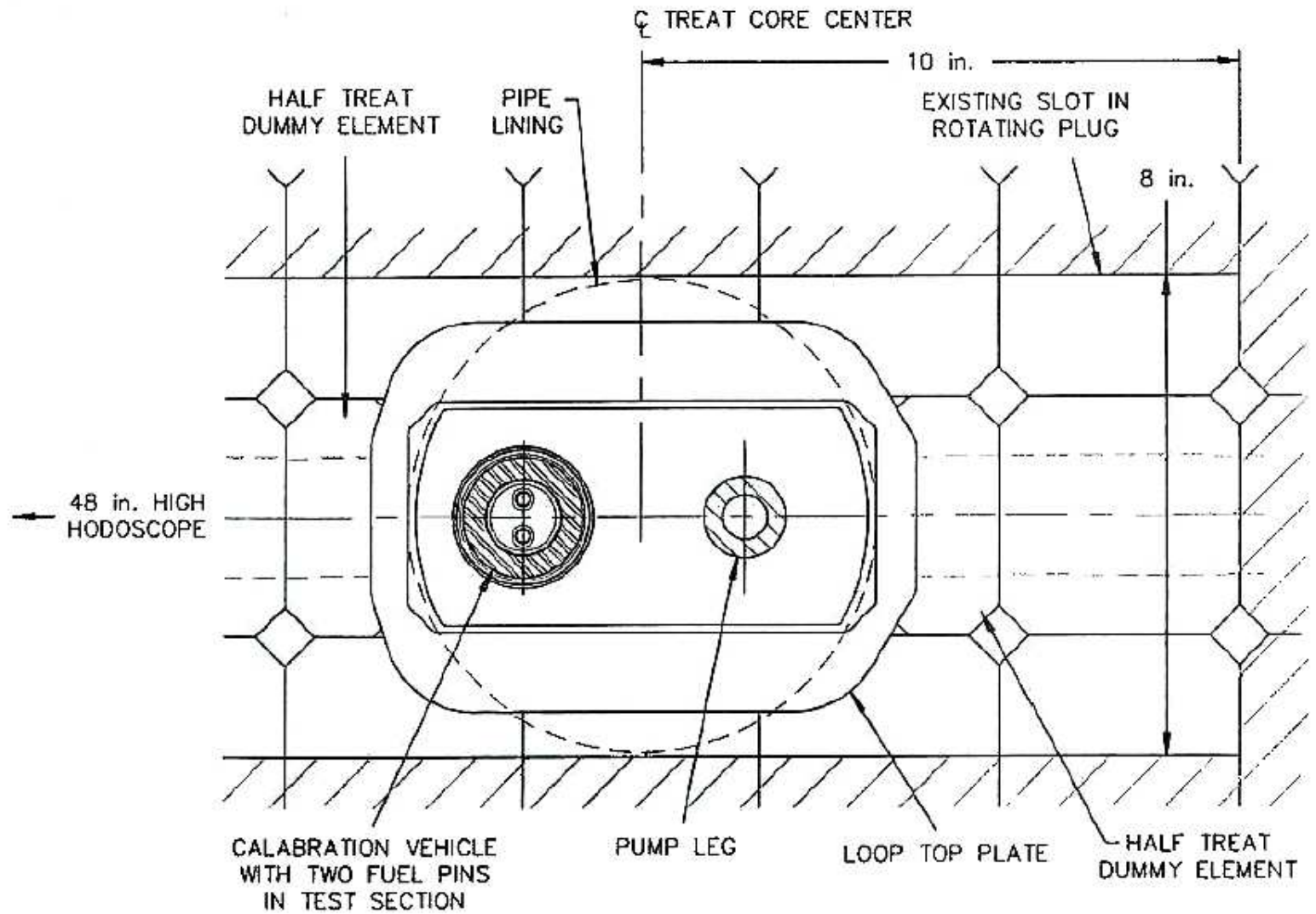

Figure [4.5]: Cross Section View of the Fueled M8CAL Vehicle in the Center of TREAT (Dimensions in Inches) 


\subsection{Sources of Uncertainty}

The uncertainty of the boron content inside the TREAT fuel is the most important source of error in the MCNP calculations. It was calculated that a \pm 1 ppm change of the boron impurity induces nearly a $\mp 1 \%$ $\Delta \mathrm{k} / \mathrm{k}(1000 \mathrm{pcm})$ change in the effective multiplication factor, $\mathrm{k}_{\mathrm{eff}}$. The boron impurity concentration and its distribution inside the TREAT fuel are unknown. A series of spectro-chemical analyses of 50 core graphite samples reported a boron impurity with an average value of $7.6 \pm 1.4 \mathrm{ppm}$ [1]. The average value was used in the MCNP models and a uniform distribution within the fuel was assumed. Other sources of uncertainty are the rod position (reported values differ by \pm 0.3 inches for every rod [3]), and the density of $\mathrm{B}_{4} \mathrm{C}$ (the neutron absorbing material of the rods) reported as having a range of 1.5 to $1.8 \mathrm{~g} / \mathrm{cm}^{3}$. Impurities in the rods' absorbing material $\left(\mathrm{B}_{4} \mathrm{C}\right)$ were unknown and hence were not included in the MCNP model.

\subsection{MCNP HEU Model Validation}

Validation of the MCNP model of the HEU core was performed in several steps, using data from the M8CAL irradiations. The first step was to compute the reactivity for experimentally-established M8CAL critical core configurations. The next step was to compute the control-rod worth curves and compare them with reported measured worth curves. The third step was to compute the ratio of fission rate in a fissile test sample to the core power and compare that ratio with M8CAL measurements taken at lowpower levels with the transient rods motionless. That was further refined by computing the axial profile of the fission density in the test sample with the measured axial profile. In addition, the prompt neutron generation time and the effective delayed neutron fraction were computed for the cold critical core and compared against historically-used values. Lastly, the negative neutronics feedback due to core temperature rise (typically expressed in terms of feedback reactivity as a function of core energy generated) was computed and compared with the historically-used feedback curve. Each of these steps is described below.

\subsubsection{Critical Core Configurations}

Four measured critical TREAT configurations were simulated with MCNP. Two rod configurations were used during the low level steady state (LLSS) irradiations of three different U-Zr flux monitor wires and a set of two fuel pins placed in the center of the test-section leg of the M8CAL vehicle. The rod positions used in the irradiations were:

- Configuration A: Compensation rods $100 \%$ withdrawn, control/shutdown rods $\approx 38 \%$ withdrawn and transient rods $100 \%$ withdrawn

- Configuration B: Compensation rods $100 \%$ withdrawn, control/shutdown rods $\approx 83 \%$ withdrawn and transient rods $\sim 29 \%$ withdrawn

It is reported that during the LLSS irradiations the transient rods were $10 \%$ (4 in.) withdrawn [3] but in the MCNP calculation the transients rods maintained the initial position. Table 4.2 tabulates the deviation from criticality for the MCNP calculations. 
Table [4.2]: MCNP Criticality Calculations of the LLSS Configurations in the HEU Core

\begin{tabular}{|c|c|c|c|}
\hline Configuration & Test vehicle & Calculated $\mathrm{k}_{\mathrm{eff}} * *$ & $(\mathrm{k}-1) / \mathrm{k}(\mathrm{pcm} *)$ \\
\hline A & 8 inch-long flux wire & 1.00276 & 275 \\
\hline B & 8 inch-long flux wire & 1.00177 & 177 \\
\hline$A$ & T-462/T-433 fuel pins & 1.00350 & 349 \\
\hline$A$ & 60 inch-long flux wire & 1.00287 & 287 \\
\hline \multirow{2}{*}{\multicolumn{3}{|c|}{$\begin{array}{l}\text { RMS } \\
\text { SRMS }\end{array}$}} & 279 \\
\hline & & & 62 \\
\hline
\end{tabular}

The root mean square (RMS) deviation from criticality was $279 \mathrm{pcm}$ and is acceptable considering the $\pm 1000 \mathrm{pcm}$ bias induced by the $\pm 1.4 \mathrm{ppm}$ uncertainty in the Boron concentration in the TREAT fuel. RMS and the error $\delta \mathrm{RMS}$ were calculated using the equations: $R M S=\sqrt{\frac{\sum_{i=1}^{N} x_{i}^{2}}{N}}$ and $\delta R M S=\sqrt{\frac{\sum_{i}^{N}\left(x_{i}-\bar{x}\right)^{2}}{N}}$.

\subsubsection{Transient Rods Available Reactivity and Rod Withdrawal}

During an experiment in TREAT the transient rods are withdrawn as required to deliver the desired fission power to the irradiated sample (shaped transients). It is very important for the reactor operator to know the available reactivity as a function of the transient rods withdrawal in order to plan the rod movement. The control rods in TREAT were calibrated in increments following the "rod bump" method. The position of the control rods was reported for the pre-transient criticality check and immediately before the fast withdrawal of the transient rods. Based on this data it is possible to obtain values of initial transient $k_{\text {ex }}$ from the previously prepared rod calibrations, independently of the initial $k_{\text {ex }}$ calculated from the asymptotic periods determined from the log power records. However, the original calibration was later found to be in error by $5 \%$, introducing an uncertainty into such a procedure [8]. At this writing, it is uncertain whether that error also applies to the present reactor.

Before a transient the core was set at a critical state by adjusting the position of the control/shutdown rods. The transient rods were then $100 \%$ withdrawn out of the core and the change of the effective multiplication factor was calculated. These calculation steps were repeated with other transient rod bank insertion positions to cover the entire length of the transient rods, thereby determining the available reactivity as a function of rod bank withdrawal. The statistical error in the MCNP $k_{\text {eff }}$ calculations was $0.02 \%$.

Figure 4.6 presents the measured and calculated available reactivity of the transient rod bank as a function of rod withdrawal. 


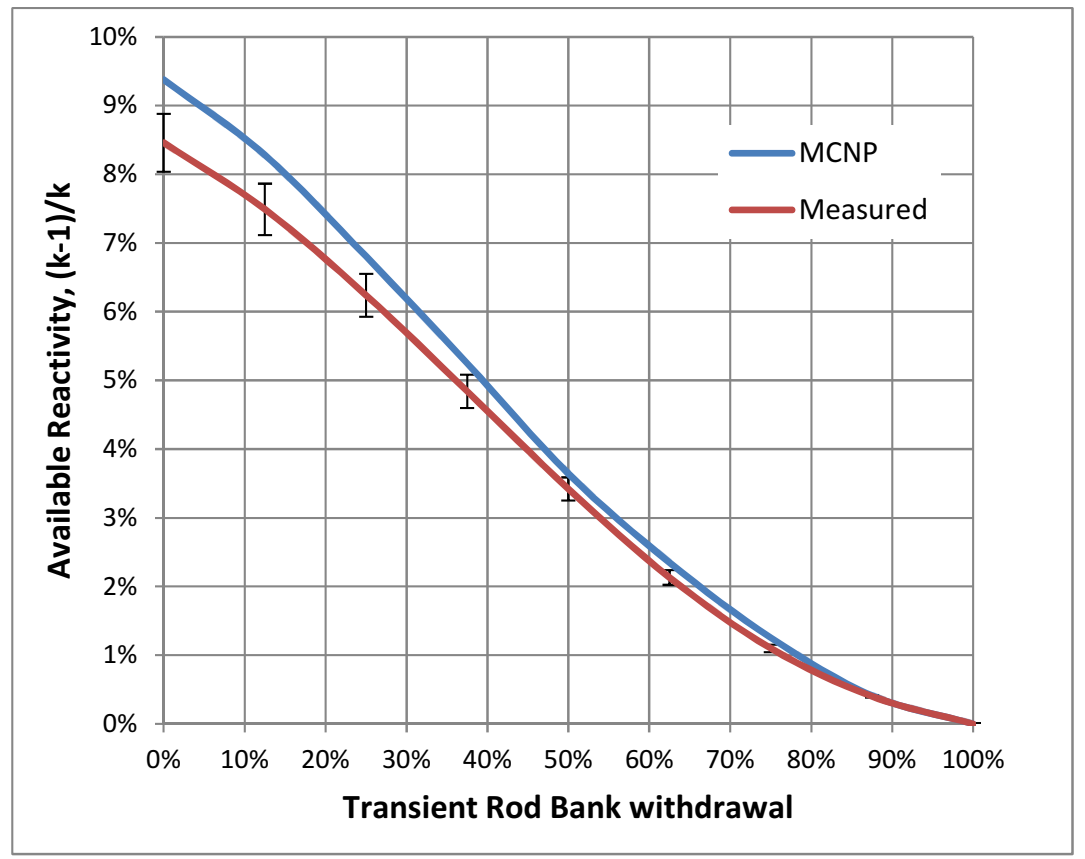

Figure [4.6]: MCNP Calculated and Measured Transient Rod Bank Available Reactivity as a Function of Rod Withdrawal for the HEU Core

The average calculated-to-measured transient rods reactivity ratio was $0.92 \pm 0.03$. In view of the uncertainties on the $\mathrm{B}_{4} \mathrm{C}$ density (section 4.2), the rod position uncertainty (Ref. 6 indicates $\mathrm{a} \pm 0.3$ inches in a position range of 0 to 40 inches), and the unknown impurities content, this ratio was used as a correction factor for the MCNP-calculated transient rods available reactivity. The corrected transient rod reactivity is presented in Figure 4.7.

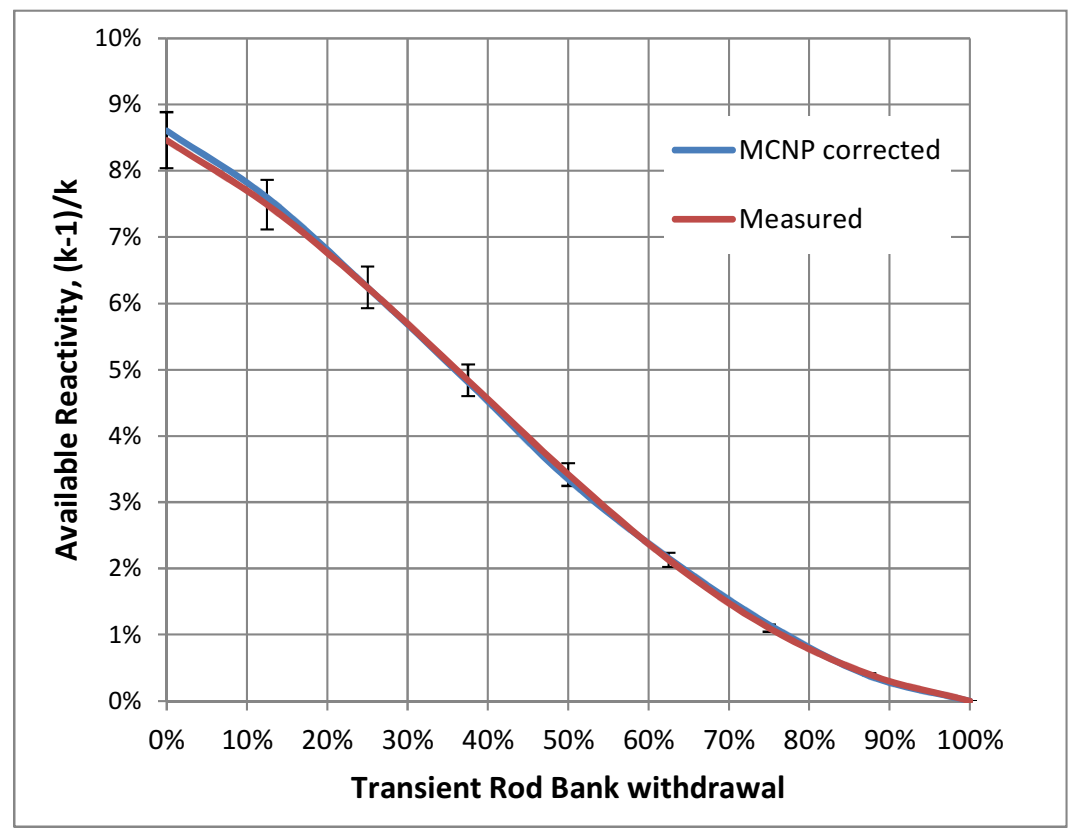

Figure [4.7]: Corrected-MCNP Calculated and Measured Transient Rod Bank Available Reactivity as a Function of Rod Withdrawal for the HEU Core 
Measured, calculated and corrected transient rods available reactivity as a function of withdrawal is presented in Table 4.3. The effect of uncertainty in measured rod position was not evaluated.

Table [4.3]: Measured, MCNP Calculated and Corrected-MCNP Calculated Transient Rod Reactivity as a Function of Percentage of Transient Rod bank withdrawal for the HEU Core

\begin{tabular}{|c|c|c|c|}
\hline Withdrawn (\%) & Measured & MCNP* & MCNP corrected \\
\hline $0 \%$ & $8.46 \%$ & $9.38 \%$ & $8.61 \%$ \\
\hline $13 \%$ & $7.49 \%$ & $8.28 \%$ & $7.60 \%$ \\
\hline $25 \%$ & $6.24 \%$ & $6.80 \%$ & $6.24 \%$ \\
\hline $38 \%$ & $4.84 \%$ & $5.25 \%$ & $4.82 \%$ \\
\hline $50 \%$ & $3.42 \%$ & $3.64 \%$ & $3.34 \%$ \\
\hline $63 \%$ & $2.13 \%$ & $2.35 \%$ & $2.15 \%$ \\
\hline $75 \%$ & $1.10 \%$ & $1.25 \%$ & $1.15 \%$ \\
\hline $88 \%$ & $0.40 \%$ & $0.41 \%$ & $0.38 \%$ \\
\hline
\end{tabular}

* The statistical error in the MCNP calculations was $0.02 \%$

\subsubsection{Power Coupling Factor for the Low Level Steady State (LLSS) Irradiations}

The power coupling factor (PCF) is defined as the energy deposited or fissions produced in the test sample per unit of total core energy. During the LLSS irradiations the TREAT core was air-cooled to maintain a constant average temperature of $26^{\circ} \mathrm{C}$.

The number of absolute fissions per gram for the wire and the fuel pin segments was measured with an estimated error of $\pm 2.5 \%$ [3]. The uncertainties in the log power instrument deflections would produce much larger uncertainties in the power values and, for typical cases, would correspond to an uncertainty of about $10 \%$ [8]. The same level of uncertainty (10\%) was also assumed for the energy measurements, but no evidence has been found to indicate if this level of uncertainty still applies to the present core. The combined errors in the fissions per gram measurements and the $10 \%$ value for the error in total energy determined the error in the reported measurements.

Four LLSS irradiations were simulated using MCNP assuming a uniform core temperature of $20.6^{\circ} \mathrm{C}$ (the room-temperature value of the MCNP cross section libraries). In practice, when planning TREAT experiments it was generally assumed that the measured TREAT core power and energy were mainly useful in comparing various transient runs with the same core loading. Thus, reasonable consistency among the accuracy of those measurements was assumed for that loading, but consistency from one core loading to another was not reliable. The number of fissions in the test wire was calculated using the F4 neutron flux tally with the (-6) FM tally multiplier [9] in MCNP.

The number of fissions was tallied in 20 axial segments $(1.016 \mathrm{~cm}$ long) along the wire, and the peak value was compared to the measured one. The normalization of the tally results to the power level of the reactor was done assuming $180 \mathrm{MeV}$ of energy released per fission in core [15].

The tally result was normalized as follows (tally units in the parentheses):

$\left(\frac{\text { fissions }}{\text { source neutron } \times \mathrm{cm}^{3}}\right) \times \frac{\text { source neutron }}{\text { fission }} \times \frac{\text { fission }}{180 \mathrm{MeV}} \times \frac{\mathrm{cm}^{3}}{{ }^{235} \mathrm{U} \text { grams in wire }} \times \frac{1 \mathrm{MeV}}{1.602 \cdot 10^{-13} \mathrm{MJ}}$ 
The MCNP-calculated and measured power coupling factor (in units of fissions per gram of U-235 per total core energy in $\mathrm{MJ}$ ), and the resulting calculated (C) to measured (M) ratio, are indicated in Table 4.4. The $\mathrm{C} / \mathrm{M}$ error was calculated using error propagation theory: $\delta\left(\frac{C}{M}\right)=$ $\sqrt{\left(\frac{1}{M} \times \delta C\right)^{2}+\left(\frac{C}{M^{2}} \times \delta M\right)^{2}}$ where $\delta C$ and $\delta M$ is the error in the calculated and the measured value, respectively.

Table [4.4]: MCNP Calculated (C) and Measured (M) Axial Peak Fissions per U-235 gram per Total Core Energy for the LLSS Irradiations of the Flux Wire and the C/M Ratio in the HEU Core (C: Compensation Rods, C/S: Compensation Shutdown Rods, T: Transient Rods)

\begin{tabular}{|c|c|c|c|c|c|c|}
\hline \multirow{2}{*}{$\begin{array}{c}\text { Flux Wire } \\
\text { Length (in.) }\end{array}$} & \multicolumn{2}{|c|}{ Rod Withdrawal } & \multicolumn{2}{|c|}{ Peak f/g $\mathbf{g}^{235} \mathbf{U}-\mathbf{M J} \times 10^{12}$} & \\
\cline { 2 - 7 } & $\mathbf{C}$ & $\mathbf{C} / \mathbf{S}$ & $\mathbf{T}$ & $\begin{array}{c}\text { Calculated } \\
\text { (C) }\end{array}$ & $\begin{array}{c}\text { Measured** } \\
\text { (M) }\end{array}$ & $\mathbf{C / M}$ \\
\hline 8 & $100 \%$ & $38 \%$ & $100 \%$ & $1.49 \pm 0.04^{*}$ & $1.42 \pm 0.15$ & $1.05 \pm 0.11$ \\
\hline 8 & $100 \%$ & $38 \%$ & $100 \%$ & $1.49 \pm 0.04 *$ & $1.44 \pm 0.15$ & $1.03 \pm 0.11$ \\
\hline 60 & $100 \%$ & $38 \%$ & $100 \%$ & $1.46 \pm 0.03$ & $1.40 \pm 0.14$ & $1.04 \pm 0.11$ \\
\hline 8 & $100 \%$ & $83 \%$ & $29 \%$ & $1.55 \pm 0.04$ & $1.84 \pm 0.19$ & $0.84 \pm 0.09$ \\
\hline
\end{tabular}

* The same MCNP calculation

** The PCF error calculated based on the $2.5 \%$ error in the measured fissions per gram and the $10 \%$ in the total energy

In the case of the LLSS irradiation of the two fuel pins, the fuel-pin energy per fuel mass per total core energy is reported, so the calculations were performed in a coupled neutron/photon MCNP simulation and the energy deposition was tallied using the F6 tally in 27 axial segments $(1.27 \mathrm{~cm}$ long) along each pin. The tally result was normalized as follows (tally units shown in the parentheses):

$$
\left(\frac{\mathrm{MeV}}{\text { source neutron } \times \mathrm{cm}^{3}}\right) \times \frac{\text { source neutron }}{\text { fission }} \times \frac{\text { fission }}{180 \mathrm{MeV}} \times \frac{\mathrm{cm}^{3}}{\text { fuel grams }} \times 10^{6} \mathrm{~J} / \mathrm{MJ}
$$

The results, the measurements and the calculated to measured ratio are tabulated in Table 4.5.

Table [4.5]: MCNP Calculated (C) and Measured (M) Axial-Peak Energy per Fuel Pin Mass per Total Core Energy for the LLSS Irradiations of the Fuel Pins and the C/M Ratio in the HEU Core (C: Compensation Rods, C/S: Compensation Shutdown Rods, T: Transient Rods)

\begin{tabular}{|c|c|c|c|c|c|c|}
\hline \multirow{2}{*}{ Fuel Pin (wt.) } & \multicolumn{4}{|c|}{ Rod Withdrawal } & \multicolumn{3}{|c|}{ Peak J/g-MJ } & \\
\cline { 2 - 7 } & C & C/S & T & $\begin{array}{c}\text { Calculated } \\
\text { (C) }\end{array}$ & $\begin{array}{c}\text { Measured* } \\
\text { (M) }\end{array}$ & C/M \\
\hline T-433 $\left({ }^{235} \mathrm{U}: 62 \%\right)$ & $100 \%$ & $38 \%$ & $100 \%$ & $6.36 \pm 0.07$ & $5.1 \pm 0.5$ & $1.26 \pm 0.13$ \\
\hline T-462 $\left({ }^{235} \mathrm{U}: 40 \%\right.$, Pu: $\left.19 \%\right)$ & $100 \%$ & $38 \%$ & $100 \%$ & $6.11 \pm 0.07$ & $4.7 \pm 0.5$ & $1.30 \pm 0.13$ \\
\hline
\end{tabular}

* The PCF error calculated based on the $2.5 \%$ error in the measured fissions per gram and the $10 \%$ in the total energy

It should be noted that the error reported in the measured PCF was calculated taking into account the $2.5 \%$ and $10 \%$ error in the fissions per gram and total core energy measurements, respectively. The effect of the uncertainties associated with the rod position (the transient rods were reported to be withdrawn 4 inches during the steady state irradiations), the axial position and the composition of the test sample (pins and wire) or the boron impurity concentration was not included. A sensitivity analysis 
is planned to address these issues and further investigate the observed $16 \%$ and $30 \%$ differences between the calculated and measured PCF.

\subsubsection{Fission Density Axial Profile in Monitor Wire and Fuel Pins}

After the irradiations the wire and the fuel pins were cut into $1 / 2$-inch $(1.27 \mathrm{~cm})$ long segments and were measured for relative activity on a $\mathrm{Ge}(\mathrm{Li})$ gamma spectrometer. Selected segments were dissolved, and an aliquot was taken for gamma ray analysis. The ${ }^{140}$ La photopeak (1.5916 MeV) was counted on a Ge(Li) gamma spectrometer. The reported estimated error of both spectrometer measurements was $\pm 5 \%$ [3] During the preparation of this report there was no available info about the Ge(Li) measurements (detector calibration, efficiency etc) so the sources of error were not known. The normalized-tomaximum number of fissions per gram axial profile in the flux wire was calculated with MCNP using the F4 tally with the FM (-6) multiplier placed in every wire segment. The statistical error of the calculations was lower than $1 \%$.

During the measurements the absolute axial positioning of the all data was somewhat uncertain (approximately 0.5 in.) and the nominal axial positioning of scan data was shifted by a small amount to optimize alignment with data from the fuel segments [3]. Considering the uncertainty of the axial position of the measurements the MCNP tally results were shifted accordingly for the best match between the measured and the calculated maximum fissions per gram. In particular, the calculated axial profile of the fissions per gram for the 60 in. wire and the fuel pins was shifted by 0.69 and 0.5 inches towards the top, respectively.

The measured and calculated normalized-to-peak axial fission per gram profiles for the flux wire, the T462 and T-433 fuel pins are presented in Figures 4.8, 4.9 and 4.10, respectively. The shape corresponds to a combination of the chopped-cosine axial power profile in the TREAT core and the attenuation due to the stepped shaping collars (Figure 4.4) on the calibration vehicle. 


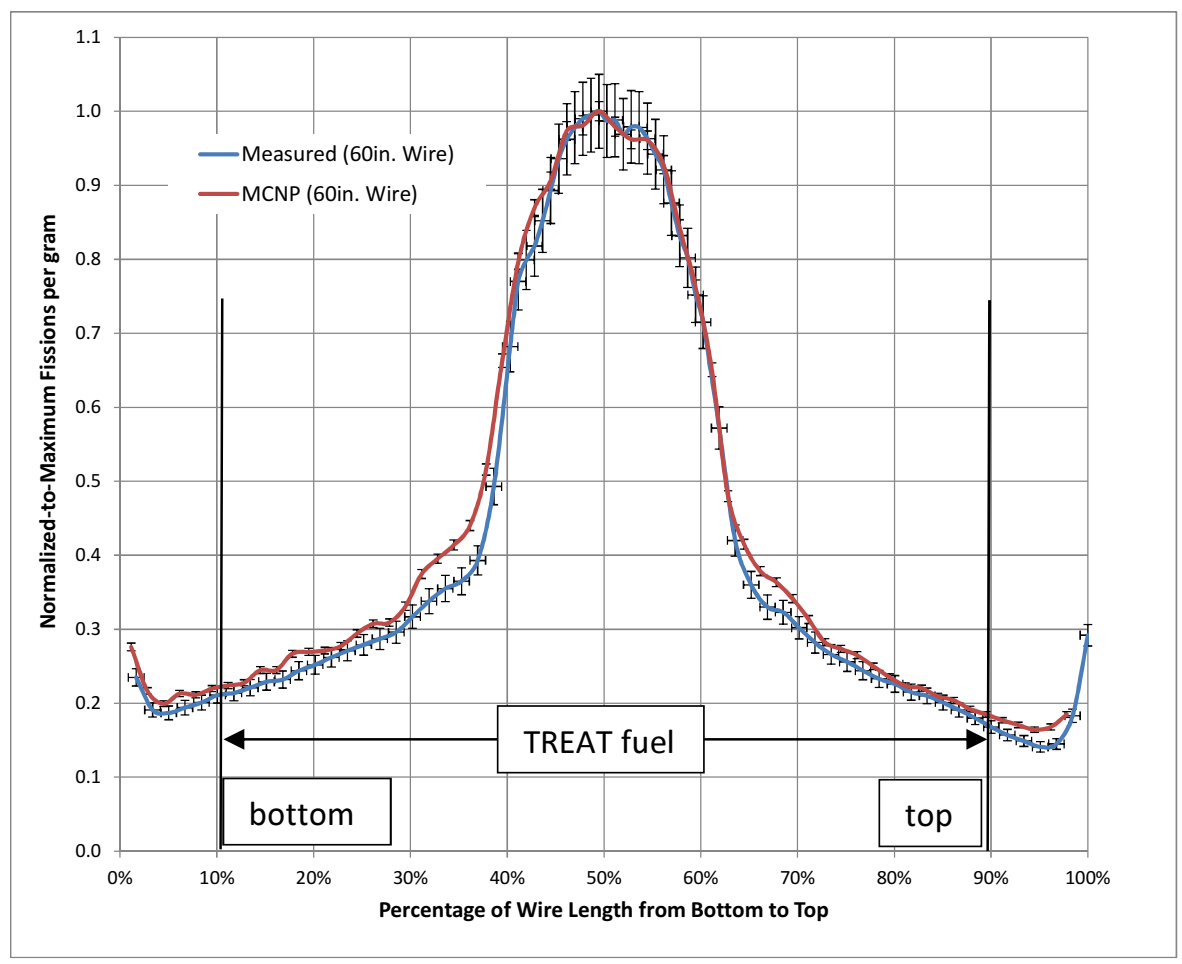

Figure [4.8]: MCNP Calculated and Measured Normalized-to-Maximum Axial Fissions per Gram Axial Distribution for the 60 inches $(\mathbf{1 5 2 . 4} \mathrm{cm})$ Long Flux Wire Irradiated in the HEU Core

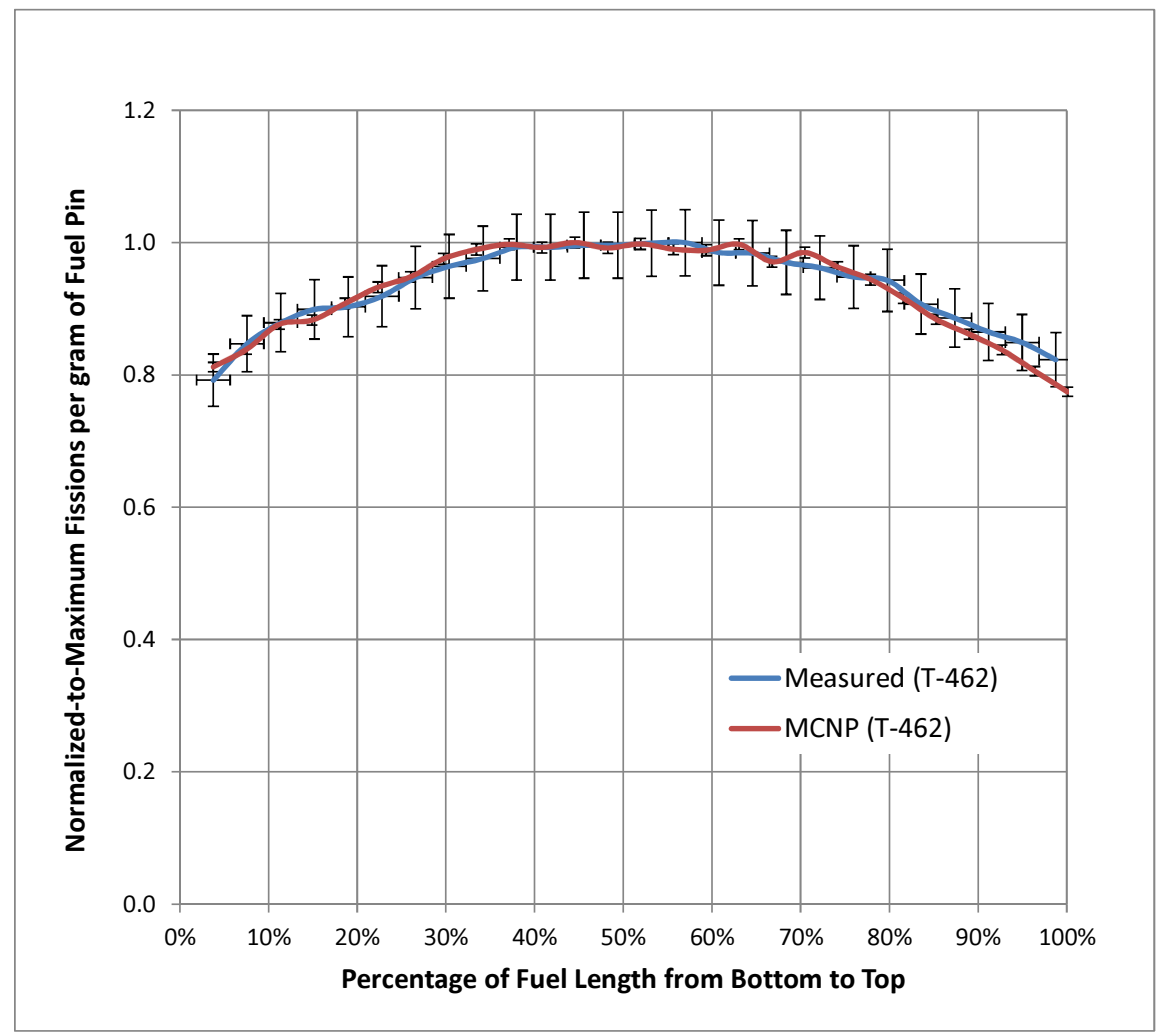

Figure [4.9]: MCNP Calculated and Measured Normalized-to-Maximum Axial Distribution of Fissions per Gram for the T- 462 Fuel Pin in the HEU Core 


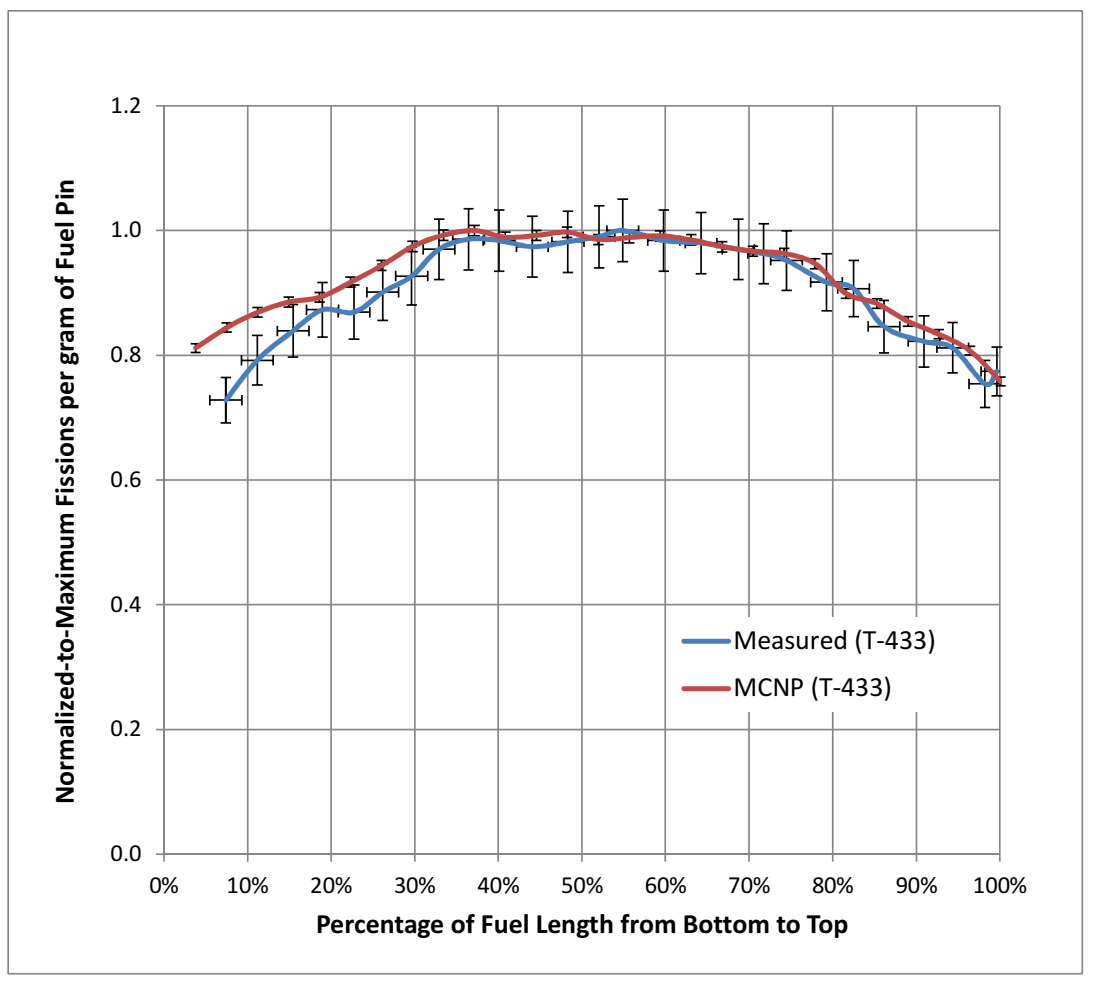

Figure [4.10]: Calculated and Measured Normalized-to-Maximum Axial Distribution of Fissions per Gram for the T- 433 Fuel Pin in the HEU Core

\subsubsection{Prompt Generation Lifetime and Effective Delayed Neutron Fraction}

The prompt neutron generation time $\left(I_{p}\right)$ and the effective delayed neutron fraction $\left(\beta_{\text {eff }}\right)$ were calculated for a cold and critical HEU core using the MCNP kopts card (default blocksize value) [9] for the 60 in. flux wire irradiation. The results were compared against the reported [8] values (Table 4.6). The reported error in the $\beta_{\text {eff }}$ measurement was $7 \%$ [8].

Table [4.6]: MCNP Calculated (C) and Reported (R) Effective Delayed Neutron Fraction, Prompt Neutron Lifetime and the C/R Ratio for the HEU Core

\begin{tabular}{|l|c|c|c|}
\hline Parameter & Calculated (C) & Reported (R) & C/R \\
\hline Effective Delayed Neutron Fraction, $\beta_{\text {eff }}\left(\mathrm{pcm}^{*}\right)$ & $691 \pm 5$ & $720 \pm 50$ & $0.96 \pm 0.07$ \\
\hline Prompt Neutron Lifetime, $\mathrm{I}_{\mathrm{p}}(\mu \mathrm{s})$ & $898.6 \pm 0.8$ & $900 \pm 30$ & $0.998 \pm 0.001$ \\
\hline
\end{tabular}

\subsubsection{Temperature Distribution and Temperature Reactivity Feedback}

The TREAT reactor power excursions are self-limiting due to the inherent negative temperature reactivity feedback. As the temperature of the core graphite increases, the neutron spectrum hardens, and consequently the fission rate relative to the neutron leakage from the core is decreased, generating a negative temperature reactivity coefficient. The temperature reactivity feedback depends on the temperature distribution, which is not constant during a transient operation because of the changes in the neutron flux distribution induced by the movement of the control rods. During the TREAT experiments the reactor operators used pre-calculated temperature reactivity feedback "sets" (feedback as a function of total core energy) adjusted with a constant multiplicative factor called 
"SLOTK" to give the best fit between the calculated and measured parameters (temperature, power, total energy). Various physical parameters (absence or presence of half or full slot, different experiments, etc.) were ruled out as the source of variation of the feedback set. The calibration of the nuclear instrumentation during steady-state heat-balance reactor runs seemed to be the source of error [10]. The detectors are placed inside the reactor's bioshield in fixed positions and are affected by the spatial tilts of the neutron flux corresponding to the positions of the control rods.

A method to calculate the temperature reactivity feedback as a function of total core energy based on MCNP simulations was developed and was applied in the HEU core for validation. This method was also applied in the studied LEU cores to evaluate the changes in the temperature distribution and temperature feedback. The following section describes the steps for the calculation of the temperature distribution and the resulting temperature reactivity feedback.

\subsubsection{Temperature Reactivity Feedback MCNP Calculations}

Historically, TREAT neutronics analysts computed temperature reactivity feedback using the point kinetics approximation assuming that for a step reactivity insertion there is a linear relationship between the inserted reactivity step and the magnitude of the reactivity feedback due to the core temperature rise during the transient. According to the TREAT reactor's SAR the temperature reactivity feedback was computed as a function of core average temperature assuming a $1 / v$ behavior of the cross sections and that the thermal neutrons have a Maxwellian energy distribution.

A curve of peak-to-average temperature ratio as a function of average core temperature was developed using an initial value of peak-to-average power of 1.70 , the enthalpy curve for the TREAT fuel and the temperature dependent fission cross sections for ${ }^{235} \mathrm{U}$. This was accomplished by the use of an iterative method in which the initial peak-to-average power value is assumed to hold true for a small incremental increase in peak core temperature. The corresponding increase in the average core temperature is determined from the enthalpy curve and the peak-to-average power value. The peak-to-average power value is then corrected using the ratios of the hot ${ }^{235} \mathrm{U}$ fission cross section to the cold ${ }^{235} \mathrm{U}$ fission cross section for the peak and the average power. This procedure is then repeated using the newly corrected peak-to-average power value. This method makes the assumption that neutron flux distribution does not change. This assumption is fundamental to all "point-reactor" models. It is noted that the value of peak-to-average temperature derived by this method was 1.4 .

In this study a method based on MCNP simulations was developed to calculate the temperature reactivity feedback as a function of peak core temperature and total core energy. The average power density in every fuel assembly was calculated for a single rod configuration (compensation/shutdown $100 \%$ withdrawn, control/shutdown $49.5 \%$ withdrawn and transient rods $100 \%$ withdrawn) using the track length estimate of energy deposition tally, F6, in the MCNP simulations in a neutron/photon mode (the F6 tally in a coupled neutron/photon calculation represents the true heating whereas the F7 tally assumes that the fission photons are deposited locally). The power density was computed with the transient rods fully withdrawn because this is the position (a) at the end of temperature limited transients (natural bursts) after moving at maximum withdrawal rate (b) at the end of maximumallowed-energy shaped transients. Of course, no single rod configuration can represent: 1) the shaped 
transients where there is constant rod movement (and not at the maximum speed), 2) the transients with different rod starting positions (reflecting different reactivity insertions) and 3) the temperature limited transients where the transients rods are not fully withdrawn from the core.

Approximating the heating of the fuel as an adiabatic process and using the graphite heat capacity [7] as a function of temperature (Figure 4.11), the average temperature of every fuel assembly was calculated for total core energies of 500, 1000, 2000, 3500 and 5000 MJ. Integrating the heat capacity function [7] over temperature gives the energy density $(\mathrm{J} / \mathrm{g})$ required for a temperature increase from the $\mathrm{T}_{\mathrm{o}}$ to $\mathrm{T}_{\mathrm{x}}$ :

$$
\begin{gathered}
\frac{\mathrm{J}}{\mathrm{g}}=\int_{\mathrm{T}_{\mathrm{o}}}^{\mathrm{T}_{\mathrm{x}}}\left(10^{-9} \times \mathrm{T}^{3}-3 \times 10^{-6} \times \mathrm{T}^{2}+0.0034 \times \mathrm{T}+0.602\right) \mathrm{dT}= \\
=\left[2.5 \times 10^{-10} \times T^{4}-10^{-6} \times T^{3}+1.7 \times 10^{-3} \times T^{2}+0.602 \times T\right]_{T_{o}}^{T_{x}}
\end{gathered}
$$

For a given total core energy the MCNP model estimates the energy density in every fuel assembly, and by solving the fourth degree polynomial equation (Eq. 4.3.1) the final temperature $T_{x}$ is calculated.

Appendix $B$ shows the positive solution to the equation.

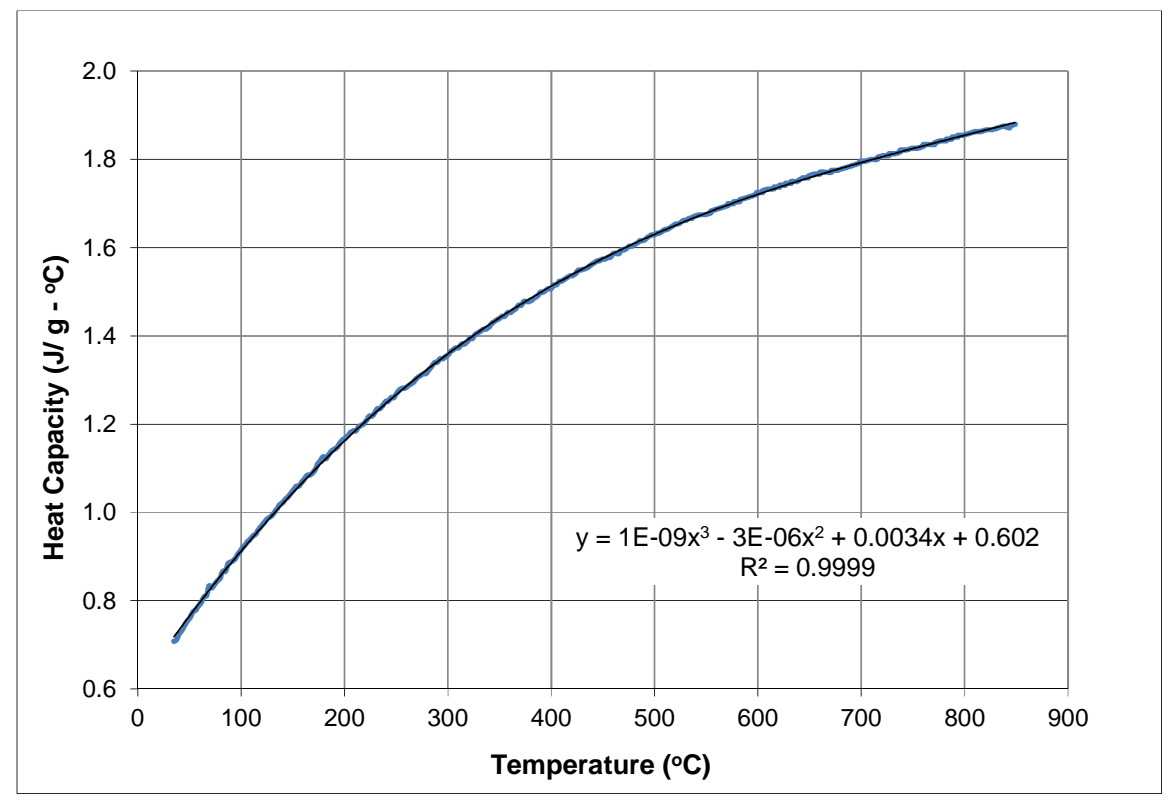

Figure [4.11]: Graphite Heat Capacity as a Function of Graphite Temperature in the HEU Fuel

The fuel assemblies were divided into three temperature groups after visual assessment of the fuel assembly average temperature distribution in the core. To each fuel assembly group, a temperature was assigned that was equal to the average temperature of all the fuel assemblies in the group. The temperature structure of the fuel assembly groups (the temperature range included in every group) was then optimized using the "solver" add-in of Microsoft Excel. Using the 'solver,' the term $\sum_{i=1}^{n}\left(X_{i}-\right.$ $\left.A V G_{j}\right)^{2}\left(\mathrm{X}_{\mathrm{i}}\right.$ is the fuel assembly temperature and $\mathrm{AVG}_{\mathrm{i}}$ is the average temperature of each group) was minimized by accordingly changing the $A V G_{i}$ values [16]. The result of this analysis was the presentation 
of the radial temperature distribution of the TREAT core with three temperature zones. (As a result, assemblies in a group were not necessarily geometrically contiguous.) In order to take also into account the axial power density distribution, three axial geometric zones were defined using the MCNP calculated core average power density distribution.

For every axial zone a weighting factor was defined:

$$
w_{z}=\frac{\text { average axial zone power density }}{\text { average core power density }}
$$

The temperature of each of the three radial zones was multiplied by the weighting factor defining three axial temperature zones. The result of these calculations was the definition of 3 axial and 3 radial temperature zones describing the temperature distribution of the TREAT core. Temperature-dependent cross section libraries were produced using the MAKXSF utility of the MNCP code package and were assigned to each of the three radial and three axial temperature zones. The temperature reactivity feedback was calculated as the change of the multiplication factor from the core with cross sections at room temperature ('cold' core) to the core with cross sections at the temperature of the nine zones ('hot' core) for the same rod configuration. The rod configuration that was used to calculate the relative power density distribution with MCNP was compensation/shutdown: $100 \%$, control/shutdown: $49.5 \%$, and transient: $100 \%$ withdrawal.

The calculation steps are summarized in the flow diagram of Figure 4.12.

The maximum fuel assembly temperature as a function of total core energy, needed for use in the TREKIN table TEMPER, was computed using the axial maximum-to-average power density calculated with MCNP for the hottest fuel assembly (i.e., the assembly having the highest temperature). For every total core energy value the core average temperature and the fuel assembly maximum temperature were calculated.

Figure 4.13 shows the fuel assembly maximum temperature calculated using the MCNP-produced power density distribution and, for comparison, the reported (historic) one. 

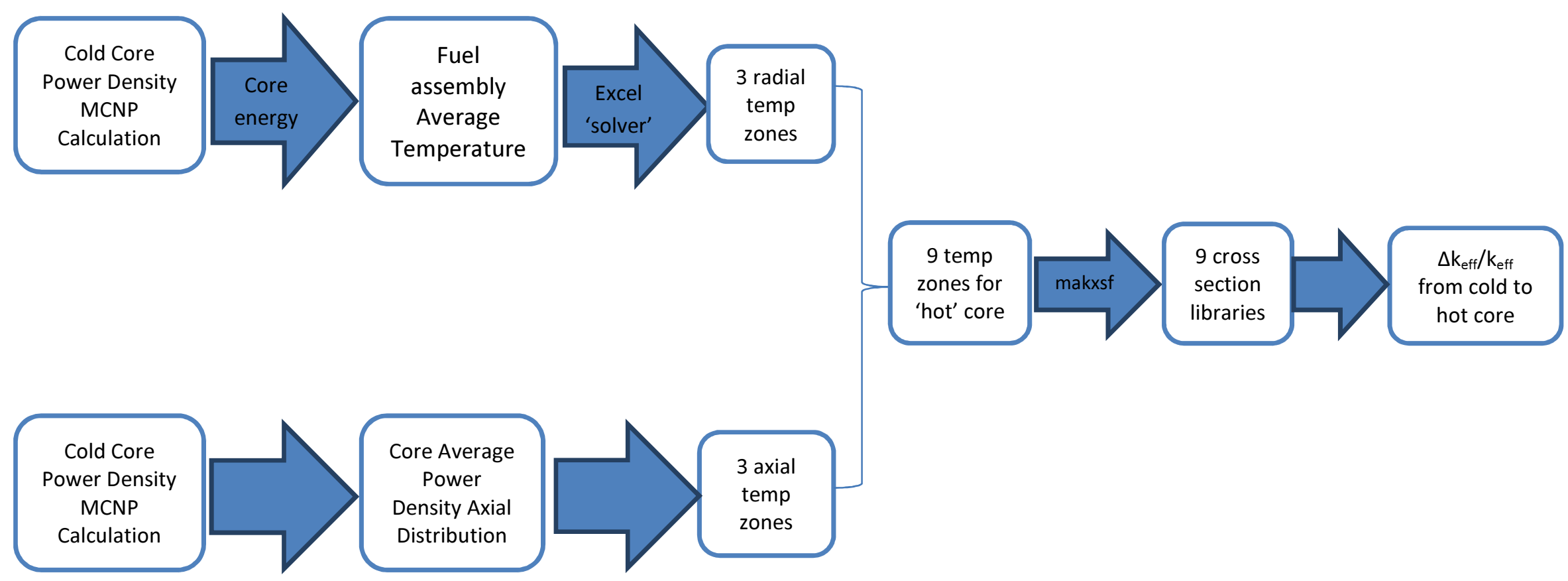

Figure [4.12] Flow Diagram for the Temperature Distribution Calculations using MCNP and the MAKXS Utility. The Temperature Reactivity Feedback was Calculated from the Change of the Multiplication Factor from the 'Cold' to the 'Hot' Core 


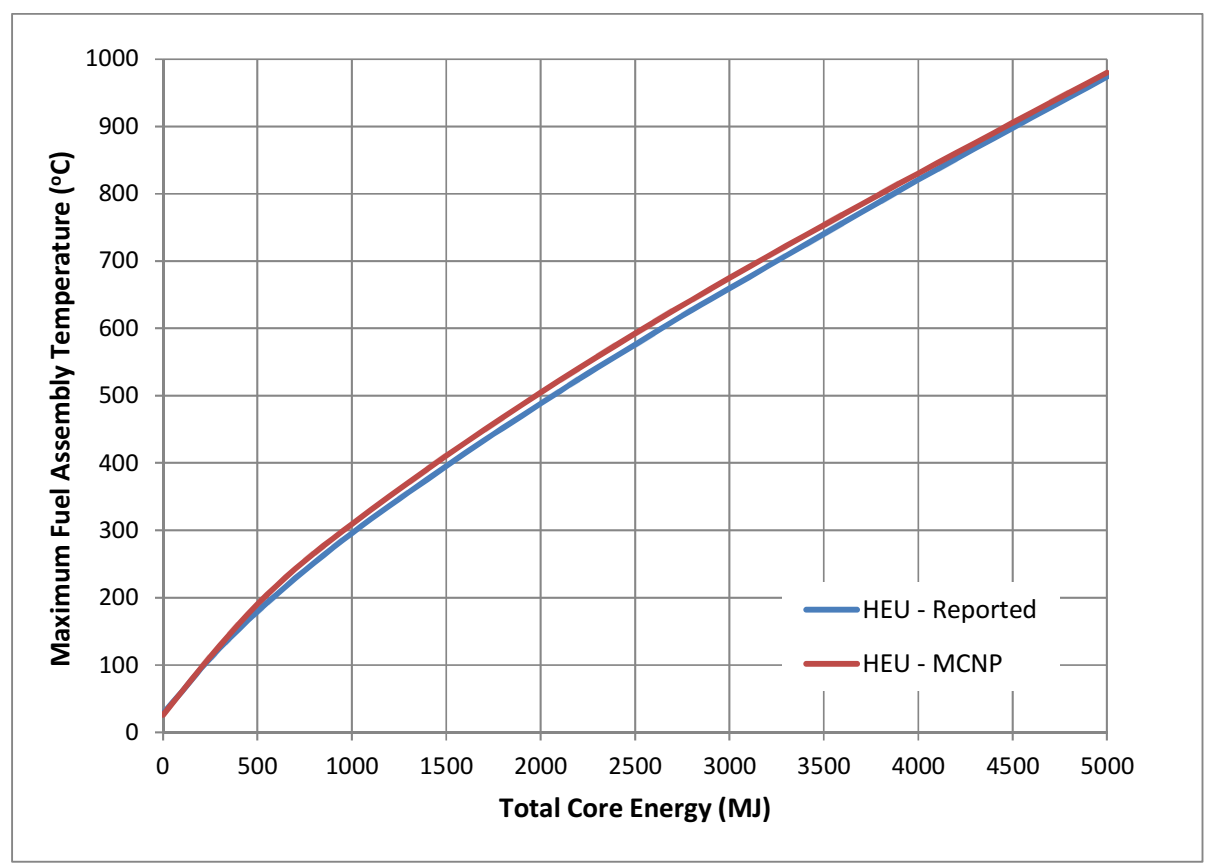

Figure [4.13]: Reported and Calculated Using the MCNP Produced Power Density Distribution Maximum Fuel Assembly Temperature as a Function of the Total Core Energy for the HEU

The calculated maximum fuel assembly temperatures are on average $2.5 \%$ higher than the reported ones. Figure 4.14 shows the HEU - reported (historical) and the HEU - MCNP calculated temperature reactivity feedback. Using cubic spline interpolation the temperature reactivity feedback was calculated up to $5000 \mathrm{MJ}$ in $100 \mathrm{MJ}$ steps.

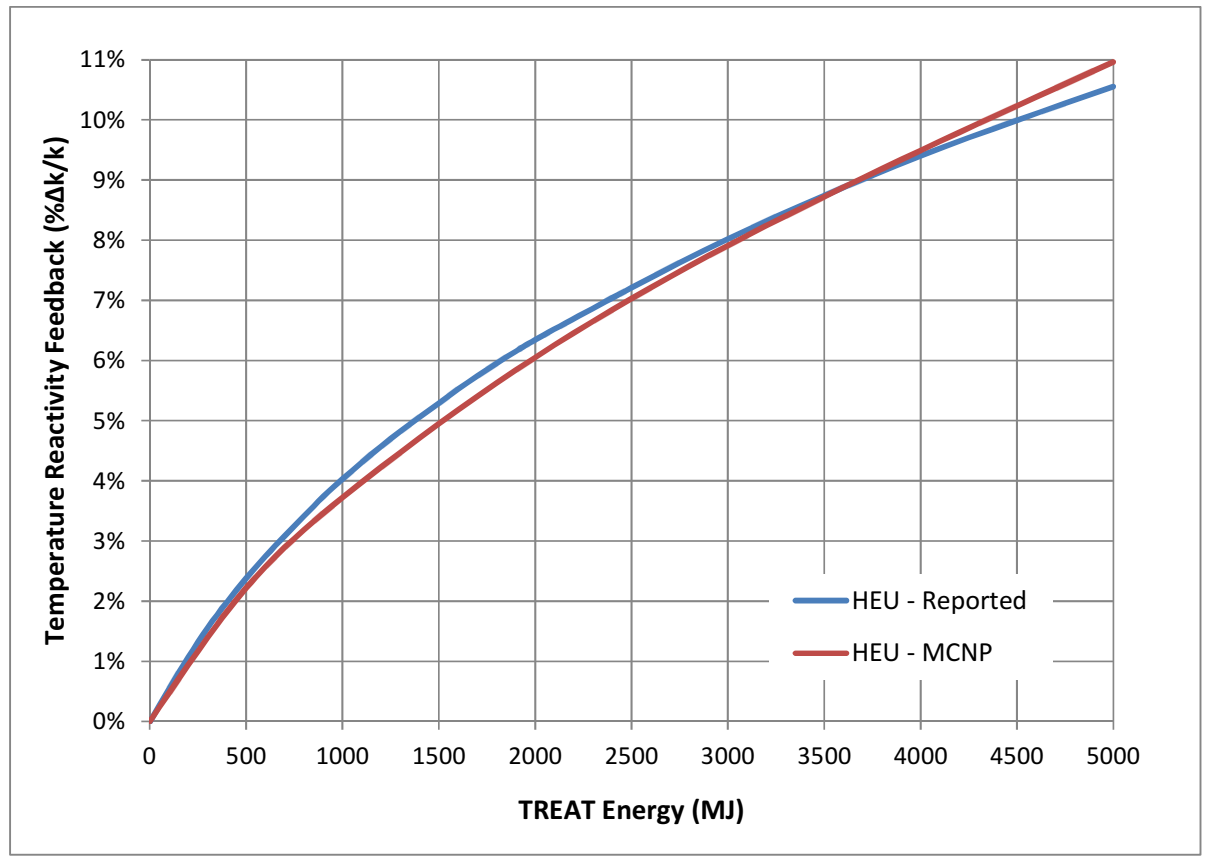

Figure [4.14]: Reported and MCNP Calculated Temperature Reactivity Feedback as a Function of Total Core Energy for the HEU Core 
There is very good agreement between the calculated and the reported (historical) temperature reactivity feedback values. In particular, for the experimentally-performed temperature limited transients \#2855, \#2856 and \#2857, the reported core energy and temperature reactivity feedback values are shown in Table 4.7 as well the MCNP calculated values for comparison. The difference between the calculated and reported values is less than $2 \%$.

Table [4.7]: MCNP Calculated and Reported Temperature Reactivity for the Experimentally Performed Temperature Limited Transients \#2855, \#2856 and \#2857

\begin{tabular}{|c|c|c|c|c|}
\hline & & \multicolumn{2}{|c|}{ Temperature Reactivity Feedback } & \\
\hline Transient & Core Energy (MJ) & MCNP Calculated (C) & Reported (R) & C/R \\
\hline$\# 2855$ & 792 & $3.17 \%$ & $3.25 \%$ & 0.98 \\
\hline \#2856 & 1572 & $5.12 \%$ & $5.15 \%$ & 0.99 \\
\hline \#2857 & 2265 & $6.58 \%$ & $6.44 \%$ & 1.02 \\
\hline
\end{tabular}

\subsection{HEU Core Relative Power Density Distribution}

The fuel assembly power density relative-to-core-average power density (ratio of the power density in the assembly to the average power density of the fuel in the entire core) was calculated in the case of the flux wire irradiation in the HEU core with the control rods positioned according to the configuration A (compensation rods $100 \%$ withdrawn, control/shutdown rods $\approx 38 \%$ withdrawn and transient rods $100 \%$ withdrawn, per section 4.3.1).

Figure 4.15 shows the relative power density distribution for the HEU core. The maximum relative power density is observed in assembly N12 (highlighted in Figure 4.15 with yellow shading) with a value of 1.42 . 


\begin{tabular}{|c|c|c|c|c|c|c|c|c|c|c|c|c|c|c|c|c|c|c|c|}
\hline & A & B & C & D & $E$ & $\mathbf{F}$ & G & $\mathrm{H}$ & $\mathrm{J}$ & K & $\mathbf{L}$ & $\mathbf{M}$ & $\mathbf{N}$ & 0 & $\mathbf{P}$ & $\mathbf{R}$ & $S$ & $\mathbf{T}$ & $\mathbf{U}$ \\
\hline 1 & & & 0.65 & 0.64 & 0.65 & 0.65 & 0.64 & 0.64 & 0.64 & & 0.64 & 0.63 & 0.64 & 0.64 & 0.63 & 0.63 & 0.63 & & \\
\hline 2 & & 0.67 & 0.66 & 0.66 & 0.66 & 0.65 & 0.63 & 0.61 & 0.64 & & 0.64 & 0.61 & 0.63 & 0.65 & 0.66 & 0.66 & 0.66 & 0.68 & \\
\hline 3 & 0.70 & 0.69 & 0.72 & 0.73 & 0.71 & 0.67 & 0.65 & 0.60 & 0.67 & & 0.67 & 0.60 & 0.65 & 0.67 & 0.71 & 0.73 & 0.73 & 0.71 & 0.73 \\
\hline 4 & 0.74 & 0.75 & 0.79 & 0.82 & 0.78 & 0.69 & 0.75 & 0.76 & 0.77 & & 0.77 & 0.76 & 0.75 & 0.70 & 0.79 & 0.83 & 0.81 & 0.78 & 0.78 \\
\hline 5 & 0.80 & 0.83 & 0.88 & 0.92 & 0.92 & 0.90 & 0.92 & 0.91 & 0.87 & & 0.87 & 0.91 & 0.92 & 0.91 & 0.93 & 0.93 & 0.90 & 0.85 & 0.85 \\
\hline 6 & 0.87 & 0.90 & 0.97 & 1.01 & 1.06 & 1.07 & 1.07 & 1.03 & 0.95 & & 0.95 & 1.03 & 1.07 & 1.08 & 1.07 & 1.03 & 0.99 & 0.93 & 0.91 \\
\hline 7 & 0.94 & 0.97 & 1.04 & 1.12 & 1.17 & 1.19 & 1.17 & 1.11 & 0.99 & & 1.00 & 1.11 & 1.18 & 1.20 & 1.18 & 1.13 & 1.06 & 0.99 & 0.97 \\
\hline 8 & 0.99 & 1.03 & 1.10 & 1.19 & 1.25 & 1.26 & 1.25 & 1.16 & 0.99 & & 1.00 & 1.16 & 1.26 & 1.28 & 1.27 & 1.21 & 1.12 & 1.05 & 1.02 \\
\hline 9 & 1.03 & 1.07 & 1.16 & 1.26 & 1.32 & 1.34 & 1.31 & 1.19 & 0.95 & & 0.95 & 1.20 & 1.31 & 1.35 & 1.34 & 1.27 & 1.18 & 1.09 & 1.05 \\
\hline 10 & 1.05 & 1.10 & 1.20 & 1.29 & 1.36 & 1.39 & 1.36 & 1.23 & 0.96 & & 0.96 & 1.24 & 1.37 & 1.40 & 1.38 & 1.31 & 1.21 & 1.12 & 1.07 \\
\hline 11 & 1.05 & 1.10 & 1.20 & 1.30 & 1.37 & 1.41 & 1.39 & 1.31 & 1.11 & & 1.11 & 1.32 & 1.40 & 1.42 & 1.39 & 1.32 & 1.21 & 1.12 & 1.07 \\
\hline 12 & 1.04 & 1.08 & 1.16 & 1.27 & 1.36 & 1.39 & 1.41 & 1.38 & 1.31 & 1.26 & 1.31 & 1.39 & 1.42 & 1.40 & 1.37 & 1.29 & 1.18 & 1.10 & 1.06 \\
\hline 13 & 1.01 & 1.05 & 1.13 & 1.23 & 1.31 & 1.36 & 1.39 & 1.40 & 1.39 & 1.38 & 1.39 & 1.40 & 1.40 & 1.37 & 1.32 & 1.24 & 1.15 & 1.07 & 1.03 \\
\hline 14 & 0.97 & 1.00 & 1.08 & 1.14 & 1.21 & 1.27 & 1.31 & 1.34 & 1.36 & 1.37 & 1.36 & 1.35 & 1.32 & 1.28 & 1.23 & 1.16 & 1.09 & 1.02 & 0.99 \\
\hline 15 & 0.91 & 0.94 & 1.00 & 1.06 & 1.08 & 1.09 & 1.15 & 1.22 & 1.26 & 1.28 & 1.26 & 1.22 & 1.17 & 1.10 & 1.10 & 1.08 & 1.02 & 0.96 & 0.93 \\
\hline 16 & 0.86 & 0.87 & 0.92 & 0.95 & 0.93 & 0.85 & 0.96 & 1.02 & 1.10 & 1.13 & 1.10 & 1.03 & 0.97 & 0.86 & 0.95 & 0.97 & 0.94 & 0.89 & 0.88 \\
\hline 17 & 0.81 & 0.80 & 0.83 & 0.86 & 0.85 & 0.83 & 0.84 & 0.80 & 0.93 & 0.99 & 0.94 & 0.81 & 0.85 & 0.85 & 0.88 & 0.88 & 0.86 & 0.83 & 0.84 \\
\hline 18 & & 0.78 & 0.77 & 0.78 & 0.80 & 0.81 & 0.81 & 0.81 & 0.86 & 0.89 & 0.87 & 0.82 & 0.82 & 0.83 & 0.83 & 0.82 & 0.80 & 0.81 & \\
\hline 19 & & & 0.75 & 0.75 & 0.77 & 0.80 & 0.82 & 0.83 & 0.85 & 0.87 & 0.86 & 0.85 & 0.84 & 0.83 & 0.81 & 0.80 & 0.79 & & \\
\hline
\end{tabular}

Figure [4.15]: MCNP Calculated Power Density Relative-to-Core-Average Distribution for the Flux Wire Irradiation in the HEU Core. The Different Colors Show the In-Core

Positions of the Rods (Red: Transient Rods, Green: Control/Shutdown, Light Blue: Compensation) and the Assembly with the Maximum Value (Yellow) 


\subsection{LEU Direct Replacement Core (LEU-D)}

The simplest case to evaluate the conversion of the TREAT core to LEU $\left(19.75 \%{ }^{235} \mathrm{U}\right.$ enrichment) was by replacing the HEU fuel with LEU fuel keeping the same fuel impurities and geometry as in the HEU core and calculate the carbon to uranium ratio that produces equal excess reactivity with the HEU core. The resulting core configuration is labeled as LEU-D. The neutronics calculations of the LEU-D core are presented below.

\subsubsection{Carbon to Uranium Ratio (C/U)}

The $\mathrm{C} /{ }^{235} \mathrm{U}$ ratio in the LEU fuel to produce equal excess reactivity as the cold and unperturbed (all control rods were $100 \%$ withdrawn) HEU core for the same number of fuel assemblies and equal boron and iron impurities content was determined. The excess reactivity calculated with MCNP for the HEU half-slotted core having all rods $100 \%$ withdrawn from the core in terms of $(k-1) / k$ was $7.206 \pm 0.005 \%$. MCNP runs were performed by changing each time the $\mathrm{C} / \mathrm{U}$ ratio (increasing the uranium content) until the desired excess reactivity of the LEU core was achieved.

Table 4.8 presents the HEU fuel characteristics and the resulting LEU fuel characteristics that produce equal excess reactivity. The LEU-D core has 1.9 times more ${ }^{235} \mathrm{U}$ and 107 times more ${ }^{238} \mathrm{U}$ than the HEU core. It should be emphasized that in the analyzed LEU fuel composition the same impurities content (including the unplanned high boron content) was used as in the HEU fuel. The boron impurity in the HEU fuel was the result of the baking process of the fuel blocks inside borated stainless steel separators [1]. This impurity content is not expected to be of the same magnitude in the new LEU fuel so the neutronics analyses will be updated as soon as the composition of the LEU fuel has been determined. As it has already been mentioned a $1 \mathrm{ppm}$ change in Boron impurity changes the multiplication factor by $1 \% \Delta \mathrm{k} / \mathrm{k}(1000 \mathrm{pcm})$.

Table [4.8]: Graphite to Uranium Ratio to Produce Equal Excess Reactivity for the HEU and LEU-D (FA with C/U=5200)

\begin{tabular}{|c|c|c|}
\hline & HEU & LEU-D \\
\hline Excess Reactivity (k-1)/k (\%) & $7.206 \pm 0.005$ & $7.221 \pm 0.005$ \\
\hline $\mathrm{C} / \mathbf{U}_{\text {total }} \quad \mathrm{C}^{\mathrm{N}} \mathrm{U}_{235}$ & 9257 & 1027 \\
\hline $\mathrm{C} / \mathrm{U}_{238}$ & 9928 & 5200 \\
\hline $\mathbf{U}$ density $\left(\mathrm{g} / \mathrm{cm}^{\mathbf{3}}\right)$ & 136940 & 1280 \\
\hline enrichment & $3.64 \times 10^{-3}$ & $33.1 \times 10^{-3}$ \\
\hline
\end{tabular}

\subsubsection{Neutron Spectrum Inside the M8Cal Test Vehicle for the HEU and LEU-D Cores}

In order to study the change of the neutron spectrum from the HEU to LEU fuel cores, 69 neutron energy groups (WIMS-ANL [12] 69 energy groups) were tallied using the critical rod configuration $A$ (compensation rods $100 \%$ withdrawn, control/shutdown rods $\approx 38 \%$ withdrawn and transient rods $100 \%$ withdrawn) and assuming dry air in place of the monitor wire inside the calibration vehicle. Due to higher U-238 content and the greater neutron absorption of U-238 compared to U-235 at low neutron energies, the LEU-D core presents a harder neutron spectrum with a higher fast (energy $>0.625 \mathrm{eV}$ ) to thermal (energy $<0.625 \mathrm{eV}$ ) flux ratio as tabulated in Table 4.9. 
Table [4.9]: MCNP Calculated Fast (Energy $>0.625 \mathrm{eV}$ ) to Thermal (Energy $<0.625 \mathrm{eV}$ ) Flux Ratio for the HEU and LEU-D (FA with $C / U=5200$ ) at the Low Enriched Flux Wire

\begin{tabular}{|c|c|c|}
\hline Flux Ratio & HEU & LEU-D \\
\hline Fast (Energy $>0.625 \mathrm{eV}) /$ Thermal (Energy $<0.625 \mathrm{eV})$ & 3.8 & 5.6 \\
\hline
\end{tabular}

Figure 4.16 illustrates the calculated normalized-to-total neutron flux for the HEU and the LEU-D cores.

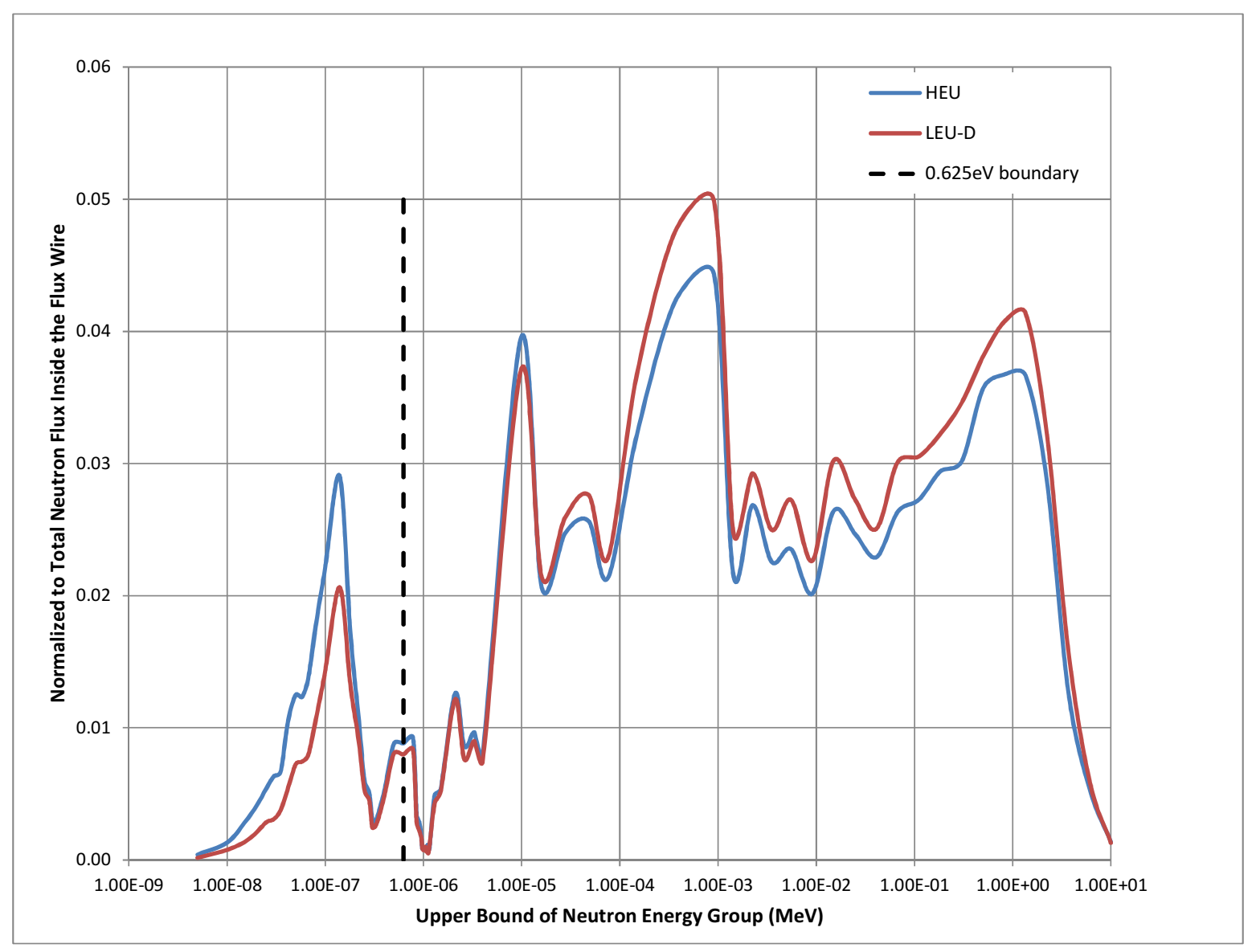

Figure [4.16]: MCNP Calculated Normalized to Total Neutron Energy Spectrum for the HEU and LEU-D (FA with C/U=5200) Inside the Low Enriched Flux Wire

\subsubsection{Control Rod Worth}

Due to the harder neutron spectrum and the resulting decreased absorption by the rod neutron absorbing material $\left(B_{4} C\right)$, the transient rod bank worth in the LEU-D core was also decreased. The total control rod worth for the HEU and the LEU-D cores was calculated by moving each rod type as a bank from $0 \%$ to $100 \%$ withdrawal for cold cores while keeping the rest of the rods outside the core. The results are tabulated in Table 4.10. It should be noted that the compensation/shutdown rods do not by themselves have enough reactivity to scram the LEU-D core (rod worth 6.53\% and excess reactivity $7.32 \%$ ) if all of the transient rods remain withdrawn. 
Table [4.10]: MCNP Calculated Control Rod Reactivity (\%) for the LEU-D (FA with C/U=5200) and HEU and the LEU-D/HEU Ratio

\begin{tabular}{|l|c|c|c|}
\cline { 2 - 3 } \multicolumn{1}{c|}{} & \multicolumn{2}{c|}{$\left(\mathbf{(}_{\text {rods IN }}-\mathbf{k}_{\text {rods OUT }}\right) /\left(\mathbf{k}_{\text {rods IN }} \times \mathbf{k}_{\text {rods OUT }}\right)$} & \multicolumn{1}{c|}{} \\
\hline Rods & LEU-D (\%) & HEU (\%) & LEU-D/HEU (\%) \\
\hline Transient & $7.32 \pm 0.01$ & $9.43 \pm 0.01$ & $77.60 \pm 0.09$ \\
\hline Control / Shutdown & $7.98 \pm 0.01$ & $10.05 \pm 0.01$ & $79.40 \pm 0.09$ \\
\hline Compensation / Shutdown & $6.53 \pm 0.01$ & $8.67 \pm 0.01$ & $75.38 \pm 0.10$ \\
\hline
\end{tabular}

\subsubsection{Effective Delayed Neutron Fraction and Prompt Generation Lifetime}

The effective delayed neutron fraction $\left(\beta_{\text {eff }}\right)$ and the prompt neutron generation lifetime $\left(I_{p}\right)$ were calculated for the LEU-D critical cold core using the MCNP kopts card [9] (using the default blocksize values in the MCNP runs).

The results of the calculations and the comparison with the HEU values are presented in Table 4.11. The LEU-D/HEU error was calculated using error propagation theory:

$$
\delta\left(\frac{[L E U-D]}{H E U}\right)=\sqrt{\left(\frac{1}{H E U} \times \delta[L E U-D]\right)^{2}+\left(\frac{[L E U-D]}{H E U^{2}} \times \delta H E U\right)^{2}}
$$

where $\delta C$ and $\delta M$ is the error in the calculated and the measured value, respectively.

Table [4.11]: MCNP Calculated Effective Delayed Neutron Fraction and Prompt Generation Lifetime for the LEU-D (FA with $\mathrm{C} / \mathrm{U}=5200$ ) and HEU and the LEU-D/HEU Ratio

\begin{tabular}{|l|c|c|c|}
\hline Parameter & LEU-D & HEU & LEU-D/HEU (\%) \\
\hline Effective delayed Neutron Fraction $\left(\mathrm{pcm}^{*}\right)$ & $679 \pm 6$ & $691 \pm 5$ & $98.3 \pm 1.1$ \\
\hline Prompt neutron lifetime, $\mathrm{I}_{\mathrm{p}}(\mu \mathrm{s}) \quad$ & $628.0 \pm 0.7$ & $898.6 \pm 0.8$ & $69.9 \pm 0.1$ \\
\hline
\end{tabular}

The $\beta_{\text {eff }}$ for the LEU-D core is similar to the one of HEU core, whereas the $I_{p}$ is reduced by $\approx 30 \%$. The shorter prompt neutron generation lifetime is expected to accelerate the power increase in the case of the LEU-D core during transient operation. This is studied in the following sections where the kinetics code TREKIN is discussed.

\subsubsection{LEU-D MCNP Calculated Temperature Reactivity Feedback}

Using the methodology described in section 4.3.6.1 the temperature reactivity feedback as a function of total core energy (for energy steps 500, 1000, 2000, 3500 and 5000 MJ) was calculated with MCNP using the same with HEU graphite heat capacity function with temperature. The rod configuration used in the MCNP simulations was Compensation/Shutdown: 100\% withdrawn, Control/Shutdown: 38.6\% withdrawn, Transients: $100 \%$ withdrawn. Three radial and three axial temperature zones were defined, and temperature dependent cross section libraries were produced using the MAKXSF program. The maximum fuel assembly temperature was calculated based on the section 4.3.6.1 methodology is presented in Figure 4.17 as a function of total core energy and is compared with the one calculated for the HEU core. 


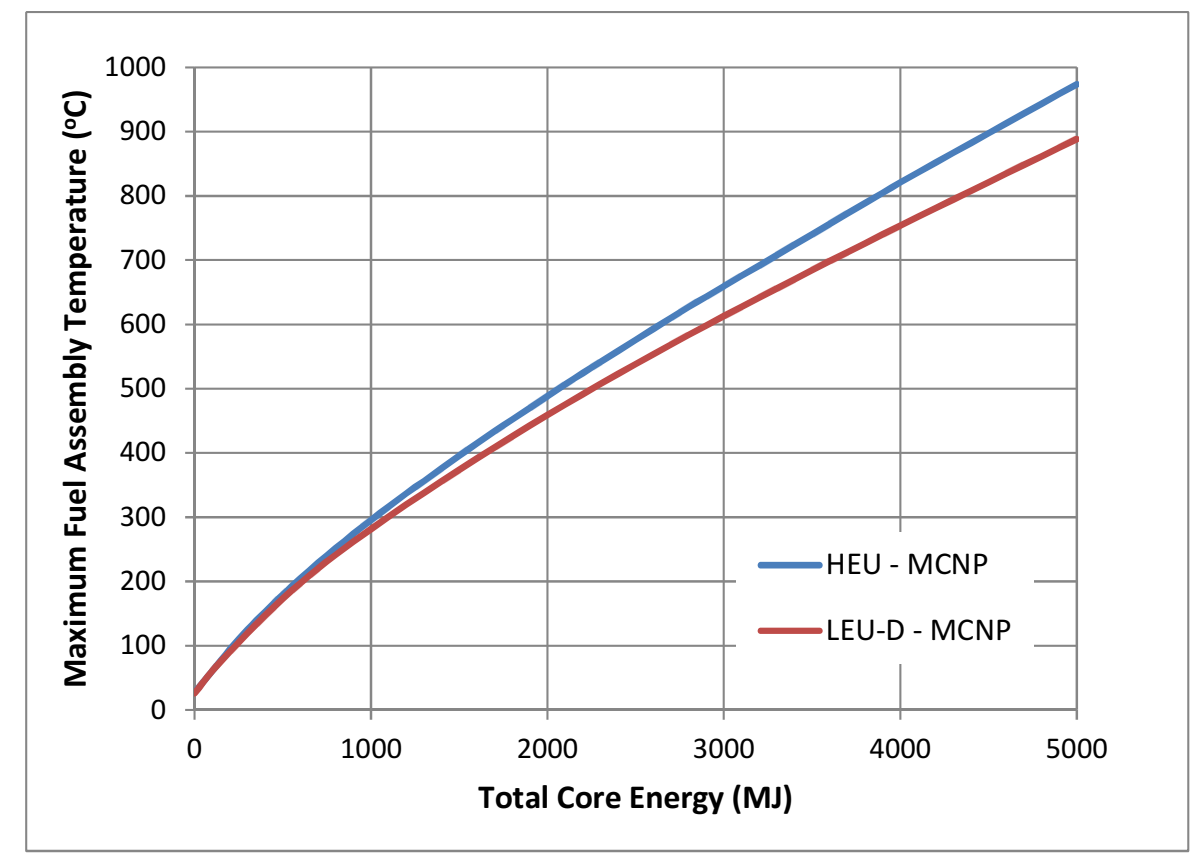

Figure [4.17]: Maximum Fuel Assembly Temperature Calculated with the MCNP Produced Power Density Distribution as a Function of the Total Core Energy for the HEU and LEU-D (FA with $C / U=5200$ )

Figure 4.18 illustrates the temperature reactivity as a function of total core energy calculated for the LEU-D and HEU cores. There is an average $36 \%$ decrease in the feedback values from the HEU to LEU-D core due to the spectrum hardening.

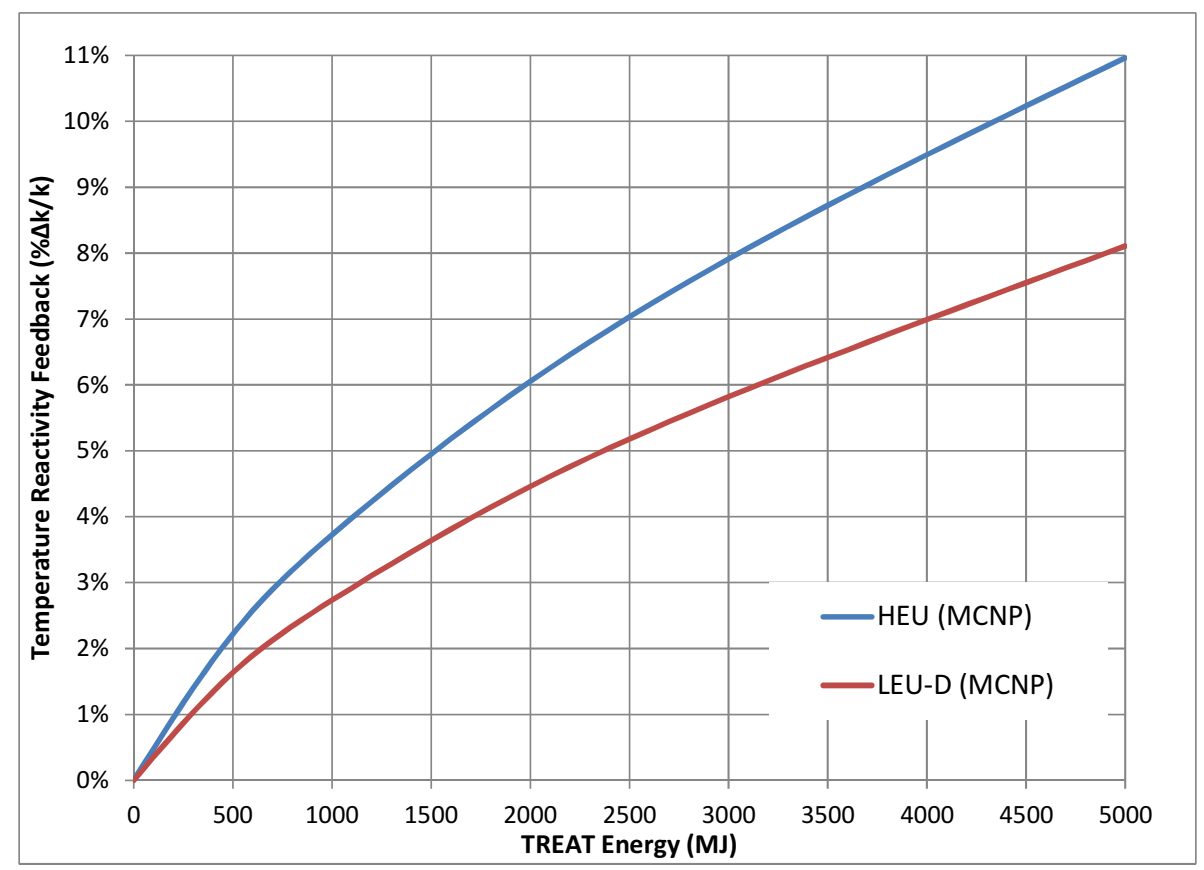

Figure [4.18]: MCNP Calculated HEU and LEU-D (FA with $C / U=5200)$ Temperature Reactivity Feedback (Rod Configuration: Compensation/Shutdown $100 \%$ Withdrawn, Control/Shutdown 38.6\% Withdrawn, Transients $100 \%$ Withdrawn) 


\subsubsection{Power Coupling Factor (PCF) for LEU-D}

The peak power coupling factor (PCF) (in fissions per gram of U-235 per total core energy) was calculated simulating the LLSS flux wire irradiation inside the M8CAL vehicle located at the center of the LEU-D core. The calculation results and the comparison with the HEU values are shown in Table 4.12. The error in the LEU-D/HEU ratio was calculated using the error propagation theory.

Table [4.12]: MCNP Calculated Peak Power Coupling Factor (PCF) in Fissions per U-235 Grams and Total Core Energy for the LEU-D (FA with $C / U=5200$ ) and HEU Cores for the LLSS Wire Irradiations. The Rod Position and the Resulting LEU-D/HEU Ratio are also Shown

\begin{tabular}{|c|c|c|c|}
\hline & LEU-D & HEU & \\
\hline & \multicolumn{2}{|c|}{ Rod Position (\% withdrawal) } & \\
\hline Transient & 22.4 & 38 & \\
\hline Control/Shutdown & 100 & 100 & \\
\hline Compensation & 100 & 100 & LEU-D/HEU (\%) \\
\hline Peak PCF (f/g u-235-MJ) $\times 10^{12}$ & $0.86 \pm 0.03$ & $1.49 \pm 0.04$ & $58 \pm 3$ \\
\hline
\end{tabular}

The peak PCF was also calculated for the fuel pins placed in the center of the M8CAL vehicle in the LEUD core, and the results were compared with the HEU results (Table 4.13).

Table [4.13]: MCNP Calculated Peak Power Coupling Factor (PCF) in Joules per Total Mass per Total Core Energy for the HEU and LEU-D (FA with $C / U=5200$ ) for the T-433 and T-462 Test Pins LLSS Irradiations. The Rod Position and the Resulting LEUD/HEU Ratio are also Shown

\begin{tabular}{|c|c|c|c|}
\hline & LEU-D & HEU & \\
\hline & \multicolumn{2}{|c|}{ Rod withdrawal (\%) } & \\
\hline Transient & 22.4 & 38 & \\
\hline Control/Shutdown & 100 & 100 & \\
\hline Compensation & 100 & 100 & LEU-D/HEU (\%) \\
\hline T-433 Peak PCF (J/g-MJ) & $4.32 \pm 0.06$ & $6.36 \pm 0.07$ & $67.4 \pm 1.2$ \\
\hline T-462 Peak PCF (J/g-MJ) & $4.12 \pm 0.06$ & $6.11 \pm 0.07$ & $67.9 \pm 1.2$ \\
\hline
\end{tabular}

The peak PCF for the flux wire irradiation was approximately $42 \%$ lower for the LEU-D core for equal total core energy as compared to the HEU core. The peak PCF decrease in the case of the fuel pins was approximately $32 \%$; this is different from the flux wire case since the PCF also depends on the irradiated sample material composition and thickness. Based on the results tabulated in Tables 4.12 and 4.13, the LEU-D core would need to produce $42 \%$ and $32 \%$ more energy than the HEU core to achieve equal energy deposition in the flux wire and the test pins, respectively.

\subsubsection{LEU-D Core Relative Power Density Distribution}

The fuel assembly power density relative-to-core-average power density (ratio of the power density in the fuel to the average power density of the fuel in the entire core) was calculated in the case of the flux wire irradiation in the LEU-D core with the control rods positioned as follows: Compensation rods $100 \%$ withdrawn, Control/Shutdown rods $\approx 23 \%$ withdrawn and Transient rods $100 \%$ withdrawn). Figure 4.19 shows the relative power density distribution for the LEU-D core. The maximum relative power density is observed in assembly 011 with a value of 1.38 (highlighted in Figure 4.19 with yellow shading). 


\begin{tabular}{|c|c|c|c|c|c|c|c|c|c|c|c|c|c|c|c|c|c|c|c|}
\hline & A & B & C & D & $E$ & $\mathbf{F}$ & G & $\mathbf{H}$ & J & K & $\mathbf{L}$ & $M$ & $\mathbf{N}$ & 0 & $\mathbf{P}$ & $\mathbf{R}$ & $S$ & $T$ & U \\
\hline 1 & & & 0.80 & 0.76 & 0.75 & 0.74 & 0.73 & 0.72 & 0.73 & & 0.73 & 0.72 & 0.72 & 0.73 & 0.73 & 0.74 & 0.79 & & \\
\hline 2 & & 0.80 & 0.72 & 0.69 & 0.68 & 0.66 & 0.63 & 0.61 & 0.66 & & 0.66 & 0.60 & 0.62 & 0.65 & 0.67 & 0.69 & 0.72 & 0.81 & \\
\hline 3 & 0.87 & 0.76 & 0.74 & 0.73 & 0.69 & 0.64 & 0.61 & 0.55 & 0.66 & & 0.66 & 0.55 & 0.61 & 0.64 & 0.69 & 0.74 & 0.75 & 0.78 & 0.91 \\
\hline 4 & 0.88 & 0.80 & 0.80 & 0.81 & 0.75 & 0.62 & 0.69 & 0.72 & 0.76 & & 0.76 & 0.72 & 0.70 & 0.63 & 0.75 & 0.82 & 0.82 & 0.82 & 0.94 \\
\hline 5 & 0.94 & 0.86 & 0.88 & 0.91 & 0.89 & 0.85 & 0.87 & 0.88 & 0.86 & & 0.86 & 0.88 & 0.88 & 0.86 & 0.90 & 0.92 & 0.91 & 0.90 & 1.00 \\
\hline 6 & 1.02 & 0.94 & 0.97 & 1.01 & 1.03 & 1.04 & 1.03 & 1.01 & 0.95 & & 0.95 & 1.01 & 1.04 & 1.05 & 1.05 & 1.03 & 0.99 & 0.97 & 1.07 \\
\hline 7 & 1.09 & 1.01 & 1.05 & 1.10 & 1.15 & 1.16 & 1.14 & 1.09 & 0.99 & & 1.00 & 1.10 & 1.15 & 1.18 & 1.16 & 1.12 & 1.07 & 1.04 & 1.13 \\
\hline 8 & 1.14 & 1.06 & 1.11 & 1.18 & 1.23 & 1.25 & 1.22 & 1.14 & 1.00 & & 1.00 & 1.15 & 1.23 & 1.26 & 1.25 & 1.20 & 1.13 & 1.09 & 1.18 \\
\hline 9 & 1.18 & 1.10 & 1.16 & 1.24 & 1.29 & 1.31 & 1.28 & 1.17 & 0.94 & & 0.94 & 1.18 & 1.29 & 1.32 & 1.31 & 1.26 & 1.18 & 1.13 & 1.22 \\
\hline 10 & 1.20 & 1.13 & 1.19 & 1.27 & 1.33 & 1.35 & 1.32 & 1.21 & 0.95 & & 0.95 & 1.22 & 1.33 & 1.36 & 1.35 & 1.29 & 1.21 & 1.15 & 1.23 \\
\hline 11 & 1.21 & 1.13 & 1.19 & 1.27 & 1.33 & 1.36 & 1.35 & 1.27 & 1.10 & & 1.10 & 1.28 & 1.36 & 1.38 & 1.35 & 1.29 & 1.21 & 1.15 & 1.24 \\
\hline 12 & 1.19 & 1.11 & 1.16 & 1.24 & 1.31 & 1.35 & 1.35 & 1.32 & 1.27 & 1.23 & 1.27 & 1.33 & 1.37 & 1.36 & 1.33 & 1.26 & 1.19 & 1.13 & 1.22 \\
\hline 13 & 1.15 & 1.07 & 1.12 & 1.19 & 1.25 & 1.29 & 1.31 & 1.32 & 1.31 & 1.31 & 1.32 & 1.33 & 1.33 & 1.31 & 1.27 & 1.21 & 1.14 & 1.09 & 1.18 \\
\hline 14 & 1.11 & 1.02 & 1.06 & 1.11 & 1.15 & 1.18 & 1.22 & 1.25 & 1.27 & 1.27 & 1.27 & 1.26 & 1.23 & 1.20 & 1.17 & 1.13 & 1.08 & 1.04 & 1.13 \\
\hline 15 & 1.05 & 0.95 & 0.98 & 1.01 & 1.01 & 0.99 & 1.05 & 1.11 & 1.15 & 1.17 & 1.16 & 1.12 & 1.06 & 1.01 & 1.03 & 1.03 & 1.00 & 0.98 & 1.08 \\
\hline 16 & 1.00 & 0.89 & 0.90 & 0.91 & 0.85 & 0.73 & 0.84 & 0.91 & 0.99 & 1.03 & 0.99 & 0.92 & 0.86 & 0.75 & 0.87 & 0.93 & 0.92 & 0.92 & 1.03 \\
\hline 17 & 0.98 & 0.85 & 0.83 & 0.83 & 0.79 & 0.75 & 0.74 & 0.68 & 0.83 & 0.89 & 0.84 & 0.69 & 0.75 & 0.77 & 0.82 & 0.85 & 0.86 & 0.88 & 1.02 \\
\hline 18 & & 0.89 & 0.80 & 0.78 & 0.78 & 0.77 & 0.75 & 0.75 & 0.80 & 0.84 & 0.81 & 0.76 & 0.77 & 0.79 & 0.81 & 0.82 & 0.84 & 0.93 & \\
\hline 19 & & & 0.88 & 0.84 & 0.85 & 0.86 & 0.87 & 0.89 & 0.91 & 0.92 & 0.91 & 0.90 & 0.90 & 0.90 & 0.90 & 0.90 & 0.94 & & \\
\hline
\end{tabular}

Figure [4.19]: MCNP Calculated Relative to Core Average Power Density Distribution for the Flux-Wire Irradiation in the LEU-D (FA with C/U=5200) Core. The Different Colors

Show the Position of the Rods (Red: Transient Rods, Green: Control/Shutdown, Light Blue: Compensation) and the Assembly with the Maximum Value (Yellow) 


\subsection{Alternative LEU Cores}

The experiments performed in TREAT involve simulation of accident conditions that require maximum test sample energy generation and/or maximum rate of reactivity addition during shaped transients. To overcome the calculated decrease of the power coupling factor in the case of the LEU-D core, possible core changes were considered. The hardening of the neutron spectrum in the case of the LEU-D core is mainly responsible for the $42 \%$ decrease of the energy deposition in the transient irradiation of lowenriched ${ }^{235} \mathrm{U}$ flux wire targets as compared with the HEU core so ways to enhance the population of the thermal neutrons were considered.

\subsubsection{LEU-D with BeO Reflectors}

Preliminary analyses indicate that by replacing 12 fuel assemblies around the M8CAL vehicle with beryllium oxide ( $\mathrm{BeO}$ ) aluminum-canned blocks (the $\mathrm{BeO}$ assemblies have the same dimensions and cladding as the graphite reflector blocks) (Figure 4.20) increases the power coupling factor by increasing the population of the thermal neutrons reaching the test sample and consequently the number of occurring fissions.

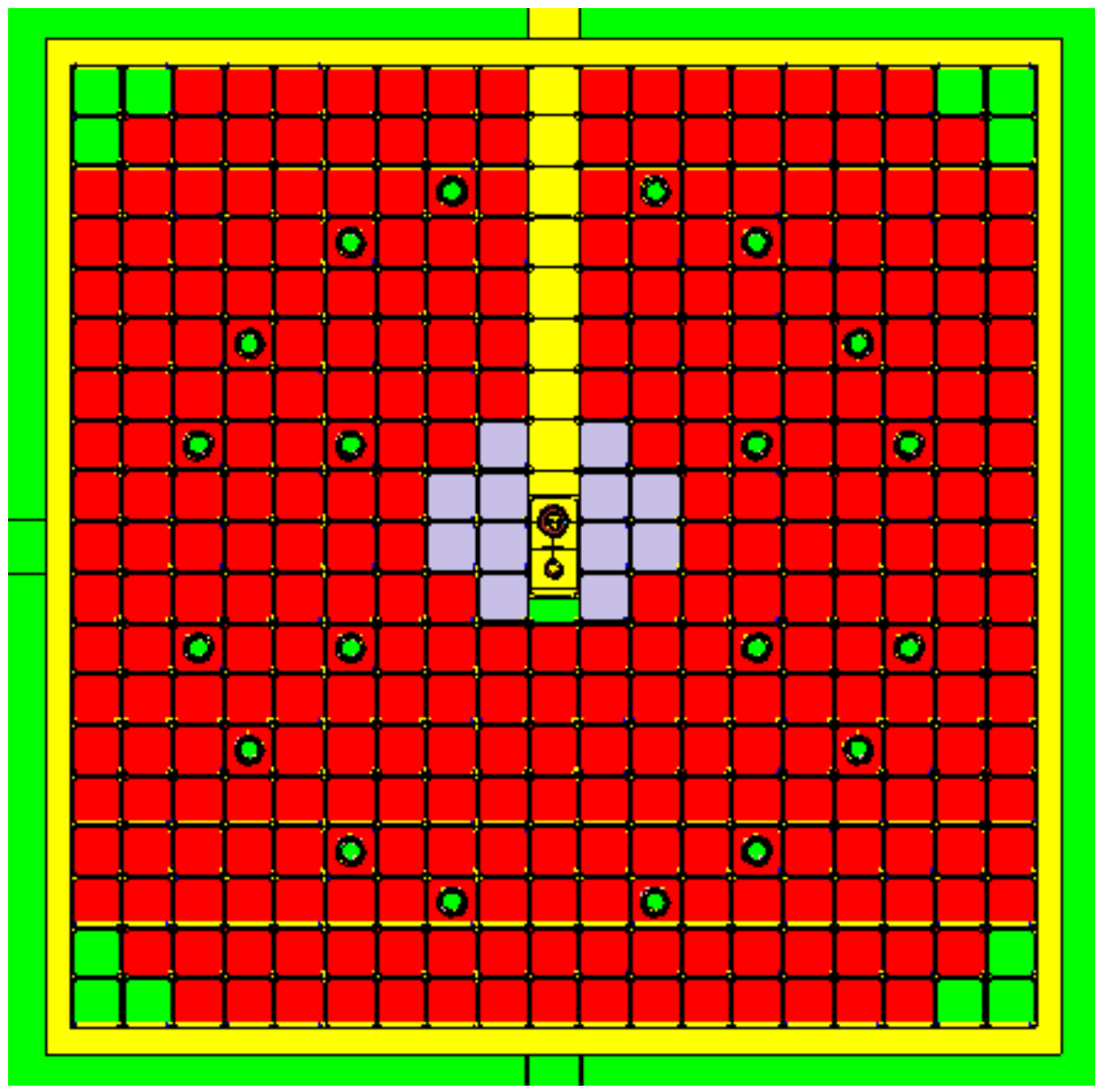

Figure [4.20]: MCNP Model of the Half Slotted LEU-D Core with 12 BeO Blocks Around M8CAL 
To assess the impact of the $\mathrm{BeO}$ blocks on the power coupling factor and the temperature distribution, the LLSS flux wire irradiation was simulated with MCNP using the method described in section 4.3.6.1 and the following rod configuration: compensation rods $100 \%$ withdrawn, control/shutdown rods $\approx 29 \%$ withdrawn and transient rods $100 \%$ withdrawn for total core energy of 500 MJ. Table 4.14 shows the power coupling factor relative to the HEU core.

Table [4.14]: MCNP Calculated Relative to HEU Peak Power Coupling Factor in the Flux Wire for the LEU-D (FA with $C / U=5200$ ) and LEU-D (FA with $C / U=5200)$ w/BeO Core Configurations

\begin{tabular}{|c|c|}
\hline Core & Peak PCF relative to HEU (\%) \\
\hline HEU & 100 \\
\hline LEU-D (FA with C/U=5200) & $58 \pm 3$ \\
\hline LEU-D (w/BeO FA with $C / U=5200)$ & $96 \pm 3$ \\
\hline
\end{tabular}

The LEU-D w/BeO core delivers $96 \%$ (Table 4.14) of the fissions delivered in the flux wire by the HEU core and at the same time the presence of the BeO blocks the neutron spectrum softening increase the temperature in the fuel assemblies especially those adjacent to the blocks with a maximum-to-average ratio of 1.54 (Table 4.15 ).

Table [4.15]: MCNP Calculated Core Average Fuel Assembly (FA) Maximum Temperatures for the HEU, LEU-D (FA with $C / U=5200)$ and LEU-D (w/BeO FA with $C / U=5200$ ) Core Configurations and the Resulting Maximum to Average Ratio for Total Core Energy $500 \mathrm{MJ}$

\begin{tabular}{|c|c|c|c|}
\hline Core & $\begin{array}{c}\text { Fuel Assembly (FA) } \\
\left.\text { Maximum Temp ( }{ }^{\circ} \mathbf{C}\right)\end{array}$ & $\begin{array}{c}\text { Core Average } \\
\text { Temp }\left({ }^{\circ} \mathbf{C}\right)( \pm s t d)\end{array}$ & $\begin{array}{c}\text { FA Max/Core } \\
\text { Average }\end{array}$ \\
\hline HEU & 156 & $122 \pm 19$ & 1.28 \\
\hline LEU-D(FA with C/U=5200) & 147 & $117 \pm 17$ & 1.25 \\
\hline LEU-D (w/BeO FA with C/U=5200) & 188 & $122 \pm 22$ & 1.54 \\
\hline
\end{tabular}

\subsubsection{LEU-D with BeO Relative Power Density Distribution}

The fuel assembly power density relative-to-core-average power density (ratio of the power density in the fuel to the average power density of the fuel in the entire core) was calculated in the case of the flux wire irradiation in the LEU-D core with the $12 \mathrm{BeO}$ reflectors and with the control rods positioned as follows: Compensation rods $100 \%$ withdrawn, Control/Shutdown rods $\approx 29 \%$ withdrawn and Transient rods $100 \%$ withdrawn.

Figure 4.21 shows the relative power density distribution for the LEU-D core with the BeO blocks. The maximum relative power density appears in assembly M11, which is adjacent to the BeO block, with a value of 1.86 (highlighted in Figure 4.21 with yellow shading) that is 1.35 times higher than in the maximum of the LEU-D core without the BeO blocks (1.38 in 011). 


\begin{tabular}{|c|c|c|c|c|c|c|c|c|c|c|c|c|c|c|c|c|c|c|c|}
\hline & A & B & C & D & $\mathbf{E}$ & $\mathbf{F}$ & G & H & $\mathbf{J}$ & $\mathrm{K}$ & $\mathbf{L}$ & $M$ & $\mathbf{N}$ & 0 & $\mathbf{P}$ & $\mathbf{R}$ & $S$ & $\mathbf{T}$ & $\mathbf{U}$ \\
\hline 1 & & & 0.76 & 0.72 & 0.70 & 0.69 & 0.67 & 0.66 & 0.67 & & 0.67 & 0.66 & 0.66 & 0.68 & 0.69 & 0.70 & 0.75 & & \\
\hline 2 & & 0.78 & 0.70 & 0.67 & 0.64 & 0.61 & 0.57 & 0.54 & 0.60 & & 0.60 & 0.54 & 0.57 & 0.60 & 0.64 & 0.66 & 0.70 & 0.79 & \\
\hline 3 & 0.86 & 0.75 & 0.72 & 0.71 & 0.65 & 0.58 & 0.54 & 0.47 & 0.61 & & 0.61 & 0.48 & 0.54 & 0.58 & 0.65 & 0.71 & 0.73 & 0.77 & 0.90 \\
\hline 4 & 0.88 & 0.79 & 0.79 & 0.78 & 0.70 & 0.55 & 0.63 & 0.65 & 0.72 & & 0.72 & 0.66 & 0.63 & 0.56 & 0.71 & 0.79 & 0.81 & 0.82 & 0.93 \\
\hline 5 & 0.94 & 0.86 & 0.88 & 0.89 & 0.86 & 0.80 & 0.82 & 0.84 & 0.85 & & 0.85 & 0.84 & 0.83 & 0.81 & 0.87 & 0.91 & 0.90 & 0.90 & 0.99 \\
\hline 6 & 1.02 & 0.94 & 0.97 & 1.00 & 1.02 & 1.01 & 1.01 & 1.01 & 1.01 & & 1.01 & 1.01 & 1.02 & 1.02 & 1.03 & 1.02 & 0.99 & 0.97 & 1.06 \\
\hline 7 & 1.09 & 1.01 & 1.05 & 1.10 & 1.14 & 1.17 & 1.19 & 1.24 & 1.25 & & 1.25 & 1.24 & 1.20 & 1.18 & 1.16 & 1.12 & 1.08 & 1.04 & 1.13 \\
\hline 8 & 1.15 & 1.07 & 1.12 & 1.19 & 1.25 & 1.30 & 1.42 & 1.67 & $\mathrm{BeO}$ & & $\mathrm{BeO}$ & 1.68 & 1.43 & 1.31 & 1.26 & 1.21 & 1.14 & 1.10 & 1.18 \\
\hline 9 & 1.19 & 1.12 & 1.18 & 1.25 & 1.32 & 1.41 & 1.69 & $\mathrm{BeO}$ & $\mathrm{BeO}$ & & $\mathrm{BeO}$ & $\mathrm{BeO}$ & 1.70 & 1.42 & 1.33 & 1.27 & 1.19 & 1.14 & 1.22 \\
\hline 10 & 1.21 & 1.14 & 1.20 & 1.28 & 1.35 & 1.46 & 1.74 & $\mathrm{BeO}$ & $\mathrm{BeO}$ & & $\mathrm{BeO}$ & $\mathrm{BeO}$ & 1.76 & 1.47 & 1.37 & 1.30 & 1.22 & 1.17 & 1.24 \\
\hline 11 & 1.22 & 1.15 & 1.20 & 1.28 & 1.35 & 1.43 & 1.57 & 1.85 & $\mathrm{BeO}$ & & $\mathrm{BeO}$ & 1.86 & 1.58 & 1.44 & 1.37 & 1.30 & 1.22 & 1.16 & 1.24 \\
\hline 12 & 1.20 & 1.12 & 1.17 & 1.25 & 1.31 & 1.36 & 1.42 & 1.49 & 1.51 & 1.44 & 1.52 & 1.50 & 1.43 & 1.38 & 1.33 & 1.27 & 1.19 & 1.14 & 1.22 \\
\hline 13 & 1.16 & 1.08 & 1.13 & 1.19 & 1.24 & 1.28 & 1.31 & 1.33 & 1.34 & 1.33 & 1.34 & 1.34 & 1.32 & 1.30 & 1.26 & 1.21 & 1.15 & 1.10 & 1.19 \\
\hline 14 & 1.11 & 1.03 & 1.06 & 1.10 & 1.13 & 1.15 & 1.18 & 1.21 & 1.23 & 1.24 & 1.24 & 1.22 & 1.20 & 1.17 & 1.15 & 1.12 & 1.08 & 1.05 & 1.13 \\
\hline 15 & 1.05 & 0.96 & 0.97 & 1.00 & 0.97 & 0.94 & 0.99 & 1.05 & 1.10 & 1.12 & 1.10 & 1.06 & 1.01 & 0.95 & 0.99 & 1.02 & 1.00 & 0.98 & 1.07 \\
\hline 16 & 0.99 & 0.89 & 0.89 & 0.89 & 0.81 & 0.66 & 0.77 & 0.84 & 0.92 & 0.96 & 0.92 & 0.84 & 0.78 & 0.67 & 0.83 & 0.91 & 0.91 & 0.91 & 1.01 \\
\hline 17 & 0.97 & 0.84 & 0.82 & 0.80 & 0.75 & 0.69 & 0.67 & 0.60 & 0.76 & 0.83 & 0.76 & 0.61 & 0.68 & 0.70 & 0.77 & 0.83 & 0.84 & 0.87 & 1.00 \\
\hline 18 & & 0.87 & 0.78 & 0.76 & 0.74 & 0.72 & 0.69 & 0.68 & 0.74 & 0.77 & 0.74 & 0.69 & 0.71 & 0.74 & 0.77 & 0.79 & 0.82 & 0.91 & \\
\hline 19 & & & 0.85 & 0.81 & 0.81 & 0.81 & 0.81 & 0.82 & 0.84 & 0.85 & 0.85 & 0.83 & 0.83 & 0.84 & 0.85 & 0.86 & 0.90 & & \\
\hline
\end{tabular}

Figure [4.21]: MCNP Calculated Relative to Core Average Power Distribution for the Flux Irradiation in the LEU-D (w/ BeO FA with C/U=5200) Core. The Different Colors Show the Position of the Rods (Red: Transient Rods, Green: Control/Shutdown, Light Blue: Compensation), the Assembly with the Maximum Value (Yellow) and of the BeO Blocks (Grey) 


\subsubsection{LEU-A Core}

In order to decrease the power density and consequently the temperature rise in the assemblies adjacent to the $\mathrm{BeO}$ blocks, lower U-235 loading was considered (this produced higher $\mathrm{C} / \mathrm{U}$ ratio since the graphite content remained constant). The LEU-A core was composed of $12 \mathrm{BeO}$ assemblies, 314 control and standard fuel assemblies with $C / U=5200$, and 12 fuel assemblies with $C / U=6619$ (plus the usual slotted assemblies, dummy assemblies and M8CAL vehicle), is presented in Figure 4.22.

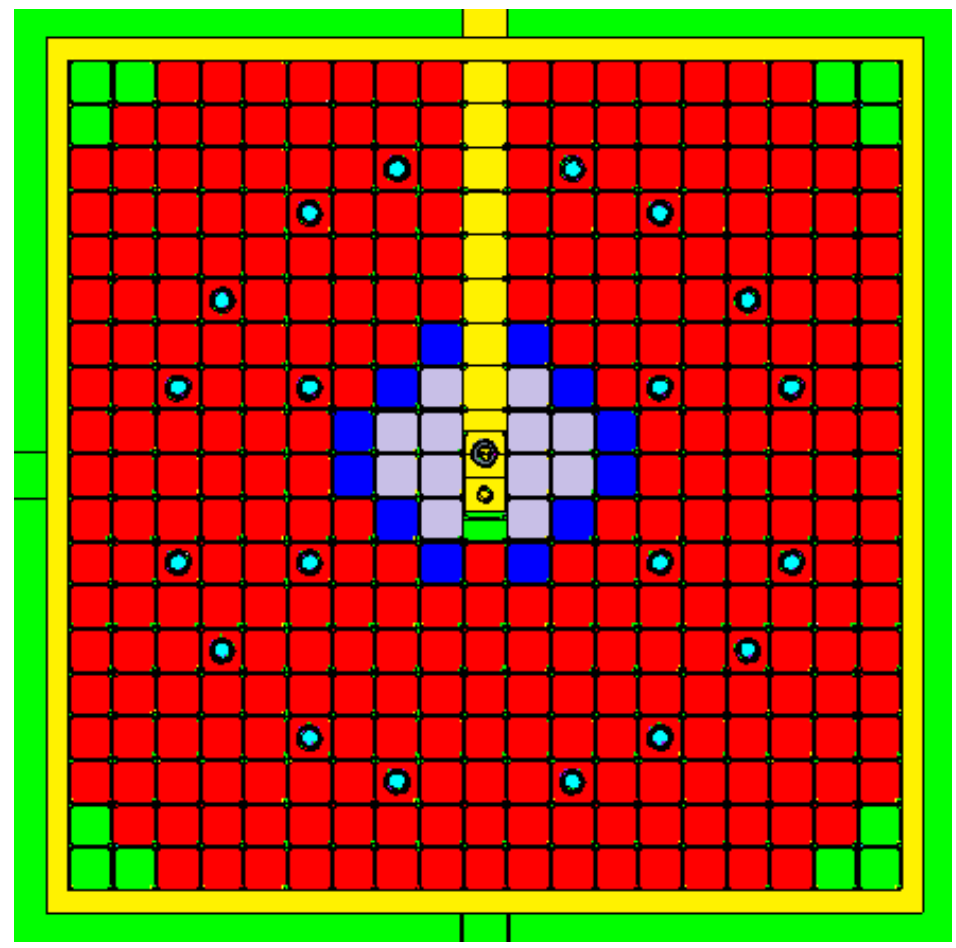

Figure [4.22]: MCNP Model of the Half Slotted LEU-A TREAT Core with $12 \mathrm{BeO}$ Blocks and 12 Fuel Assemblies (FA) with Higher C/U Ratio (C/U=6619)

Graphite Reflector,

FA $(C / U=5200)$

$\mathrm{FA}(\mathrm{C} / \mathrm{U}=6619)$

Control Assembly,

Air,

$\mathrm{BeO})$

\subsubsection{LEU-A Core Relative Power Density Distribution and Power Coupling Factor}

In Figure 4.23 is illustrated the relative power density distribution for the flux wire irradiation in the LEUA core (with $12 \mathrm{BeO}$ blocks and 12 fuel assemblies with lower uranium loading) with the control rods positioned as follows: compensation rods $100 \%$ withdrawn, control/shutdown rods $\approx 30 \%$ withdrawn and transient rods $100 \%$ withdrawn.

The maximum relative power is observed in assembly N11 with a value of 1.58 (highlighted in Figure 4.23 with yellow shading) that is 1.18 times lower than in the maximum of the LEU-D with BeO blocks and all fuel assemblies with the same uranium loading core (1.86 in M11). 


\begin{tabular}{|c|c|c|c|c|c|c|c|c|c|c|c|c|c|c|c|c|c|c|c|}
\hline & A & B & C & D & $E$ & $\mathbf{F}$ & G & $\mathbf{H}$ & J & K & $\mathbf{L}$ & $M$ & $\mathbf{N}$ & 0 & $\mathbf{P}$ & $\mathbf{R}$ & $S$ & $\mathbf{T}$ & $\mathbf{U}$ \\
\hline 1 & & & 0.76 & 0.73 & 0.72 & 0.71 & 0.70 & 0.69 & 0.70 & & 0.70 & 0.69 & 0.70 & 0.70 & 0.71 & 0.71 & 0.75 & & \\
\hline 2 & & 0.77 & 0.70 & 0.68 & 0.66 & 0.64 & 0.62 & 0.60 & 0.64 & & 0.64 & 0.59 & 0.61 & 0.64 & 0.66 & 0.67 & 0.70 & 0.78 & \\
\hline 3 & 0.84 & 0.74 & 0.72 & 0.71 & 0.68 & 0.63 & 0.61 & 0.55 & 0.66 & & 0.66 & 0.55 & 0.61 & 0.64 & 0.69 & 0.72 & 0.73 & 0.76 & 0.88 \\
\hline 4 & 0.85 & 0.77 & 0.78 & 0.79 & 0.74 & 0.63 & 0.69 & 0.70 & 0.75 & & 0.75 & 0.71 & 0.69 & 0.64 & 0.75 & 0.80 & 0.80 & 0.80 & 0.90 \\
\hline 5 & 0.91 & 0.84 & 0.86 & 0.88 & 0.87 & 0.84 & 0.85 & 0.86 & 0.87 & & 0.88 & 0.86 & 0.85 & 0.85 & 0.88 & 0.90 & 0.88 & 0.87 & 0.96 \\
\hline 6 & 0.98 & 0.91 & 0.94 & 0.97 & 1.00 & 1.01 & 1.01 & 1.01 & 1.02 & & 1.02 & 1.02 & 1.02 & 1.02 & 1.02 & 0.99 & 0.96 & 0.94 & 1.03 \\
\hline 7 & 1.05 & 0.97 & 1.01 & 1.07 & 1.11 & 1.14 & 1.18 & 1.24 & 1.02 & & 1.02 & 1.25 & 1.19 & 1.16 & 1.13 & 1.09 & 1.04 & 1.00 & 1.09 \\
\hline 8 & 1.10 & 1.03 & 1.07 & 1.14 & 1.20 & 1.27 & 1.41 & 1.35 & $\mathrm{BeO}$ & & $\mathrm{BeO}$ & 1.36 & 1.43 & 1.29 & 1.22 & 1.16 & 1.09 & 1.06 & 1.14 \\
\hline 9 & 1.14 & 1.07 & 1.12 & 1.20 & 1.27 & 1.39 & 1.36 & $\mathrm{BeO}$ & $\mathrm{BeO}$ & & $\mathrm{BeO}$ & $\mathrm{BeO}$ & 1.38 & 1.40 & 1.29 & 1.22 & 1.15 & 1.10 & 1.17 \\
\hline 10 & 1.16 & 1.09 & 1.15 & 1.23 & 1.31 & 1.43 & 1.41 & $\mathrm{BeO}$ & $\mathrm{BeO}$ & & $\mathrm{BeO}$ & $\mathrm{BeO}$ & 1.42 & 1.45 & 1.33 & 1.26 & 1.18 & 1.12 & 1.20 \\
\hline 11 & 1.17 & 1.10 & 1.16 & 1.24 & 1.31 & 1.40 & 1.57 & 1.49 & $\mathrm{BeO}$ & & $\mathrm{BeO}$ & 1.51 & 1.58 & 1.42 & 1.33 & 1.26 & 1.18 & 1.12 & 1.20 \\
\hline 12 & 1.15 & 1.08 & 1.13 & 1.21 & 1.28 & 1.34 & 1.41 & 1.50 & 1.23 & 1.45 & 1.24 & 1.52 & 1.43 & 1.36 & 1.31 & 1.24 & 1.16 & 1.11 & 1.18 \\
\hline 13 & 1.12 & 1.05 & 1.10 & 1.17 & 1.23 & 1.27 & 1.31 & 1.34 & 1.35 & 1.35 & 1.36 & 1.35 & 1.33 & 1.29 & 1.25 & 1.19 & 1.12 & 1.08 & 1.15 \\
\hline 14 & 1.08 & 1.00 & 1.05 & 1.10 & 1.14 & 1.17 & 1.21 & 1.24 & 1.26 & 1.26 & 1.26 & 1.25 & 1.22 & 1.19 & 1.16 & 1.12 & 1.07 & 1.03 & 1.11 \\
\hline 15 & 1.03 & 0.95 & 0.98 & 1.01 & 1.02 & 1.01 & 1.06 & 1.11 & 1.15 & 1.16 & 1.15 & 1.12 & 1.07 & 1.02 & 1.04 & 1.03 & 1.00 & 0.97 & 1.06 \\
\hline 16 & 0.98 & 0.89 & 0.90 & 0.92 & 0.88 & 0.78 & 0.88 & 0.93 & 1.00 & 1.04 & 1.01 & 0.94 & 0.89 & 0.79 & 0.90 & 0.94 & 0.93 & 0.91 & 1.01 \\
\hline 17 & 0.97 & 0.85 & 0.83 & 0.84 & 0.82 & 0.79 & 0.78 & 0.74 & 0.86 & 0.92 & 0.87 & 0.74 & 0.79 & 0.81 & 0.84 & 0.87 & 0.86 & 0.88 & 1.00 \\
\hline 18 & & 0.89 & 0.81 & 0.79 & 0.80 & 0.80 & 0.79 & 0.78 & 0.83 & 0.86 & 0.84 & 0.79 & 0.80 & 0.82 & 0.83 & 0.83 & 0.85 & 0.93 & \\
\hline 19 & & & 0.88 & 0.85 & 0.86 & 0.88 & 0.89 & 0.91 & 0.93 & 0.94 & 0.93 & 0.92 & 0.92 & 0.92 & 0.91 & 0.91 & 0.94 & & \\
\hline
\end{tabular}

Figure [4.23]: MCNP Calculated Relative to Core Average Power Distribution for the Flux Irradiation in the LEU-A Core (With 12 BeO Blocks and 12 Fuel Assemblies with Lower Uranium Loading). The Different Colors Show the Position of the Rods and the Fuel Assemblies with the Lower Uranium Loading (Red: Transient Rods, Green: Control/Shutdown, Light Blue: Compensation, Purple: Fuel Assemblies with $\mathrm{C} / \mathrm{U}=6619$ ), the Assembly with the Maximum Value (Yellow) and of the BeO Blocks (Grey) 
Table 4.16 shows the relative to HEU power coupling factors for the LEU-D, LEU-D w/BeO and LEU-A cores.

Table [4.16]: MCNP Calculated Relative to HEU Peak Power Coupling Factor in the Flux Wire for the HEU, LEU-D (FA with $C / U=5200)$, LEU-D (BeO FA with $C / U=5200$ ) and LEU-A (BeO FA with $C / U=5200$ and $C / U=6619$ ) Core Configurations

\begin{tabular}{|c|c|}
\hline Core & Peak PCF relative to HEU (\%) \\
\hline HEU & 100 \\
\hline LEU-D (FA with C/U=5200) & $58 \pm 3$ \\
\hline LEU-D (BeO, FA with $C / U=5200)$ & $96 \pm 3$ \\
\hline LEU-A (BeO, FA with $C / U=6619)$ & $94 \pm 4$ \\
\hline
\end{tabular}

Table 4.17 shows the core average and maximum FA average temperature for the HEU, LEU-D, LEU-D $\mathrm{w} / \mathrm{BeO}$ and LEU-A core configurations calculated for total core energy of $500 \mathrm{MJ}$.

Table [4.17]: MCNP Calculated Core Average and Fuel Assembly Average (FA) Maximum Temperatures for the HEU, LEU-D (FA with $C / U=5200$ ), LEU-D (BeO FA with $C / U=5200$ ) and LEU-A (BeO FA with $C / U=5200$ and $C / U=6619$ ) Core Configurations and the Maximum to Average Ratio

\begin{tabular}{|c|c|c|c|}
\hline Core & $\begin{array}{c}\text { Fuel Assembly (FA) } \\
\text { Maximum Temp } \\
\left({ }^{\circ} \mathbf{C}\right)\end{array}$ & $\begin{array}{c}\text { Core Average } \\
\text { Temp }\left({ }^{\circ} \mathbf{C}\right)( \pm s t d)\end{array}$ & FA Max/Core Average \\
\hline HEU & 156 & $122 \pm 19$ & 1.28 \\
\hline LEU-D (FA with C/U=5200) & 147 & $117 \pm 17$ & 1.25 \\
\hline LEU-D (BeO, FA with C/U=5200) & 188 & $122 \pm 23$ & 1.54 \\
\hline LEU-A (BeO, FA with C/U=6619) & 170 & $124 \pm 19$ & 1.38 \\
\hline
\end{tabular}

The LEU-A delivers $94 \%$ of the fissions that the HEU core delivers in the flux wire. The fuel assembly average maximum temperature and the maximum-to-core-average temperature ratio for the LEU-A core were decreased approximately by $10 \%$ as compared to the LEU-D w/BeO case. The LEU-A core was further analyzed in the following sections.

\subsubsection{Neutron Spectrum in Flux Wire}

The neutron spectrum inside the flux wire (the composition of the wire in the MCNP model was replaced with air) was calculated as described in section 4.5.2, and Figure 4.24 illustrates the spectra normalized to the total flux for the HEU, LEU-D and LEU-A cores. The fast (energy $>0.625 \mathrm{eV}$ ) to thermal (energy $<0.625 \mathrm{eV}$ ) neutron flux ratio for the three cores is tabulated in Table 4.18.

Table [4.18]: MCNP Calculated Fast (Energy > 0.625eV) to Thermal (Energy < 0.625eV) Flux Ratio for the HEU, LEU-D (FA with $\mathrm{C} / \mathrm{U}=5200)$ and LEU-A (BeO, FA with $\mathrm{C} / \mathrm{U}=5200$ and $\mathrm{C} / \mathrm{U}=6619)$ Core Configurations Inside the Flux Wire

\begin{tabular}{|c|c|c|c|}
\hline Flux Ratio & HEU & LEU-D & LEU-A \\
\hline Fast $($ Energy $>0.625 \mathrm{eV}) /$ Thermal (Energy $<0.625 \mathrm{eV})$ & 3.8 & 5.6 & 2.7 \\
\hline
\end{tabular}




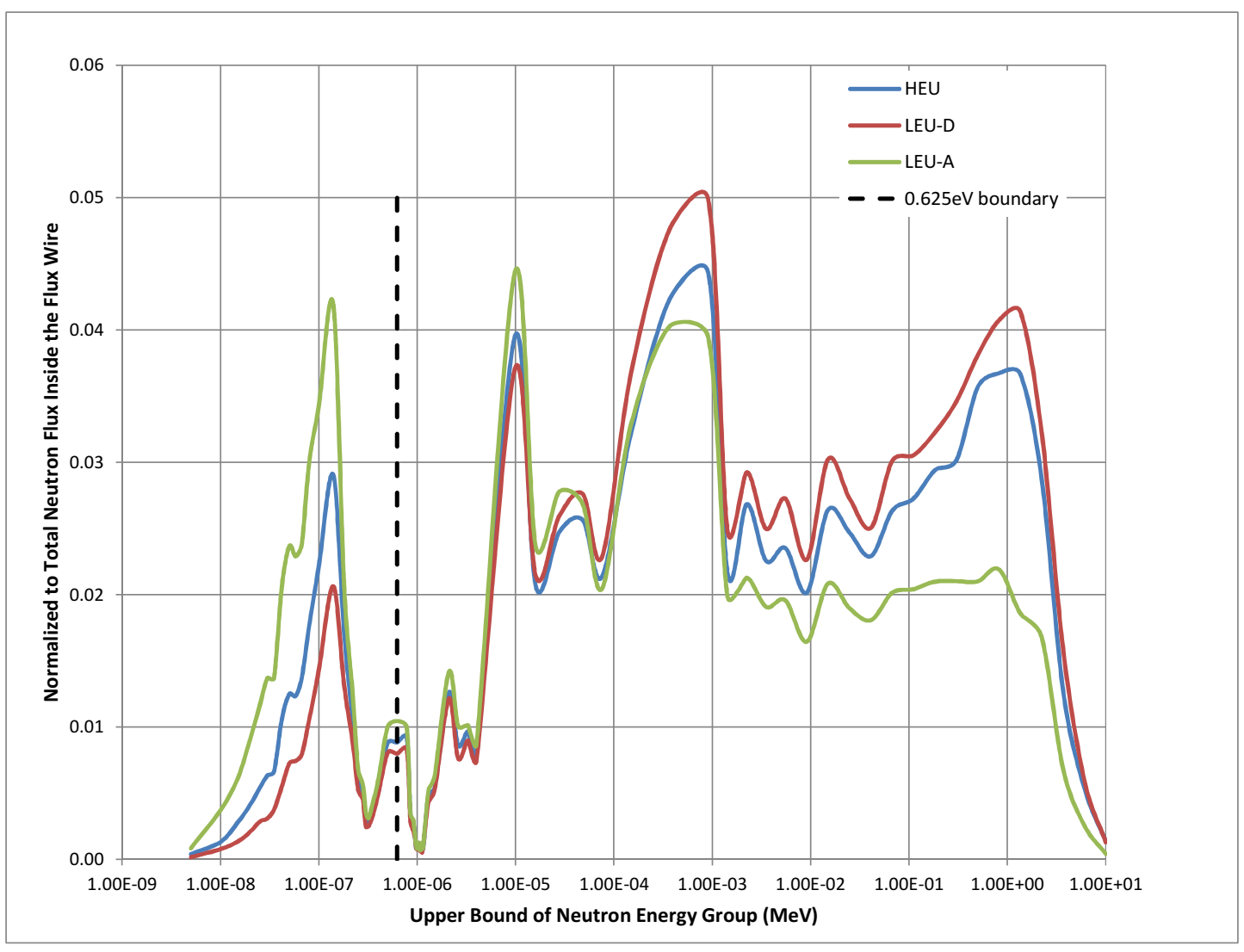

Figure [4.24]: MCNP Calculated Normalized-to-Total Neutron Energy Spectrum for the HEU, LEU-D (FA with C/U=5200) and LEU-A (BeO, FA with $\mathrm{C} / \mathrm{U}=\mathbf{5 2 0 0}$ and $\mathrm{C} / \mathrm{U}=6619$ ) Core Configurations Inside the Flux Wire

\subsubsection{Control Rod Worth}

The bank control rod worth was calculated with MCNP from a $100 \%$ to $0 \%$ withdrawal while keeping the rest of the rods out of the core. The results and the comparison with the HEU values are tabulated in Table 4.19. The results for the LEU-A core are nearly the same as for the LEU-D core (Table 4.10).

Table [4.19]: MCNP Calculated Control Rod Worth for the LEU-A (BeO FA with $C / U=5200$ and $C / U=6619$ ) and HEU Core Configurations and the LEU-A/HEU Ratio

\begin{tabular}{|l|c|c|c|}
\cline { 2 - 3 } \multicolumn{1}{c|}{} & $\left(\mathbf{k}_{\text {rods IN }}-\mathbf{k}_{\text {rods ouT }}\right) /\left(\mathbf{k}_{\text {rods IN }} \times \mathbf{k}_{\text {rods out }}\right)$ & \multicolumn{1}{c|}{} \\
\hline Rods & LEU-A $(\%)$ & HEU $(\%)$ & LEU-A/HEU (\%) \\
\hline Transient & $7.55 \pm 0.01$ & $9.43 \pm 0.01$ & $80.10 \pm 0.09$ \\
\hline Control / Shutdown & $8.08 \pm 0.01$ & $10.05 \pm 0.01$ & $80.40 \pm 0.09$ \\
\hline Compensation / Shutdown & $6.48 \pm 0.01$ & $8.67 \pm 0.01$ & $74.74 \pm 0.10$ \\
\hline
\end{tabular}

\subsubsection{Effective Delayed Neutron Fraction and Prompt Generation Lifetime}

The effective delayed neutron fraction $\left(\beta_{\text {eff }}\right)$ and the prompt neutron generation lifetime $\left(I_{p}\right)$ were calculated for the LEU-A critical cold core (for the 60 inches wire irradiation core setup) using the MCNP kopts card (default blocksize values). 
The results of the calculations and the comparison with the HEU values are presented in Table 4.20. The prompt generation lifetime was increased by $8 \%$ as compared to the LEU-D core (Table 4.11 ) and the effective delayed neutron fraction was almost unaffected.

Table [4.20]: MCNP Calculated Effective Delayed Neutron Fraction, $\boldsymbol{\beta}_{\text {eff, }}$ and Prompt Generation Lifetime $\left(I_{p}\right)$ for the LEU-A (BeO FA with $\mathrm{C} / \mathrm{U}=5200$ and $\mathrm{C} / \mathrm{U}=6619$ ) and HEU Core Configurations and the LEU-A/HEU Ratio (Error Calculated Using Error Propagation Theory)

\begin{tabular}{|l|c|c|c|}
\hline Parameter & LEU-A & HEU & LEU-A/HEU (\%) \\
\hline Effective delayed neutron fraction , $\beta_{\text {eff }}\left(\mathrm{pcm}^{*}\right)$ & $684 \pm 6$ & $691 \pm 5$ & $99.0 \pm 1.1$ \\
\hline Prompt neutron lifetime, $\mathrm{I}_{\mathrm{p}}(\mu \mathrm{s})$ & $678.1 \pm 0.7$ & $898.6 \pm 0.8$ & $75.5 \pm 0.1$ \\
\hline
\end{tabular}

\subsubsection{LEU-A MCNP Calculated Temperature Reactivity Feedback}

Using the methodology described in section 4.3.6.1 the temperature reactivity feedback as a function of total core energy $(500,1000,2000,3500$ and $5000 \mathrm{MJ})$ was calculated with MCNP assuming the same with the HEU fuel heat capacity function with temperature. The rod configuration used in the MCNP simulations was: Compensation/Shutdown 100\% withdrawal, Control/Shutdown 29\% withdrawal, Transients $100 \%$ withdrawal. Three radial and three axial temperature zones were defined and temperature dependent cross section libraries were produced using the MAKXSF program.

The calculated maximum fuel assembly temperature for the LEU-A, LEU-D and HEU cores is presented in Figure 4.25.

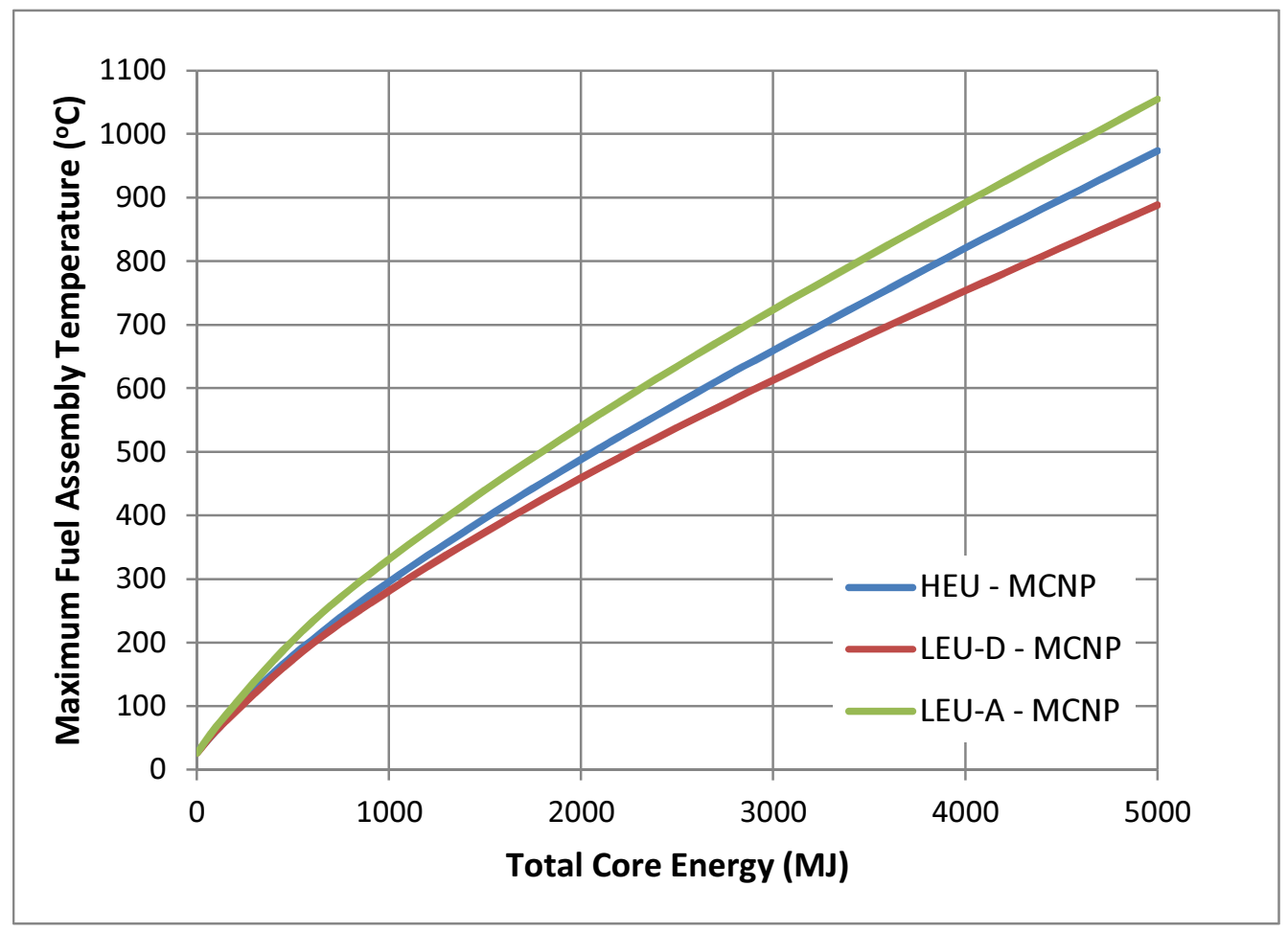

Figure [4.25]: Maximum Fuel Assembly Temperature Calculated with the MCNP Produced Power Density Distribution as a Function of the Total Core Energy for the HEU, LEU-D (FA with $C / U=5200$ ) and LEU-A (BeO, FA with $C / U=5200$ and $C / U=6619$ ) Core Configurations 
The MCNP calculated temperature reactivity feedback as a function of TREAT energy for the HEU, LEU-D and LEU-A cores is presented in Figure 4.26. The average temperature reactivity feedback for the LEU-D and LEU-A core is 1.36 and 1.26 times lower than in the HEU core, respectively.

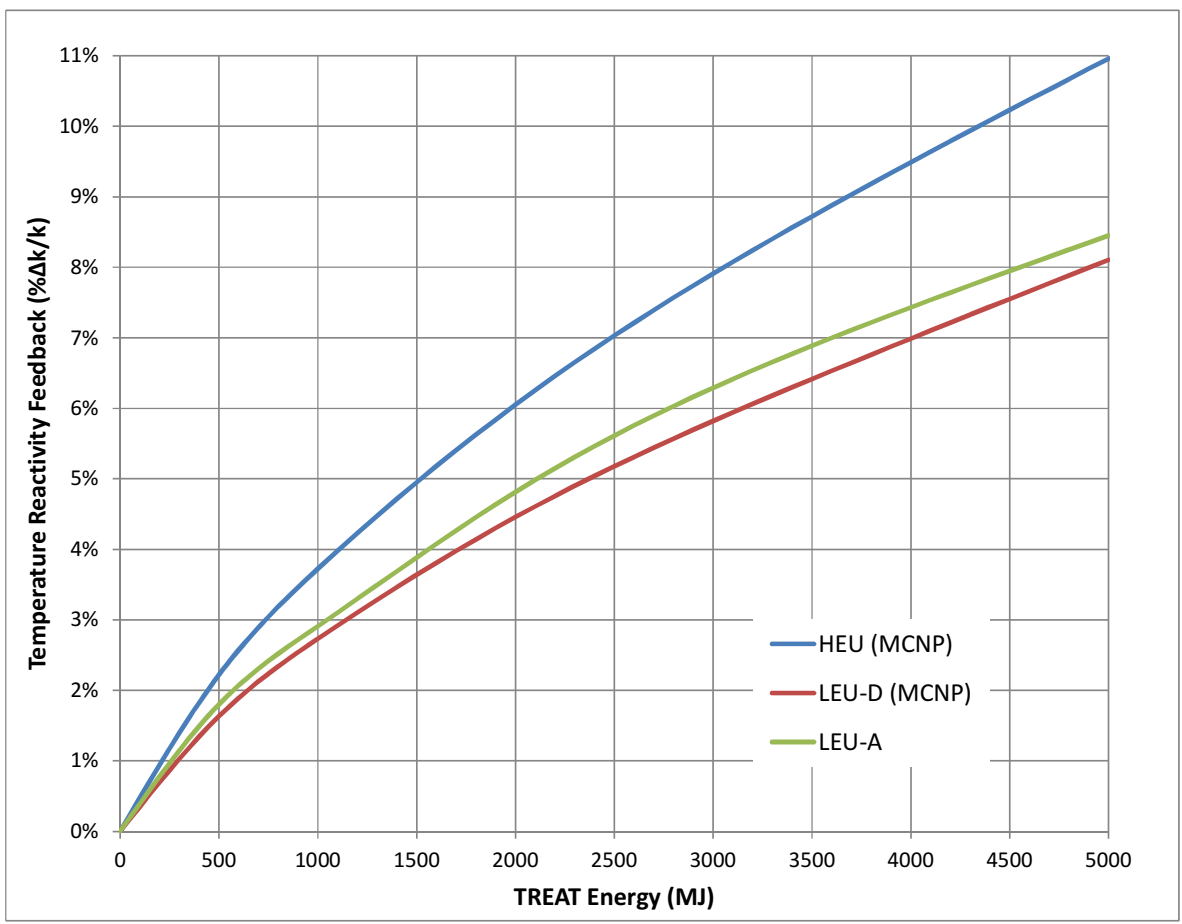

Figure [4.26]: MCNP Calculated Temperature Reactivity Feedback for the HEU, LEU-D (FA with C/U=5200), and LEU-A (BeO, FA with $C / U=5200$ and $C / U=6619)$ Core Configurations

The LEU-A core presents higher temperature reactivity feedback than the LEU-D core for the same core energy due to the softer neutron spectrum and the resulting higher maximum-to-average temperature ratio.

\subsection{Fuel Pins Irradiation Comparison}

To study the effect of the material composition of the test sample, the LLSS irradiation of the fuel pins was calculated with MCNP for the HEU, LEU-D, LEU-D with BeO and LEU-A cores. The PCF for every core in joules per total mass per total core energy was calculated using the F6 tally in coupled neutron/photon MCNP simulations. Table 4.21 shows the PCF values relative to the HEU one. LEU-A presents a PCF that is $94 \%$ of the HEU one for the low enriched flux wire and $78 \%$ in the case of the high enriched fuel pins.

Table [4.21]: MCNP Calculated Relative to HEU Peak Power Coupling Factor (PCF) for the Fuel Pins Irradiations (T-462 and T433) for the HEU, LEU-D (FA with $C / U=5200)$, LEU-D (BeO, FA with $C / U=5200$ ) and LEU-A (BeO, FA with $C / U=5200$ and $\mathrm{C} / \mathrm{U}=6619)$ Core Configurations

\begin{tabular}{|c|c|c|c|}
\hline & \multicolumn{3}{|c|}{ Peak PCF Relative to HEU (\%) } \\
\hline & $\boldsymbol{T}-\mathbf{4 6 2}$ & $\boldsymbol{T}-433$ & Flux Wire \\
\hline HEU & 100 & 100 & 100 \\
\hline LEU-D (FA with C/U=5200) & $67.4 \pm 1.2$ & $67.9 \pm 1.2$ & $58 \pm 3$ \\
\hline LEU-D (BeO and FA with C/U=5200) & $79.0 \pm 1.4$ & $81.6 \pm 1.4$ & $96 \pm 3$ \\
\hline LEU-A (BeO and FA with C/U=6619) & $78.6 \pm 1.4$ & $78.3 \pm 1.4$ & $94 \pm 4$ \\
\hline
\end{tabular}




\subsection{Neutronics Calculations Summary}

A MCNP model of the half slotted HEU TREAT core was designed and was validated against measured critical rod positions and control rod worth. The power coupling factor was calculated for experimentally performed low level steady state (LLSS) irradiations of low enriched flux wires and fuel pins positioned at the center of the M8CAL vehicle. A method to calculate the temperature reactivity feedback as a function of total core energy was designed. This method is based on the calculation of the temperature rise of every fuel assembly (assuming adiabatic heating) using the MCNP calculated relative power distribution and the heat capacity of graphite. Three axial and three radial zones were used to describe the temperature distribution in the MCNP TREAT core simulations and temperature dependent cross section libraries (calculated with MAKXSF) were assigned to each zone. The core loading of the LEU core to give equal excess reactivity with the HEU core was calculated assuming a direct replacement of the HEU fuel assemblies with LEU ones using the same fuel impurities content (boron 7.6 ppm and iron 600 ppm).

Several experimentally performed low level steady state irradiations (LLSS) in the HEU core were simulated with MCNP to study the change of the resulting power coupling factor for the flux wire and fuel pins. The harder neutron spectrum of the LEU core caused a decrease in the power coupling factor by $42 \%$ in the case of the flux wire irradiations. Replacing 12 fuel assemblies around the M8CAL vehicle with $12 \mathrm{BeO}$ blocks was considered as an alternative core design to enhance the thermal neutrons population and consequently increase the number of fissions occurring inside the flux wire. The enhanced thermal neutron population also increased the number of fissions in the fuel assemblies adjacent to the blocks resulting in higher temperatures. In order to decrease the resulting temperatures lower uranium loading for those assemblies was considered $(C / U=6619)$. It was calculated that the alternative LEU core delivers in the flux wire $94 \%$ of fissions delivered by the HEU core whereas in the fuel pins case the percentage is $78 \%$.

MCNP performs steady state calculations, so the point kinetics code TREKIN was utilized in order to perform transient calculations. The capability of the LEU core designs to produce transients with similar to the HEU core power time profiles and total energy deposition in the test sample was analyzed. 


\section{TREKIN Point Kinetics Calculations}

TREKIN is a TREAT point kinetics/transient simulation code that relates the reactivity insertion with reactor power and total energy release. TREKIN has the TREAT neutronics parameters "built-in" so it is only necessary to specify parameters of step or rate reactivity insertion. TREKIN then solves the kinetics equation using six delayed neutron energy groups in either of two modes; "rod/reactivity-driven" and "power-driven" with input being the time-dependent rod (or reactivity insertion) and the timedependent power, respectively. The core uses the following input data (the label of the data card used in the TREKIN input is mentioned in the parentheses):

a. Available transient rod reactivity as a function of rod bank withdrawal (TROD)

b. Effective delayed neutron fraction $\left(\beta_{\text {eff }}\right)$, prompt neutron generation lifetime $\left(I_{p}\right)$ and six delayed neutron energy group structure (PHYSICS CONSTANTS)

c. Maximum core (hot-spot) temperature as a function of TREAT energy (TEMPER)

d. Temperature reactivity feedback as a function of TREAT energy (HSLOT)

e. Power time history for power-driven mode

f. Transient rod position time history or Input reactivity time history for rod driven mode.

The version of TREKIN and the input data tables (labeled from this point as "historic") used during the M8CAL experiment series were available for this study.

The aim of the kinetics analyses was to compute for the proposed LEU core:

- For temperature-limited transients, the energy and peak power delivered to the test sample that was irradiated without exceeding the allowable fuel assembly temperature limits, and then to compare the results with the HEU core; and

- For shaped transient, the rod reactivity needed to deliver the same power-time history to the test sample as with the HEU core.

The TREKIN kinetics analysis was focused on three unshaped (temperature-limited) transients and one shaped transient that were experimentally performed as part of the M8CAL irradiations. The temperature-limited transients were analyzed because of their relative simplicity. The shaped transient was analyzed because it was a good representative of a maximum-energy transient run in the M8CAL series. The maximum allowed temperature limited and shaped transients for the HEU and LEU cores were also simulated with TREKIN to compare the maximum power and energy delivered in irradiated target (flux wire and fuel pins).

\subsection{Temperature Reactivity Feedback and SLOTK Factor}

TREKIN "handles" the temperature reactivity feedback with the HSLOT table, which is a set of negative reactivity feedback values as a function of TREAT core energy. The feedback table (historically referred to as HSLOT table) is determined using data from temperature-limited transients performed before the planned experiment and reactivity calculations as a function of average temperature for a point reactor. To evaluate transients at even higher energies (beyond those reached in the performed transients), extrapolation techniques were used to calculate the reactivity values for the $600^{\circ} \mathrm{C}$ and $820^{\circ} \mathrm{C}$ fuel assembly temperature limits. Knapp [10] expressed a concern regarding the proper extrapolation of the feedback set to energies higher than those used during the experiments. Knapp noted that the reactivity 
feedback values change each time the neutron flux detectors are recalibrated between experiments. Because of this variability in the feedback set from one experiment to another (or from one core loading to another), a feedback factor (SLOTK) was incorporated by TREAT operations personnel to adjust the calculations to the measurements for each core configuration and detector calibration. SLOTK is a simple multiplier applied to the reactivity feedback values. During the TREAT operations spanning many tests, a range of SLOTK values was used. Such values were generated for temperature-limited transients in which the transient rods move out of the core very early in the power rise. Knapp reported that the calibration of the nuclear instrumentation by heat-balance reactor runs at steady state seemed to be the source of variation between calculations and measurements. As the control rods move out of the core during a transient the neutron flux distribution and consequently the neutrons reaching the detectors located outside of the core changes, as compared to the heat-balance calibration runs, during which the control rods do not move. For different core loadings a different feedback factor value was used to "adjust" the calculations to the measurements. According to Knapp there were attempts to use different SLOTK values in order to force calculations to fit shaped transients but, as he notes, this approach seemed far too simple because it ignores many factors that come into play during the transients.

Feedback sets were developed strictly for reactivity step input (unshaped, temperature-limited) transients without rod motion until scram (with scram set at $60 \mathrm{~s}$ after the start of the transient). The amount of reactivity initially inserted was determined from the initial period (before the temperature effect had become apparent) using the in-hour equation.

In summary the following points should be considered when simulating transients with TREKIN:

- TREKIN uses the temperature reactivity feedback as a function of core temperature and energy, so the temperature reactivity feedback needs to be based upon measurements;

- The experimentally-performed temperature-limited transients used to determine the temperature reactivity feedback cover core temperatures which are well below the allowed temperature limit, so for higher temperatures the calculations depend on the particular extrapolation method used. Thus, additional caution is required when choosing the extrapolation function to avoid over- or under- estimating the temperature reactivity feedback for high fuel assembly temperatures $\left(>600^{\circ} \mathrm{C}\right)$;

- SLOTK factor is a simple multiplier on the temperature reactivity feedback values so its use provides only an approximate simulation of shaped transients where there is a strong dependence between the rod positions (that change during the transient) and the temperature reactivity feedback (the temperature distribution changes as the rod move). Hence, TREKIN calculations for shaped transients are useful to simulate and design experiments, but should be used with caution when determining transients that approach the allowable core temperature limits. 


\subsection{TREKIN Calculations Outline}

The TREKIN calculations performed in this study are summarized below:

Section 5.3: Three temperature-limited transients and one shaped transient were analyzed with TREKIN using the HEU historic temperature reactivity feedback table and historic core parameter values (TROD, $I_{p}, \beta_{\text {eff, }}$ TEMPER). Comparisons with measured time histories of power, energy, and rod position were made, and the effect of different values of SLOTK on the computations was evaluated. This step was to check if TREKIN performs as well as it had been when it was routinely used during TREAT operations.

Section 5.4: TREKIN HEU-core computations of section 5.3 were repeated using an MCNP-calculated temperature reactivity feedback data set (HSLOT table) and core parameter values (TROD, $I_{p}, \beta_{\text {eff, }}$, TEMPER). This step was in anticipation of computations with the LEU cores, for which no measured critical rod configurations and no initial reactivity vs total core energy data are available.

Section 5.5: The LEU cores were analyzed with TREKIN simulations based on the parameter values (TROD, $I_{p}, \beta_{\text {eff, }}$ TEMPER) calculated with MCNP following the methodology described in section 5.4. Temperature limited and shaped transients were analyzed and the peak power and total energy produced in the flux wire and the fuel pins were compared with the values obtained from the experimentally performed temperature limited transients (\#2855, \#2856 and \#2857) and the shaped transient \#2874. This analysis was expanded for the maximum allowed temperature limited and shaped transient in terms of the $600^{\circ} \mathrm{C}$ and $820^{\circ} \mathrm{C}$ fuel assembly temperature limits to evaluate the maximum capabilities of the LEU cores.

\subsection{TREKIN and Historic Input Data Validation for the HEU Core}

TREKIN and the historic input data (TROD, $I_{p}, \beta_{\text {eff, }}$ TEMPER, HSLOT) were validated by analyzing three temperature-limited transients (transient numbers \#2855, \#2856, \#2867) and one shaped transient (transient number \#2874) which had been experimentally performed in the HEU core. The historic temperature reactivity feedback data set [13] used in the computations is reported as calculated with the Monte Carlo code KENO-V [14]. During the preparation of this report no available information on the KENO-V modeling or the approximations used to calculate the temperature reactivity as a function of total core energy was available. The parameters calculated with TREKIN were: temperature reactivity feedback, maximum core temperature, peak core power and total core energy. In the case of shaped transients, the power and rod position time histories were calculated with rod-driven, power-driven and period-driven TREKIN runs.

\subsubsection{Temperature-Limited Transients for the HEU Core Using Historic Input Data}

Three experimentally-performed temperature-limited transients (\#2855, \#2856 and \#2857) were analyzed with TREKIN using the historic input data (TROD, $I_{p}, \beta_{\text {eff }}$, TEMPER, HSLOT). These transients were experimentally performed in the half-slotted TREAT core with the M8CAL vehicle in the core center to determine the maximum allowed reactivity insertion for the fuel assembly temperature limits of $600^{\circ} \mathrm{C}$ and the $820^{\circ} \mathrm{C}$. According to the TREAT SAR using the calculated (using point kinetics theory) temperature feedback as a function of peak core temperature and the initiating reactivity and resulting peak core temperature of at least three temperature limited transients the reactivity limits for $600^{\circ} \mathrm{C}$ and $820^{\circ} \mathrm{C}$ can be determined. The value relating to $600^{\circ} \mathrm{C}$ is the maximum permissible reactivity for step input initiation of a transient and the value of $820^{\circ} \mathrm{C}$ is the maximum permissible reactivity available in 
the transient rods. The temperature limited transients were simulated with TREKIN using the reported reactivity insertion of $1.81 \%, 3.02 \%$ and $3.87 \%$. The SLOTK value that produced the best agreement between the calculated and the reported core energy was also calculated with a value of 0.94 .

Table 5.1 presents the reported values, the TREKIN calculation results for SLOTK $=1.0$ and 0.94 , and the resulting calculated-to-measured ratio for the three temperature-limited transients.

Table [5.1]: HEU Core TREKIN Calculated and Measured Temperature Reactivity Feedback, Maximum Temperature, Total Energy and Peak Power Using the Historic Input Data (TROD, $I_{p}, \beta_{\text {eff, }}$ TEMPER, HSLOT). The Calculated-to-Measured Ratio $(\mathrm{C} / \mathrm{M})$ is also Presented

\begin{tabular}{|c|c|c|c|c|c|c|c|}
\hline & Transient $\rightarrow$ & \multicolumn{2}{|c|}{$\# 2855$} & \multicolumn{2}{|c|}{ \#2856 } & \multicolumn{2}{|c|}{ \#2857 } \\
\hline & Step Reactivity & \multicolumn{2}{|c|}{$1.81 \%$} & \multicolumn{2}{|c|}{$3.02 \%$} & \multicolumn{2}{|c|}{$3.87 \%$} \\
\hline & SLOTK $\rightarrow$ & 1 & 0.94 & 1 & 0.94 & 1 & 0.94 \\
\hline \multirow{3}{*}{$\begin{array}{c}\text { Temperature } \\
\text { Feedback } \\
\text { (dk/k) }\end{array}$} & Calculated (C) & -0.0321 & -0.0320 & -0.0516 & -0.0513 & -0.0645 & -0.0638 \\
\hline & Measured (M) & \multicolumn{2}{|c|}{-0.0325} & \multicolumn{2}{|c|}{-0.0515} & \multicolumn{2}{|c|}{-0.0644} \\
\hline & $\mathrm{C} / \mathrm{M}$ & 0.99 & 0.98 & 1.00 & 1.00 & 1.00 & 0.99 \\
\hline \multirow{3}{*}{$\begin{array}{c}\text { Max FA } \\
\operatorname{Temp}\left({ }^{\circ} \mathrm{C}\right)\end{array}$} & Calculated (C) & 237 & 251 & 384 & 409 & 498 & 533 \\
\hline & Measured (M) & \multicolumn{2}{|c|}{236} & \multicolumn{2}{|c|}{378} & \multicolumn{2}{|c|}{488} \\
\hline & $\mathrm{C} / \mathrm{M}$ & 1.01 & 1.06 & 1.02 & 1.08 & 1.02 & 1.09 \\
\hline \multirow{3}{*}{$\begin{array}{c}\text { Total Energy } \\
\text { (MJ) }\end{array}$} & Calculated (C) & 737 & 795 & 1442 & 1570 & 2055 & 2251 \\
\hline & Measured (M) & \multicolumn{2}{|c|}{792} & \multicolumn{2}{|c|}{1572} & \multicolumn{2}{|c|}{2265} \\
\hline & $\mathrm{C} / \mathrm{M}$ & 0.93 & 1.00 & 0.92 & 1.00 & 0.91 & 0.99 \\
\hline \multirow{3}{*}{$\begin{array}{l}\text { Peak Power } \\
\text { (MW) }\end{array}$} & Calculated (C) & 1291 & 1376 & 5781 & 6199 & 11398 & 12355 \\
\hline & Measured (M) & \multicolumn{2}{|c|}{1281} & \multicolumn{2}{|c|}{6171} & \multicolumn{2}{|c|}{12493} \\
\hline & $\mathrm{C} / \mathrm{M}$ & 1.01 & 1.07 & 0.94 & 1.00 & 0.91 & 0.99 \\
\hline
\end{tabular}

In the case of the \#2855 the SLOTK value of 0.94 produces the best agreement between the measured and the calculated total core energy but increases the peak power C/M from 1.01 to 1.07. This is attributed to the sensitivity of TREKIN results on the temperature reactivity feedback data set that was calculated using a point kinetics core model and to the fact that SLOTK factor is a rough approximation of the effect of all the parameters on the temperature reactivity feedback (detector calibration, rods position).

The less than $\pm 10 \%$ difference between the calculated and measured parameters is considered acceptable based on the reported measurement errors [8] so the TREKIN code and the historic input tables are considered validated for simulating temperature-limited transients.

\subsubsection{Shaped Transient: HEU Rod Driven and Power Driven TREKIN Runs Using the Historic Input Data}

The power-time history in the case of the shaped transient \#2874 was calculated with a TREKIN roddriven run using as input the measured rod withdrawal as a function of time after the initial rise to power. Because the rod-position data had erroneous fluctuations during the initial rise to power (due to the coarse digitization of the original analog data), the computation had to be initiated with a constantperiod input (period $=0.3 \mathrm{~s}$ ) to generate the initial measured power rise ("pre-heat" phase). To smoothly transit from the $0.3 \mathrm{~s}$ period rise to the subsequent slower (rod driven) power rise, the computation was then driven by a second constant-period input (period $=8 \mathrm{~s}$ ) beginning at $4.3 \mathrm{~s}$ and 
lasting for $0.4 \mathrm{~s}$ at which point the simulation was switched to rod-driven input. Figure 5.1 shows the measured (blue line) and calculated (red) power time history using SLOTK $=1$. The wiggles in the computed curve are probably due to incomplete smoothness of the input rod position data and the temperature reactivity data set calculated for temperature limited transients.

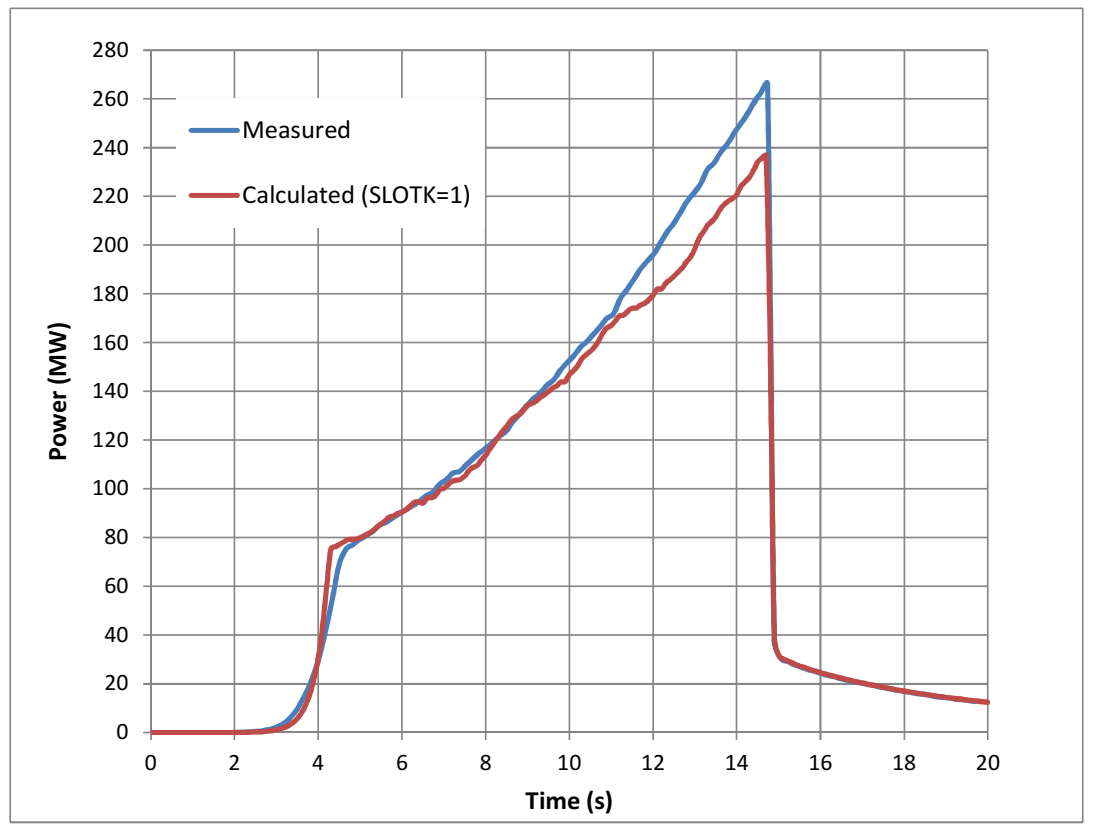

Figure [5.1]: HEU Core Measured (Blue Line) and TREKIN Rod-Driven Calculated Power Time History (Red Line) with SLOTK=1 Using Historic Input Data (TROD, $I_{p}, \beta_{\text {eff, }}$ TEMPER, HSLOT)

There is a very good agreement between the calculated and measured power time history for the first $11 \mathrm{~s}$. Beyond $11 \mathrm{~s}$ and until the power peak TREKIN underestimates power with a decreasing calculatedto-measured ratio $(\mathrm{C} / \mathrm{M})$ from 0.98 to 0.89 . This difference is attributed to the HSLOT reflecting an overestimation of the temperature reactivity feedback that was calculated for a point reactor without taking into account the different rod positions that happen during the shaped transient. The overestimation of the temperature reactivity feedback was compensated with the use of a SLOTK factor of 0.93. This value of SLOTK was chosen to produce the best agreement between the calculated and the measured peak power. Figure 5.2 presents the measured (blue line) and the TREKIN-calculated power time history with SLOTK $=1.0$ (red line) and SLOTK $=0.93$ (green line). As it has already been discussed SLOTK is a simple multiplier in the temperature reactivity feedback values so the resulting power time history overestimates the power by a $\mathrm{C} / \mathrm{M}$ that decreases from 1.08 to 1.00 from $\mathrm{t}=11 \mathrm{~s}$ until the power peak.

It should be reemphasized that according to Knapp [10] reports the SLOTK adjustment is not applicable to shaped transients because there are a lot of parameters affecting the power time history as the rods move out of the core. The calculated-to-measured ratio for the peak power using SLOTK=1.0 and 0.93 was found to be 0.89 and 0.99 , respectively. The transient rods position time history was calculated with two power-driven TREKIN runs, using SLOTK 1.0 and 0.98 , and was compared with the measurements. For the first $2.8 \mathrm{~s}$, the simulation was period-driven (with a period of $0.3 \mathrm{~s}$ ) and then switched to powerdriven until the end of the transient to eliminate the fluctuations caused by the input power-time history. 


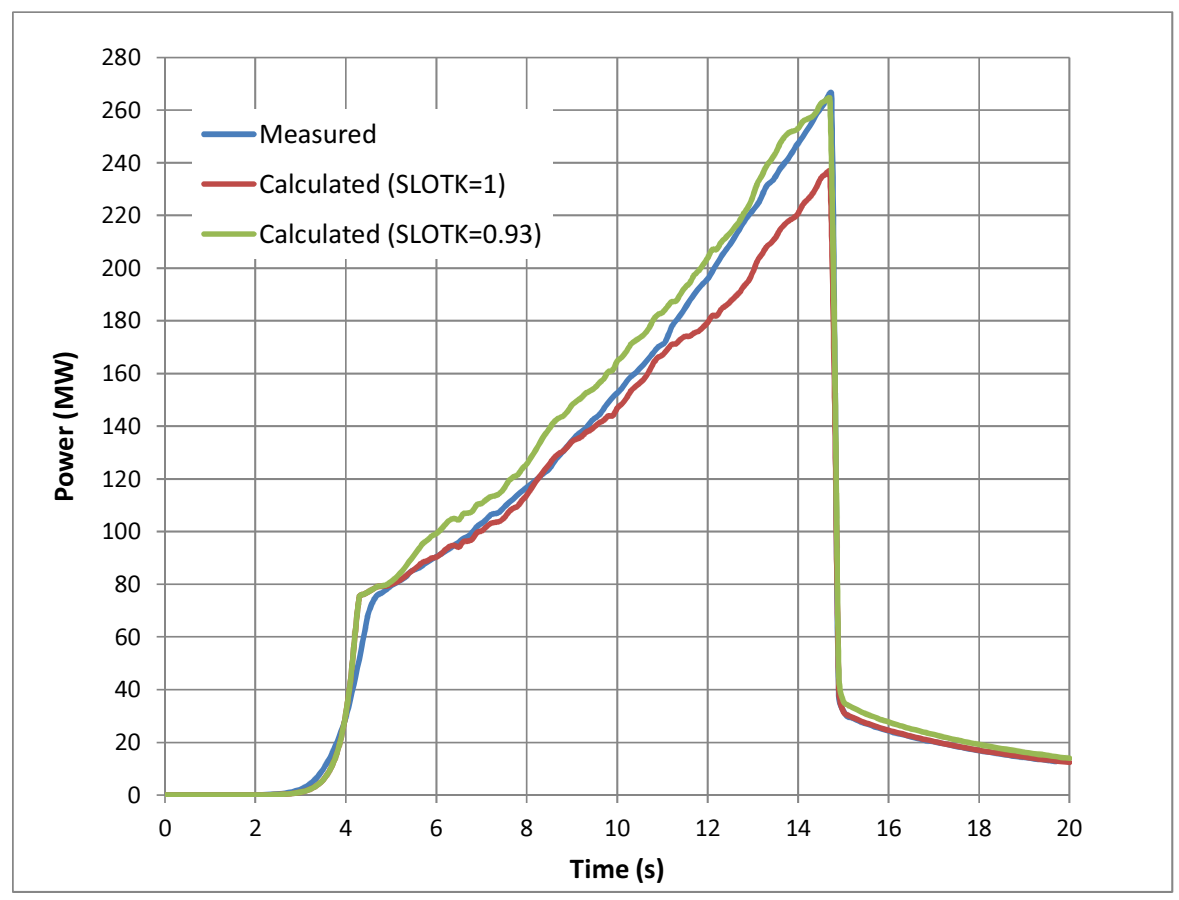

Figure [5.2]: HEU Core Measured (Blue Line) and Rod Driven TREKIN Calculated Power Time History with SLOTK=1.0 (Red Line) and SLOTK=0.93 (Green Line) Using Historic Input Data (TROD, $I_{p}, \beta_{\text {eff, }}$ TEMPER, HSLOT)

Figure 5.3 shows the measured (blue line) and the calculated rod time history with SLOTK = 1 (red line) and SLOTK $=0.98$ (green line). The calculated-to-measured ratios for the maximum rod withdrawal using SLOTK equal to 1.0 and 0.98 were found to be 1.04 and 1.0 , respectively.

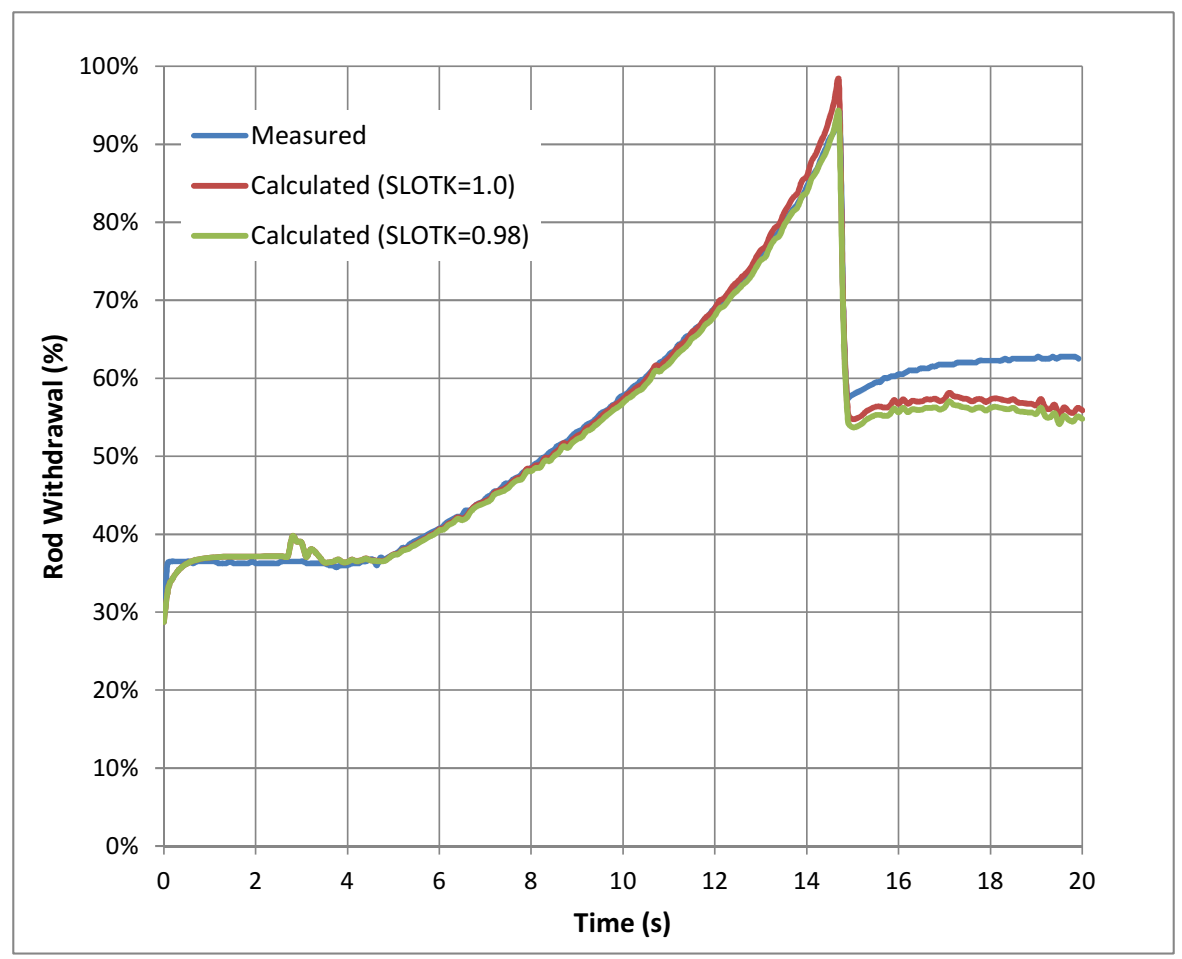

Figure [5.3]: HEU Core Measured (Blue Line) and TREKIN Power Driven Calculated Rod Position with SLOTK=1 (Red Line) and SLOTK=0.98 (Green Line) Using Historic Input Data (TROD, $I_{p}, \beta_{\text {eff }}$, TEMPER, HSLOT) 


\subsection{TREKIN Calculations Using MCNP-Produced Input Data}

The historic TREKIN calculations for the temperature limited and shaped transients were repeated using MCNP-produced input data for the parameters TROD, $I_{p}, \beta_{\text {eff, TEMPER, and HSLOT. The HSLOT }}$ (temperature reactivity feedback) was calculated as described in section 4.3.6.1.

\subsubsection{Temperature-Limited Transients for the HEU Core}

Table 5.2 presents the results of the TREKIN calculations for the temperature-limited transients \#2855, \#2856, and \#2857 without adjusting the temperature feedback reactivity data set (SLOTK = 1) and for a SLOTK value that produces the best agreement between the calculated and measured total energy. For the \#2857 there was no need to use the SLOTK adjustment. A different SLOTK value could have been used to achieve the best agreement between the calculated and the measured peak power, but in the context of this study matching the total energy was considered adequate.

Table [5.2]: HEU TREKIN Calculations for the Temperature-Limited Transients Using MCNP Produced Input Data (TROD, Ip,

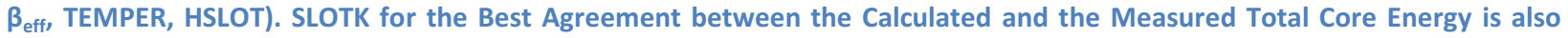
Shown (for \#2857 no SLOTK Adjustment was not needed)

\begin{tabular}{|c|c|c|c|c|c|c|}
\hline & Transient $\rightarrow$ & \multicolumn{2}{|c|}{ \#2855 } & \multicolumn{2}{|c|}{ \#2856 } & \#2857 \\
\hline & Step Reactivity & \multicolumn{2}{|c|}{$1.81 \%$} & \multicolumn{2}{|c|}{$3.02 \%$} & $3.87 \%$ \\
\hline & SLOTK $\rightarrow$ & 1 & 1.03 & 1 & 1.015 & 1 \\
\hline \multirow{3}{*}{$\begin{array}{c}\text { Temperature } \\
\text { Feedback } \\
\text { (dk/k) }\end{array}$} & Calculated (C) & -0.0324 & -0.0326 & -0.0520 & -0.0520 & -0.0659 \\
\hline & Measured (M) & \multicolumn{2}{|c|}{-0.0325} & \multicolumn{2}{|c|}{-0.0515} & -0.0644 \\
\hline & $\mathrm{C} / \mathrm{M}$ & 1.00 & 1.00 & 1.01 & 1.01 & 1.02 \\
\hline \multirow{3}{*}{$\begin{array}{c}\text { Max FA } \\
\left.\text { Temp ( }{ }^{\circ} \mathrm{C}\right)\end{array}$} & Calculated (C) & 270 & 264 & 431 & 425 & 552 \\
\hline & Measured (M) & \multicolumn{2}{|c|}{236} & \multicolumn{2}{|c|}{378} & 488 \\
\hline & $\mathrm{C} / \mathrm{M}$ & 1.15 & 1.12 & 1.14 & 1.13 & 1.13 \\
\hline \multirow{3}{*}{$\begin{array}{l}\text { Total Energy } \\
\text { (MJ) }\end{array}$} & Calculated (C) & 820 & 791 & 1608 & 1576 & 2267 \\
\hline & Measured (M) & \multicolumn{2}{|c|}{792} & \multicolumn{2}{|c|}{1572} & 2265 \\
\hline & $\mathrm{C} / \mathrm{M}$ & 1.03 & 1.00 & 1.02 & 1.00 & 1.00 \\
\hline \multirow{3}{*}{$\begin{array}{l}\text { Peak Power } \\
\text { (MW) }\end{array}$} & Calculated (C) & 1578 & 1533 & 6712 & 6602 & 12739 \\
\hline & Measured (M) & \multicolumn{2}{|c|}{1281} & \multicolumn{2}{|c|}{6171} & 12493 \\
\hline & $\mathrm{C} / \mathrm{M}$ & 1.23 & 1.20 & 1.09 & 1.07 & 1.02 \\
\hline
\end{tabular}

The $\mathrm{C} / \mathrm{M}$ ratio for the peak power ranges from 1.23 to 1.02. TREKIN with the MCNP-produced input data (TROD, $I_{p}, \beta_{\text {eff, }}$ TEMPER, HSLOT) is overestimating the maximum fuel assembly temperature by factor ranging from 1.13 to 1.15 . These differences are attributed to the temperature reactivity feedback (Figure 4.13), the maximum fuel assembly temperature calculations that were based on a single rod configuration (assuming the transients rods out of the core) and the same power density distribution for the entire range of total core energy values.

For the experimentally performed temperature limited transients the different reactivity insertion reflects to a different pre-transient rod configuration and consequently to a different power density and temperature distribution at the end of each pulse. The different pre-transient rod positions could be used to calculate a new temperature reactivity data set but this method could not be applied in the LEU cores since it requires the knowledge of the relation between total core energy and reactivity insertion that is determined only by performing a series of temperature limited transient. 


\subsubsection{Shaped Transient for the HEU Core}

Figure 5.4 presents the rod-driven TREKIN calculated power time history using SLOTK $=1.0$ (red line) and SLOTK $=0.985$ (green line) as well as the measured history (blue line) for the transient \#2874.

The peak power calculated-to-measured ratio was found to be 0.98 and 1.00 for SLOTK $=1.0$ and 0.985 , respectively. The power fluctuation observed between $5 \mathrm{~s}$ and $8 \mathrm{~s}$ is a result of the underestimated temperature reactivity feedback (as compared to the historic one) and the measured rod time history that was used in the rod-driven TREKIN calculation. The source for this power fluctuation seems to be the result of a reactivity insertion produced by difference of the lower temperature reactivity feedback and the rod reactivity (defined by the rod time history).

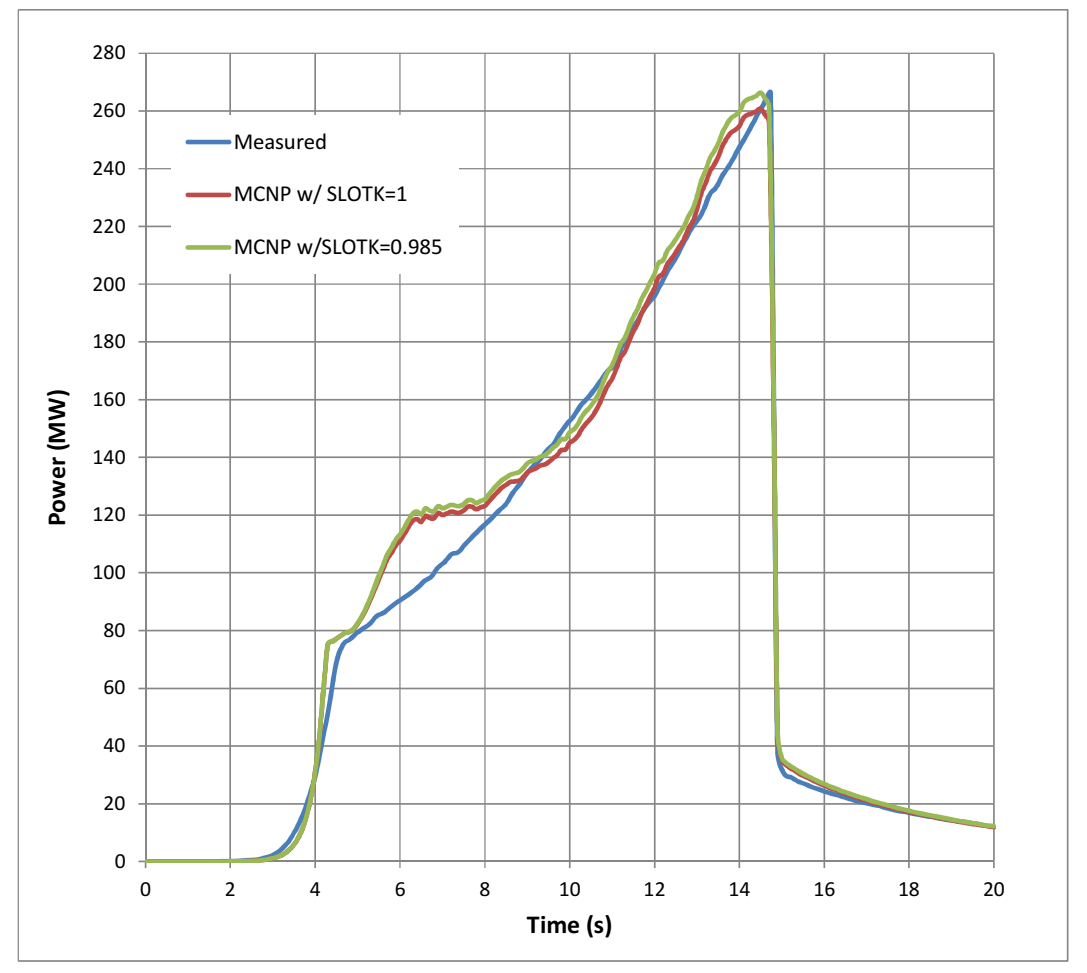

Figure [5.4]: HEU Core Power Time History Measured (Blue Line) and TREKIN Calculated with SLOTK = 1.0 (Red Line) and SLOTK = 0.985 (Green Line) for Transient \#2874 with a Rod Driven TREKIN Run Based on MCNP Produced Input Data (TROD, $I_{p}, \beta_{\text {eff, }}$ TEMPER, HSLOT)

Figure 5.5 presents the measured (blue line) and calculated (with power-driven TREKIN runs) rod time histories using SLOTK = 1.0 (red line) and 1.053 (green line). The maximum rod withdrawal calculated-tomeasured the maximum rod ratio for SLOTK $=1.0$ and 1.1 was 0.84 and 0.92 , respectively. 


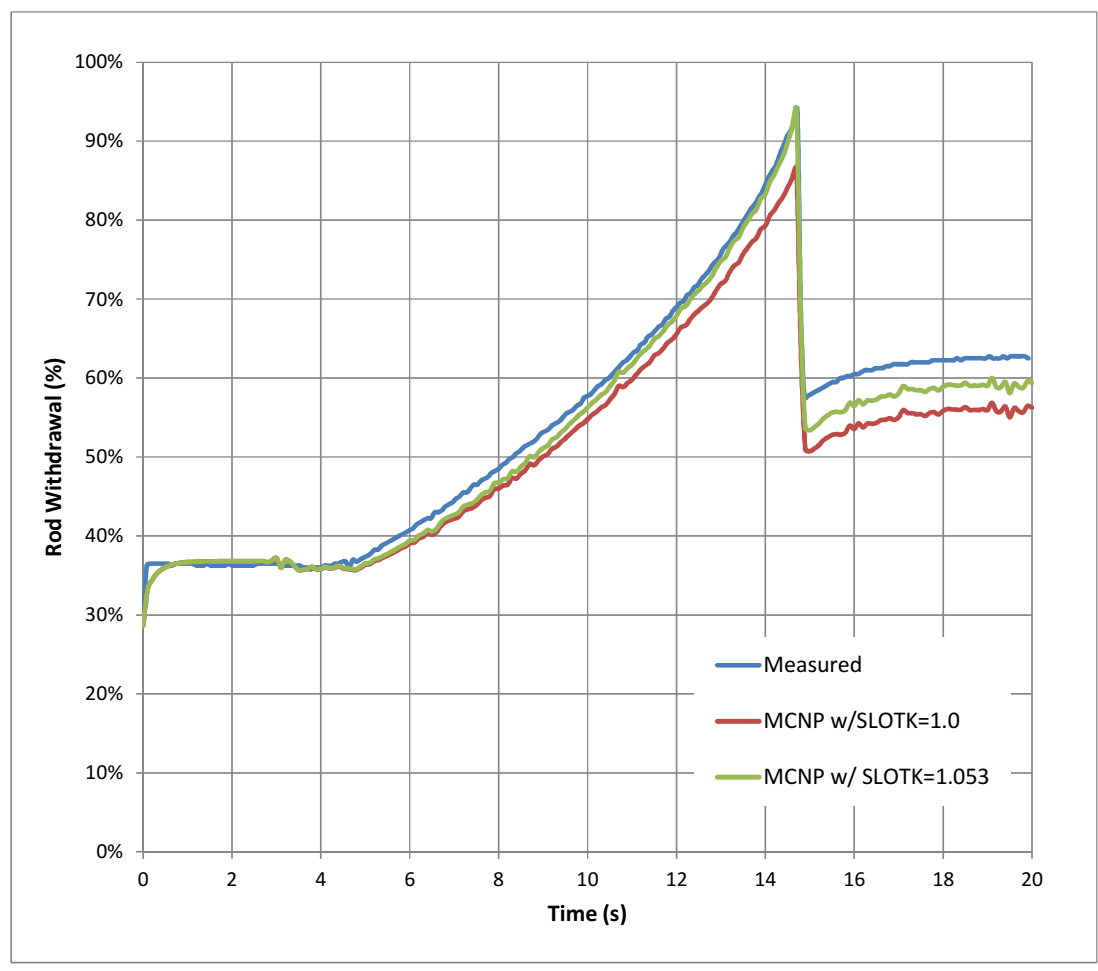

Figure [5.5]: HEU Core Measured (Blue Line) and TREKIN Calculated Rod Withdrawal History with SLOTK = 1.0 (Red Line) and SLOTK = 1.053 (Green Line) for Transient \#2874 with a Power Driven TREKIN Run Based on MCNP Produced Input Data (TROD, $I_{p}, \beta_{\text {eff }}$, TEMPER, HSLOT)

\subsection{TREKIN Calculations for the LEU Cores}

TREKIN with the MCNP-computed input data (TROD, $I_{p}, \beta_{\text {eff, }}$ TEMPER, HSLOT) was used to analyze transients generated by the LEU-D and the LEU-A cores. The first step to evaluate the LEU cores was to simulate the temperature limited transients \#2855, \#2856 and \#2857 and the shaped transient \#2874 to estimate the energy and peak power the LEU cores would deliver if a low enriched flux wire was irradiated and the results were compared with the HEU core ones. For these calculations the end of the pulse (reactor scram) was considered to happen at $5 \mathrm{~s}$.

The performance of the LEU cores was also analyzed for the maximum allowed reactivity insertion considering the fuel assembly temperature limits and was compared with the maximum capability of the HEU core for the irradiation of the flux wire and the fuel test pins. In order to be conservative the maximum temperature was calculated $60 \mathrm{~s}$ after the reactivity insertion. Shaped transients were simulated with period-driven TREKIN runs, and the rod time history was determined for the LEU cores such as to produce peak power in the flux wire and the test pins equal to that produced with the HEU core. Since there are no available measurements for the LEU cores, all the TREKIN calculations were performed using SLOTK $=1$.

\subsubsection{Limiting Safety System Settings (LSSS) and Safety Limits (SL)}

The reactor safety limits (SL) are the values of reactivity, power and energy that would cause the maximum fuel assembly temperature to reach the safety limit of $820^{\circ} \mathrm{C}$. The limiting safety system settings (LSSS) are the limits that would prevent the maximum fuel assembly temperature from exceeding the limit of $600^{\circ} \mathrm{C}$ during normal operations. According to the TREAT SAR, the temperature of the clad is not measured so the fuel temperature is used as the limit. The maximum permissible 
reactivity available in the transient rods before a shaped transient is that which would result in a maximum fuel assembly temperature of $820^{\circ} \mathrm{C}$ in the event all of that reactivity was inserted as a step (at the maximum rod speed). The SL and LSSS values for the HEU core were calculated with TREKIN (using the MCNP produced input data tables) and the results were compared with the reported values.

Table 5.3 compares the TREKIN calculated (using MCNP produced tables, the historic tables and SLOTK = 1) and reported step-inserted reactivity which would, after $60 \mathrm{~s}$ into the transient, result in peak fuel assembly temperatures equal to the $600^{\circ} \mathrm{C}$ and $820^{\circ} \mathrm{C}$ limits. It is important to note, however, that (a) the $600^{\circ} \mathrm{C}$ applies to transients as planned, without assuming failure of the reactor control or scram systems and (b) planned temperature-limited experiment transients would generally be scrammed long before $60 \mathrm{~s}$ into the transient. Thus, the reactivity values shown here relative to the LSSS limit are more conservative than would apply to most temperature-limited experiment transients; they are shown here for a more-direct comparison with the maximum reactivity insertions allowed by the SL temperature limit.

Table [5.3] HEU Reactivity LSSS and SL Values Calculated with TREKIN and Reported for the HEU Half-Slotted Core for the Maximum Fuel Assembly Temperature of $600^{\circ} \mathrm{C}$ and $820^{\circ} \mathrm{C}$. Maximum Temperature at $60 \mathrm{~s}$

\begin{tabular}{|c|c|c|}
\hline & $\begin{array}{c}\text { LSSS Reactivity for } \\
\mathbf{6 0 0}^{\circ} \mathbf{C} \text { Max. FA Temp. }\end{array}$ & $\begin{array}{c}\text { SL Reactivity for } \\
\mathbf{8 2 0}^{\circ} \mathbf{C} \text { Max. FA Temp. }\end{array}$ \\
\hline Calculated w/MCNP Tables & $4.20 \%$ & $5.65 \%$ \\
\hline Calculated w/Historic Tables & $4.29 \%$ & $5.55 \%$ \\
\hline Reported (R) & $4.63 \%$ & $5.95 \%$ \\
\hline
\end{tabular}

Table 5.4 presents the reactivity LSSS and SL for the fuel assembly temperature limits of $600^{\circ} \mathrm{C}$ and $820^{\circ} \mathrm{C}$ were calculated with TREKIN for the HEU, LEU-D and LEU-A using SLOTK=1 and the MCNP produced data tables (TROD, $I_{p}, \beta_{\text {eff, }}$ TEMPER, HSLOT).

Table [5.4]: Reactivity LSSS and SL Values Calculated with TREKIN for the HEU, LEU-D (FA with C/U=5200) and LEU-A (BeO, FA with $\mathrm{C} / \mathrm{U}=5200$ and $\mathrm{C} / \mathrm{U}=6619$ ) Cores with $\mathrm{SLOTK}=1$ that Produce the Maximum Fuel Assembly Temperature of $600^{\circ} \mathrm{C}$ and $820^{\circ} \mathrm{C}$. Maximum Temperature at $60 \mathrm{~s}$

\begin{tabular}{|c|c|c|}
\hline Core & $\begin{array}{l}\text { Reactivity (LSSS) for } \\
600^{\circ} \mathrm{C} \text { Max. FA Temp. }\end{array}$ & $\begin{array}{c}\text { Reactivity (SL) for } \\
820^{\circ} \mathrm{C} \text { Max. FA Temp. }\end{array}$ \\
\hline HEU & $4.20 \%$ & $5.65 \%$ \\
\hline LEU-D (FA with C/U=5200) & $3.40 \%$ & $4.55 \%$ \\
\hline LEU-A (BeO and FA with $\mathrm{C} / \mathrm{U}=6619$ ) & $3.115 \%$ & $4.206 \%$ \\
\hline
\end{tabular}

It should be underlined that TREKIN does not use physics to calculate the maximum fuel assembly temperature but simply uses the pre-calculated table of the maximum fuel assembly temperature as a function of total core energy (TEMPER table) to determine the maximum fuel assembly temperature for the resulting total core energy. So, the calculations based on the temperature limits depend on the maximum fuel assembly temperatures that in this study were determined using the MCNP-calculated spatial power density core distribution and the heat capacity of graphite.

For comparison purposes the MCNP-calculated total core energy as a function of maximum fuel assembly temperature used in TREKIN for the HEU, LEU-D and the LEU-A cores is illustrated in Figure 5.6. The LEU-A core reaches the $600^{\circ} \mathrm{C}$ temperature limit for total core energy that is 0.88 and 0.80 times the 
total core energy of the HEU and LEU-D cores, respectively. The LEU-A core has $12 \mathrm{BeO}$ reflectors in the place of 12 fuel assemblies around the M8CAL vehicle enhancing the thermal neutron population and consequently increasing the temperature in the fuel assemblies near the center of the core.

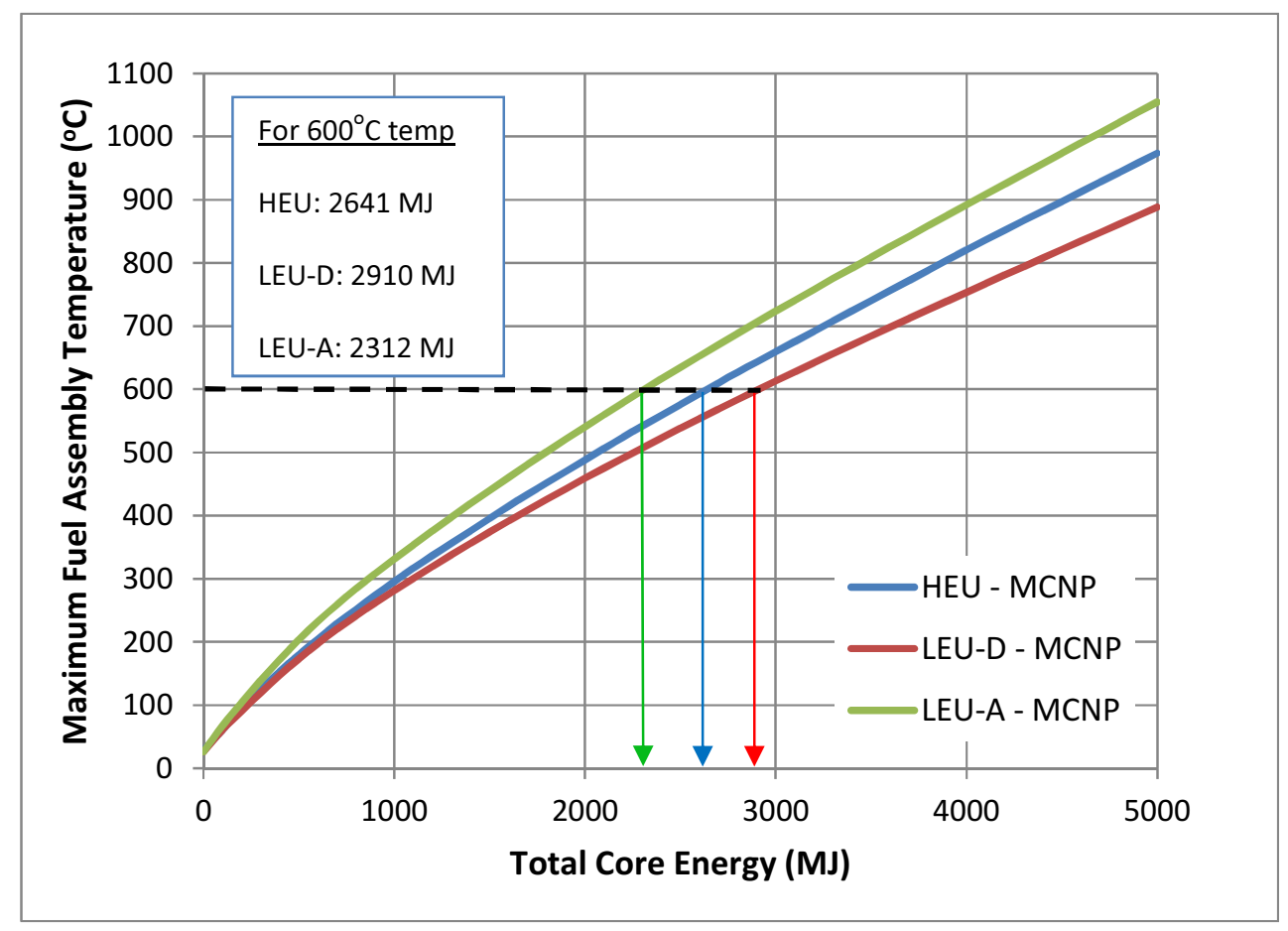

Figure [5.6]: MCNP Calculated Maximum Fuel Assembly Temperature as a Function of Core Energy for the HEU, LEU-D (FA with $C / U=5200$ ) and LEU-A (BeO, FA with $C / U=5200$ and $C / U=6619)$ core. The Total Core Energy for the $600^{\circ} \mathrm{C}$ Maximum Fuel Assembly Temperature (after $60 \mathrm{~s}$ ) are Shown

\subsubsection{Temperature-Limited Transients for the LEU-D and LEU-A Cores}

The low level steady state irradiations of the flux wires and the temperature limited transients \#2855, \#2856 and \#2857 were well documented so they were chosen to be analyzed with MCNP and TREKIN. For the LEU-D and LEU-A cores the required reactivity insertion was calculated to deliver equal peak power to the flux wire as the HEU core would do for a temperature limited transient. For this purpose several TREKIN calculations were performed until the required peak power in the flux wire was achieved without exceeding the fuel assembly temperature limit of $600^{\circ} \mathrm{C}$.

For the calculated maximum input reactivity for which the $600^{\circ} \mathrm{C}$ fuel assembly temperature limit is not exceeded (Table 5.4) temperature-limited transients were simulated with TREKIN to determine the maximum core power and total energy the LEU cores can (allowably) produce in the flux wire and fuel pins assuming that the entire mass of the sample was subject to the peak power coupling factor (Table 4.21). The maximum reactivity insertion rates (derived by the rod worth curves and the maximum rod movement speed) used in the TREKIN calculations for the HEU and the LEU cores were $0.458 \% / \mathrm{s}$ and $0.375 \% / \mathrm{s}$, respectively, and the maximum transient rod speed was set at $387 \mathrm{~cm} / \mathrm{s}(152 \mathrm{in} . / \mathrm{s})$ in all cases.

\subsubsection{Temperature Limited Transients \#2855, \#2856 and \#2857}

Table 5.5 shows the TREKIN calculated and relative-to-HEU peak power and total energy delivered to the flux wire, the maximum fuel assembly temperature and the full width at half maximum (FWHM) for the 
\#2855, \#2856 and \#2857 temperature limited transients for the LEU cores. The end of the power pulse was assumed to happen at $t=5 \mathrm{~s}$ when the core would be scrammed. The maximum fuel assembly and total energy were calculated at $5 \mathrm{~s}$.

Table [5.5]: TREKIN Calculated Reactivity Insertion, Maximum Fuel Assembly Temperature, Full Width at Half Maximum (FWHM) and Flux Wire Total Energy for the LEU-D (FA with $C / U=5200$ ) and LEU-A (BeO, FA with $C / U=5200$ and $C / U=6619$ ) Cores to Deliver Equal Peak Power and Total Energy to the Flux Wire as the HEU Core Did for the Temperature Limited Transients \#2855, \#2856 and \#2857. End of Transient at $5 \mathrm{~s}$

\begin{tabular}{|l|c|c|c|c|c|}
\hline Core & $\begin{array}{c}\text { Inserted } \\
\text { Reactivity }\end{array}$ & $\begin{array}{c}\text { Max FA } \\
\text { Temp ( } \\
\text { at 5 } \mathbf{~ s}\end{array}$ & $\begin{array}{c}\text { FWHM } \\
\mathbf{( s )}\end{array}$ & $\begin{array}{c}\text { Normalized to HEU Flux } \\
\text { Wire Peak Power (kW) }\end{array}$ & $\begin{array}{c}\text { Normalized to HEU Flux } \\
\text { Wire Total Energy (kJ) at 5 s }\end{array}$ \\
\hline \multicolumn{7}{|c|}{ Transient \#2855 } \\
\hline HEU & $1.81 \%$ & 233 & 0.290 & 1.0 & 1.0 \\
\hline LEU-D & $1.74 \%$ & 265 & 0.219 & 1.0 & 1.0 \\
\hline LEU-A & $1.59 \%$ & 259 & 0.273 & 1.0 & 1.0 \\
\hline \multicolumn{7}{|c|}{ Transient \#2856 } \\
\hline HEU & $3.02 \%$ & 395 & 0.151 & 1.0 & 1.0 \\
\hline LEU-D & $2.85 \%$ & 457 & 0.124 & 1.0 & 1.0 \\
\hline LEU-A & $2.58 \%$ & 448 & 0.151 & 1.0 & 0.8 \\
\hline \multicolumn{7}{|c|}{} \\
\hline HEU & $3.87 \%$ & 516 & 0.123 & 1.0 & 1.0 \\
\hline LEU-D & $3.61 \%$ & 594 & 0.097 & 1.0 & 1.0 \\
\hline LEU-A & $3.22 \%$ & 572 & 0.119 & 1.0 & \\
\hline
\end{tabular}

The LEU-A core can reproduce the peak power and total energy delivered in the flux wire for the three temperature limited transients resulting in maximum fuel assembly temperatures $10-13 \%$ higher than in the HEU core. Although the LEU-D delivers the same peak power to the flux wire as with the HEU core, the resulting total energy in the flux wire is $20 \%$ lower than in the HEU core case. This is attributed to the shorter FWHM (narrower pulse and consequently lower energy for equal peak power) that is a result of the core prompt neutron generation lifetime being shorter than for the HEU core. Based on these results the LEU-A core seems to be able to deliver equal peak power and total energy in the flux wire as the HEU core.

\subsubsection{TREKIN Calculations for the Maximum Allowed HEU Temperature-Limited Transient} Although the results for the flux wire irradiation by the LEU-A core were promising, further analyses were performed on the basis of the maximum capability of the LEU cores and for different irradiated samples (sample size and composition). For this purpose temperature limited transients were simulated with TREKIN for the LEU cores considering the maximum allowed reactivity insertion and a pulse duration of $60 \mathrm{~s}$ (as opposed to the $5 \mathrm{~s}$ that was used in section 5.5.2.1). The calculated temperatures at $5 \mathrm{~s}$ are expected to be approximately $8 \%$ lower than at $60 \mathrm{~s}$.

The power and energy delivered in the flux wire and fuel pins for the maximum reactivity insertion (considering the $600^{\circ} \mathrm{C}$ temperature limit) by the HEU and LEU cores were compared. The total power and energy produced by the HEU, LEU-D and LEU-A cores were calculated with temperature limited transient TREKIN simulations with SLOTK $=1$ and reactivity insertion of $4.20 \%, 3.40 \%$ and $3.115 \%$, respectively (values from Table 5.4). Figures 5.7, 5.8 and 5.9 show the calculated total core power and the power delivered in the flux wire and fuel pin. 


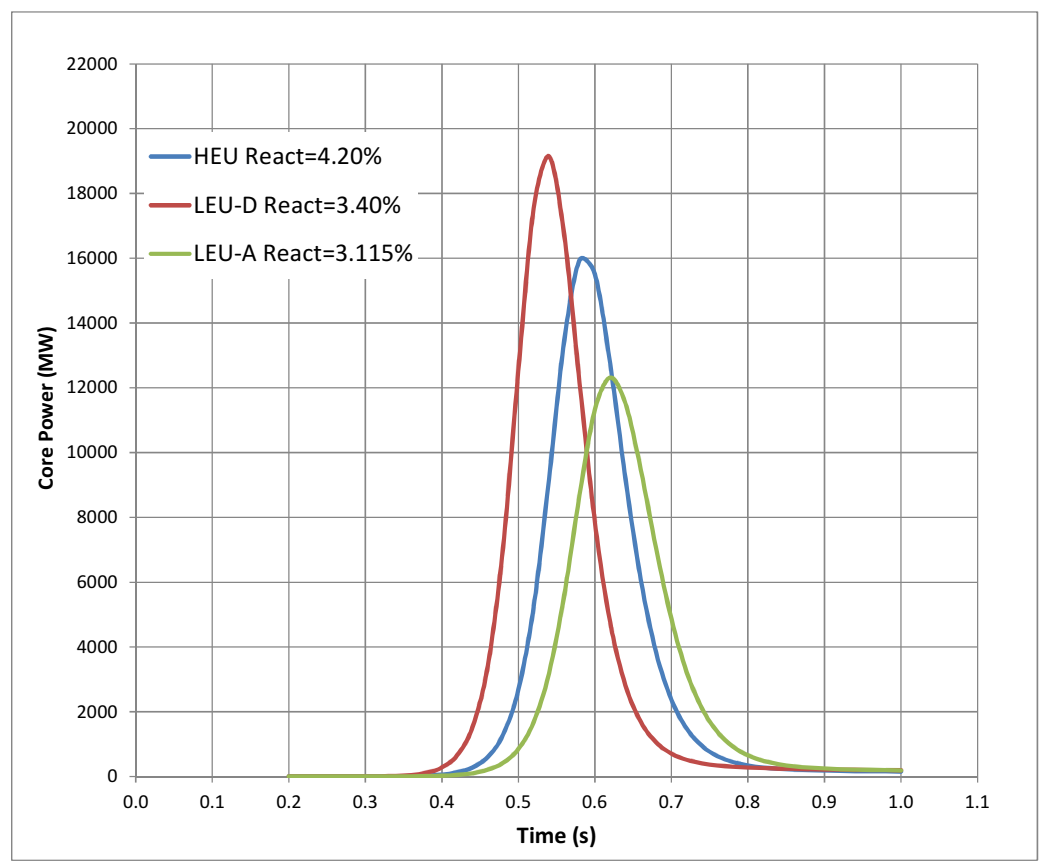

Figure [5.7]: TREKIN Calculated Core Power Time History Delivered by HEU, LEU-D (FA with C/U=5200) and LEU-A (BeO, FA with $C / U=5200$ and $C / U=6619$ ) Temperature Limited Transients for the Maximum Allowed Reactivity Insertion

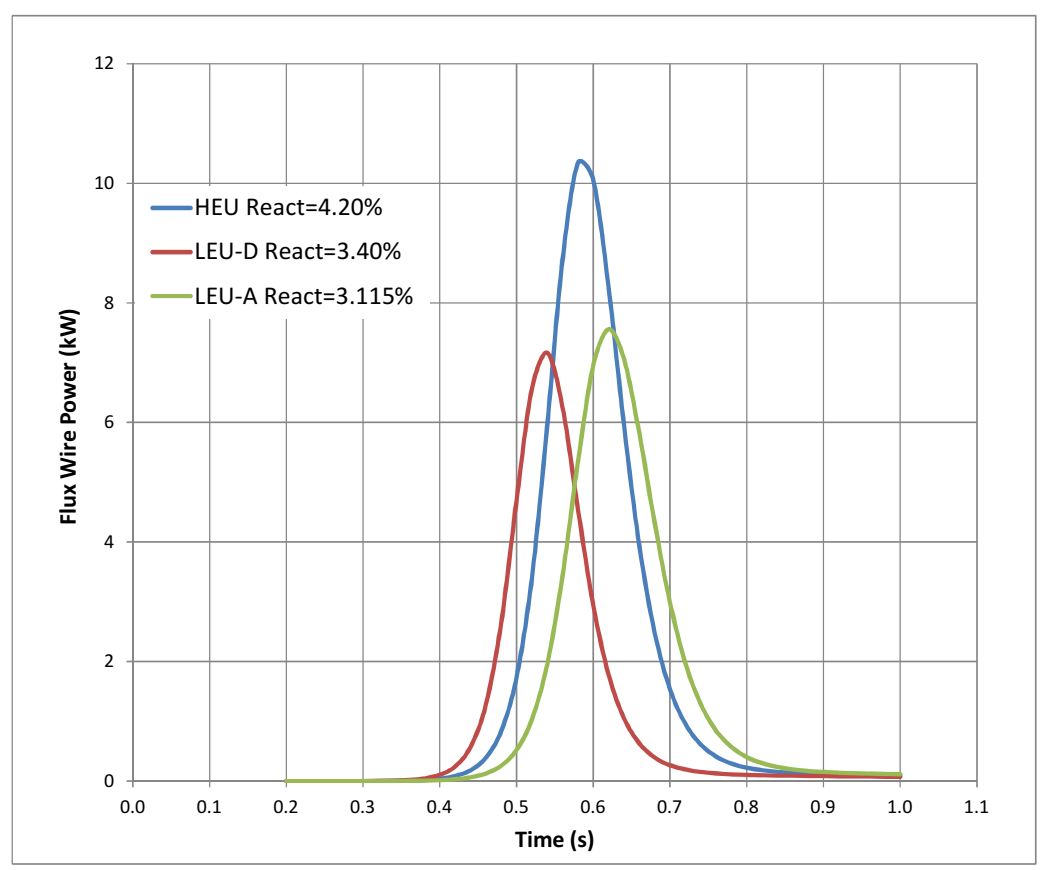

Figure [5.8]: TREKIN Calculated Flux Wire Power Time History Delivered by HEU, LEU-D (FA with C/U=5200) and LEU-A (BeO, FA with $C / U=5200$ and $C / U=6619)$ Temperature Limited Transients for the Maximum Allowed Reactivity Insertion. Wire Peak Power and Total Energy were Calculated Using the MCNP Calculated Peak Power Coupling Factors 


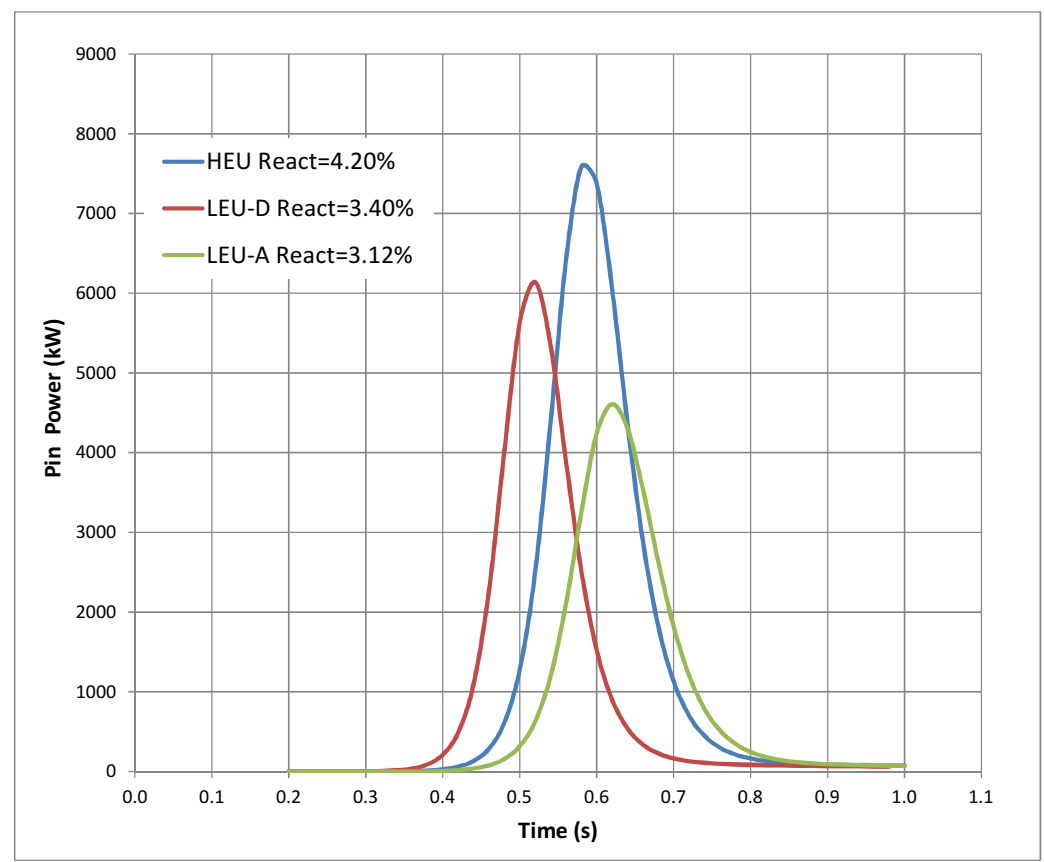

Figure [5.9]: TREKIN Calculated Fuel Pin Power Time History Delivered by HEU, LEU-D (FA with C/U=5200) and LEU-A (BeO, FA with $C / U=5200$ and $C / U=6619)$ Temperature Limited Transients for the Maximum Allowed Reactivity Insertion. Wire Peak Power and Total Energy were Calculated Using the MCNP Calculated Peak Power Coupling Factors

The results of the TREKIN calculations for the maximum-allowed step reactivity insertions are summarized in Table 5.6 for the flux wire and in Table 5.7 for the fuel pin.

Table [5.6] TREKIN Calculated Flux Wire Temperature-Limited Transients for the HEU, LEU-D (FA with C/U=5200) and LEU-A (BeO, FA with $\mathrm{C} / \mathrm{U}=5200$ and $\mathrm{C} / \mathrm{U}=6619)$ Cores for the Maximum Allowed Reactivity Insertion. Flux Wire Peak Power and Total Energy were Calculated Using the MCNP Calculated Peak Power Coupling Factors. Total Energy and Maximum Temperature at $60 \mathrm{~s}$

\begin{tabular}{|l|c|c|c|}
\hline & \multicolumn{3}{|c|}{ Flux Wire $\left(^{235} \mathrm{U} 1.19 \%\right.$ wt.) } \\
\hline & HEU & LEU-D & LEU-A \\
\hline Max-Allowed Step Reactivity $(\Delta \mathrm{k} / \mathrm{K})$ & $4.20 \%$ & $3.40 \%$ & $3.115 \%$ \\
\hline Maximum FA Temperature $\left({ }^{\circ} \mathrm{C}\right)$ & 600 & 600 & 600 \\
\hline Peak Core Power $(\mathrm{MW})$ & 15945 & 20613 & 13965 \\
\hline Total Core Energy $(\mathrm{MJ})$ & 2546 & 3155 & 2600 \\
\hline & \multicolumn{3}{|c|}{ Flux Wire Results } \\
\hline Peak Wire Power $(\mathrm{kW})$ & 10.3 & 7.2 & 7.6 \\
\hline Total Wire Energy $(\mathrm{kJ})$ & 1.7 & 1.1 & 1.4 \\
\hline & \multicolumn{3}{|c|}{ Relative to HEU } \\
\hline Rel to HEU Peak Wire Power & $100 \%$ & $69 \%$ & $73 \%$ \\
\hline Rel to HEU Total Wire Energy & $100 \%$ & $66 \%$ & $86 \%$ \\
\hline
\end{tabular}

For the flux wire irradiation, the LEU-A core provides better performance than the LEU-D core due to the softer neutron spectrum. For the same reason and also due to self-absorption the harder spectrum of the LEU-D core presents better performance for the thicker and high enriched fuel pin. This difference highlights the need to specify the experimental needs of the TREAT core in terms of planned experiments and required power and energy range delivered to the samples to be irradiated. 
Table [5.7]: Wire Peak Power and Total Energy Calculated Using the MCNP Calculated Peak Power Coupling Factors. Total Energy and Maximum Temperature at $60 \mathrm{~s}$, calculated with TREKIN for the Fuel Pin Temperature Limited Transient for the HEU, LEU-D (FA with $C / U=5200$ ) and LEU-A (BeO, FA with $C / U=5200$ and $C / U=6619)$ Cores Using the Maximum Allowed Reactivity.

\begin{tabular}{|l|c|c|c|}
\hline & \multicolumn{3}{|c|}{ T-462 Pin } \\
& HEU & LEU-D & LEU-A \\
\hline & $4.20 \%$ & $3.40 \%$ & $3.115 \%$ \\
\hline Max Step Reactivity $(\Delta \mathrm{k} / \mathrm{K})$ & 600 & 600 & 600 \\
\hline Maximum FA Temperature $\left({ }^{\circ} \mathrm{C}\right)$ & 15945 & 19145 & 12318 \\
\hline Peak Core Power $(\mathrm{MW})$ & 2546 & 2913 & 2313 \\
\hline Total Core Energy (MJ) & \multicolumn{3}{|c|}{ Pin Results } \\
\hline & 7585 & 6141 & 4608 \\
\hline Peak Pin Power (kW) & 1211 & 934 & 865 \\
\hline Total Pin Energy (kJ) & \multicolumn{3}{|c|}{ Relative to HEU } \\
\hline & $100 \%$ & $81 \%$ & $61 \%$ \\
\hline Rel to HEU Peak Pin Power & $100 \%$ & $77 \%$ & $71 \%$ \\
\hline Rel to HEU Total Pin Energy & \multicolumn{3}{|c|}{} \\
\hline
\end{tabular}

\subsubsection{Maximum Core Temperature for the LEU Cores Delivering Equal with the HEU Core Peak Power and Energy}

The next step was to calculate how much the $600^{\circ} \mathrm{C}$ fuel assembly temperature limit should be increased in the case of the LEU cores in order to deliver equal peak power and total energy with the HEU core in the flux wire and the fuel pin. The results of the TREKIN calculations are summarized in Tables 5.8 and 5.9 .

Table [5.8]: TREKIN Calculated Temperature Limited Transients for the LEU-D (FA with C/U=5200) and LEU-A (BeO, FA with $\mathrm{C} / \mathrm{U}=5200$ and $\mathrm{C} / \mathrm{U}=6619$ ) Cores for Equal to the HEU Maximum Delivered Peak Power and Energy to the Flux Wire. Wire Peak Power and Total Energy were Calculated Using the MCNP Calculated Peak Power Coupling Factors. Core Energy and Maximum Temperature at $60 \mathrm{~s}$

\begin{tabular}{|l|c|c|c|c|c|}
\hline \multicolumn{1}{|c|}{ Wire Calculations } & & $\begin{array}{c}\text { Match HEU-generated } \\
\text { Wire Power }\end{array}$ & \multicolumn{2}{c|}{$\begin{array}{c}\text { Match HEU-generated } \\
\text { Wire Energy }\end{array}$} \\
\hline & HEU & LEU-D & LEU-A & LEU-D & LEU-A \\
\hline Input Reactivity & $4.20 \%$ & $3.87 \%$ & $3.48 \%$ & $4.50 \%$ & $3.46 \%$ \\
\hline Max Fuel Assembly Temp $\left({ }^{\circ} \mathrm{C}\right)$ & 600 & 688 & 671 & 810 & 667 \\
\hline Max Core Power (MW) & 15945 & 27570 & 16893 & 40188 & 16547 \\
\hline Total Core Energy (MJ) & 2546 & 3524 & 2702 & 4418 & 2680 \\
\hline & \multicolumn{5}{|c|}{ Wire Power } \\
\hline Max Wire Power (kW) & 10.3 & 10.3 & 10.4 & 15.0 & 10.2 \\
\hline Rel to HEU Wire Power & $100 \%$ & $100 \%$ & $100 \%$ & $145 \%$ & $98 \%$ \\
\hline & \multicolumn{5}{|c|}{ Wire Energy } \\
\hline Total Wire Energy (kJ) & 1.7 & 1.3 & 1.7 & 1.7 & 1.6 \\
\hline Rel to HEU Wire Energy & $100 \%$ & $80 \%$ & $100 \%$ & $100 \%$ & $100 \%$ \\
\hline
\end{tabular}

For the flux wire irradiations, the harder spectrum of the LEU-D core and the lower wire PCF (42\% lower than the HEU one) requires higher input reactivity to match the total energy in the wire delivered by the $\mathrm{HEU}$ resulting in a maximum fuel assembly temperature of $810^{\circ} \mathrm{C}$. In the case of the LEU-A core (wire PCF only $6 \%$ lower than in the HEU core), the maximum fuel assembly temperature is $667^{\circ} \mathrm{C}$. 
Table [5.9]: TREKIN Calculated Temperature Limited Transients for the LEU-D (FA with $C / U=5200$ ) and LEU-A (BeO, FA with $C / U=5200$ and $C / U=6619)$ Cores for Equal to HEU Maximum Delivered Peak Power and Energy to the Fuel Pin. Wire Peak Power and Total Energy were Calculated using the MCNP Calculated Peak Power Coupling Factors. Core Energy and Maximum Temperature at $60 \mathrm{~s}$

\begin{tabular}{|l|c|c|c|c|c|}
\hline \multicolumn{1}{|c|}{ Pin Calculations } & & Match HEU Pin Power & Match HEU Pin Energy \\
\hline & HEU & LEU-D & LEU-A & LEU-D & LEU-A \\
\hline Input Reactivity & $4.20 \%$ & $3.67 \%$ & $3.74 \%$ & $4.05 \%$ & $3.93 \%$ \\
\hline Max Fuel Assembly Temp $\left({ }^{\circ} \mathrm{C}\right)$ & 600 & 650 & 722 & 722 & 762 \\
\hline Max Core Power (MW) & 15945 & 23700 & 20248 & 31072 & 23569 \\
\hline Total Core Energy (MJ) & 2546 & 3257 & 2991 & 3771 & 3222 \\
\hline & \multicolumn{5}{|c|}{ Pin Power } \\
\hline Max Pin Power (kW) & 7585 & 7602 & 7575 & 9966 & 8817 \\
\hline Rel to HEU Pin Power & $100 \%$ & $100 \%$ & $100 \%$ & $131 \%$ & $116 \%$ \\
\hline & \multicolumn{5}{|c|}{ Pin Energy } \\
\hline Total Pin Energy (kJ) & 1211 & 1045 & 1119 & 1210 & 1205 \\
\hline Rel to HEU Pin Energy & $100 \%$ & $84 \%$ & $90 \%$ & $100 \%$ & $100 \%$ \\
\hline
\end{tabular}

For the fuel pin irradiation, matching the peak power delivered by the HEU produces maximum fuel assembly temperature of $650^{\circ} \mathrm{C}$ in the LEU-D and $722^{\circ} \mathrm{C}$ in the LEU-A. Matching the total energy in the fuel pin the maximum fuel assembly temperature was $722^{\circ} \mathrm{C}$ in the LEU-D and $762^{\circ} \mathrm{C}$ in the LEU-A core. This analysis indicates that methods to decrease the maximum fuel assembly temperature and/or to increase the maximum-allowable fuel assembly temperature (e.g., increased fuel heat capacity or cladding with higher temperature capability) should be also investigated to increase the power and energy delivered in high-fissile-content targets (e.g., fuel pins).

\subsubsection{Peak Power and Total Energy Delivered for Different Wire Compositions and Diameter}

The effect of the wire composition and diameter on the power coupling factor and consequently on the peak power and total core energy was studied. The power coupling factor for the 8 inch-long flux wire was calculated with MCNP for two diameters (0.04 and 0.173 inches) and for three compositions; (A) 6.0\% wt. uranium (19.8\% wt.U-235 enrichment), 94\% wt. zirconium, (B) 3.6\% wt. uranium (93.1\% wt. U235 enrichment), $96.5 \%$ wt. zirconium and (C) the same as the T-433 pin: $90.2 \%$ wt. uranium (68.5\% wt. U-235 enrichment), 9.76\% wt. zirconium. The same rod configuration was used in the MCNP calculations (rod withdrawal: Compensation 100\%, Control/Shutdown 38\%, Transient 100\%). Table 5.10 summarizes the MCNP peak power coupling factor calculations.

Table [5.10]: MCNP Calculated Peak Power Coupling Factor (PCF) for the HEU, LEU-D (FA with C/U=5200) and LEU-A (BeO, FA with $C / U=5200$ and $C / U=6619)$ Cores for Three Compositions; A: $1.19 \%$ wt. U-235 B: 3.35\% wt. U-235 and C: $61.8 \%$ wt. U-235 and Two Wire Diameters (0.04 in. and 0.173 in.)

\begin{tabular}{|c|c|c|c|c|c|c|c|c|c|}
\hline \multicolumn{5}{|c|}{ Test Sample Composition and Diameter } & \multicolumn{3}{|c|}{$\begin{array}{c}\text { PCF } \\
\text { (J/g-MJ) }\end{array}$} & \multicolumn{2}{|c|}{$\begin{array}{c}\text { PCF } \\
\text { Relative to HEU }\end{array}$} \\
\hline $\begin{array}{l}\text { Diameter } \\
\text { (in.) }\end{array}$ & $\begin{array}{l}\text { Density } \\
\left(\mathrm{g} / \mathrm{cm}^{3}\right)\end{array}$ & $\begin{array}{l}{ }^{235} \mathrm{U} \text { Mass } \\
\text { (g) }\end{array}$ & $\begin{array}{l}\text { Uranium } \\
\text { (wt) }\end{array}$ & $\begin{array}{c}{ }^{235} \mathrm{U} \\
\text { Enrich (wt) }\end{array}$ & HEU & LEU-D & LEU-A & LEU-D & LEU-A \\
\hline 0.04 & 8.16 & 0.016 & $6.0 \%$ & $19.8 \%$ & 0.48 & 0.28 & 0.45 & $58 \%$ & $94 \%$ \\
\hline 0.04 & 7.28 & 0.040 & $3.6 \%$ & $93.1 \%$ & 1.29 & 0.75 & 1.22 & $58 \%$ & $94 \%$ \\
\hline 0.04 & 14.91 & 1.518 & $90.2 \%$ & $68.5 \%$ & 15.81 & 9.74 & 14.07 & $62 \%$ & $89 \%$ \\
\hline 0.173 & 14.91 & 28.39 & $90.2 \%$ & $68.5 \%$ & 7.63 & 5.13 & 6.17 & $67 \%$ & $81 \%$ \\
\hline
\end{tabular}


As it was expected the PCF increases for higher U-235 content. But this increase is not proportional to the U-235 mass increase due to the neutron self-shielding. The effect of the neutron shielding is more pronounced in the case of the LEU-A core that produces a softer neutron spectrum as compared to the HEU and LEU-D so the thermal neutrons are absorbed in the outer layers of the irradiated sample. Table 5.11 shows the change of the PCF relative to the value for the 0.04 in. wire and the $6.0 \%$ wt. uranium (19.8\% wt.U-235 enrichment) composition.

Table [5.11]: Peak Power Coupling Factor (PCF) Relative to 0.04 in. $0.016 \mathrm{~g}^{235} \mathrm{U}$ Test Sample for the HEU, LEU-D (FA with $\mathrm{C} / \mathrm{U}=5200)$ and LEU-A (BeO, FA with $\mathrm{C} / \mathrm{U}=5200$ and $\mathrm{C} / \mathrm{U}=6619)$ Cores

\begin{tabular}{|c|c|c|c|c|c|}
\hline \multicolumn{3}{|c|}{ Test Sample } & \multicolumn{3}{c|}{$\begin{array}{c}\text { PCF Relative to } \\
\mathbf{0 . 0 4} \text { in. } \mathbf{0 . 0 1 6} \mathbf{g}^{\mathbf{2 3 5}} \mathbf{U}\end{array}$} \\
\hline $\begin{array}{c}\text { Diameter } \\
\text { (in.) }\end{array}$ & $\begin{array}{c}\text { Density } \\
\left(\mathbf{g} / \mathbf{c m}^{\mathbf{3}}\right)\end{array}$ & $\begin{array}{c}\mathbf{2 3 5}^{\mathbf{U}} \mathbf{U} \text { Mass } \\
\mathbf{( g )}\end{array}$ & HEU & LEU-D & LEU-A \\
\hline 0.04 & 8.16 & 0.016 & 1.00 & 1.00 & 1.00 \\
\hline 0.04 & 7.28 & 0.039 & 2.7 & 2.7 & 2.7 \\
\hline 0.04 & 14.91 & 1.519 & 32.9 & 34.8 & 31.3 \\
\hline 0.173 & 14.91 & 28.41 & 15.9 & 18.3 & 13.7 \\
\hline
\end{tabular}

Based on the TREKIN calculated core peak power and total energy for the HEU, LEU-D and LEU-A cores in the case of temperature limited transients using the maximum allowed reactivity (considering the $600^{\circ} \mathrm{C}$ temperature limit and the conservative $60 \mathrm{~s}$ transient duration), the relative to HEU peak power and total energy were calculated for the three different compositions and two diameters. The results of the calculations are shown in table 5.12.

Table [5.12]: TREKIN Calculated Relative to HEU Peak Power and Total Energy Delivered by the LEU-D (FA with C/U=5200) and LEU-A (BeO, FA with $C / U=5200$ and $C / U=6619)$ Cores in the Flux Wire for Two Wire Diameters and Three Compositions; A) $1.19 \%$ wt. U-235 B) $3.35 \%$ wt. U-235 and C) $61.8 \%$ wt. U-235

\begin{tabular}{|c|c|c|c|c|c|c|}
\hline \multicolumn{3}{|c|}{ Test Sample } & \multicolumn{2}{c|}{$\begin{array}{c}\text { Relative to HEU } \\
\text { Power in Sample }\end{array}$} & \multicolumn{2}{c|}{$\begin{array}{c}\text { Relative To HEU } \\
\text { Energy in Sample }\end{array}$} \\
\hline $\begin{array}{c}\text { Diameter } \\
\text { (in.) }\end{array}$ & $\begin{array}{c}\text { Density } \\
\left(\mathbf{g} / \mathbf{c m}^{\mathbf{3}} \text { ) }\right.\end{array}$ & $\begin{array}{c}\mathbf{2 3 5} \mathbf{U} \text { Mass } \\
\text { (g) }\end{array}$ & LEU-D & LEU-A & LEU-D & LEU-A \\
\hline 0.04 & 8.16 & 0.016 & $70 \%$ & $73 \%$ & $67 \%$ & $86 \%$ \\
\hline 0.04 & 7.28 & 0.039 & $70 \%$ & $73 \%$ & $67 \%$ & $86 \%$ \\
\hline 0.04 & 14.91 & 1.519 & $74 \%$ & $69 \%$ & $70 \%$ & $81 \%$ \\
\hline 0.173 & 14.91 & 28.41 & $81 \%$ & $63 \%$ & $77 \%$ & $73 \%$ \\
\hline
\end{tabular}

For the sample with 0.04 in. diameter the LEU core delivers about $30 \%$ less peak power than the HEU. The LEU-A produces $86 \%$ energy whereas the LEU-D 67\%, a difference that is attributed to the harder neutron spectrum and the shorter prompt neutron generation lifetime. (The power pulses produced by LEU-D are narrower than the LEU-A.) As the diameter and ${ }^{235} \mathrm{U}$ mass increase, both the self-shielding effect and fissile density are enhanced, so the PCF factor increases but not in direct proportion with ${ }^{235} \mathrm{U}$ mass.

\subsubsection{Shaped Transients for the LEU-D and LEU-A Cores}

The experimentally performed shaped transient \#2874 was chosen as the basis to compare the HEU and LEU cores in the case of the flux wire irradiation. The maximum allowed available reactivity before the transient is equal to the reactivity that would result in a fuel assembly temperature of $820^{\circ} \mathrm{C}$ if it was 
inserted as a step. The maximum allowed reactivity insertion for the $820^{\circ} \mathrm{C}$ temperature limited has already been calculated with TREKIN as the reactivity safety limit (Table 5.4): HEU: 5.65\%, LEU-D: 4.55\% and LEU-A: $4.206 \%$. Based on these reactivity values TREKIN determines the starting position of the transient rods and the available rod movement range for the shaped transient. As the available pretransient reactivity is increased the initial rod withdrawal is decreased. The rod time history was first calculated with power-driven TREKIN runs in order the LEU cores to deliver the same power time history to the flux wire. The rod time history was adjusted for the maximum allowed pre-transient reactivity and with rod-driven TREKIN runs the power time history delivered by the LEU cores was calculated.

Transient \#2874 was designed for the HEU core to deliver energy to the test sample with two successive power rises; the first with period of $0.3 \mathrm{~s}$ and the second with period $8 \mathrm{~s}$. In order to compare the ability of the LEU cores to produce such power time history, period-driven TREKIN calculations were performed, and the power delivered to the flux wire and test pin was calculated. For these shapedtransient calculations, the maximum allowed reactivity of Table 5.4 for the HEU, LEU-D and LEU-A cores was used. In the HEU core the first period of $0.3 \mathrm{~s}$ drives the power until the level of $75 \mathrm{MW}$ that in TREKIN language is labeled as 'Flattop'. The Flattop value was adjusted (using the relative-to-HEU power coupling factor ratio) such that the LEU-D and LEU-A cores would deliver equal power in the flux wire and the test pin as the HEU core did:

Power in Flux Wire or Test Pin from HEU $=$ Power in Flux Wire or Test Pin from HEU $\Rightarrow$

$$
\begin{aligned}
& \text { Core Power }_{H E U} \times P C F_{H E U}=\text { Core } \text { Power }_{L E U} \times P C F_{L E U} \Rightarrow \\
& \text { Core } \text { Power }_{L E U}=\text { Core Power } \text { PEU }_{\text {P }} \times \frac{P C F_{H E U}}{P C F_{L E U}} \Rightarrow
\end{aligned}
$$

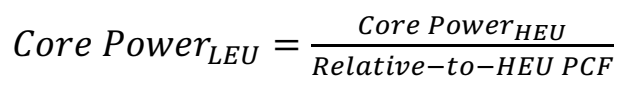

The available pre-transient reactivity of the transient rods was the limiting factor in the TREKIN perioddriven calculations. When this reactivity was reached (reflecting to a $100 \%$ transient rod withdrawal), the transient rods were inserted to end the transient.

The calculated core power time history (in MW) was multiplied by the peak power coupling factor for the flux wire (in fissions per U-235 g-MJ), the total wire U-235 mass (g) and the energy deposition per fission $\left(2.72 \times 10^{-11} \mathrm{~J} /\right.$ fission) to give the power time history in the flux wire in Watts. In the case of the T462 fuel pin, the core power time history (MW) was multiplied by the peak power coupling factor for the pin (J/g-MJ) and the total pin mass (g) to yield a pin power time history in kW. Since the peak power coupling factors for the T-462 and T-433 fuel pins are similar, the TREKIN calculations were performed only for the T-462 pin.

Due to the neutron spectrum hardening in the case of the LEU cores and the resulting decrease of the transient rod worth, it was expected that the rod withdrawal rate would not be enough to produce peak power in the test samples equal to that in the HEU core. To provide a simple way of comparison, several TREKIN calculations were performed by only changing the second period and consequently the rod 
withdrawal rate as needed to achieve peak power delivered to the flux wire and the fuel pin equal to that achieved in the HEU core.

\subsubsection{Rod-Driven TREKIN Calculations for Equal Peak Power Delivered in the Flux Wire as with Transient \#2874}

The experimentally performed \#2874 shaped transient (basically a power rise with 8-s period to maximum-allowed reactivity insertion) was chosen to be analyzed with TREKIN because it was well documented. Based on the HEU core power time history of the \#2874 transient, the power time history for the LEU-D and LEU-A cores was calculated such as to generate the same flux-wire power vs time as in the HEU core. For the TREKIN calculations the pre-transient available reactivity for each core was set at the value that would cause a maximum fuel assembly temperature of $820^{\circ} \mathrm{C}$ (at $60 \mathrm{~s}$ into the transient) if it was inserted as a step. The values for the HEU, LEU-D and LEU-A as already calculated (Table 5.4) were $5.65 \%, 4.55 \%$ and $4.206 \%$, respectively. The pre-transient available reactivity reflects to the initial rod withdrawal and consequently to the maximum reactivity that is available for the transient. During the transient the temperature limit of $600^{\circ} \mathrm{C}$ should not be exceeded. The flux wire power and total energy were calculated by applying the peak-axial power coupling factor over the entire limit of the wire. The rod position time history for the LEU cores were calculated with power-driven TREKIN runs and the results are shown in Figure 5.10.

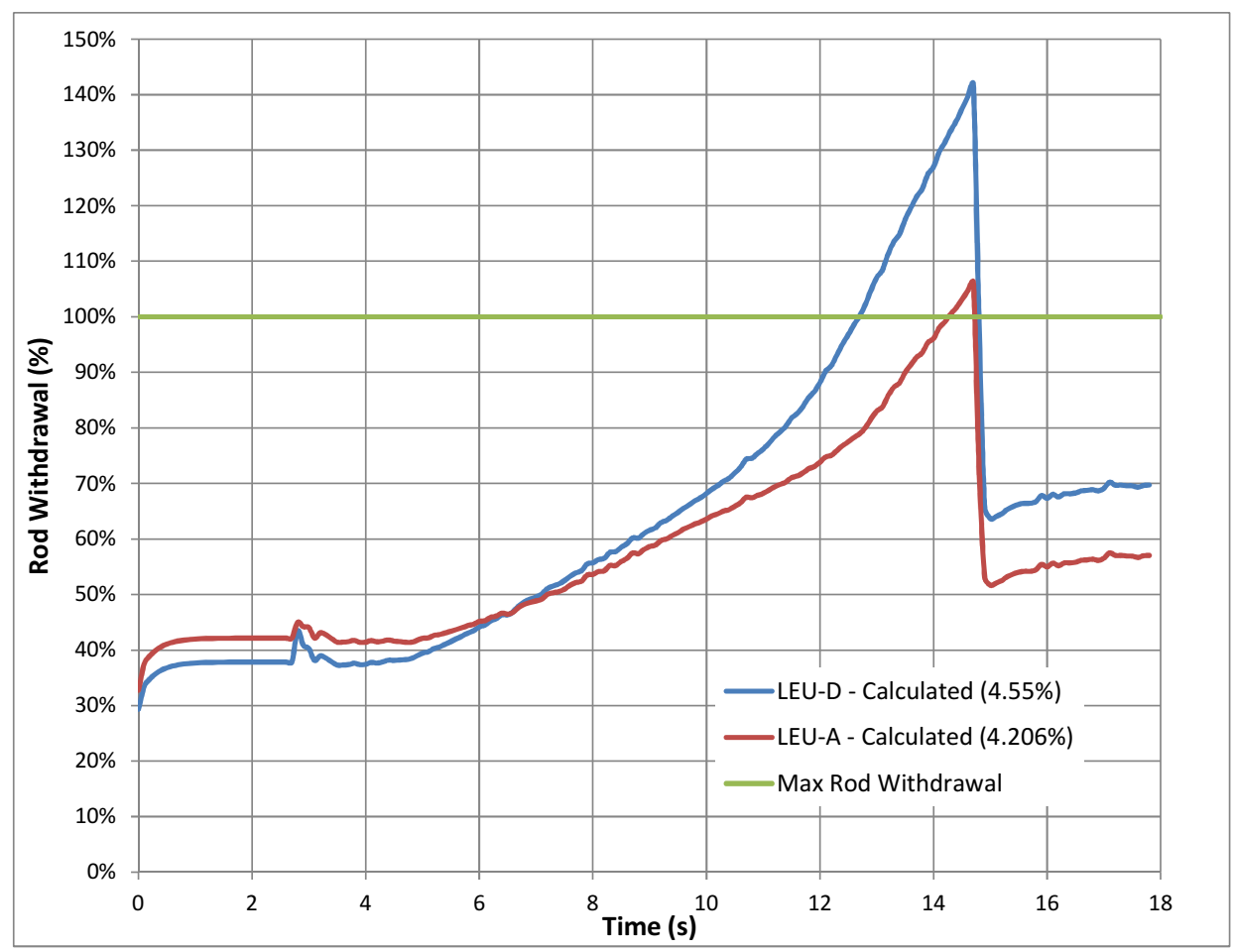

Figure [5.10]: Rod Position Time Histories Calculated for the LEU-D (FA with $C / U=5200$ ) and (BeO, FA with C/U=5200 and $\mathrm{C} / \mathrm{U}=6619)$ Cores with Power Driven TREKIN Runs that Produce the Same Peak Power to the Flux Wire with HEU Core with a Rod Starting Position Limited by the Pre-Transient Reactivity Limited. The Pre-Transient Reactivity Limit for each Core is Shown in the Parentheses

For the LEU-D core TREKIN calculated a $142 \%$ rod withdrawal to compensate for the relative-to-HEU peak-axial power coupling factor of $58 \%$. In the case of the LEU-A core the calculated rod withdrawal was $106 \%$ with a relative-to-HEU peak-axial power coupling factor of $94 \%$. 
The rod time histories for the LEU cores were then truncated as necessary so as not to exceed the physical limit of rod withdrawal based on the rod starting position (defined by the pre-transient available reactivity) and were used for rod-driven TREKIN computations to calculate the power and the energy delivered in the flux wire without exceeding the physical limit of rod travel.

The TREKIN calculated power time history for the HEU, LEU-D and LEU-A cores are presented in Figure 5.11.

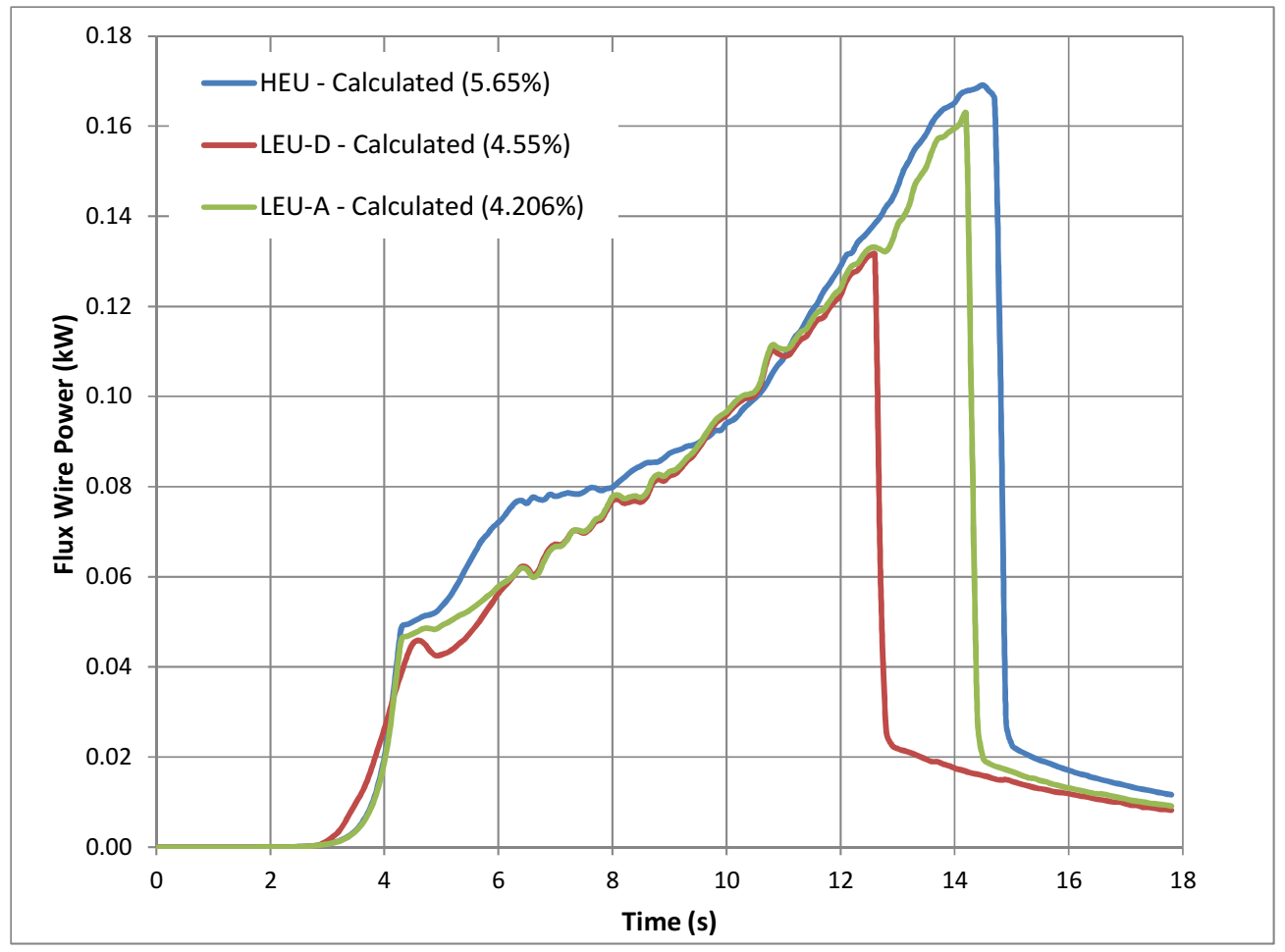

Figure [5.11]: Power Delivered in the Flux Wire by the HEU, LEU-D (FA with C/U=5200) and LEU-A (BeO, FA with C/U=5200 and $C / U=6619$ ) Cores for Shaped Transients Limited by the Reactivity Safety Limits and the Transient Rods Span

Table 5.13 shows the resulting calculated peak power and total energy in the flux wire as well as the maximum core temperature.

Table [5.13]: Calculated Maximum Fuel Assembly (FA) Temperature, Peak Power and Total Energy Delivered in the Flux Wire for the \#2874 Shaped Transient Limited by the Safety Limits (SL) for the HEU, LEU-D (FA with C/U=5200) and LEU-A (BeO, FA with $\mathrm{C} / \mathrm{U}=5200$ and $\mathrm{C} / \mathrm{U}=6619$ ) Cores

\begin{tabular}{|c|c|c|c|c|}
\hline $\begin{array}{c}\text { Pre-Transient } \\
\text { Available } \\
\text { Reactivity }\end{array}$ & Core & $\begin{array}{c}\text { Wire Peak } \\
\text { Power } \\
\text { (kW) }\end{array}$ & $\begin{array}{c}\text { Wire Total } \\
\text { Energy } \\
\mathbf{( k J )}\end{array}$ & $\begin{array}{c}\text { Max FA } \\
\text { Temp } \\
\left.\text { ( }{ }^{\circ} \mathbf{C}\right)\end{array}$ \\
\hline $5.65 \%$ & HEU & 0.169 & 1.165 & 467 \\
\hline $4.55 \%$ & LEU-D & 0.131 & 0.794 & 479 \\
\hline $4.206 \%$ & LEU-A & 0.163 & 1.032 & 477 \\
\hline \multirow{3}{*}{} & LEU-D & $77 \%$ & $68 \%$ & $102 \%$ \\
\cline { 2 - 5 } & LEU-A & $96 \%$ & $89 \%$ & $102 \%$ \\
\cline { 2 - 5 } & & \multicolumn{3}{|c|}{ Relative to HEU } \\
\cline { 2 - 5 }
\end{tabular}




\subsubsection{Period-Driven TREKIN Calculations Using Equal Periods with HEU}

Period-driven TREKIN calculations were performed with periods of $0.3 \mathrm{~s}$ and $8 \mathrm{~s}$ to approximate the experimentally performed \#2874 transient in the HEU core. The Flattop value (the power level where the period changes from 0.3 to $8 \mathrm{~s}$ ) for the LEU cores was adjusted using the relative-to-HEU power coupling factors from Table 4.21 for the flux wire and the fuel pin irradiations. In each case, the maximum-allowed reactivity insertion was used.

Figure 5.12 shows the flux wire power time history calculated with period-driven TREKIN runs for the HEU core (maximum pre-transient reactivity $=5.65 \%$, Flattop $=75 \mathrm{MW}$ ), the LEU-D core, (maximum pretransient $=4.55 \%$, Flattop $=129.3 \mathrm{MW}$ ) and the LEU-A core (maximum pre-transient $=4.206 \%$, Flattop $=$ $79.8 \mathrm{MW})$.

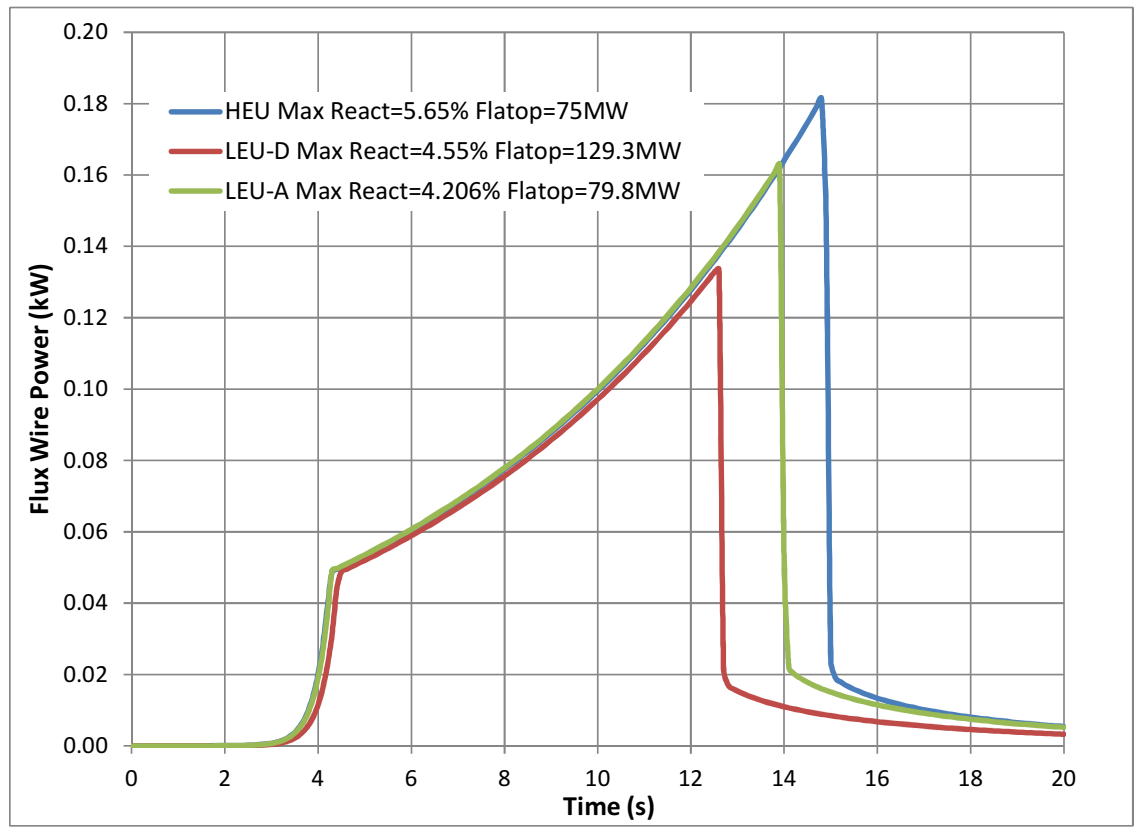

Figure [5.12]: TREKIN Rod Driven Calculated Power Time History in the Flux Wire for $0.3 \mathrm{~s}$ and $8 \mathrm{~s}$ Period Power Increase in the HEU, LEU-D (FA with $C / U=5200$ ) and LEU-A (BeO, FA with $C / U=5200$ and $C / U=6619$ ) Cores Using Adjusted with the Peak Power Coupling Flattop Values of 75, 129.3 and 79.8 MW, Respectively

The TREKIN-calculated rod time history driven by the two periods and the different flattop values for the HEU, LEU-D and LEU-A cores in the case of the flux wire irradiations is shown in Figure 5.13. 


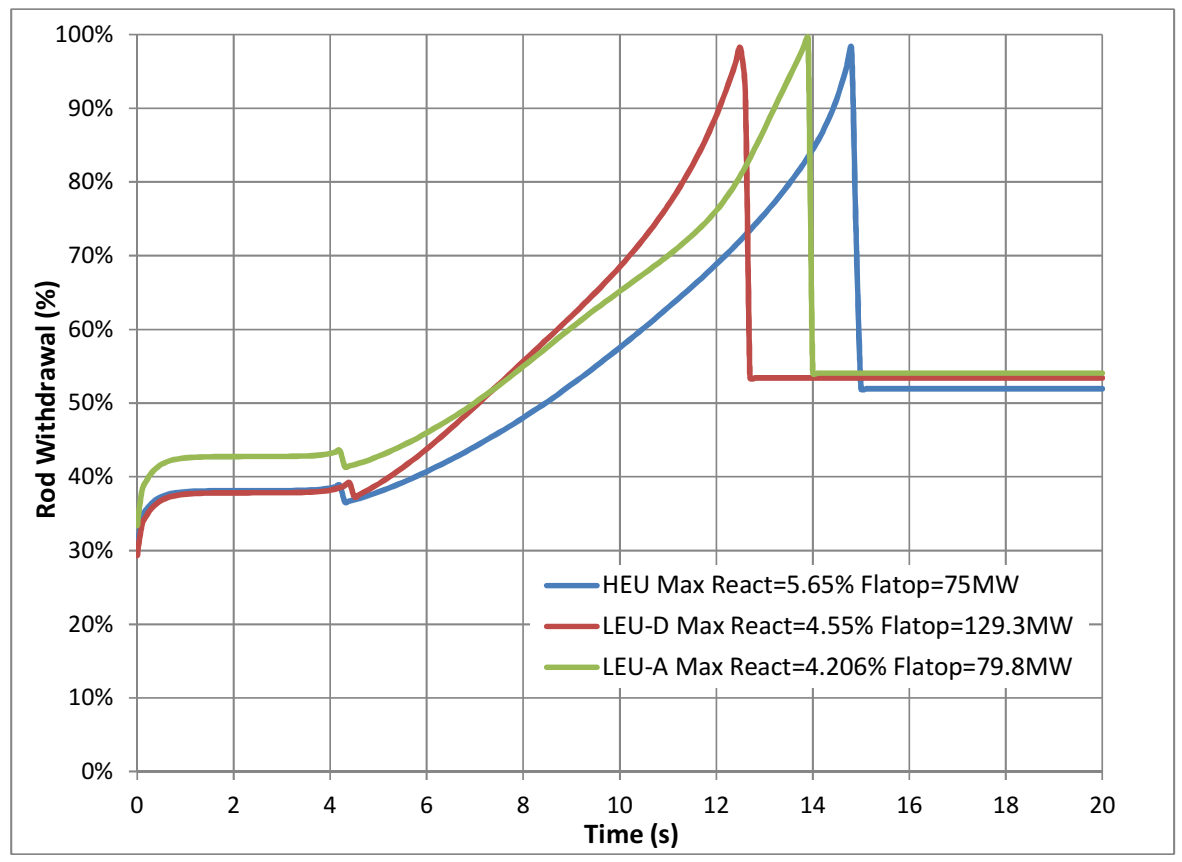

Figure [5.13]: TREKIN Calculated Rod Time History in the Flux Wire for $0.3 \mathrm{~s}$ and $8 \mathrm{~s}$ Period Power Increase in the HEU, LEU-D (FA with $C / U=5200)$ and LEU-A (BeO, FA with $C / U=5200$ and $C / U=6619$ ) Cores Using Adjusted with the Peak Power Coupling Factor Flattop of 75, 129.3 and $79.8 \mathrm{MW}$, Respectively

The results of the TREKIN calculations for the flux wire are summarized in Table 5.14.

Table [5.14]: TREKIN Period Driven Calculations For Flux Wire Irradiations for 0.3s and 8s Period Power Increase in the HEU, LEU-D (FA with $C / U=5200$ ) and LEU-A (BeO, FA with $C / U=5200$ and $C / U=6619)$ Cores

\begin{tabular}{|l|c|c|c|}
\hline & \multicolumn{3}{|c|}{ Flux Wire (U-235 1.19\% wt.) } \\
\hline & HEU & LEU-D & LEU-A \\
\hline Limiting Pre-Transient Reactivity $(\Delta \mathrm{k} / \mathrm{K})$ & $5.65 \%$ & $4.55 \%$ & $4.206 \%$ \\
\hline Flattop Power $(\mathrm{MW})$ & 75 & 129 & 80 \\
\hline \#1 Period $(\mathrm{s})$ & 0.3 & 0.3 & 0.3 \\
\hline \#2 Period $(\mathrm{s})$ & 8 & 8 & 8 \\
\hline Maximum FA Temperature $\left({ }^{\circ} \mathrm{C}\right)$ & 463 & 465 & 467 \\
\hline Peak Core Power $(\mathrm{MW})$ & 280 & 357 & 265 \\
\hline Total Core Energy $(\mathrm{MJ})$ & 1775 & 2038 & 1633 \\
\hline & \multicolumn{3}{|c|}{ Flux Wire Results } \\
\hline Peak Wire Power $(\mathrm{kW})$ & 0.18 & 0.13 & 0.16 \\
\hline Total Wire Energy (kJ) & 1.15 & 0.76 & 1.00 \\
\hline & \multicolumn{4}{|c|}{ Relative to HEU } \\
\hline Relative to HEU Peak Wire Power & $100 \%$ & $74 \%$ & $90 \%$ \\
\hline Relative to HEU Total Wire Energy & $100 \%$ & $66 \%$ & $87 \%$ \\
\hline
\end{tabular}

The softer neutron spectrum of the LEU-A core increases the energy and consequently the peak power delivered in the flux wire as compared to the LEU-D. In particular, the LEU-A core delivers $90 \%$ of the power delivered by the HEU core whereas the LEU-D delivers 74\%. Figure 5.14 shows the TREKINcalculated power time history in the fuel pin for the HEU core (maximum pre-transient reactivity = $5.65 \%$, flattop $=75 \mathrm{MW}$ ), the LEU-D core (maximum pre-transient reactivity $=4.55 \%$, flattop $=110.3 \mathrm{MW}$ ) 
and the LEU-A core (maximum pre-transient reactivity $=4.206 \%$, flattop $=96.2 \mathrm{MW}$ ). The power in the fuel pin was calculated by applying the peak-axial power coupling factor in the entire length of the pin.

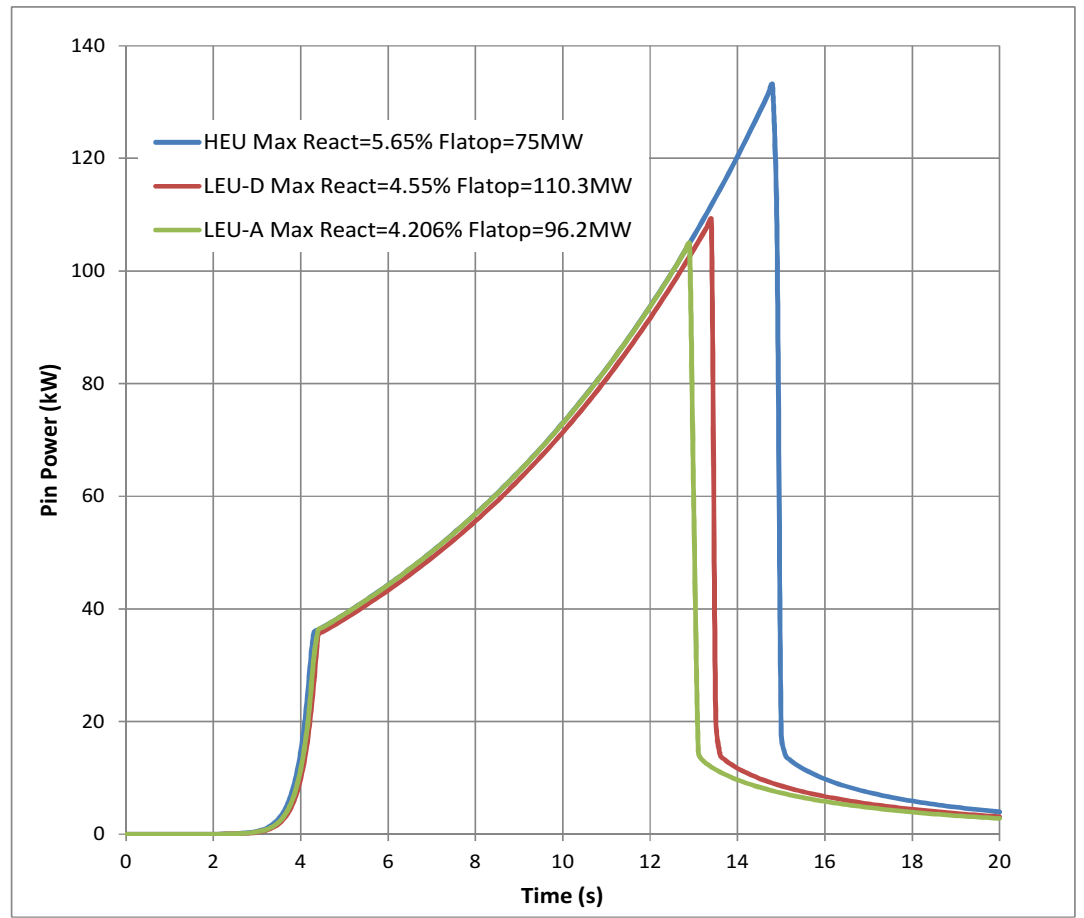

Figure [5.14]: TREKIN Calculated Power Time History in the T-462 Pin for $0.3 \mathrm{~s}$ and $8 \mathrm{~s}$ Period Driven Power Increase in the HEU, LEU-D (FA with $C / U=5200)$ and LEU-A (BeO, FA with $C / U=5200$ and $C / U=6619)$ Cores

Figure 5.15 shows the TREKIN calculated rod time history for the three cores for the fuel pin irradiation.

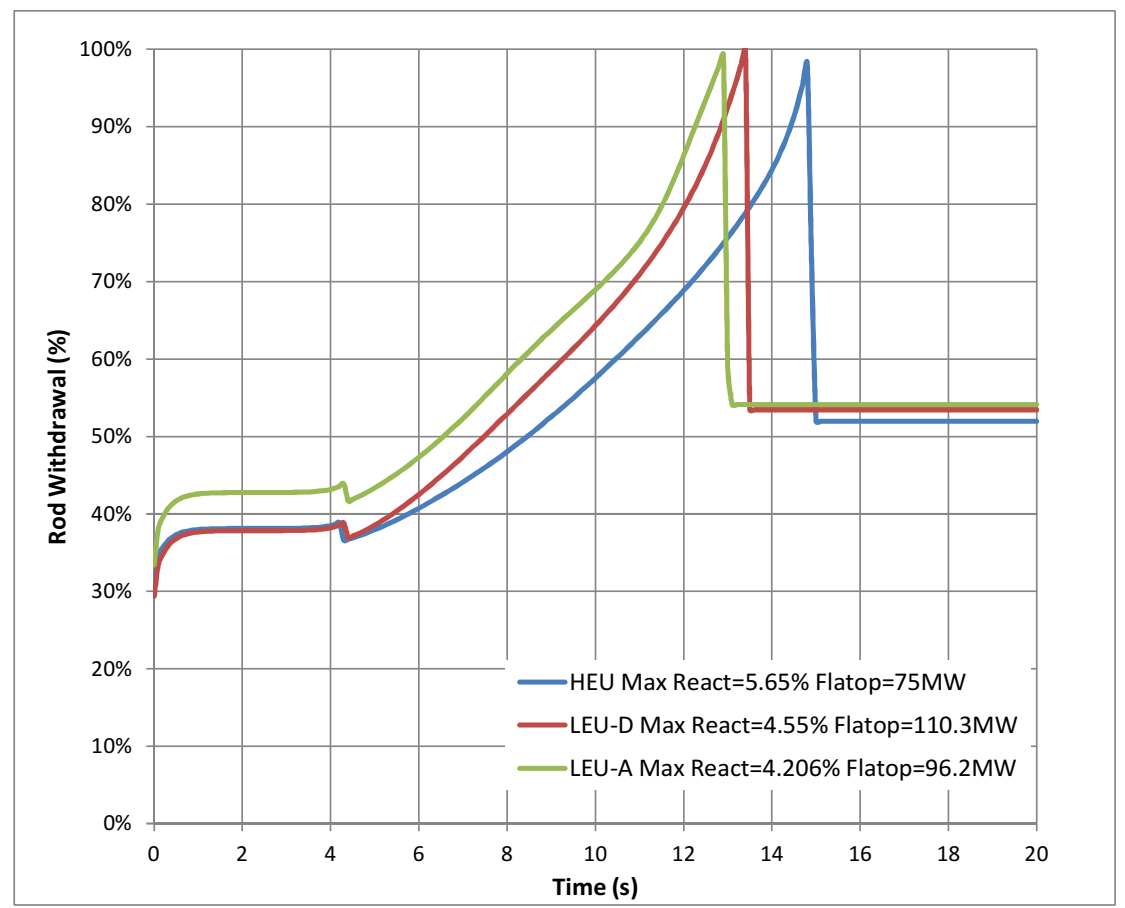

Figure [5.15]: TREKIN Calculated Rod Time History in the T-462 Pin for $0.3 \mathrm{~s}$ and $8 \mathrm{~s}$ Period Power Increase in the HEU, LEU-D (FA with $C / U=5200$ ) and LEU-A (BeO, FA with $C / U=5200$ and $C / U=6619)$ Cores 
The results of the TREKIN calculations for the T-462 pin are summarized in Table 5.15.

Table [5.15]: TREKIN Period Driven Calculations for $0.3 \mathrm{~s}$ and $8 \mathrm{~s}$ Period Power Increase in the T-462 Pin Irradiations in the HEU, LEU-D (FA with $C / U=5200)$ and LEU-A (BeO, FA with $C / U=5200$ and $C / U=6619)$ Cores

\begin{tabular}{|l|c|c|c|}
\hline & \multicolumn{4}{|c|}{ T-462 Pin (U 71.02\% wt., Pu 19.15\% wt.) } \\
\hline & HEU & LEU-D & LEU-A \\
\hline Limiting Pre-Transient Reactivity $(\Delta \mathrm{k} / \mathrm{K})$ & $5.65 \%$ & $4.55 \%$ & $4.206 \%$ \\
\hline Flattop Power $(\mathrm{MW})$ & 75 & 110 & 96 \\
\hline \#1 Period $(\mathrm{s})$ & 0.3 & 0.3 & 0.3 \\
\hline \#2 Period $(\mathrm{s})$ & 8 & 8 & 8 \\
\hline Maximum FA Temperature $\left({ }^{\circ} \mathrm{C}\right)$ & 463 & 463 & 470 \\
\hline Peak Core Power $(\mathrm{MW})$ & 280 & 340 & 280 \\
\hline Total Core Energy $(\mathrm{MJ})$ & 1775 & 2027 & 1645 \\
\hline & \multicolumn{4}{|c|}{ Pin Results } \\
\hline Peak Pin Power $(\mathrm{kW})$ & 133 & 109 & 105 \\
\hline Total Pin Energy (kJ) & 844 & 650 & 615 \\
\hline & \multicolumn{4}{|c|}{ Relative to HEU } \\
\hline Relative to HEU Peak Pin Power & $100 \%$ & $82 \%$ & $79 \%$ \\
\hline Relative to HEU Total Pin Energy & $100 \%$ & $77 \%$ & $73 \%$ \\
\hline
\end{tabular}

The performance of the LEU-D core is similar to that of the LEU-A core in the case of the fuel pin irradiation delivering $82 \%$ and $79 \%$ of the peak power delivered by the HEU core, respectively. The respective percentages for the total pin energy are $77 \%$ for the LEU-D and $73 \%$ for the LEU-A core.

\subsubsection{Power-Driven TREKIN Calculations with Second Period Adjusted to Produce Equal-to- HEU Peak Power in Test Sample}

The total reactivity used in the TREKIN simulations of the shaped transient is the maximum allowed reactivity such that the $820^{\circ} \mathrm{C}$ fuel temperature limit is not to be exceeded in the case of an accidental withdrawal of the transient rods at the maximum speed. As a further means of comparing the performance of the three cores, achieving the equal test-sample peak power with the LEU cores by decreasing the second period was considered. The decrease of the period reflects to the increase of the rod withdrawal speed during the shaped transient. Although the test-sample power is affected by the period change, the core, wire and pin energies are not expected to be affected since the inserted reactivity for each core remains the same.

Figures 5.16 and 5.17 show the calculated power and transient rod time history for HEU, LEU-D and LEUA cores in the case of the flux wire irradiation. 


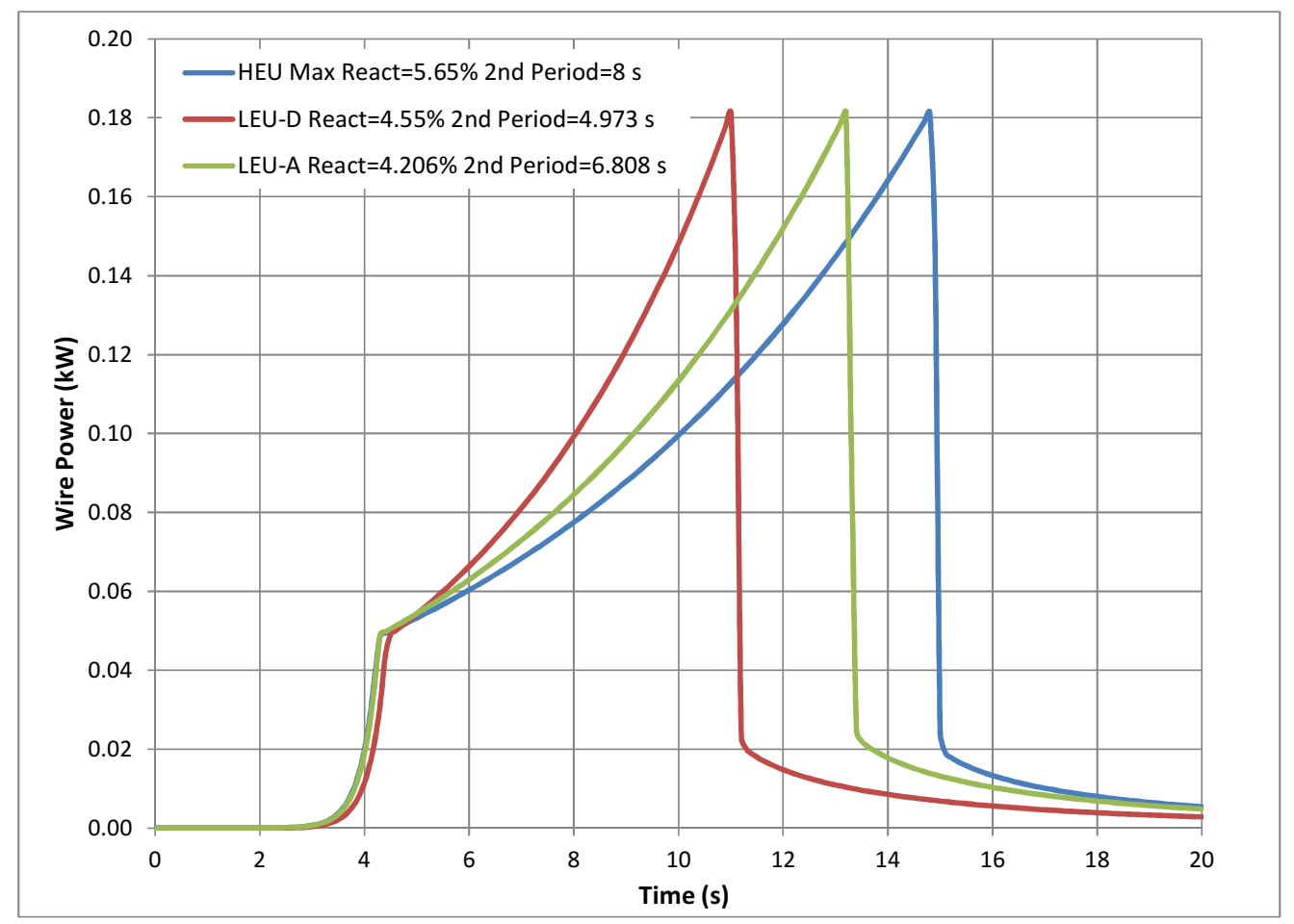

Figure [5.16]: TREKIN Calculated Power Time History in the Flux Wire for the HEU, LEU-D (FA with C/U=5200) and LEU-A (BeO, FA with $C / U=5200$ and $C / U=6619)$ Cores with Adjusted Second Period to Produce Equal to HEU Peak Power

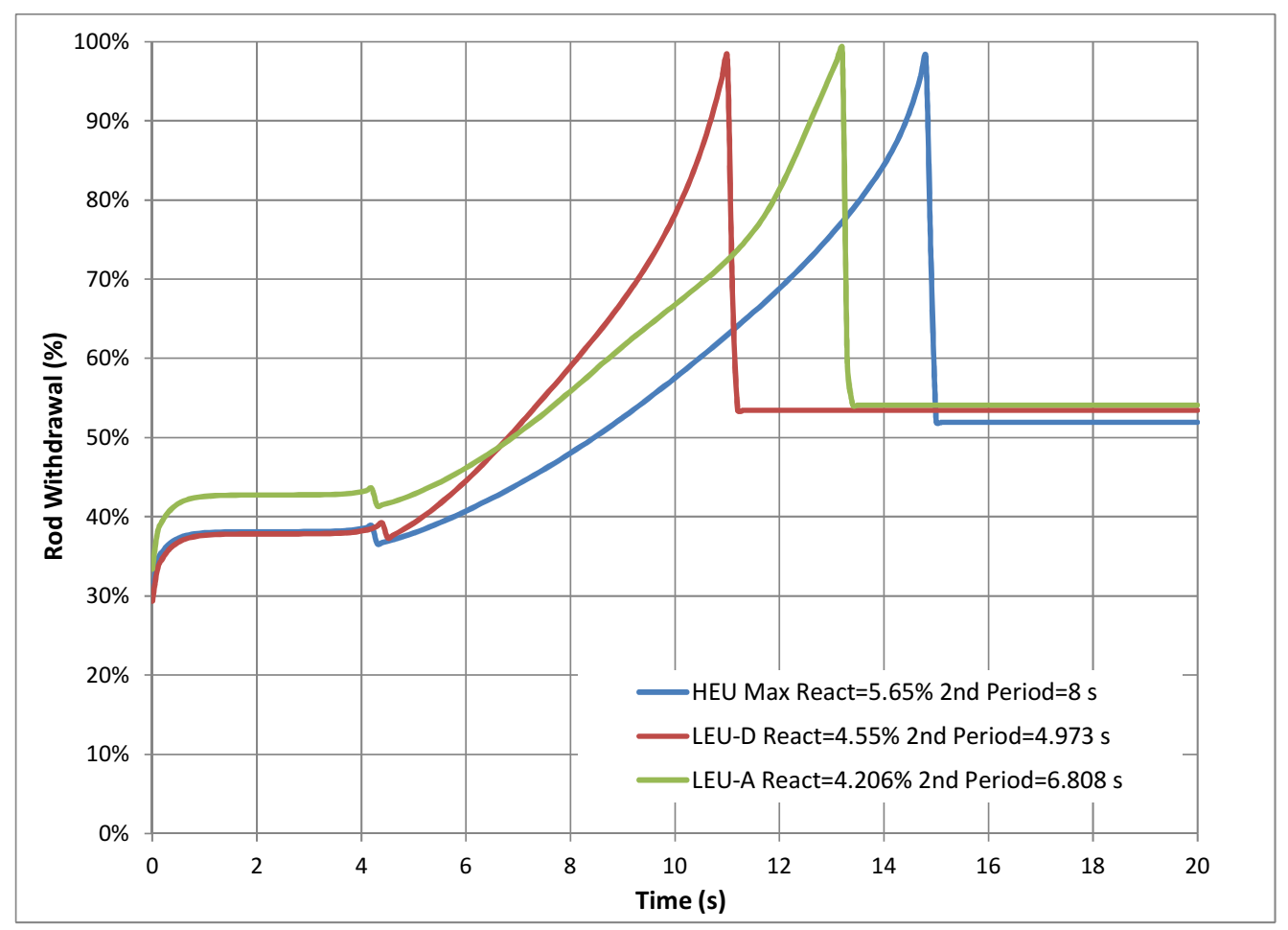

Figure [5.17]: TREKIN Calculated Rod Time History in the Flux Wire for the HEU, LEU-D (FA with C/U=5200) and LEU-A (BeO, FA with $C / U=5200$ and $C / U=6619$ ) Cores with Adjusted Second Period to Produce Equal to HEU Peak Power 
Table 5.16 presents the results of the TREKIN calculations for a second period that delivers peak power in the flux wire equal to that produced with the HEU core.

Table [5.16]: TREKIN Period Driven Calculations for the LEU-D (FA with $C / U=5200$ ) and LEU-A (BeO, FA with C/U=5200 and $\mathrm{C} / \mathrm{U}=6619$ ) for the Flux Wire Irradiation with Second Period to Deliver in the Flux Wire Equal Power with the HEU Core

\begin{tabular}{|l|c|c|c|}
\hline & \multicolumn{3}{|c|}{ Flux Wire (U-235 $1.19 \%$ wt.) } \\
\hline & HEU & LEU-D & LEU-A \\
\hline Limiting Pre-Transient Reactivity $(\Delta \mathrm{k} / \mathrm{K})$ & $5.65 \%$ & $4.55 \%$ & $4.206 \%$ \\
\hline Flattop Power $(\mathrm{MW})$ & 75 & 129 & 80 \\
\hline \#1 Period (s) & 0.3 & 0.3 & 0.3 \\
\hline \#2 Period (s) & 8 & 4.973 & 6.808 \\
\hline Maximum FA Temperature $\left({ }^{\circ} \mathrm{C}\right)$ & 463 & 466 & 468 \\
\hline Peak Core Power (MW) & 280 & 485 & 296 \\
\hline Total Core Energy (MJ) & 1775 & 2044 & 1637 \\
\hline & \multicolumn{4}{|c|}{ Flux Wire Results } \\
\hline Peak Wire Power (kW) & 0.18 & 0.18 & 0.18 \\
\hline Total Wire Energy (kJ) & 1.15 & 0.77 & 1.00 \\
\hline & \multicolumn{4}{|c|}{ Relative to HEU } \\
\hline Relative to HEU Peak Wire Power & $100 \%$ & $100 \%$ & $100 \%$ \\
\hline Relative to HEU Total Wire Energy & $100 \%$ & $66 \%$ & $87 \%$ \\
\hline
\end{tabular}

The softer neutron spectrum of the LEU-A core delivers more energy and hence more power in the low enriched flux wire as compared to the LEU-D core. The adjusted second period for the LEU-D and the LEU-A core was $4.973 \mathrm{~s}$ and $6.808 \mathrm{~s}$, respectively. The calculations were repeated for the T-462 fuel pin. Table 5.17 presents the results of the TREKIN calculations for a second period that delivers to the T-462 fuel pin equal peak power as the HEU peak core did. The resulting second-period for the LEU-D and LEUA with cores was $5.899 \mathrm{~s}$ and $5.625 \mathrm{~s}$, respectively.

Table [5.17]: TREKIN Period Driven Calculations for the LEU-D (FA with $C / U=5200$ ) and LEU-A (BeO, FA with $C / U=5200$ and $\mathrm{C} / \mathrm{U}=6619)$ for the T-462 Pin Fuel Irradiations with Second Period to Deliver the Same Peak Power as the HEU Core

\begin{tabular}{|l|c|c|c|}
\hline & \multicolumn{3}{|c|}{ T-462 Pin (U 71.02\% wt., Pu 19.15\% wt.) } \\
\hline & HEU & LEU-D & LEU-A \\
\hline Limiting Pre-Transient Reactivity $(\Delta \mathrm{k} / \mathrm{K})$ & $5.65 \%$ & $4.55 \%$ & $4.206 \%$ \\
\hline Flattop Power $(\mathrm{MW})$ & 75 & 110 & 96 \\
\hline \#1 Period $(\mathrm{s})$ & 0.3 & 0.3 & 0.3 \\
\hline \#2 Period (s) & 8 & 5.899 & 5.625 \\
\hline Maximum FA Temperature $\left({ }^{\circ} \mathrm{C}\right)$ & 463 & 465 & 471 \\
\hline Peak Core Power $(\mathrm{MW})$ & 280 & 415 & 356 \\
\hline Total Core Energy $(\mathrm{MJ})$ & 1775 & 2034 & 1649 \\
\hline & \multicolumn{4}{|c|}{ Pin Results } \\
\hline Peak Pin Power $(\mathrm{kW})$ & 133 & 133 & 133 \\
\hline Total Pin Energy (kJ) & 844 & 652 & 617 \\
\hline & \multicolumn{4}{|c|}{ Relative to HEU } \\
\hline Relative to HEU Peak Pin Power & $100 \%$ & $100 \%$ & $100 \%$ \\
\hline Relative to HEU Total Pin Energy & $100 \%$ & $77 \%$ & $73 \%$ \\
\hline
\end{tabular}


Figures 5.18 and 5.19 show the calculated power and transient rod time history for HEU, LEU-D and LEUA cores in the case of the fuel pin irradiation. The second period for the LEU cores was chosen as such to produce equal-to-HEU peak power in the fuel pin.

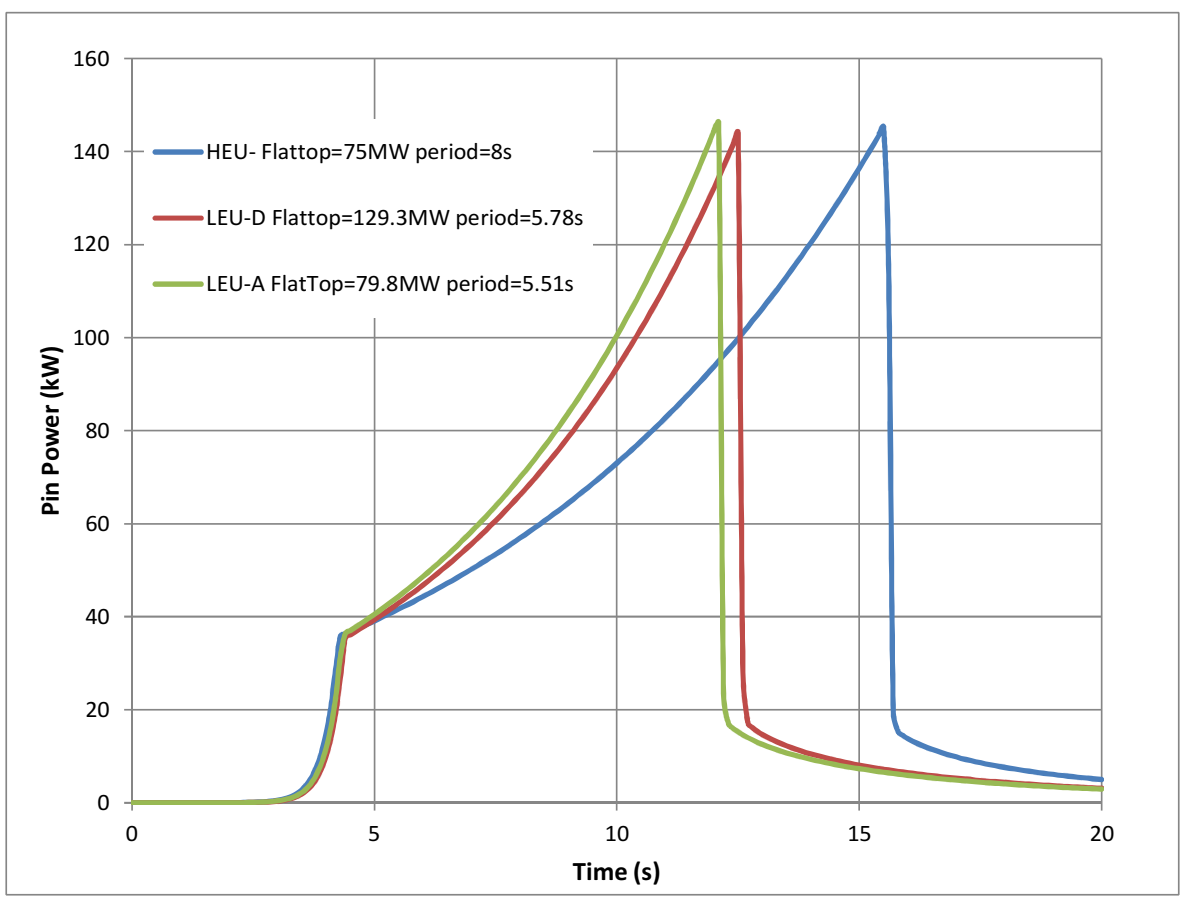

Figure [5.18]: TREKIN Calculated Power Time History in the T-462 Pin for the HEU, LEU-D (FA with C/U=5200) and LEU-A (BeO, FA with $C / U=5200$ and $C / U=6619$ ) Cores with Adjusted Second Period to Produce Equal with HEU Peak Power

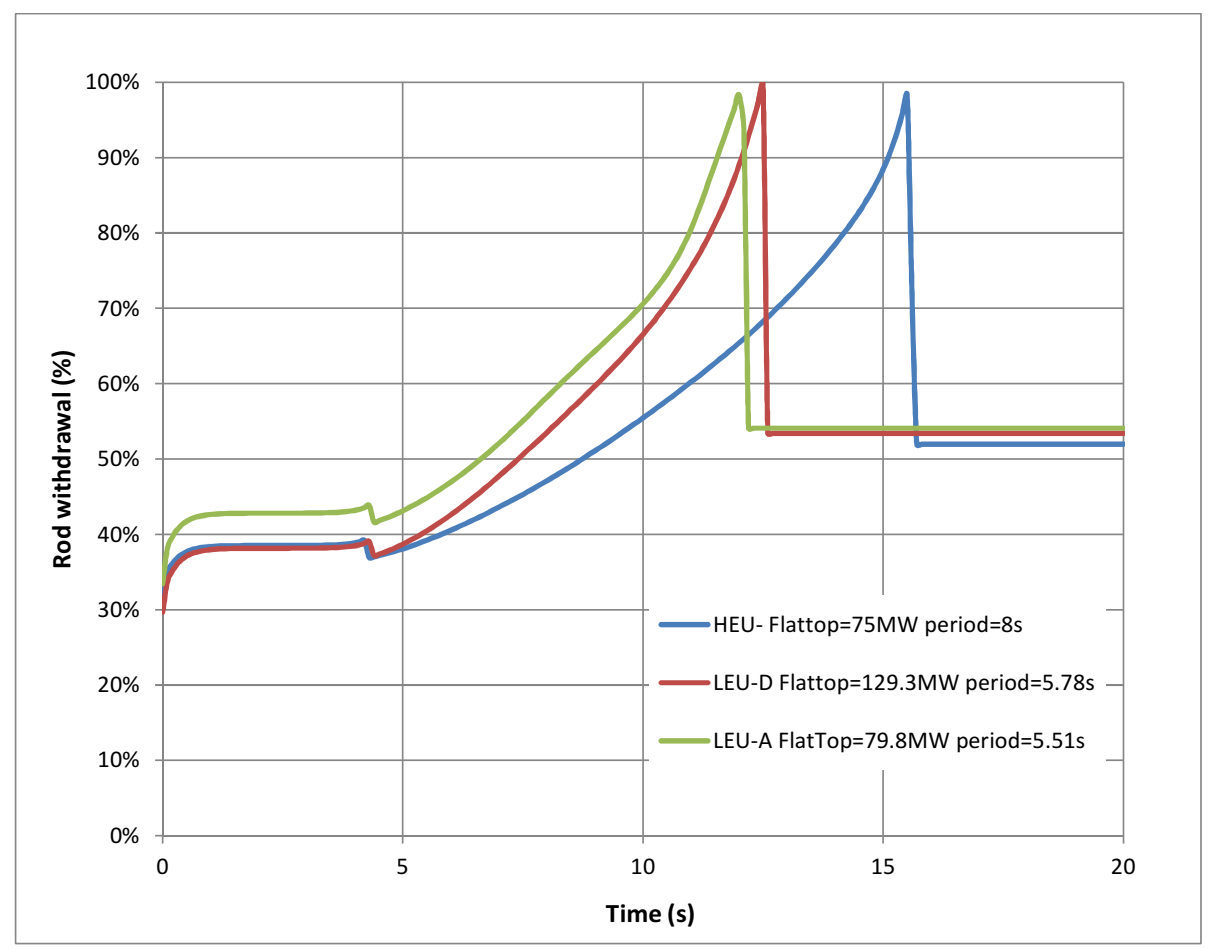

Figure [5.19]: TREKIN Calculated Rod Time History for the T-462 Fuel Pin for the HEU, LEU-D (FA with C/U=5200) and LEU-A (BeO, FA with $C / U=5200$ and $C / U=6619$ ) Cores with Adjusted Second Period to Produce the Same Peak Power as the HEU Core 


\subsection{TREKIN Calculations Summary}

The point kinetics code TREKIN was resurrected with the input data (TROD, $I_{p}, \beta_{\text {eff, }}$ TEMPER, HSLOT) that were historically used during TREAT operations. The code and the historic tables were validated by comparison with measurements of maximum fuel assembly temperature, peak power and total energy during temperature limited transients, using only the data from the M8CAL irradiations and with limited information regarding measurement uncertainties. A method to produce the TREKIN input data with MCNP without using experimental results was presented and the simulations were compared with the experimentally performed temperature limited and shaped transients. This method was designed for analyzing the transient capabilities of the LEU core since there are no available measurements.

The LEU cores were analyzed with TREKIN by comparing the power and energy delivered in the flux wire during the temperature limited transients \#2855, \#2856 and \#2857 that were experimentally performed in the HEU core. The LEU-A core design was initially considered promising because of its capability of matching the power and energy delivered in the low-enriched flux wire by the HEU core. The LEU cores were further analyzed simulating the irradiation of the flux wire and two high enriched fuel pins using the maximum-allowed step reactivity insertion and the maximum-allowed pre-transient available reactivity in temperature-limited and shaped transients, respectively. The results of the calculations show a $30 \%$ decrease in power and energy delivered by the LEU cores compared to the HEU core. The calculations also show that for thicker and higher-enriched targets, the harder spectrum of the LEU-D performs better than the LEU-A.

The uncertainty in the TREKIN calculations strongly depends on the accuracy of the input data regarding the rod worth change with rod position, reactivity feedback function with total core energy, and maximum fuel assembly temperature change with total core energy. Simulation of additional and welldocumented TREAT experiments is required to further benchmark the computations, to study the effect of uncertainties associated with the values in the input tables, and to determine the corresponding margin of error in the calculations.

\section{Summary}

A detailed 3-D MCNP model of the TREAT M8CAL HEU core was designed and validated against measured critical rod configurations and transient rod worth. The root mean square (RMS) deviation from criticality was $279 \mathrm{pcm}$ and is acceptable considering the $\pm 1000 \mathrm{pcm}$ bias induced by the $\pm 1.4 \mathrm{ppm}$ uncertainty in the boron concentration in the TREAT fuel.

For a representative half-slotted HEU core loading (with the M8CAL calibration vehicle at the core center), low-power-level steady-state irradiations of low-enriched flux wire and highly-enriched fuel pins in the calibration vehicle were simulated with the MCNP model. The calculated power coupling factors (C) were found to be in good agreement with the measured one (M) for the flux wire (C/M ranging from 0.84 to 1.05 depending upon the control-rod configuration in the core). In the case of the test pins irradiations, however, the $\mathrm{C} / \mathrm{M}$ was found to be about 1.26 to 1.30 for the reference control-rod configuration used in the M8CAL irradiations. Thus, the uncertainties affecting the results for fuel pins need to be further investigated. 
A method to calculate the temperature feedback as a function of maximum fuel assembly temperature based on MCNP simulations was designed. Three radial and three axial temperature zones were used to describe the core temperature distribution based on MCNP power density distribution calculations approximating the heating of the TREAT fuel with an adiabatic process. Using the same impurity content reported for the HEU fuel, the graphite-to-uranium ratio was calculated for the LEU-D core (direct replacement of HEU fuel assemblies with LEU assemblies) that produces equal excess reactivity as the $\mathrm{HEU}$ core and was found to be $\mathrm{C} / \mathrm{U}_{235}=5200$. The neutron spectrum inside the M8CAL vehicle, the control rod worth, the effective delayed neutron fraction and the prompt neutron generation lifetime were calculated with MCNP for the LEU-D core.

The power coupling factor for the LEU-D core for the low-enriched flux wire for steady-state irradiation was found to be $58 \%$ of the peak power coupling for the flux wire using the HEU core. This decrease was attributed to the harder neutron spectrum reaching the flux wire. Therefore, replacing 12 fuel assemblies around the irradiation vehicle with $12 \mathrm{BeO}$ reflectors to enhance neutron thermalization was considered. Use of the $\mathrm{BeO}$ reflectors increased the peak power coupling factor in the flux wire to $96 \%$ of the HEU value. However, the temperature of the fuel assemblies adjacent to the BeO reflectors was also increased, resulting in a maximum-to-core average temperature ratio of 1.54 (compared to 1.28 and 1.25 for the HEU and LEU-D cores, respectively). To compensate for this effect, the uranium loading was decreased to $C / U=6619$ in the 12 assemblies presenting the highest temperatures, the resultant core is referred to as the LEU-A core. The flux wire peak power coupling factor for the LEU-A core was found to be $94 \%$ of the HEU value, and the maximum-to-average core temperature was found to be 1.38 , which is $10 \%$ lower than the ratio for the LEU-D core with BeO blocks.

The point kinetics code TREKIN and the input tables historically used for TREKIN computations for the M8CAL core were validated against experimentally-performed M8CAL temperature-limited transients in the HEU half-slotted core. Because of various factors affecting the temperature feedback as a function of core temperature, a multiplicative constant (the SLOTK factor in TREKIN) was historically used as a simplistic approach to adjust the temperature reactivity feedback, in an attempt to account for the strong dependence of the feedback reactivity on the temperature distribution and consequently on the power distribution and control rod position. The error involved in using the SLOTK factor is increased when analyzing shaped transients because during such transients the control rods are constantly moving, complicating the determination of the temperature reactivity feedback.

A MCNP method to calculate the temperature reactivity feedback set without available measurements was designed in order to analyze the LEU cores. It was first tested for the HEU core. TREKIN input tables for the LEU-D and LEU-A cores were produced with MCNP simulations implementing the methods designed for the HEU core.

The irradiation of the flux wire with temperature-limited transients performed in the LEU cores was simulated by determining the reactivity step insertion needed to produce peak power and total energy in the flux wire equal to that produced by the HEU core. The LEU-A core (with the BeO reflectors and the lower uranium loading in 12 fuel assemblies) produced promising results by matching the peak power and total core energy that the HEU core produced without exceeding the fuel temperature limits. 
However, the initial analyses compared the maximum allowed transients of LEU designs to submaximum transients that were actually performed for the HEU core. In order to compare the performance on a more consistent basis, subsequent analyses used maximum allowed transients for the HEU core as reference. Furthermore, the initial analyses focused on flux wire cases rather than fuel test pin cases.

The maximum transient capability of the LEU core was studied by simulating (a) temperature-limited transients using the maximum-allowed reactivity insertion as to not exceed the fuel assembly temperature limit of $600^{\circ} \mathrm{C}$ and (b) shaped transients using the maximum-allowed pre-transient available reactivity that would not exceed the $820^{\circ} \mathrm{C}$ fuel assembly temperature limit if it was inserted as a step.

The peak power and total energy delivered in the flux wire and fuel pin relative to those for the HEU core are summarized in Table 6.1.

Table [6.1]: Summary of Peak Power and Total Energy Delivered by the LEU-D (FA with C/U=5200) and LEU-A (BeO, FA with $C / U=5200$ and $C / U=6619)$ Cores in Flux Wire and Fuel Pin Computed for M8CAL Temperature-Limited Transient and $8 \mathrm{~s}$ Period Shaped Transient, for Low-enriched Flux Wire and for High-enriched Fuel Pin (T-462) Presented as Relative Values to the HEU Core

\begin{tabular}{|c|c|c|c|c|}
\hline & \multicolumn{2}{|c|}{$\begin{array}{c}\text { Maximum Allowed } \\
\text { Temperature- } \\
\text { Limited Transient }\end{array}$} & $\begin{array}{c}\text { Maximum Allowed } \\
\text { Shaped Transient with } \\
\text { 8 s Period }\end{array}$ \\
\hline & LEU-D & LEU-A & LEU-D & LEU-A \\
\hline FLUX WIRE & & & & \\
\hline Peak wire Power relative to HEU & $69 \%$ (a) & $73 \%$ (a) & $74 \%$ (c)* & $90 \%$ (c)** \\
\hline Total wire Energy relative to HEU & $66 \%$ (a) & $86 \%$ (a) & $66 \%$ (c) & $87 \%$ (c) \\
\hline FUEL PIN & & & & \\
\hline Peak pin Power rel. to HEU & $81 \%$ (b) & $61 \%$ (b) & $82 \%$ (d) $\dagger$ & $79 \%$ (d) $\ddagger$ \\
\hline Total pin energy rel. to HEU & $77 \%$ (b) & $71 \%$ (b) & $77 \%$ (d) & $73 \%$ (d) \\
\hline
\end{tabular}

(a) From Table 5.6

(b) From Table 5.7

(c) From Table 5.14

(d) From Table 5.15

* Could be increased to $100 \%$ by decreasing the second period from $8.0 \mathrm{~s}$ to $4.973 \mathrm{~s}$

** Could be increased to $100 \%$ by decreasing the second period from $8.0 \mathrm{~s}$ to $6.808 \mathrm{~s}$

† Could be increased to $100 \%$ by decreasing the second period from $8.0 \mathrm{~s}$ to $5.899 \mathrm{~s}$

¥ Could be increased to $100 \%$ by decreasing the second period from $8.0 \mathrm{~s}$ to $5.625 \mathrm{~s}$

For heating the flux wire, with both transient types the LEU-A core performs significantly better than the LEU-D core but can generate only $87 \%$ of the flux-wire energy compared to the HEU core. For heating the fuel pin, the LEU-D core performs better than the LEU-A core in temperature-limited transients, and about equal to the LEU-A core in the shaped transient, but can generate only $77 \%$ of the pin energy compared to the HEU core. These results indicate that the performance of the LEU core is experimentdependent. Thus, instead of just a single experiment, a representative set of experiments pertinent to comparison of LEU vs. HEU core performance needs to be analyzed. 


\section{Conclusions}

A set of methods for MCNP-based TREAT performance simulations implementing the point-kinetics code TREKIN was developed and validated against measurements. The spectrum hardening in the LEU-D core decreases the power coupling factor by an amount that depends on the composition of the sample to be irradiated. The decrease of the power coupling factor for a low-enriched flux wire and a high-enriched test pin is $42 \%$ and $33 \%$, respectively, for the LEU-D core that has the same number of fuel assemblies as the HEU core. The use of BeO blocks (for the LEU-A core) around the irradiation vehicle softens the neutron spectrum and consequently increases the power coupling factor up to $94 \%$ for the flux wire and $78 \%$ for the fuel pins relative to the HEU-core value.

Further characterization of the capability of the LEU-A core, or improvement of that core, is needed to support an assessment of its performance against that of the HEU core. This characterization should be performed using results from a set of previously-performed experiments in the HEU core that are representative of the experimental requirements for future utilization of the reactor (e.g. proposed test vehicles, test sample geometry and composition, test-sample power shapes or energy). The same set of experiments should be used to further benchmark the MCNP model and the TREKIN data tables to identify the uncertainties affecting the results and in particular the calculated power coupling factor.

After the completion of this report data about the level of graphitization of the TREAT HEU fuel was obtained. The TREAT fuel is graphitized by $59 \%$ so in the MCNP calculations the $S(a, b)$ treatment will be applied into that percentage of carbon in the fuel. The change of graphitization from $100 \%$ to $59 \%$ of the HEU fuel the calculated $\mathrm{k}_{\text {eff }}$ is increased by $2.2 \%$ and the power coupling factor is decreased by $8.8 \%$. 


\section{References}

[1] Iskenderian, H, "Post Critical Studies on the TREAT Reactor", ANL-6115, February 1960.

[2] Iskenderian, H, "Physics Analysis of the TREAT Reactor Design", ANL-6025, August 1959.

[3] W R Robinson, T H Bauer, "The M8 Power Calibration Experiment (M8CAL)", ANL-IFR-232, May 1994.

[4] X-5 Monte Carlo Team, "MCNP - A General N-Particle Transport Code, Version 5 - Volume I: Overview and Theory", LA-UR-03-1987, Los Alamos National Laboratory, April 2003.

[5] D G Naberejnev, Unpublished Information, Argonne National Laboratory, 2002 - 2003.

[6] J R Liaw, Unpublished Information, Argonne National Laboratory, December 1979.

[7] Kirn F, Boland J, Lawroski H, Cook R, "Reactor Physics Measurements in TREAT", ANL-6173, October 1960.

[8] Okrent D et al, "The Reactor Kinetics of the Transient Reactor Test Facility (TREAT)", ANL-6174, September 1959.

[9] Brian C Kiedrowski et al, "MCNP5-1.60 Feature Enhancements \& Manual Clarifications", LA-UR10-06217, Los Alamos Laboratory.

[10] Knapp WG, Unpublished Information, Argonne National Laboratory, September 1980.

[11] Forrest B Brown, "The makxsf Code with Doppler Broadening", LA-UR-06-7002, 2006.

[12] Deen JR et al, Unpublished Information, Argonne National Laboratory,, February 2003.

[13] Kramer N A, Argonne National Laboratory, personal communication, August, 1992.

[14] Swanson R W, Argonne National Laboratory, personal communication, July, 1992.

[15] X-5 Monte Carlo Team, "MCNP - A General N-Particle Transport Code, Version 5. Volume II: User's Guide", LA-CP-03-0245 (April, 2003).

[16] Aravind H et al, "A Simple Approach to Clustering in Excel", International Journal of Computer Applications, Volume 11, No. 7, December 2010. 


\section{Appendix A : Material Compositions Used in the HEU MCNP Model}

\begin{tabular}{|c|c|c|c|}
\hline Material & Isotope & MCNP Label & Atom Density \\
\hline \multirow{10}{*}{ HEU Fuel } & $\mathrm{U}-235$ & $92235.70 c$ & $8.6849 \mathrm{E}-06$ \\
\hline & U-238 & $92238.70 c$ & $6.2967 \mathrm{E}-07$ \\
\hline & C-0 & $6000.70 c$ & $8.6227 \mathrm{E}-02$ \\
\hline & Fe-54 & $26054.70 c$ & $6.5286 \mathrm{E}-07$ \\
\hline & Fe-56 & $26056.70 c$ & $1.0239 \mathrm{E}-05$ \\
\hline & Fe-57 & $26057.70 c$ & $2.3659 \mathrm{E}-07$ \\
\hline & Fe-58 & $26058.70 c$ & $3.1248 \mathrm{E}-08$ \\
\hline & $0-16$ & $8016.70 c$ & $1.8623 \mathrm{E}-05$ \\
\hline & B-10 & $5010.70 c$ & $1.4495 \mathrm{E}-07$ \\
\hline & B-11 & 5011.70c & $5.8343 \mathrm{E}-07$ \\
\hline \multirow{19}{*}{ Zr-3 Alloy } & $\mathrm{Zr}$ & $40000.66 c$ & $4.2865 \mathrm{E}-02$ \\
\hline & $\mathrm{Fe}-54$ & $26054.70 c$ & $1.1659 \mathrm{E}-05$ \\
\hline & Fe-56 & $26056.70 c$ & $1.8285 \mathrm{E}-04$ \\
\hline & Fe-57 & $26057.70 c$ & 4.2252E-06 \\
\hline & Fe-58 & $26058.70 c$ & $5.5804 \mathrm{E}-07$ \\
\hline & $\mathrm{Ni}-58$ & $28058.70 c$ & $2.2803 \mathrm{E}-07$ \\
\hline & $\mathrm{Ni}-60$ & $28060.70 c$ & $8.7821 \mathrm{E}-08$ \\
\hline & $\mathrm{Ni}-61$ & $28061.70 c$ & $3.8183 \mathrm{E}-09$ \\
\hline & $\mathrm{Ni}-62$ & $28062.70 c$ & $2.2207 \mathrm{E}-08$ \\
\hline & $\mathrm{Ni}-64$ & $28064.70 c$ & 3.1149E-09 \\
\hline & $\mathrm{Cr}$ & $24050.70 c$ & $9.8706 \mathrm{E}-08$ \\
\hline & Cr-52 & $24052.70 c$ & $1.9013 \mathrm{E}-06$ \\
\hline & Cr-53 & $24053.70 c$ & $2.1556 \mathrm{E}-07$ \\
\hline & Cr-54 & $24054.70 c$ & $5.3551 \mathrm{E}-08$ \\
\hline & $\mathrm{Cd}$ & $48000.50 c$ & 6.9974E-09 \\
\hline & Sn & $50000.42 c$ & $9.2780 \mathrm{E}-05$ \\
\hline & $\mathrm{Hf}$ & $72000.60 c$ & $2.2034 \mathrm{E}-06$ \\
\hline & B-10 & $5010.70 c$ & $1.3751 \mathrm{E}-07$ \\
\hline & B-11 & $5011.70 c$ & 5.9006E-07 \\
\hline \multirow{7}{*}{ Graphite } & Fe-54 & $26054.70 c$ & $1.0536 \mathrm{E}-06$ \\
\hline & Fe-56 & $26056.70 c$ & $1.6524 \mathrm{E}-05$ \\
\hline & Fe-57 & $26057.70 c$ & $3.8181 \mathrm{E}-07$ \\
\hline & Fe-58 & $26058.70 c$ & $5.0428 \mathrm{E}-08$ \\
\hline & $\mathrm{C}$ & $6000.70 c$ & $8.3655 \mathrm{E}-02$ \\
\hline & B-10 & 5010.70c & 3.5167E-08 \\
\hline & B-11 & 5011.70c & $1.5090 \mathrm{E}-07$ \\
\hline \multirow{5}{*}{ Al-2 alloy } & Al-27 & $13027.70 c$ & 5.9477E-02 \\
\hline & Fe-54 & $26054.70 c$ & $2.5591 \mathrm{E}-05$ \\
\hline & Fe-56 & $26056.70 c$ & $4.0136 \mathrm{E}-04$ \\
\hline & Fe-57 & $26057.70 c$ & $9.2739 \mathrm{E}-06$ \\
\hline & $\mathrm{Fe}-58$ & $26058.70 c$ & $1.2249 \mathrm{E}-06$ \\
\hline
\end{tabular}




\begin{tabular}{|c|c|c|c|}
\hline Material & Isotope & MCNP Label & Atom Density \\
\hline \multirow{3}{*}{$\mathrm{B}_{4} \mathrm{C}$} & C & $6000.70 c$ & $1.7438 \mathrm{E}-02$ \\
\hline & B-10 & $5010.70 c$ & $1.3881 \mathrm{E}-02$ \\
\hline & B-11 & $5011.70 c$ & $5.5872 \mathrm{E}-02$ \\
\hline \multirow{6}{*}{ Carbon-steel } & $\mathrm{Fe}-54$ & $26054.70 c$ & $5.0819 \mathrm{E}-03$ \\
\hline & Fe-56 & $26056.70 c$ & 7.6860E-02 \\
\hline & $\mathrm{Fe}-57$ & $26057.70 c$ & $1.7447 \mathrm{E}-03$ \\
\hline & $\mathrm{Fe}-58$ & $26058.70 c$ & $2.2647 \mathrm{E}-04$ \\
\hline & Mo & $42000.66 c$ & $5.4700 \mathrm{E}-04$ \\
\hline & $\mathrm{C}$ & $6000.70 c$ & $1.4000 \mathrm{E}-03$ \\
\hline \multirow{19}{*}{ Zr-2 alloy } & $\mathrm{Zr}$ & $40000.66 c$ & $4.2498 \mathrm{E}-02$ \\
\hline & Fe-54 & $26054.70 c$ & $5.3721 \mathrm{E}-06$ \\
\hline & Fe-56 & $26056.70 c$ & $8.4254 \mathrm{E}-05$ \\
\hline & Fe-57 & $26057.70 c$ & $1.9468 \mathrm{E}-06$ \\
\hline & $\mathrm{Fe}-58$ & $26058.70 c$ & $2.5712 \mathrm{E}-07$ \\
\hline & $\mathrm{Ni}-58$ & $28058.70 c$ & $2.2872 \mathrm{E}-05$ \\
\hline & $\mathrm{Ni}-60$ & $28060.70 c$ & $8.8091 \mathrm{E}-06$ \\
\hline & $\mathrm{Ni}-61$ & $28061.70 c$ & $3.8301 \mathrm{E}-07$ \\
\hline & $\mathrm{Ni}-62$ & $28062.70 c$ & $2.2275 \mathrm{E}-06$ \\
\hline & $\mathrm{Ni}-64$ & $28064.70 c$ & $3.1245 \mathrm{E}-07$ \\
\hline & $\mathrm{Cr}-50$ & $24050.70 c$ & $3.6634 \mathrm{E}-06$ \\
\hline & Cr-52 & $24052.70 c$ & $7.0565 \mathrm{E}-05$ \\
\hline & Cr-53 & $24053.70 c$ & $8.0005 \mathrm{E}-06$ \\
\hline & Cr-54 & $24054.70 c$ & $1.9875 \mathrm{E}-06$ \\
\hline & $\mathrm{Cd}$ & $48000.50 c$ & $1.0528 \mathrm{E}-08$ \\
\hline & Sn & $50000.42 c$ & 4.7529E-05 \\
\hline & B-10 & $5010.70 c$ & $1.3793 \mathrm{E}-07$ \\
\hline & B-11 & 5011.70c & 5.9187E-07 \\
\hline & $\mathrm{Hf}$ & $72000.60 c$ & $2.2102 \mathrm{E}-06$ \\
\hline \multirow{18}{*}{ SS304 } & C & $6000.70 c$ & $3.1863 \mathrm{E}-04$ \\
\hline & P-31 & $15031.70 c$ & $6.9503 \mathrm{E}-05$ \\
\hline & Mn-55 & $25055.70 c$ & $1.7416 \mathrm{E}-03$ \\
\hline & Fe-54 & $26054.70 c$ & $3.3825 \mathrm{E}-03$ \\
\hline & Fe-56 & $26056.70 c$ & $5.3353 \mathrm{E}-02$ \\
\hline & Fe-57 & $26057.70 c$ & $1.2205 \mathrm{E}-03$ \\
\hline & Fe-58 & $26058.70 c$ & $1.6273 \mathrm{E}-04$ \\
\hline & $\mathrm{Ni}-58$ & $28058.70 c$ & $5.5650 \mathrm{E}-03$ \\
\hline & $\mathrm{Ni}-61$ & $28061.70 c$ & $9.2111 \mathrm{E}-05$ \\
\hline & $\mathrm{Ni}-64$ & $28064.70 c$ & $7.4178 \mathrm{E}-05$ \\
\hline & $\mathrm{Ni}-60$ & $28060.70 c$ & $2.1275 \mathrm{E}-03$ \\
\hline & $\mathrm{Ni}-62$ & $28062.70 c$ & $2.9264 \mathrm{E}-04$ \\
\hline & $\mathrm{Cr}-50$ & $24050.70 c$ & $7.6043 \mathrm{E}-04$ \\
\hline & $\mathrm{Cr}-52$ & $24052.70 c$ & 1.4647E-02 \\
\hline & $\mathrm{Cr}-53$ & $24053.70 c$ & 1.6607E-03 \\
\hline & $\mathrm{Cr}-54$ & $24054.70 c$ & $4.1255 \mathrm{E}-04$ \\
\hline & $\mathrm{Si}$ & $14000.60 c$ & $1.7033 \mathrm{E}-03$ \\
\hline & $\mathrm{S}$ & $16000.66 \mathrm{c}$ & 4.4759E-05 \\
\hline
\end{tabular}




\section{Appendix B : Equation Used to Calculate the Fuel Assembly Temperature}

The fuel temperature is the positive solution of a fourth degree polynomial: $\quad a x^{4}+b x^{3}+c x^{2}+d x+e=0$

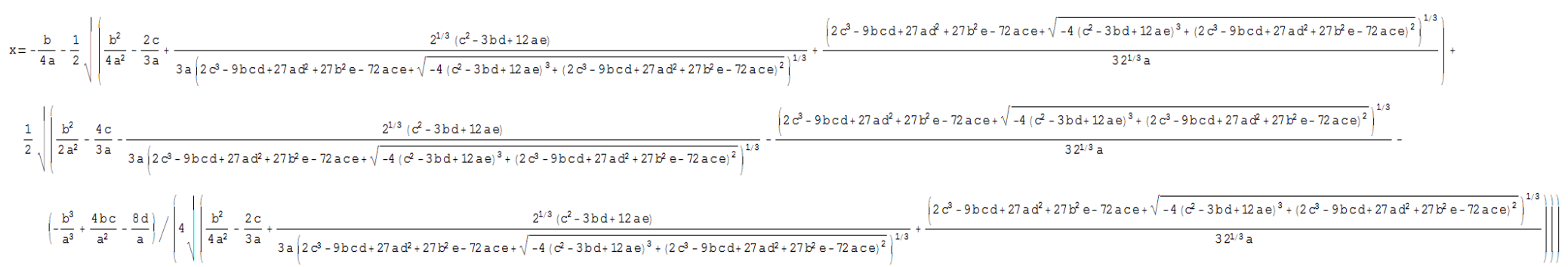


Argonne

Nuclear Engineering Division

Argonne National Laboratory

9700 South Cass Avenue, Bldg. 208

Argonne, IL 60439-4842

www.anl.gov 